NBSIR 76-1146

\title{
A Study of Personal Fall-Safety Equipment
}

Harold L. Steinberg

Product Systems Analysis Division Institute for Applied Technology National Bureau of Standards

Washington, D. C. 20234

June 1977

Final

Prepared for OSHA 



\section{A STUDY OF PERSONAL FALL-SAFETY EQUIPMENT}

Harold L. Steinberg

Product Systems Analysis Division Institute for Applied Technology National Bureau of Standards Washington, D.C. 20234

June 1977

Final

Prepared for OSHA

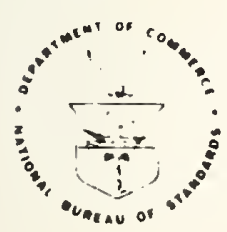

U.S. DEPARTMENT OF COMMERCE, Juanita M. Kreps, Secretary Dr. Sidney Harman. Under Secretary Jordan J. Baruch. Assistant Secretary for Science and Technology NATIONAL BUREAU OF STANDARDS. Ernest Ambler, Acting Director 

TABLE OF CONTENTS

1.0 Introduction

1.1 Purpose

1.2 Project Approach

1.3 General Background 3

1.4 Terminology and symbols 4

1.5 Units of Measure 7

2.0 Physiological Aspects of Fall Injuries 9

2.1 Human Body Reactions 10

2.2 Tolerable Limits 13

2.3 Information from Accidents Involving Fall- 20 Arrest Systems

3.0 Fal1-Safety systems 23

3.1 The Physics of Fall-Arrest 23

3.2 Anthropometric Basis 32

3.3 Behavior of a Fall-Safety System During Fall- 35 Arrest

3.3.1 Containment

3.3.2 Energy Absorption 40

3.3.3 Limited Fall Distance 41

3.3.4 Rescue 43

3.4 Classification and Description of Systems 43

3.4.1 Class I Systems 45

3.4.2 Class II Systems 46

3.4.2.1 Class IIa Systems (Ascent/ 46 Rescue)

3.4.2.2 Class IIb Systems (Descent/ Rescue) 
3.4.3 Class III Systems

3.4.4 Class IV Systems

3.4.5 Class V Systems

3.4.6 Class VI Systems

3.5 Descriptions and Functions of Components

3.5.1 Containment Devices

3.5.2 Lanyards

3.5.3 Lifelines

3.5.4 Rope Grabs and Shock Absorbers

3.5.5 Ascent and Controlled Descent Devices

3.5.6 Anchorage

3.5.7 Other Components

3.6 Components, Requirements, and Limitations

3.6.1 Mechanical Requirements

3.6.2 Electrical Requirements

3.6.3 Environmental

3.6.4 Deterioration in Use

3.6.5 Other Use Factors

3.7 Test Procedures

3.7.1 Static Strength Tests

3.7.2 Elongation (Extensibility) Tests

3.7.3 Dynamic (Drop) Tests

3.7.4 Electrical Tests

3.7.5 Other Tests

3. 8 Prototype, Production Line, and Field Testing 
4.0 Recommendations

4.1 General Considerations

4.2 Design and Fabrication

4.3 Performance

4. 4 Use

4. 5 Testing

4.6 Information To Be Furnished

4.7 Suggested Areas for Additional Work

Appendix A - Experimental Program

A. 1 Introduction

A.1.1 Purpose

$\mathrm{A}-1$

A. 1.2 Scope

$\mathrm{A}-1$

A.2 Rationale

$\mathrm{A}-2$

A.2.1 Rationale for Testing Components A-2 Separately

A.2.2 Rationale for Using Static Test Results A-4 to Predict Impact Parameters

A. 3 Experimental Procedures A-6

A.3.1 Test Specimens A-6

A.3.1.1 Lanyards A-6

A.3.1.2 Body Belts A-8

A.3.2 Testing Apparatus A-8

A.3.3 Lanyard Tests A-14

A.3.4 Body Belt Tests A-18 
A. 4 Data Analysis

A. 4.1, Reduction of Experimental Data

A.4.2 Computations Using Analytical Model

$A-25$

A.4.3 Model Validation and Comparison with $A-32$ Other Results

A. 5 Computation of Load vs. Elongation Functions $\mathrm{A}-72$ for Various Length Lanyards 
1. Factors for Converting from U.S. Customary to

SI Units of Measure

2. Body Centered Geometry System Used to Describe Accelerations

3. Peak Force on Lap Belt and/or Torso

4. Acceleration Levels Accepted by the Naval Aerospace Medical Research Laboratory

5. Ratio of Tension in Lifeline to Tension in Lanyard

6. Weights for Selected Percentiles of Males by Age for the United States

7. Estimated Weights of Construction Workers when Clothed and Equipped

8. Waist Depths of Various Segments of the Population

9. Proposed Classification for Active, Personal

Fall-Safety systems

10. CSAO's Conclusions and Recommendations Regarding

Fall-Safety Equipment with Rope Grabs

11. Criteria for Determining Performance Requirements for Fall-Safety Equipment

12. Recommended Working Load as a Percentage of Breaking Strength for Various Fiber Ropes

13. Effects of Environments on Rope Strength

14. NPTR Knot Test Data

15. Anchorages and Anchor Linkages to be Used when

Strength Testing Lanyards

16. Performance Criteria for Fall-Safety Equipment

17. Recommended Maximum Permissible Drop Line Extensibilities

18. Fall Parameter Limits above which Impacted Lanyards should be Replaced 
$A-1$

$A-2$

A-3(a-c) Typical Output from a Third Degree Polynomial Fit of L/E Data

A-4 (a,b) Example of Output of Main Computer Program

A -5

A-6

$A-7(a-d)$

$A-8(a-d)$

A-9

$A-10$

$A-11$

$A-12$

A-13

$\mathrm{A}-14$

$A-15$

A-16

Calibration of Rope Testing Machine

Typical Data for Manually Obtained Lanyard Central-Section L/E Measurements

Summary of Calculated Peak Impact Forces

for Selected Fall Parameters

Summary of Calculated Peak Impact Decelerations for Selected Fall Parameters

Calculated Peak Impact Forces for Selected

Fall Parameters

Calculated Peak Impact Accelerations for

Selected Fall Parameters

Comparison of Absorbed Energy as Measured with A-65 a Planimeter and Calculated Using a

Computerized Model

Comparison of Calculated and Actual Forces for A-66

a Test Spring Obeying Hooke's Law

Comparison of Given Breaking Strengths (BS)

with Average Values for Various Lanyards

Comparison of Calculated Peak Impact Forces with Comparable Values as Experimentally Determined by Equipment Manufacturers

Comparison of Calculated, Deak Impact Durations with A-70 Comparable Values as Determined by

Equipment Manufacturers

Coefficients of the Polynomial Equations for

$1.8 \mathrm{~m} \mathrm{(6} \mathrm{ft}$ ) Lanyards

Coefficients of the Polynomial Equations for

Pure Rope Sections of Lanyards

Elongation of 9/16 inch New Spun Nylon Lanyard A-75

$\underline{\text { Page }}$

A -9

$A-17$

A -27

thru $A-29$

$A-35 \& 36$

$A-37 \& 38$

$A-39 \& 40$

A -42

A -46

$A-67$

A -69

A -73

$A-74$ Computed from Test Data 
1. Acceleration tolerance along the $z$ axis 15

2. Damped spring mass system 24

3. Assumed force-elongation relationship for 26 damped spring

4. Computed acceleration imparted to a rigid mass 29 as a function of the ratio of free fali distance, $h$, to spring length, $L$, when $\mathrm{k} / \mathrm{Mg}_{\mathrm{n}}=70$

5. Simulated horizontal lifeline 30

6. Commonly used types of body containment devices 38

7. Equal energy absorption by two idealized 42 fall-safety systems

8. Comparative sunlight and weather resistance cf commercial ropes

9. Impact strength vs. temperature curves for a carbon and an alloy steel

10. A possible setup for tensile testing of linemen's pole straps

11. A possible setup for tensile testing of linemen's body belts

12. Schematic diagram of a drop test

13. A possible test weight configuration 86

14. A possible setup for dynamic testing of 87 linemen's body belts

15. A possible setup for dynamic testing of linemen's pole straps

16. Electric contact configuration for dielectric testing of ropes

17. Correlation between lanyard extensibility at two loads 
A-1 Flow diagram of experimental procedures $\quad$ A-7

$\mathrm{A}-2$

Initial experimental setup used to measure

A -11 the extension of lanyard center (pure rope) sections

The step-interval extensometer developed at NBS for use in load-extension testing or ropes

A -4

Load-elongation curve for lanyard using

A-13 step-interval extensometer

Record sheet for lanyard test

Load-elongation curve for $9 / 16$ inch new spun nylon lanyard

Length-measurement configuration for body belts

Tensile test configuration for body belts

Load elongation curve for a tongue buckle belt

$A-10$

Load elongation curve for a friction buckle belt

A-II Load/relative extension curves obtained for 13 lanyard types

$A-12$

Load/relative extension curves obtained for

$A-31$ 13 lanyard types; center rope sections

$A-13$

Load/relative extension curves obtained for

A -33 $1 / 2$ inch filament nylon lanyards

$A-14$

Load/relative extension curves obtained for A-34 $1 / 2$ inch gold filament nylon lanyards

A-15 a-m Calculated peak impact acceleration as a function of the ration of free fall distance, $h$, to lanyard length, L 
Richard Yates was responsible for much of the modeling of fall-arrest systems and both Mr. Yates and Michael Vogt share credit for transformation of the model into a computer program and for related computations. Martin Cordes and Ron Rehm of the Mathemetical Analysis Section, Applied Mathematics Division, National Bureau of Standards, gave invaluable assistance in several different mathematical aspects of the physics required for our model development.

The author wishes to extend his appreciation to John Michalak of the Engineering Mechanics Section, National Bureau of Standards, who performed our tensile tests and whose careful and conscientious work and frequent suggestions were much appreciated.

Recognition should be extended to the NBS Instruments Shops Division for assistance in the design and fabrication of the special device used to measure lanyard extensions. Thanks are also in order for William Beine of my section who assisted the project at an early stage. Sincere thanks are also in order for the safety equipment manufacturers who so willingly gave of their time and who contributed test samples and test data. A similar note of thanks must go to the users of these equipments who so graciously allowed project team members to visit job sites to gain a working knowledge of worker/fall-safety-system interactions.

Finally, the author wishes to express a special acknowledgment to Roscoe L. Bloss for his extensive editorial organization and textual revision of this report. His contributions as editor were to emphasize the essential experimental results of the study, to focus on the findings that are particularly relevant to the development of safety criteria, and to summarize safety equipment data for use by manufacturers of fall-safety equipment, construction workers, and standard setting groups. 

A STUDY OF PERSONAL FALL-SAFETY EQUIPMENT

\subsection{Introduction}

\subsection{Purpose}

Each year falls injure, maim, or kill many thousands of United States citizens, and a significant fraction of these accidents occur in an occupational setting. Some of these injuries are the result of falls experienced by workers whose jobs require that they perform tasks many feet above the ground. The Occupational Safety and Health Administration (OSHA) recognizes the need for performance standards for fall-safety systems to protect such workers and also recognizes that current standards are inadequate. Therefore, OSHA is drafting a performance standard for worker restraint systems, with primary focus on the construction industry. It is anticipated that this will lay the groundwork for related standards to protect linemen, tree pruners, window washers, etc.

The work covered by this report was directed towards providing a valid basis for a comprehensive OSHA performance standard for fall-safety systems and their components, in particular safety belts, harnesses, lanyards, and lifelines. The major effort was devoted to fall-arrest systems in contrast to fall-restraint systems.

\subsection{Project Approach}

The project approach involved a literature search, written and telephone inquiries, work site visits, visits to safety equipment manufacturers, the conduct of laboratory tests, analyzing and correlating data from laboratory tests and from the literature, examining all of the information obtained in terms of requirements for fall-safety systems, and formulating recommendations pertaining to a performance standard for fall-arrest systems and their components.

The review phase of the project covered:

(1) Data on falls from heights, in particular those where fall-safety equipment was involved; 
(2) Relevant injury threshold limits and their physiological foundations;

(3) Test data for fall-arrest systems and components; and

(4) Relevant voluntary and mandatory standards.

The visits to work sites were planned to provide an opportunity to observe various types of fall-arrest equipment in use and the worker/work environment/safety system interactions that result. These observations were used to estimate the degree of worker acceptance and utilization of fall-safety equipment and to determine the factors that influence such acceptance.

Visits were made to manufacturers of fall-safety equipment to observe the fabrication facilities and procedures as well as the testing carried out as part of the development and quality control process. These visits served to assure that recommendations would not make unreasonable demands on the producers.

A limited experimental program was used to generate more comprehensive data on strength and energy absorbing characteristics of some components than was available in the literature. This data, though limited in scope, provide the basis for a test procedure that may be simpler and more definitive than current methods.

Information gathered in the NBS experimental program was compared with data taken from the literature to determine the variability of the component products and to compare results obtained using static and dynamic test methods.

The analysis and distilling of the information gathered was aimed at providing recommendations that would be realistic in terms worker safety and production considering the current state-of-the-art. In addition, areas were noted beyond the scope of this study where more information is needed. 
Falls are a major cause of accidental injury and death in this country. The National Safety Council recorded over 15000 deaths due to falls in 1975 (7.4 fall-related deaths per 100000 people). The construction industry has one of the highest occupational disability and death rates, and it has been estimated that one of five workers faces the prospect of being injured or killed at a construction site. Falls from walking or working surfaces are a major cause of these accidents.

The existing Code of Federal Regulation [CFR] standards covering fall-safety equipment for industrial and construction workers $[\mathrm{CF}-3, \mathrm{CF}-6, \mathrm{CF}-8]$ * is generally accepted as being unsatisfactory. The part of this document dealing with fall-safety equipment is based on insufficient and antiquated data, and it contains internal and interrelational inconsistencies. The test methods and procedures prescribed by this standard are poorly devised and inadequately described.

Because of the deficiencies in the CFR standards, industiial interests have developed and adopted a consensus regulation, ANSI A10.14 [AN-1]. Unfortunately this regulation suffers from many of the weaknesses of the previous regulations. The greatest drawback comes from a lack of sufficient, relevant, and accurate data upon which to base its requirements. In order to overcome these deficiencies and provide an adequate background for a comprehensive standard for fall-safety systems, the study covered by this report was conducted at the ivational Bureau of Standards (NBS) under the sponsorship of the Occupational Safety and Health Administration (OSHA).

Three basic modes for protecting workers from fallrelated injuries are guardrails, safety nets, and personal fall-safety equipment. Each of these have a proper role and, in many cases, more than one may be used concurrently. All three types were observed during this study, but only active, personal fall-safety equipment was evaluated. Such systems, which require that the worker secure himself to a suitable anchorage, consist of components such as body belts, body and chest harnesses, lanyards, rope grabs, shock absorbers, lifelines, pole straps, safety straps, ascent and controlled-descent devices, anchorages, and other relevant hardware. The study aid not include window cleaners' and tree trimmers' belts, ladder safety systems, and bosuns' chairs, and only marginally covered fall

* References to items in the Bibliography section of this report are shown in brackets. 
restraint systems designed to prevent a worker from maneuvering into a potential fall position.

A study of guardrails [FA-1, FA-2, FA-3] was carried out at NBS by the Center for Building Technology during the same time that this study was being made.

\subsection{Terminology and symbols}

Every attempt has been made to use terms that are generally used by the producers and users of fall-safety equipment. However, since such usage is not entirely uniform, the following terms are defined as they are used in this report and other sources $[\mathrm{AN}-1, \mathrm{BE}-2, \mathrm{IS}-1, \mathrm{OS}-1]$ :

(1) Anchorage. A secure point of attachment to which is secured a lifeline or lanyard.

(2) Arrest Force. The force imposed on the worker or test weight at the time the fall-arrest system stops the fall. This is usually the peak force experienced during the fall.

(3) Body Belt. A simple or compound strap with means for securing it about the waist and with means for securing a lanyard or snaphook to it. It is the part that secures the worker to each fall-safety system.

(4) Body-Restraint system. A simple or compound strap that is secured about the wearer and attached to a load-bearing anchorage. Body belts and chest- and body-harnesses are the usual body-restraint systems.

(5) Buckle. A device for fastening two loose ends of a belt or strap usually attached to one end and grasping the other end by friction or by a tongue passing through a hole.

(6) Drop Line. A vertical lifeline.

(7) Effective Worker Weight. Effective worker weight is taken as the gross weight of a worker including his clothes, tools, and personal protective gear.

(8) Fall-Arrest System. Any active device designed to arrest a fall in such a way as to minimize the length of fall and the potential for fall-related injury. 
(9) Fall Distance. The "free fall distance," exclusive of lanyard elongation.

(10) Fall-Restraint System. Any active device designed to prevent a worker from maneuvering into a potential fall situation.

(11) Fall-Safety System. Personal equipment designed to provide a worker at heights with protection from falls from a working or walking surface or: should he fall, to minimize the length of the fall and the potential for fall-related injury. Fall-restraint, emergency-retrieval and fall-arrest systems are all considered to be fall-safety systems.

(12) Lanyard. A short length of flexible line or strap webbing which is used to secure a safety belt or body harness to a lifeline or to a fixed anchorage.

(13) Lifeline. A line from a fixed anchorage or between two fixed anchorages, independent of walking and working surfaces, to which a lanyard is secured.

( $\perp \dot{A})$ Lineman's Body Belt. A belt which consists of a cushion section, a body belt, a tool saddle, and deering(s) which are secured to the strength member of the belt.

(15) Lineman's Pole (Safety) Strap. A strap used for support while working on poles, towers, or platforms. Snaphooks provide for attachment to the lineman's body belt.

(16) Restraint Line. A line used to secure a worker to a fixed anchorage, thus allowing limited mobility while preventing maneuvering into a position to fall from the working surface.

(17) Rollout. A physical process whereby one coupling device can inadvertently disengage from a mating unit when a torque is applied to the pair.

(18) Rope Grab (Safety Clamp). A device, used to couple a body belt or lanyard to a dropline, which, upon impaction, will actuate to arrest a fall within a short distance. 
(19) Safety Belt. Conventionally used in a generic sense to describe all fall-arrest restraint systems and/or their components. This term is not used in this report.

(20) Safety (Design) Factor. The ratio of the computed strength (or deceleration) of a load bearing member or material to the maximum load (or deceleration) the component is expected to sustain in use.

\section{(21) Safety Line. A horizontal lifeline.}

(22) Snaphook. A self-closing hook with a keeper latch or similar arrangement which will automatically close and remain closed until manually opened.

(23) Strength ilember. Any component of a fall-arrest system, including anchorages, that could be subject to loading in the event of a fall.

[24] Total Fall Distance. Fall distance plus maximum lonyard extension during impact and/or the distance along a dropline that a rope grab travelled before locking and/or any additional fall distance due to a shock absorber activating.

The following symbols are used throughout this report:

$\mathrm{a}=$ acceleration

$f=$ degradation factor to account for possible reduction in strength due to tie-off conditions

$\mathrm{h}=$ free fall distance

BS = breaking strength

$D=$ contingency, or safety factor

$F=$ force

$\mathrm{L}=$ length under unloaded conditions

$M=$ mass of a fall victim or test weight

subscript a = pertaining to acceleration

subscript $\max =$ maximum value 
subscript $\min =$ minimum value

subscript obs = observed or measured value

subscript $x, y, z$ = direction referred to orthogonal axes or body centered geometry system (Table 2).

\subsection{Units of Measure}

In general, quantities in this report are presented in botn the International System of Units (SI) and in U.S. Customary Units. This dual presentation is made in order to facilitate communication with users of the SI system adopted by the 1960 General Conference of Weights and Measures while avoiding confusion in the user area that is more familiar with U.S. Customary Units. In some cases, particularly in tabulations, where dual units would be awkward, U.S. Customary units have been chosen as being less confusing for the primary users of this report. Conversion factors for these cases are given in Table 1. A more complete listing of conversion factors can be found in the literature [AS-5]. An exception is the extensive use of the acceleration of free-fall, $g_{n},\left(9.80665 \mathrm{~m}_{.} \mathrm{s}^{-2}\right.$ or $\left.32.174 \mathrm{ft.s}-2\right)$ as the unit of acceleration. This unit is widely recognized and accepted in both technical and popular usage. 


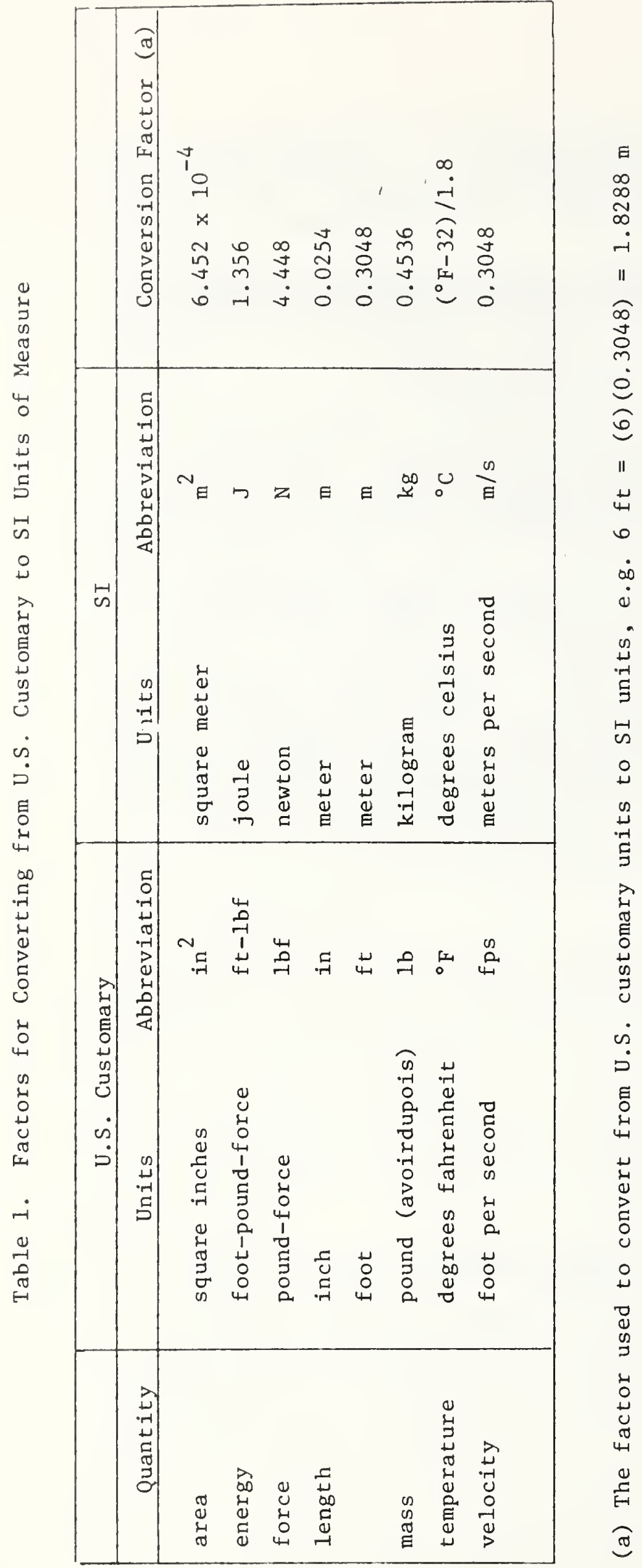




\subsection{Physiological Aspects of Fall Injuries}

Injuries can result from a fall involving a fall-safety system in several ways, including:

(1) Through breaking of a component so that the fall is not safely arrested;

(2) By forces from the containment system (belt or harness) crushing, twisting, or abrading the body of the victim;

(3) By excessive acceleration which can cause severe internal injuries, such as tearing away of organs and rupturing of blood vessels, and skeletal injuries due to flailing, twisting, and jackknifing;

(4) From colliding with parts of a structure or other objects due to excessive fall distance, swinging, etc.;

(5) Througin elongation of the containment system allowing the victims to be released.

A -atisfactory fall-safety system must be designed, constructed, and used so as to avoid such injuries or at least to reduce their severity so that substantial disabling does not result. Whereas (1), (4), and (5) above relate to the physical characteristics of the system only, (2) and (3) require that the tolerance of the human body to external and inertial forces be considered.

By far the largest portion of data relevant to arrested fall injuries is presented in terms of acceleration, almost always given in units of "g." This information is also based upon limited tests generally carried out with young, healthy, male volunteers. Most tests have been made with the subject restrained in an optimal position and anticipating the impact from the test. The acceleration levels have, of course, been deliberately kept well below the serious injury level with the effects of higher accelerations being estimated. In short, we have an inadequate basis for estimating the maximum acceptable acceleration for a frightened person of questionable physical condition, falling in a unconstrained position, with the fall being arrested through a belt or harness. It is also unknown whether the tolerance levels are the same for females and for males. 


\subsection{Human Body Reactions}

Since the acceleration tolerance of the human body is dependent upon the direction of the acceleration, a simple geometric system for identifying the direction is useful. Such a body centered system is shown in Table 2 .

Since for arrested falls we are generally concerned with a retarded motion, the acceleration is usually in the direction opposite to the motion. For example, a person falling feet first would, when the fall is being arrested, be subjected to a taz acceleration.

In addition to being sensitive to the direction of the acceleration, it has been reported [BO-1] that human tolerance to acceleration is conditioned by factors such as:

(1) magnitude of the acceleration,

(2) duration of the acceleration,

(3) rate of change of acceleration (jerk), and

(1) the distribution of restraining forces over the body.

These factors, like body orientation during a fall, are highly variable and not readily controlled or predicted. The human body is a very complex, articulated, viscoelastic structure that will almost certainly undergo twisting, tumbling, flailing and/or jackknifing during a fall. The effects of all of the above factors can be expected to vary with time and body location, and local accelerations may be expected that are considerably higher than an average value computed from measurements of total force or acceleration of the center of gravity.

The human body in a real impact will absorb a significant amount of the kinetic energy that must be dissipated. Flail, rotational, and jackknifing motions, compression of the body, redistribution of body fluids and organs, internal friction and abrasion of straps against clothes and skin torso all contribute to this energy absorption process. This effect can be seen in data from tests of lap belts using a variety of test objects ranging from a rigid mass to a human subject. Such data are shown in Table 3 [AR-3]. Such force measurements relate to an average acceleration and may not reflect the peak 
Table 2. Body Centered Geometry System Used to Describe Impact Accelerations

Equivalent

Type Acceleration

Towards the Front

Towards the Rear

Towards the Right

Towards the Left

Upwards

Downwards
Symbol

$+a_{x}$

$-a x$

$+a_{y}$

$-a y$

$+a_{z}$

$-a_{z}$
Eyeballs in

Eyeballs out

Eyeballs left

Eyeballs right

Eyeballs down

Eyeballs up 
Table 3. Peak Force on Lap Belt and/or Torso [AR-3] Test Subject $\frac{\text { Peak Force Recorded }}{\mathrm{kN}}$

Wooden body block (no moving parts) 43.4 9760

$79.4 \mathrm{~kg}$ (175 lb) articulated wooden 37.2 8370 dummy (ARL F-50)

$73.5 \mathrm{~kg}$ (162 lb) sandbag

33.5

7530

$73.5 \mathrm{~kg}$ (162 lb) highly articulated wooden dummy (ARL VI-50)

$73.5 \mathrm{~kg}$ (162 lb) highly articulated dummy with pliable thorax and some incernal structures simulating human anatomy (Sierra Engineering Co. 292-850)

Human (extrapolated from lower

18.9

6570

29.2

25.0

5630 acceleration levels) 
accelerations encountered by the non-rigid test objects. However, it is evident that peak forces with a rigid test object are about twice what would be expected with a human subject. This factor, which is important in determining strength requirements for safety systems, is corroborated by results of drop tests by Boeing Safety Engineers [BO-1] using rigid objects and an articulated dummy and by the Construction Safety Association of Ontario (CSAO) [CS-3] using rigid objects and sandbags. Although the factor of two between the force generated by a rigid mass and a human under the same fall conditions is accepted for use in this report, additional verification with a variety of fallsafety systems and fall conditions is needed.

The human body has a resonant frequency for displacement of internal organs of about 50 to $60 \mathrm{~Hz}$. Motion of these organs could be excited by forces having a pulse width approaching a half period of this resonance. Sucn short pulses, about 0.01 second duration, are not likely to occur in fall-arrest situations.

It must be noted that the majority of available data relating to human subjects undergoing arrested motion is based upun lap or snoulder belt seat belt tests. Under these conditions, the forces are applied to skeletal structures rather than the soft abdominal region that would be acted upon by a body belt. Conversations with physiologists invariably indicated that much larger forces can be sustained by the pelvic girdle than by the abdominal region without resulting in injury.

\section{2 Tolerable Limits}

The level of force or acceleration that can be tolerated by the human body without severe injury is dependent upon several factors. In particular, for the case of a person having a fall arrested by a personal fall-safety system, the chance of severe injury will depend upon the way in which the force is transmitted to the body by the containment device, the location of the attachment point and the orientation of the body at the time of impact as well as upon the levels of force and acceleration that are encountered. Unfortunately, the information that is available on the force and acceleration levels that can be tolerated is meager and has come from tests on young, healthy, male volunteers, carefully restrained in an optimal position and anticipating the impact. Such tests have 
generally been concerned with ejection seats, lap belts, and shoulder harnesses for automative and airplane use or parachutes with body harnesses. Using such data to establish limits for accidental falls, especially where body belts and chest-waist harnesses are used, must be done with extreme caution.

In discussing injuries in crashes of aircraft, H. G. Armstrong $[\mathrm{AR}-5]$ states:

"The forces transmitted to occupants of the aircraft are determined by: (1) their attenuation and absorption by structures intervening between the occupant and areas of the aircraft impinging against the ground; (2) distance and direction of displacement of the occupant; (3) area, configuration, and resistance of objects against which the occupant is decelerated; (4) attenuation and absorption of force by the body of the occupant; (5) rate of application of the forces; (6) frequency characteristics; and (7) duration.

"The problem of evaluating the effect of these factors requires controlled experimental exposure of human, animal, and anthropomorphic dummy subjects to crash type decelerations. Progressively augmented combinations of these variables will determine tolerance and survival limits. Simultaneously, the efficacy of various restraint configurations and development of basic principles of crash protection can be explored.

"Progress in the field has been limited by the formidable mechanical problems, the difficulties of developing, maintaining and operating experimental apparatus subjected to high impact forces, and the hazardous nature of the experiments for human subjects."

Since the duration of an impact has an effect on its tolerance by the human body, it is convenient to show injury potential in the form of "Eiband" curves where injury levels are shown as a function of acceleration level anā duration. Such a plot using data from [BI-l and SN-1] is shown in Figure 1. This curve shows that, for accelerations in the $a_{z}$ direction, acceleration up to $10 \mathrm{gn}$ are acceptable to volunteers while accelerations over $30 \mathrm{~g}$ can be expected to result in severe injuries. Ejection seats, where use may 


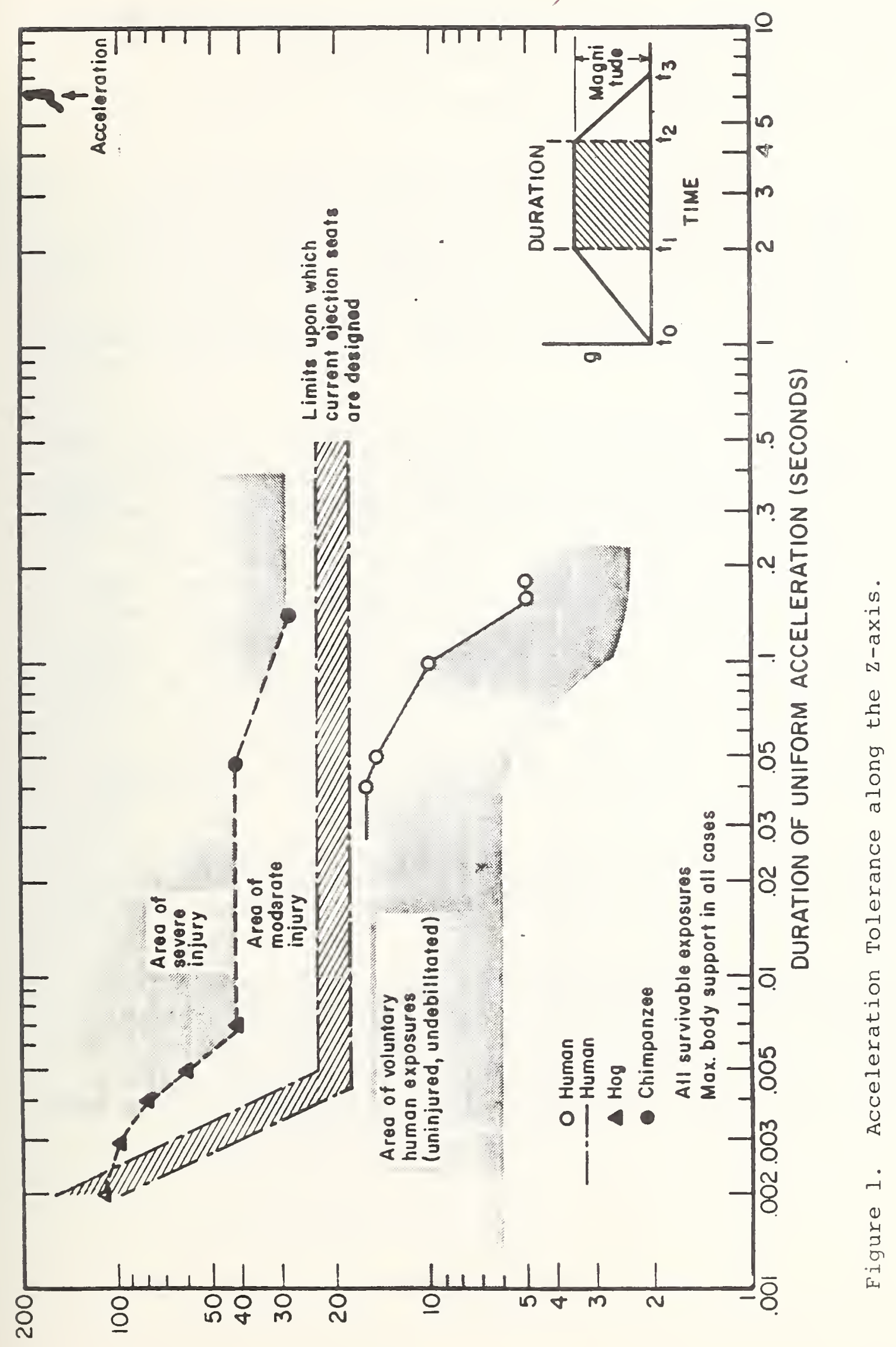

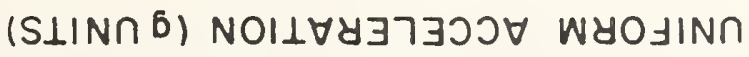


acceptably result in some injury, are designed for impacts of 18 to $20 \mathrm{gn}$. It should be noted that all of the data in Figure 1 were taken with maximum body support.

In their chapter on Aviation Medicine [GL-1], A. P. Gagge and R. S. Shaw state:

"In exposure to accelerations lasting about $1 / 10$ sec, the time is too short for development of anoxic neurologic symptoms of long-term positive acceleration and for moving sufficient volumes of blood to cause the vascular effects of long-term negative acceleration. Tolerance limits to acceleration of this duration are defined by stress limits of the supporting structures of the body, such as the bones, ligaments, and organ attachments.

"Acceleration tolerance increases as exposure time decreases to hundredths and thousandths of seconds, because in these brief periods, high forces will result in only small displacements of the portions of the body to which the force is applied relative to the rest of the body. Small displacements may be absorbed by elastic compression of the body without damage. When forces of this duration are excessive, the resultant injury is apt to be localized to the point of application of the force and characteristic of a blow. Here it is not the magnitude of the force per se which is important in causing injury, but rather the magnitude of the pressure to which tissues are subjected. Thus, the area over which the force is applied is of great importance and will be discussed under crash injury."

The IJaval Aerospace Medical Research Laboratory presently accepts the acceleration levels shown in Table 4 as design criteria for military personnel equipment such as ejection seats and parachutes.

Physiologists and others concerned with the causes of impact injuries were found to agree that significantly higher levels of impact can be tolerated with a restraining belt around the pelvic girdle rather than the abdominal region. These authorities estimate the injury threshold at less than $10 \mathrm{~g}_{\mathrm{n}}$ for restraint about the abdominal region and at 15 to $20 \mathrm{gn}$ for belts around the pelvic girdle. 
Table 4

Acceleration Levels Accepted by the Naval Aerospace Medical Research Laboratory

\begin{tabular}{|c|c|}
\hline Direction (a) & Magnitude \\
\hline$+a_{z}$ & 25 \\
\hline$-a_{z}$ & 20 \\
\hline $\pm a_{y}$ & 15 \\
\hline$+a_{x}$ & 15 \\
\hline$-a_{x}$ & 38.7 \\
\hline
\end{tabular}

(a) Referred to body centered geometry system, Table 2 . 
Best's Safety Directory 1976 [BE-2] points out that the level of shock loading in the body in a fall involving an industrial body belt will depend upon the location of the dee-ring. Since the back and ribcage will be subjected to pressure as the belt is loaded, a shock load below 8900 newtons (2000 lbf) is suggested. It is therefore recommended that, with a body belt, the shock load be limited to $8900 \mathrm{~N}(2000 \mathrm{lbf})$ or $8 \mathrm{gn}$ with a maximum free fall of 0.6 meters ( $2 \mathrm{ft})$. With a body harness a maximum free fall of $1.8 \mathrm{~m}(6 \mathrm{ft})$ is recommended.

Several organizations, including the American National Standards Institute (ANSI) [AN-1], the Canadian Standards Association (CSA) [CS-I], and the Construction Safety Association of Ontario (CSAO) [CS-3] have adopted a 10 gn acceleration limit in the $+a_{z}$ direction. Although the Iimited available injury data does not appear to contradict this value, it may be higher than should be allowed when body orientation cannot be controlled and especially with the use of body belts.

The British Standards Institute [BS-4] Iimits the free fall distance to $0.6 \mathrm{~m}$ (2 ft) and $1.8 \mathrm{~m}$ ( $6 \mathrm{ft}$ ) for use of body belts and body harnesses, respectively. This is based upon the use of a lanyard $1.8 \mathrm{~m}$ ( $6 \mathrm{ft}$ ) long.

In evaluating ejection seats and the acceleration environments experienced after separation from the aircraft, the U.S. Navy [AS-2] Iimits $+a_{z}$ to $17 g_{n}$ for an expected rate of spinal injury of $5 \%$ or less.

C. T. Morgan comments [MO-1] that the limiting factor in human tolerance to headward acceleration $\left(+a_{z}\right)$ in the normal seated posture is spinal fracture in the upper lumbar portion. With optimum alignment up to $35 \mathrm{gn}$ can be tolerated at less than $500 \mathrm{gn}$ per second onset. However, with the back bent forward to the limit of motion, this limit diminishes to less than $15 \mathrm{gn}$.

In the use of parachutes, injuries may occur as often as once in 20 uses, where accelerations exceed $20 \mathrm{gn}$. Again C. T. Morgan [MO-I] reports that parachutes opening shocks are greatest at high altitudes and that impact accelerations below $20 \mathrm{~g}_{\mathrm{n}}$ are considered safe, 20 to $30 \mathrm{gn}$ are borderline and over $30 \mathrm{~g}_{\mathrm{n}}$ are dangerous for man, parachute and harness.

Somewhat in contrast, a French medical team that watched drop tests with an articulated mannequin concluded 
that it would be an exceptional person that could withstand accelerations greater than 6 to 8 gn [AR-1, AR-2]. This same study reports that a heavily clothed stuntman jumped about $0.67 \mathrm{~m}(2.2 \mathrm{ft})$ with a belt in the thoracic position resulting in an impact force of about $4700 \mathrm{~N}$ (1058 lbf).

The pain from this impact was so intense that the experiment was terminated at the subject's request. Although the mass of the subject was not reported, an estimate of $80 \mathrm{~kg}$ (175 lb) would indicate an acceleration of about $6 \mathrm{~g}$.

In another study [NS-3] performed by the General Motors Research Laboratory, a 75 year old man jumped in the prone position (belly whopped) from $10.7 \mathrm{~m}$ (35 ft) into a shallow pool of water. Accelerometers attached to the man recorded an acceleration of $70 \mathrm{gn}$, leading to the conclusion that the human chest can withstand substantial stress without injury. However, other reports from the same laboratory [KR-2, KR-3, $\mathrm{NE}-2$, $\mathrm{NE}-3$ ] show poor correlation between thoracic impact forces and injuries, but indicate that serious injuries to cadavers occurred at force levels below $4450 \mathrm{~N}$ (1000 lbf).

The German Alpine Club has published the results of tests from which it concluded that waist tie-ins can result in death when forces exceed $3750 \mathrm{~N}(840$ 1bf). In mountaineering a rope is usually tied around the waist to form a body restraint system. Such a narrow belt would result in a higher pressure (stress) than the usual body belt.

The effect of age and physical condition on acceleration tolerance is pointed out by UIAA tests which showed that climbers under 34 years of age can normally withstand two to three times the acceleration that older climbers can accommodate.

In the use of a lineman's belt, there is a high probability that a fall would result in a tax acceleration and backbend or reverse jackknife. Because of the large chance of vertebral damage, the acceptable level of average body acceleration is probably only 4 to $5 \mathrm{gn}$.

Military specification MIL-S-18471 for airplane ejection seats calls for a maximum impact velocity for parachutists with a vertical component not exceeding $7.3 \mathrm{~m} / \mathrm{s}$ (24 ft/s). This would be equivalent to a free fall of $2.7 \mathrm{~m}$ (9 ft) and would accept a moderate level of injury since the concern is to save the life of the ejector. Experienced jumpers and physiologists suggest that the impact speed 
should not exceed $4.6 \mathrm{~m} / \mathrm{s}$ (15 ft/s), equivalent to a free fall of $1.1 \mathrm{~m}(3.6 \mathrm{ft})$, if a moderate injury rate is not acceptable.

From the above discussion, it can be seen that there is limited information available on the acceleration and force levels that would be acceptable for construction and industrial workers using personal fall-safety systems. Since even this limited information has been obtained under optimal test conditions, both in terms of the subject and the fall parameter, levels significantly lower should probably be specified. Certainly additional information should be sought to provide a better basis for specifying maximum acceptable levels.

Efforts are now being made to model the response of the human body to impact loads using mathematical modeling techniques, for example see [SA-1]. Although much of this effort is now being directed at automobile crash situations, the technique being developed may be applicable to the study of fall-arrest.

2.3 Tnformation from Accidents Involving Fall-Arrest Systems

In the course of this study more than one hundred possible sources of fall-related injury data were contacted. These included military and other Government agencies, industrial organizations, safety associations, mountain climbing and skydiving clubs, workmen's compensation organizations, and foreign groups. Little pertinent information was obtained because the reports generally did not contain sufficient details to be of use or the pertinent cases could not be readily extracted from the mass of information on file.

At least half of the fall data obtained involved fallsafety devices that were not correctly secured to an anchorage, i.e. the falling worker did not remain linked to the anchorage under the impact of the fall. These falls generally resulted in fatalities and serve more to illustrate the misuse of these devices than the effectiveness when properly secured.

Only about 35 cases involving falls into correctly secured fall-arrest systems were located, and in two of these the lanyards failed upon impact, probably due to sharp edges on the structural members they were tied around. In 
the remaining cases, the falls were successfully arrested with no significant injuries. Most falls were reported to have involved free falls of from 1.2 to $2.4 \mathrm{~m} \mathrm{(4} \mathrm{to} 8$ ft), and presumably involved fall-safety systens using body belts. The few injuries that were received came from contacts with other surfaces during the fall.

The interest in fall-safety equipment that is generated by an accident is shown in the work of the safety Engineering Department of the Boeing Company [BO-l]. To quote from this work:

"During a modification program at Wing II, an airman, wearing a safety belt, lanyard, and shock absorber, fell when an elevator work platform from which he was working failed because of improper assembly. The airman's safety devices arrested his fall and saved his life. Because similar safety equipment is used by Boeing personnel, this accident aroused much interest about shock absorption characteristics of various safety devices used and the degree of attenuation of the shock load."

Tis study instigated by this accident found considerable information relating to catapult and seat ejection situations, but found no literature or data about shock absorption properties of commonly used personnel protective devices. With a few modest exceptions, the situation is essentially the same today.

Another study by the Construction Safety Association of Ortario [CS-3] was, in part, instigated by the deaths noted above of two Canadian contruction workers in unrelated accidents due to failure of their fall-arrest systems. Both failures were attributed to lanyard severing by sharp edges of beams. As a result, tests were made to determine system strength as a function of anchorage type and tie-off method.

In contrast to the relatively good history of industrial use of fall-safety equipment, an article in a mountaineering mayazine "Summit" [KI-2] discussing the swami-belt reports:

"Of 20 swami-belted climbers who fell and were rescued after hanging in their ropes, three died immediately after rescue; two others developed kidney failure; and one could be saved. Three others died within 1 to 11 
days after rescue, despite intensive care to restore circulation."

The swami-belt is essentially a rope tied around the waist to form a body restraint device.

The relatively few documented case histories of accidents involving the proper use of current industrial type fall-safety systems indicate that radical modifications of these systems are not required. Small changes, a better understanding of the various components and their interactions to improve system selection, and more education on the proper use and limitations of the systems may be adequate. However, more adequate data based upon the use of such systems are needed and could result in future modification of a regulation controlling the production and use of these systems. 
For the purpose of this report, fall-safety systems consist of personal equipment designed to provide a, worker with protection from falls from a working or walking surface or, should he fall, to arrest his motion with a minimum chance of injury and to provide for his rescue. These include fall-restraint systems designed to prevent a worker from maneuvering into a potential fall situation, fallarrest systems designed to limit the fall distance and minimize possible injuries, and emergency retrieval systems intended to allow a fall victim or a co-worker to bring the victim to a safe location. In this report, the emphasis is on fall-arrest systems.

\subsection{The Physics of Fall-Arrest}

The functions of any requirements for a fall-arrest system can be related to the simplified, lumped parameter, damped spring mass system shown in Figure 2. In this figure, the damped spring corresponds to the fall-arrest system, in particular the lanyard; the mass, M, corresponds to the fall victim, and the pan, P, simulates the constraint system (belt, harness, etc.). For simplicity, it is assumed all parts except the mass are negligibly light and that the damping is negligible. It is also noted that previous discussions have shown concern for injuries resulting from force, acceleration, and velocity at impact.

Mass, M, falls freely, under the influence of gravity, a distance, $h$, before contacting the pan, $P$, which is rigidly attached to the damped spring, $k$. As a result of this impact, the spring will elongate a distance, $\Delta \mathrm{L}$, before the downward motion is arrested by the tension, $T$, of the spring. Depending upon the damping, there may be subsequent oscillations, but these will not be considered here since the highest values of the parameters of concern will occur during this first downward motion.

During the free fall, potential energy of the mass, PE $=\mathrm{Mg}_{\mathrm{n}} \mathrm{h}$, will be converted to kinetic energy, $\mathrm{KE}=\mathrm{Mv}^{2} / 2$. Since these quantities are equal, the velocity at impact will be

$$
v_{\text {impact }}=\sqrt{2 g_{n} h}
$$

where $g_{n}$ is the acceleration due to gravity. 


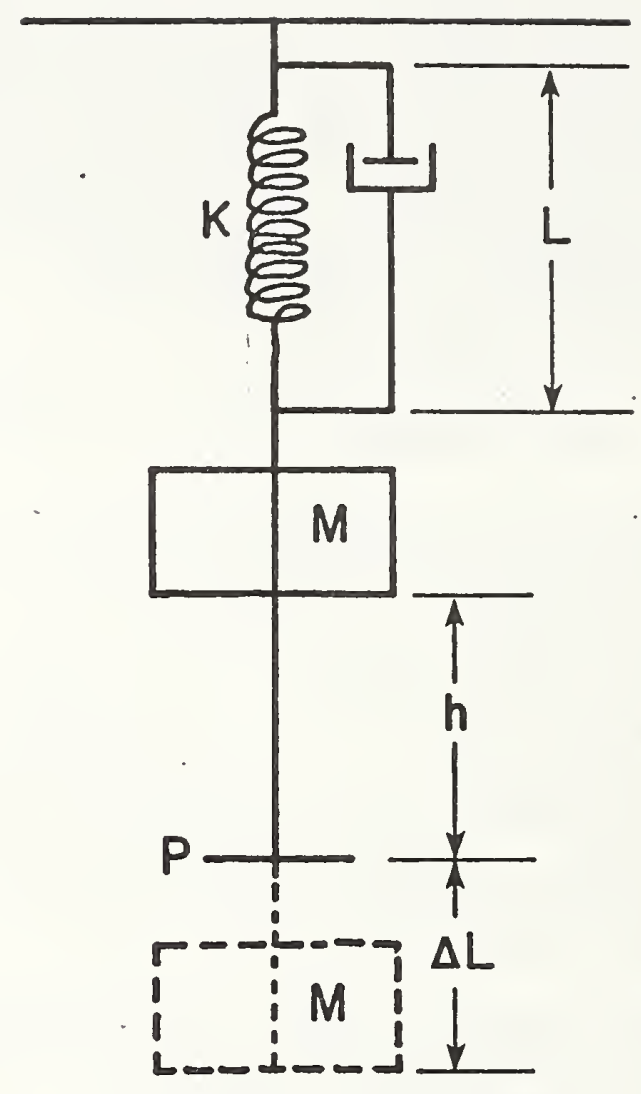

Figure 2. Damped Spring Mass System 
At any point during the fall, the change of potential energy of the mass must be equal to the kinetic energy ( $\mathrm{KE}$ ) of the mass plus the energy stored by the spring (SE). In particular, at the point of arrested motion, the spring will have extended a distance, $\Delta L$, the kinetic energy will be zero, and

$$
\mathrm{SE}=\mathrm{Mg}_{\mathrm{n}}(\mathrm{h}+\Delta \mathrm{L})
$$

The energy of the spring, SE, can also be computed from the force to elongation relationship of the spring, which might be of the form shown in Figure 3. This energy is given by the area under the curve over the elongation 0 to $\Delta \mathrm{L}$ (the shaded area). For given values of $\mathrm{M}, \mathrm{h}$, and forceelongation relationship, an iterative procedure can be used to find the maximum tension, $\mathrm{T}_{\mathrm{max}}$, and the elongation, $\Delta \mathrm{L}$. This is best done by computer techniques.

In Figure 2, the total force acting on Mass, $M$, in the upward direction is

$$
F=T-M g_{n}
$$

Using the familiar relationship, $F=m a$, the upward acceleration of mass, $M$, due to tension, $T$, in the spring (lanyard) is given by

$$
a_{1}=F / M=T / M-g_{n}
$$

However, it is probably the total acceleration imposed upon the body in a short increment of time that is a major factor in causing injury. In a fall accident situation, this quantity is more properly given by

$$
a=\left(a_{1}+g_{n}\right)=T / M
$$

This quantity, $a$, is also the one that would correlate with the results of arrested sled tests where the effect of gravity is perpendicular to the acceleration generated in the test.

In this report the acceleration is considered to be that defined by Equation 5 unless otherwise stated, and the tension in a lanyard for a given acceleration is

$$
T=M\left(a_{1}+g_{n}\right)=M a
$$




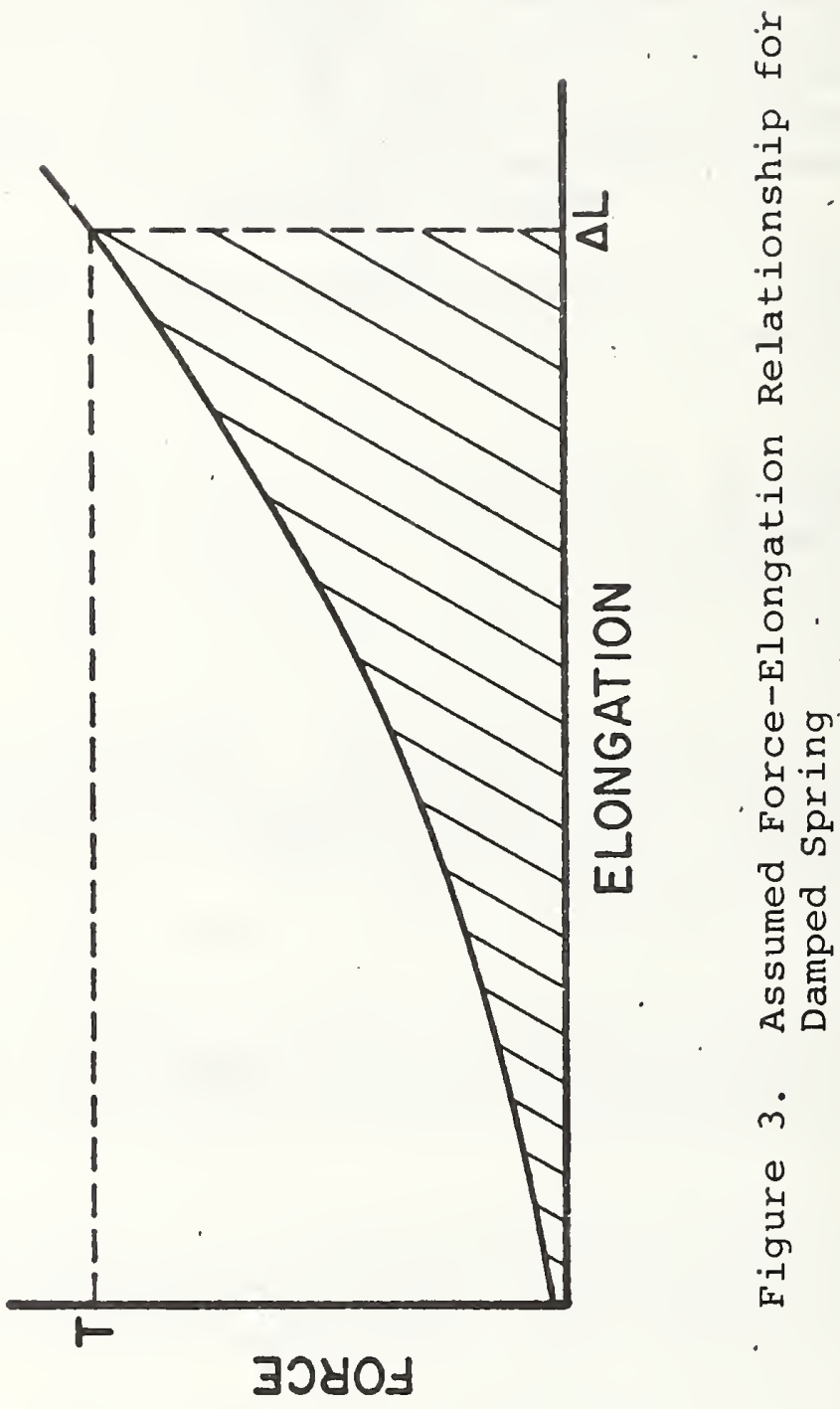


The relationship between the peak force or acceleration imposed upon the falling object, the free fall distance and the spring (lanyard) characteristics can be put in a readily usable form if the spring can be assumed to obey Hooke's law. This is a linear relationship and is given by

$$
F=k \Delta L / L \text { or } \Delta L=F L / k
$$

But the energy absorbed by the spring (lanyard) is

$$
\mathrm{SE}=\mathrm{Mg}_{\mathrm{n}}(\mathrm{h}+\Delta \mathrm{L})
$$

and, assuming a linear relationship, is also given by

$$
\mathrm{SE}=\mathrm{F}(\Delta \mathrm{L}) / 2
$$

Substituting for $\Delta \mathrm{L}$ and equating these expressions gives

$$
F^{2} / 2 M g_{n}-F-k h / L=0
$$

Solving for the force and noting that $F \geq 0$

$$
F=\left[1+\left(1+2 \mathrm{kh} / \mathrm{Mg}_{\mathrm{n}} L\right)^{\frac{1}{2}}\right] \mathrm{Mg}_{\mathrm{n}}
$$

or the acceleration in units of $g_{n}$ is

$$
\mathrm{a}=\mathrm{F} / \mathrm{Mg}_{\mathrm{n}}=\left[1+\left(1+2 \mathrm{kh} / \mathrm{Mg}_{\mathrm{n}} \mathrm{L}\right)^{\frac{1}{2}}\right]
$$

Letting the ratio of the spring stiffness, $k$, to the weight of the falling object, $\mathrm{Mg}_{\mathrm{n}}$, equal $\mathrm{k}_{1}$, gives

$$
a=\left[1+\left(1+2 k_{1} h / L\right)^{\frac{1}{2}}\right]
$$

Several things can be seen from this last equation. These include:

(1) The imparted acceleration becomes greater as $\mathrm{kl}$ increases, i.e. with a stiffer spring or a lighter object.

(2) The force or acceleration is a function of the ratio of free fall distance to spring length, $h / L$, i.e. greater fall distances can be tolerated if longer lanyards can be used without introducing other problems.

(3) The minimum acceleration when no free fall occurs, $\mathrm{h}=$ 0 , is $2 \mathrm{gn}$. The lowest peak force that a lanyard will be subjected to in arresting a fall is therefore $2 \mathrm{Mg}_{\mathrm{n}}$. 
Figure 4 shows computed values, assuming Hookian behavior, of acceleration for $\mathrm{h} / \mathrm{L}$ values from 0 to 2 (the maximum value possible), and a $\mathrm{k} / \mathrm{Mgn}$ value of 70 . A straight line fitted to the points for $h / L$ values from 0.3 to 2.0 is also shown. Although the function is not linear, it is suggested that the linear approximation could give realistic guidance for the design, selection, and use of fall-safety equipment. The assumptions of rigid mass and ideal fall conditions should also be noted.

A more detailed discussion of this concept, in particular Equation 10, as applied to safety in mountaineering can be found in [WE-l].

Another situation of interest involves the use of a horizontal lifeline to permit a worker freedom of horizontal motion while protecting him from a vertical fall. This situation corresponds to Figure 5 where the lifeline corresponds to $\mathrm{ABC}$, the lanyard to $\mathrm{BD}$, and the fall victim to the mass, M. To be conservative and for simplicity, it is again assumed that all energy is absorbed in the lanyard and the maximum tension in the lanyard can be found as described above. Using the principles of statics, the tensionc in the two ends of the lifeline are found to be:

$$
\begin{aligned}
\mathrm{T}_{1} & =\frac{\mathrm{T}}{\cos \alpha \tan \beta+\sin \alpha} \\
\mathrm{T}_{2} & =\frac{\mathrm{T}}{\cos \alpha \tan \beta+\sin \alpha}
\end{aligned}
$$

The greatest lifeline tensions occur when $\alpha$ and $\beta$ are small, and the worst case is when $\alpha=\beta$. Some values of the ratio of lifeline tension, $\mathrm{T}_{1}$, to the lanyard tension, $\mathrm{T}$, when $\alpha=\beta$

are shown in Table 5. From this table, it is seen that lifeline loads can become quite large when only a small sag is permitted.

All of the above have ignored any energy absorption or dissipation within the falling body or by rotational or swinging motions of the body. As was discussed earlier, the human body is a complex, highly articulated, non-rigid structure, and will absorb significant energy during an arrested fall. In fact, it was suggested that the peak force in an actual fall accident would be about one-half of that computed using the rigid body assumptions of the model used here. It should be noted, however, that this value is empirical and based on very limited data. 


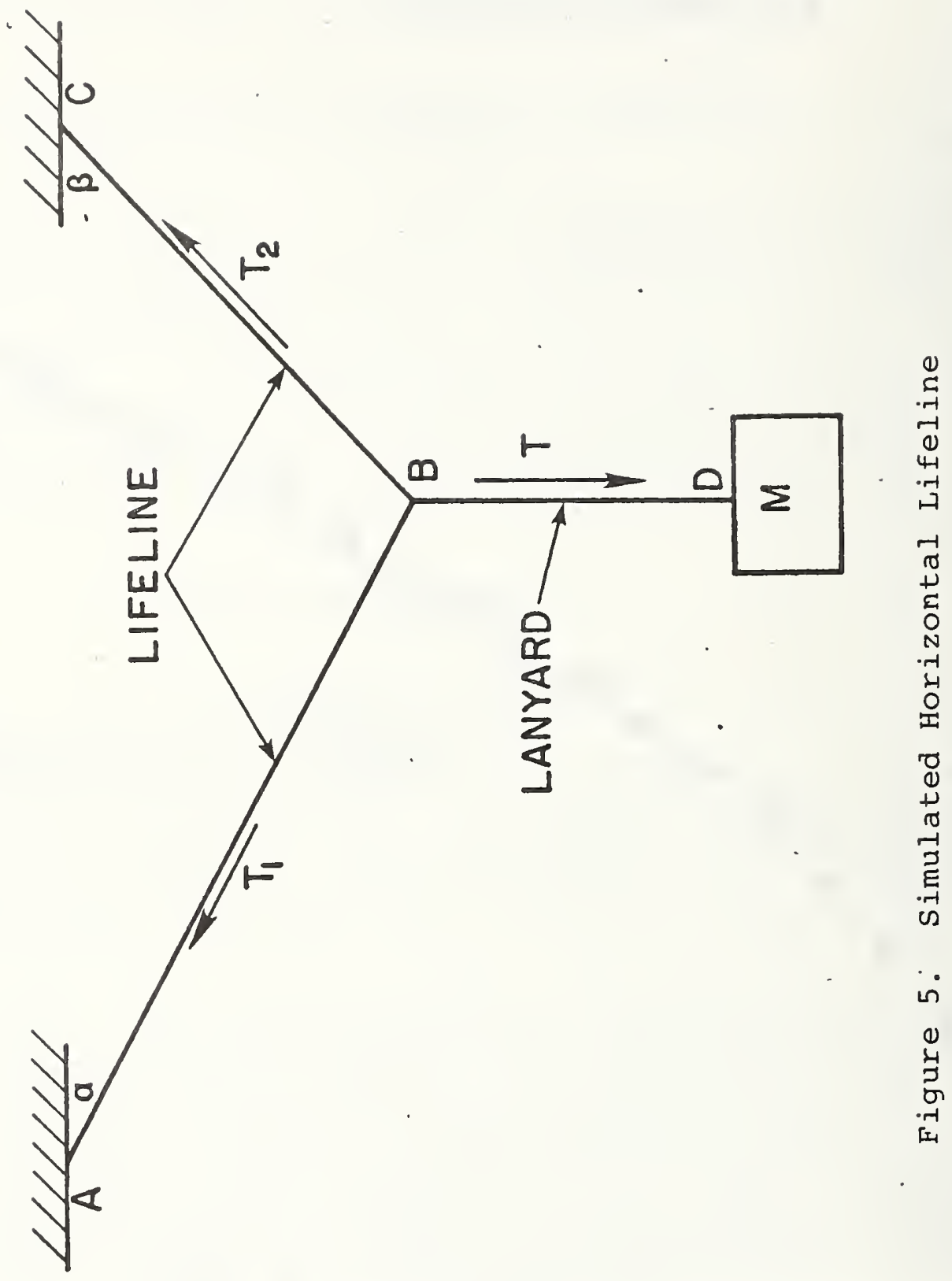




\section{Table 5}

Ratio of Tension in Lifeline to

Tension in Lanyard (Figure 5)

\begin{tabular}{cc} 
Angel $\alpha=\mathrm{B}$ & Ratio $\mathrm{T}_{1} / \mathrm{T}$ \\
\hline $\begin{array}{c}2 \text { degree } \\
10\end{array}$ & 5.74 \\
15 & 2.87 \\
30 & 1.93 \\
45 & 1.00 \\
60 & 0.71 \\
75 & 0.58 \\
80 & 0.52 \\
85 & 0.51 \\
\hline 5
\end{tabular}


The model also assumes that no energy is absorbed by any part of the fall-safety system except the lanyard. Since this will not be strictly true, the actual forces and accelerations will be less than predicted by the model.

\subsection{Anthropometric Basis}

rine design, performance requirements and testing procedures for fall-safety equipment depends upon an antingometric knowledge of the workers who are to be protected. In particular, with regard to performance requirements and testing procedures, the range of worker weight and waist dimensions are of concern.

A survey conaucted in 1962-63 by the National Center for Health statistics (NCHS) [NC-2] provides the weight data snown in Table 6. It should be noted that these data are for partially-clothed subjects ( $1 \mathrm{~kg}$ or 2 lb estimated), and that similar data for 1977 might be expected to be slightly higher, perhaps $0.5 \mathrm{~kg}$ ( I Ib). Nude weights would therefore be estimated at $0.5 \mathrm{~kg}$ ( 1 lb) less than shown in Table 6 . These data are in reasonable agreement with estimated industrial worker weight, taken from a pre-1946 survey [MC1], after corrections are again made for clothing weight and increase in average weight since 1946.

In order to obtain the effective weight of the worker, an estimate of the weight of clothing and other items is needed. For construction workers these might include:

(1) shirt, trousers, belt, socks, and undergarments;

(2) watch, wallet, keys, etc.;

(3) safety shoes:

(4) safety hat;

(5) tools and tool pouches;

(6) jacket and gloves; and

(7) body containment device of the fall safety system.

Military studies [DA-2] indicate that the standard Army uniform (underwear, shirt, trousers, shoes, socks, steel helmet, and helinet liner) adds $5.4 \mathrm{~kg}(11.8 \mathrm{lb})$ to the nude weight of a soldier and an overcoat adds an additional 3.1 $\mathrm{kg}(6.8 \mathrm{lb})$. It is therefore estimated that the clothing and equipment of a construction worker will add about $7.3 \mathrm{~kg}$ ( $16 \mathrm{lb}$ ) to his nude weight. Making these modifications to Table 6 gives the values given in Table 7 as estimated weights of equipped construction workers. 


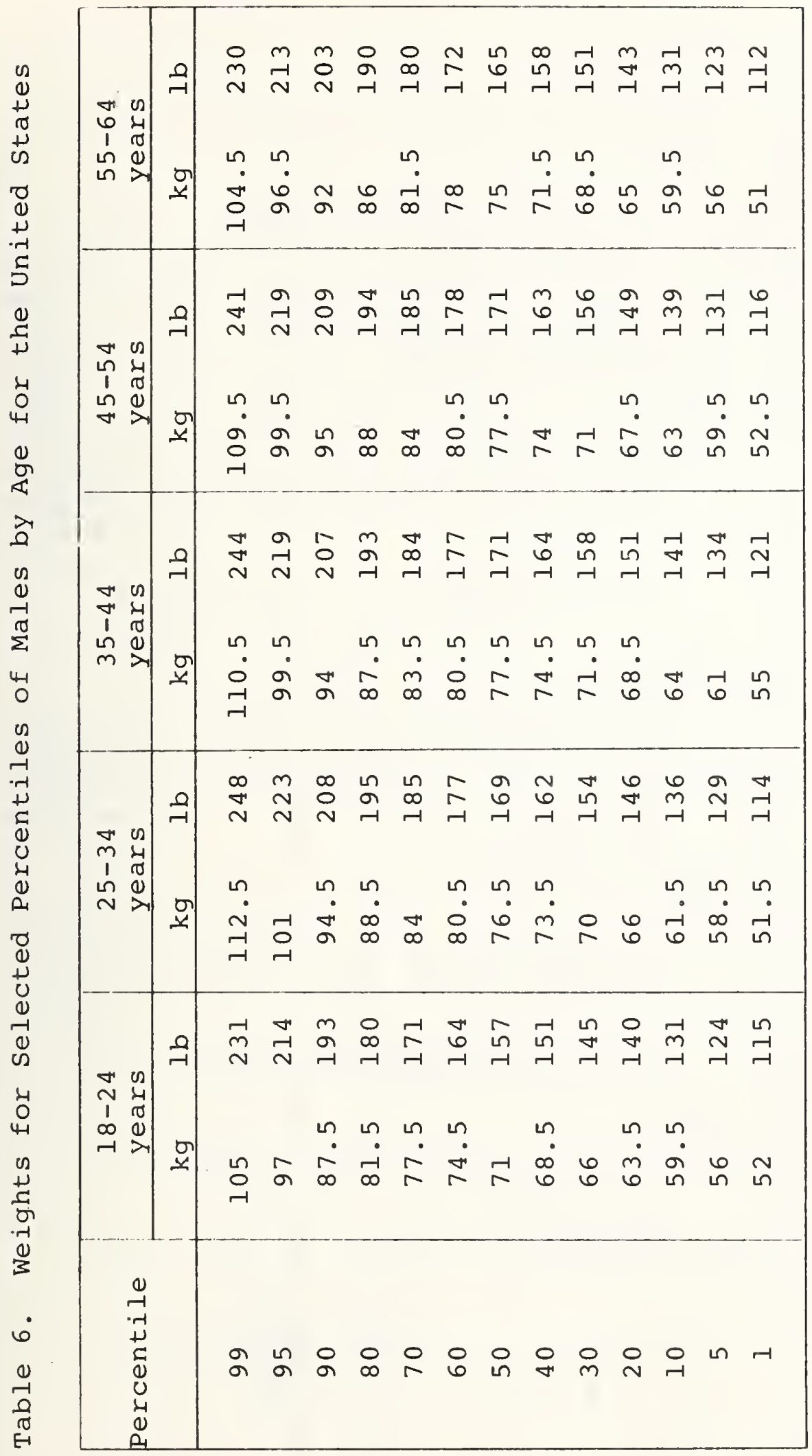




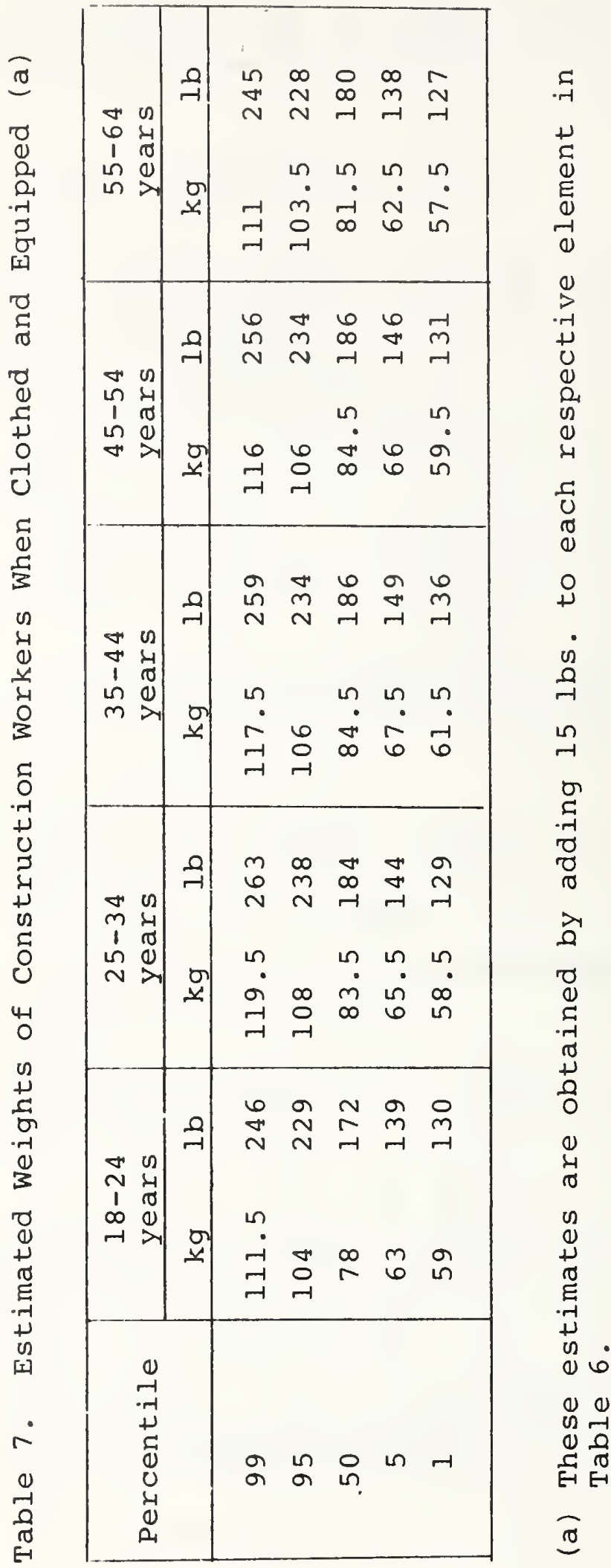


From Table 7 , it is seen that a weight range of 59 to $113 \mathrm{~kg}$ (130 to 250 lb) would include workers in the first to 98 th percentile. However, it should be noted that this does not allow for any predisposition for ethnic or age groups to enter the construction trades, nor does it consider the possibility of female workers.

Data compiled by Dr. Van Cott [VA-l] on the waist depth of various segments of the population is shown in Table 8 . A 1962 study by ivCHS [NC-1] showed that the average waist girth in the general population was $890 \mathrm{~mm}$ (35.0 in). This has probably increased at this time to 915 to $940 \mathrm{~mm}$ (36 to 37 in). Based upon Table 8 , it is estimated that the waist depth of the current construction worker is about $255 \mathrm{~mm}$ (10 in). Based upon these values and assuming that waist has an elliptical shape, the average worker's waist breadth is estimated to be about $330 \mathrm{~mm}$ (13 in). To summarize, the average construction worker is estimated to have waist dimensions of

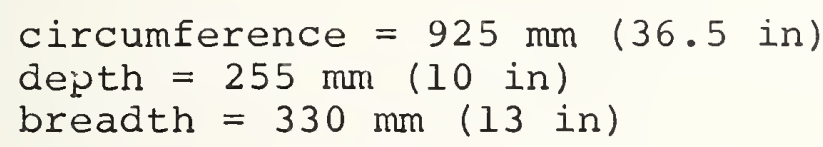

The fully dressed worker might be $13 \mathrm{~mm}$ (0.5 in) larger than this in depth and breadth and about $40 \mathrm{~mm}$ ( 1.5 in)

larger in girth. Mandrels and torso dummies of this approximate size and shape would be appropriate for testing body belts.

\subsection{Behavior of a Fall-Safety System During Fall-Arrest}

For a fall-safety system to have successfully arrested a fall, it must have:

(1) contained the body of the victim without causing injury or undue discomfort;

(2) absorbed the kinetic energy of the falling body so that force and acceleration levels remain tolerable;

(3) limited the fall distance so that injuries are not caused by contact with other objects; and

(4) provided a means for delivering the victim to a safe location. 


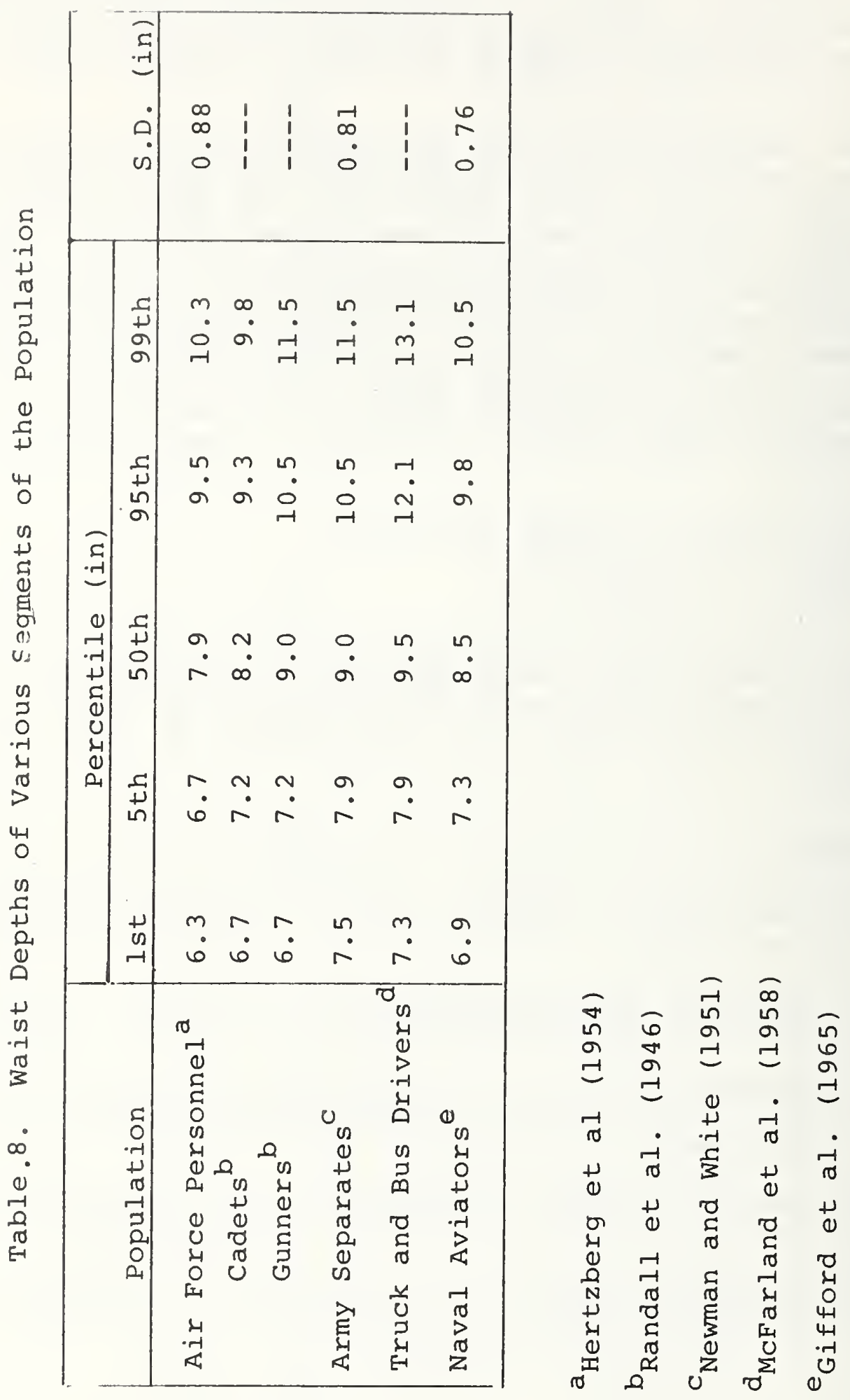


The containment device is the body belt, chest-waist harness, body harness (parachute type), or other components designed to contain the body of a falling worker and to distribute the forces resulting from an arrested fall so as to minimize the possibility of injury. The three types of containment devices most commonly used are shown in Figure 6. These devices are generally attached to a lanyard. They are not expected to absorb an appreciable amount of energy.

The observed actions of body belts during drop tests with articulated and anthropomorphic dummies was reported by Boeing safety engineers [BO-l] as follows:

"Arresting force is transmitted to the area in contact with the belts. A portion of the kinetic energy is absorbed in decreasing the linear velocity by translational and rotational acceleration imparted to the body the the arresting lanyard. The hinge points around which these forces act depend on the body attitude at the time of the application of the force. Maximum force on the body would be experienced when the hndy mass is moving in a downward direction and the restraining device is moving in the upward direction. If a body is falling in a feet-first attitude, the unrestrained parts of the body are rotated around the belt as the lanyard tightens. The rate and direction of rotation depend on the relationship of the body center of gravity to the point of the arresting force. If the body CG is below the D-ring of the belt, the belt will have tendency to pull up toward the head. If the belt is loose, there is danger of the individual slipping out, or of the body area in contact with the belt being severely abraded. As the force increases, the head and upper parts of the body are given an angular acceleration as the dee-ring of the belt is pulled normal to the axis of the belt. The portion of the body below the support area acts as a

counterbalance. Therefore, the unbalance force depends on the ratio of the center of gravity of the mass above and the center of gravity of the mass below the point of application of the arresting force. Note then, that a waist belt acts as a fulcrum around which the unrestrained parts of the body rotate. Direction of rotation depends on the location of the dee-ring. Should the dee-ring be located at the front of the person, the arresting force would be in the negative 


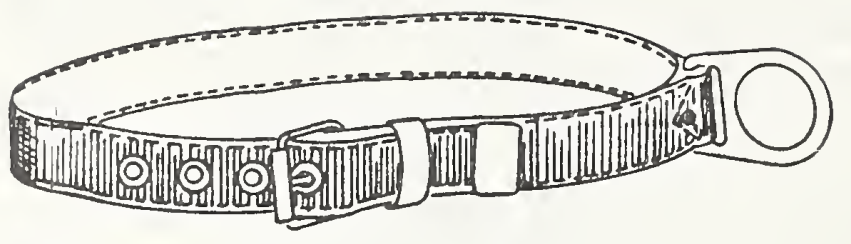

\section{BODY BELT}



Figure 6. Commonly Used Types "of Body-Containment Devices 
chest-to-back direction. Arrest from even a three foot fall with the arresting force applied in the negative airection could result in serious (if not fatal)

injury. Also, the impact force is applied over a small area of the body. Internal injuries such as tearing of arteries, spleen, and intestines, and rupture of the kidney have been caused by waist belts during impact.* Should this belt be used to arrest a fall in a confined area, there is danger of head injury as a result of the jackknifing of the body around the belt. Results of this test show that, when a safety belt is used with a rope-grab shock absorber, the shock load is in the $3 \mathrm{~g}$ range. However, from the above observations, the use of this type device for protection against an accidental fall is not recommended."

The Boeing report [BO-l] also included the evaluation of chest-waist harnesses with the following conclusions:

"The chest-waist harness distributes the shock load over a larger area of the body than a waist belt. Arrest with this type of harness is less severe and the arrested attitude is more nearly in an erect position. It is believed that there would be considerable discomfort caused by this harness from severely pulling up under the arms. It was found, that, to prevent this harness from severely pulling up under the arms, the waist belt had to be excessively tight. If this harness is used for protection against a free fall, the waist belt must be fastened uncomfortably tightly."

A body harness is quite similar to a parachute harness except for being coupled to a lanyard and anchor rather than to a parachute. If the victim falls feet first, an impact akin to a "parachute opening shock" will be experienced.

The standard parachute has four riser straps coming up from the harness and linking up with the chute above the wearer. The standard Class VI body harness, however, secures to a lanyard by means of one of several dee-rings usually present on these harnesses. Except for $-a_{z}$ acceleration (which can cause brain hemorrhages), man is most susceptible to $t a_{y}$ accelerations. For impact acceleration durations of about 0.1 to $0.2 \mathrm{~s}$, the limiting $+a_{y}$ values above which it is probable that disablements will occur, are about 12 to $13 \mathrm{gn}$ [AS-2]. Thus, were a worker to fall into a harness secured to a lanyard through a dee-ring

*The reference alluded to here is a report on seat belt protection in automobile crashes. 
at the 3 to $90^{\prime c l o c k}$ position (where the buckle corresponds to 12 noon) and were he to suffer, say a $20 \mathrm{gn}$ deceleration, a disabling injury would probably occur. It is therefore imperative that a Class VI harness only be securable from a dee-ring high up on the back (between the shoulder blades) or from riser straps coupled to a dee-ring above the worker's head.

The action of the body harness is further described in Air standard 61/1 [AS-2] as follows:

"Another important factor is the placement of the fixation point of lanyard on the belt (harness). This must be on the back and not the chest in order to avoid the quick movement of the head towards the back. It is important to place it as high as possible, so that the body is vertically suspended after a fall, this means that the fixation point should be at the point where the shoulder straps cross in the back at level of the shoulder bone in an eye provided for this purpose. The dynamic strain is thereby divided between the two shoulder straps, transmitted to the safety belt in 4 different places, which assures a good distribution of tho pressure points on the thorax."

Although an impact into a body harness is not likely to produce a force profile identical to that for a flyer ejected from an aircraft, nevertheless, both produce basically $+a_{z}$ accelerations and, in both cases vertebral injuries are possible. The flyer, besides possible age and physical condition advantages, has a basic advantage of being accelerated in an optimal configuration into which he is, essentially, locked. It is most unlikely that a construction worker falling into a body harness-lanyard system (even one with riser straps off each shoulder) will impact in an optimal configuration.

In the Boeing study [BO-1] a tested body harness pulled up severely in the crotch region of an impacted dummy. Such potential action, although not necessarily engendering serious or irreversible injuries, could generate antipathy in workers with regard to body harness utilization.

\subsubsection{Energy Absorption}

In arresting a fall, the kinetic energy of the falling body must be absorbed (stored or dissipated). For most 
fall-safety systems, it is assumed that the lanyard is the primary, if not sole, component to absorb this energy. Exceptions would be where shock absorbers or rope grab systems that can reliably absorb appreciable energy are used. The energy absorption comes from the action of the force in elongating the lanyard and, as shown in section 3.1, can be calculated as the area under the forceelongation curve. In absorbing this energy, it is also necessary to keep the maximum force (tension) below the value that will cause injury to the victim and also below the breaking strength of the lanyard and other components of the safety systems. The system must also function so as to prevent the victim from being subjected to accelerations large enough to cause injury. A consideration of Figure 7 will show that the peak force and hence the peak acceleration will be significantly less for the system that elongates to $d_{2}$ than for the stiffer system that only elongates to $d_{l}$. The areas under the two curves are the same. Of course, other factors must also be considered since a greater elongation will provide more chance for striking other objects and will also impose a longer acceleration pulse which may be more likely to cause injury.

\subsubsection{Limited Fall Distance}

The total fall distance is significant because, as shown in Section 3.1, it is this parameter combined with the mass of the falling body that determines the energy that must be absorbed, and hence the force and acceleration levels that must be sustained. The fall distance takes on further significance since all injuries found involving properly secured fall-safety systems (about 35 cases) resulted from contact with other objects during the fall.

The fall distance is limited by controlling the length of the lanyard and method of anchoring so that the free fall, before taking up the slack in the lanyard, cannot exceed a predetermined limit. The total fall distance also includes the elongation of the lanyard (and other parts of the fall-safety system) and can be limited by making these systems stiff. As discussed in the previous sections, a compromise is necessary to avoid excessive fall distance and also keep force and acceleration levels to tolerable values. 


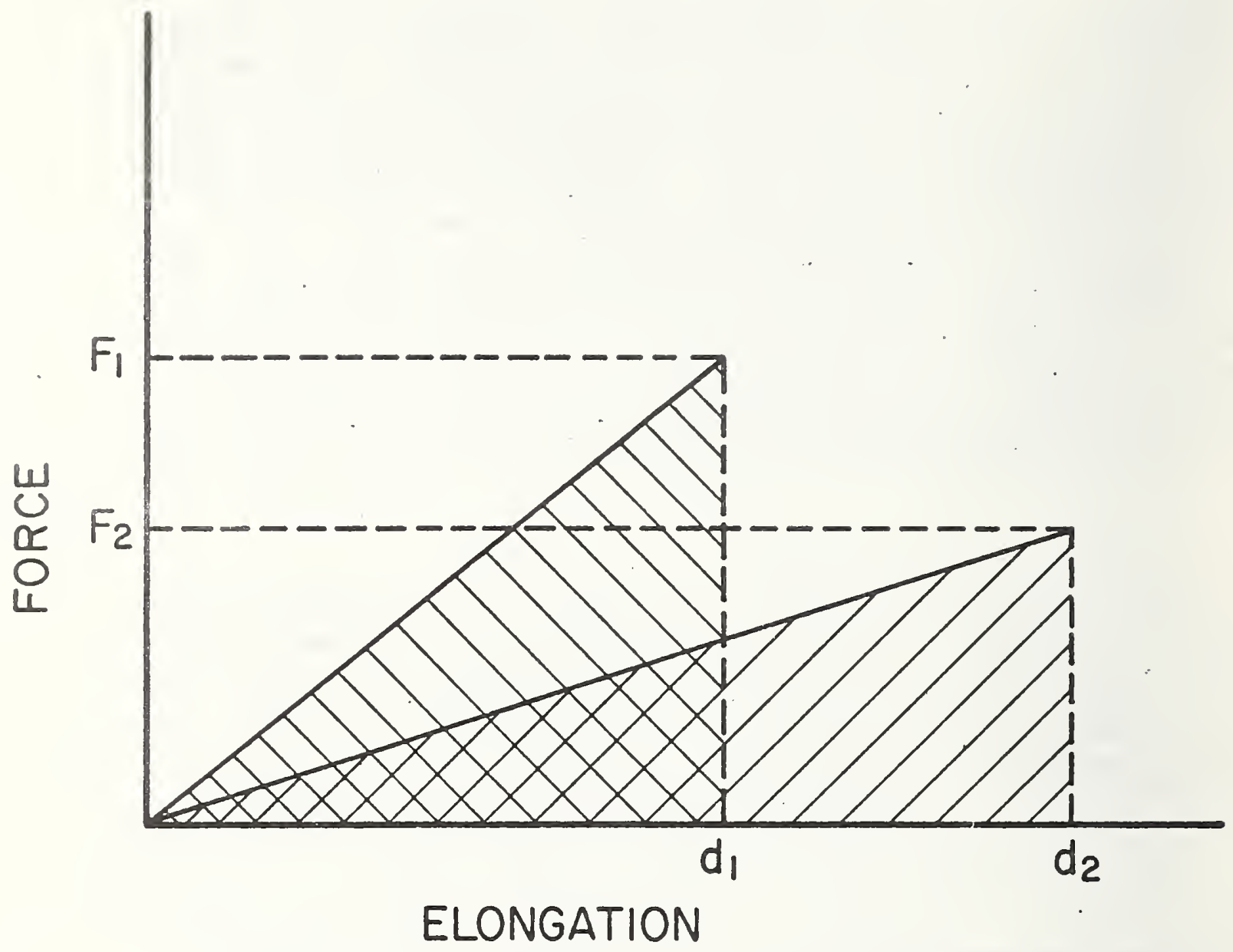

Figure 7. Equal Energy Absorption by Two Idealized Fall Safety Systems 


\subsubsection{Rescue}

Little is accomplished if a fall is arrested only to nave the victim suspended to suffer injury or death from exposure or impact due to swinging into other objects. There are also situations where a worker may descend or ascend into relatively inaccessible areas where assistance from a co-worker, or possibly a self-controlled ascentdescent device, will be needed to insure his safe return. If the worker is descending through a narrow opening and may become injured or unconscious and have to be extracted by a co-worker, it is essential that the safety system maintain him in an upright position so he can pass through the opening.

In a controlled descent situation, if the worker is immobilized, the device should lower him at a controlled, slow rate to the level below, either automatically or with the assistance of a co-worker on an independent surface. The device should also be adjustable so that the worker, if uninjured, can control his rate of descent as he finds desirable. In all events, the device must permit reaching a lower safe surface and control the speed at arrival to a safe level; perhaps $4.5 \mathrm{~m} / \mathrm{s}$ (15 ft/s) is a reasonable maximum.

\subsection{Classification and Description of Systems}

In order to provide for fall-safety systems that meet a variety of operational requirements, a scheme for dividing these systems into six classifications has been devised. This proposed method of classification is an extension and modification of the four-class scheme presented in ANSI A10.14 [AN-1]. The six classes are shown in Table 9 with proposed maximum acceptable free fall distances and examples of significant features of each class.

A principal reason for developing the six-class scheme for fall-safety equipment (see Table 9) was to accommodate those rope-grab and shock-absorbing devices not readily classified in ANSI's four-class system [AN-1]. Performance and test criteria for our Class IV systems can be unique and, thereby, cover the special characteristics that distinguish these devices. That is by expanding the classification scheme established by ANSI, we permit the development of more specific performance criteria which, in turn, may enhance the viability of these class IV systems-- 


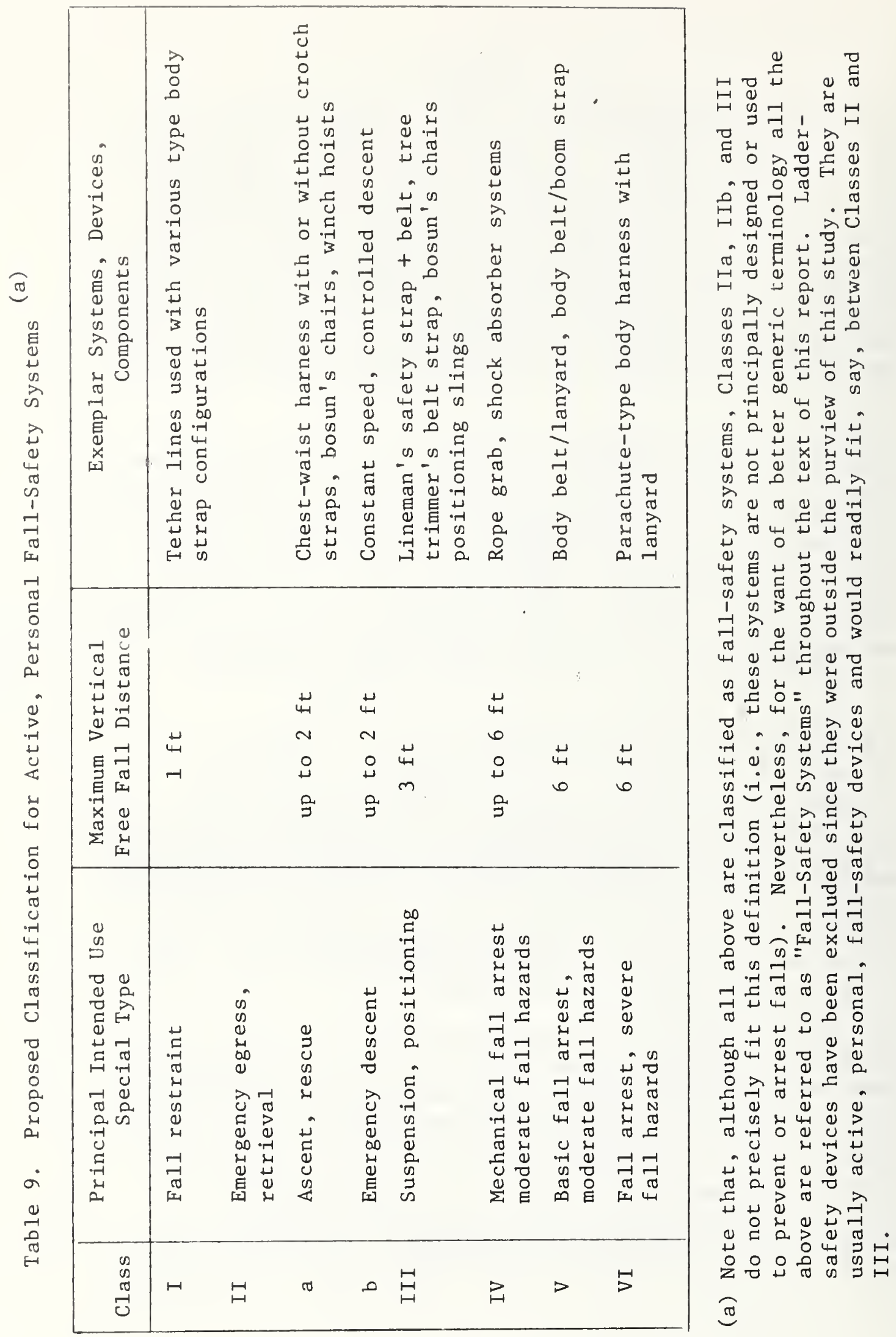


systems which frequently offer worthwhile modifications of standard Class $V$ and VI fall-arrest systems. Although it is true that the buyer must pay a premium for a class IV system or device, this premium is frequently more than compensated for by enhanced worker acceptance, efficiency, and safety.

\subsubsection{Class I systems}

The principal purpose of a Class I fall-safety system is to prevent vertical falls by preventing the worker from maneuvering into a potential fall position. These systems generally consist of a tether line attached to a minimal body belt or similar arrangement. By intent and design, they are generally not suited to arrest any significant vertical fall. The chance of injury due to the functioning of the system is minimal.

The following criteria should be considered in the design of Class I systems:

(1) A tether line cannot have enough stretch nor be sufficiently adjustable to permit the user to inadvertently maneuver into an area where a serious fall hazard exists (assuming the device was correctly installed to begin with).

(2) Should a worker in performing his duties forget that he is tethered and impact into a class I system, he must not be caused to fall or otherwise be significantly injured. Thus if a body belt is used in conjunction with a tether line, the belt should secure the worker above his center-of-gravity.

(3) The system cannot accidentally become disengaged from its anchorage nor lose its integrity upon the application of maximum anticipated forces or torques.

(4) The system should have sufficient strength to absorb anticipated impacts and pressures without failing. For example, a fall on a horizontal surface could deliver a significant impact to the system. Class I component breaking strengths in excess of 2000 lbf would appear to be reasonable. 
The Class II systems are primarily intended for emergency egress and rescue operations and not for arresting a significant vertical fall. Although they may utilize a body containment device (harness) designed to permit accelerations up to $15 \mathrm{~g}$, it must be considered that the user may be unconscious or otherwise disabled. A maximum acceleration of $4 \mathrm{~g}_{\mathrm{n}}$ is therefore proposed. For the worst case of a $113 \mathrm{~kg}$ (250 1b) worker, and allowing a safety factor of 2.5, the minimum strength of the system components, calculated using equation 6 , should be 11.1 kilonewtons (2500 lbf).

\subsubsection{Class IIa Systems (Ascent/Rescue)}

In certain industrial situations a worker must descend through a narrow opening or orifice and into an enclosed area (pit, mine, tank, bin, sewer). The worker may descend under his own power or he may be lowered into a confined area by means of a hand-operated or motorized winch. If noxious fumes may be present or if the possibility of the worker's becoming disabled within the confines exists, then an assistant on the outside must be in a position to rescue his disabled partner--and preferably without having to also descend into the confines. Thus the first worker should be secured to the ascent/rescue system at the time he makes the descent.

The partner may not have the benefit of additional assistance when performing this rescue. Therefore, the system should be designed so that one man can readily extract a worker from a confined area without further harming the disabled worker. The critical point is usually at the opening. If it is sufficiently narrow the disabled worker may only fit through if his head and upper torso remain upright. To this end a Class IIa system should confine the user so that:

(1) He cannot accidentally slip (i.e., "submarine") out of the body restraint except by specific efforts towards this end.

(2) His upper torso must be maintained in an erect posture so as to present a minimum area in the horizontal plane when suspended by the system. 
The confining space a worker finds himself in may be such that any substantial free fall would probably result in injuries due to contact with protuberances along his descent path. Therefore, a Class IIa system, if mechanized, should be so designed as to rule out the possibility of accidental rapid and/or extensive free fall descent.

For worker acceptance the confining part of the Class Ila system should be reasonably comfortable to wear and should permit the worker to perform his job when so confined.

A chest-waist harness with thigh straps, a whole body harness or a bosun's chair or sling with integrated shoulder and thigh straps are, therefore, candidate class IIa systems.

\subsubsection{Class IIb Systems (Descent/Rescue)}

There are many industrial and construction work-atheights situations (e.g., water towers, scaffolding alongside a high-rise skyscraper, bridges) where a fall, or scaffnlling or bosun's chair collapse or failure could leave a worker suspended for an extended period until some means of rescue arrives at the accident scene. It is one thing to safely arrest a fall; it is often as serious a challenge to safely return a worker to a surface where aid is available or from where a worker could return to his duty station.

The worker may be injured, in shock, or in distress from an arrested fall. Even an uninjured worker, if left suspended for an extended period, could suffer harm from restricted circulation or exposure to environmental elements. In any event, it is highly desirable that an individual worker, or the work crew as an entity, have some means of rapid and safe extraction from a post-fall suspended configuration. This "means" in most cases could take the form of a device that is either an integral part of a work-at-heights fall-safety system or is one which can be quickly brought alongside the worker, from there to effect a rescue.

Where the rescue system is an integral part of fallsafety gear, it is typically a mechanical device permitting a controlled descent from the fall site. As with any other fall-safety equipment, such a device must have certain 
features so that it may serve its intended purpose under worst-case conditions.

If an accident should leave the worker immobilized, the device should slowly, safely, and automatically deliver him to the level below. Alternatively the device could be controllable by an assistant who is located on an independent surface.

The device should be lockable or adjustable so that, if it becomes activated by a fall or collapse of a walk or work surface, it either acts as a rope grab which then gives the worker an opportunity to calmly assess his future course of action, or it begins to lower the worker at a comfortable rate that allows him to halt his descent should this appear to be the desirable course of action.

In all events the descending device should not permit the worker to arrive at the surface below him at too high a speed and the device should not run out of rope before the user reaches a safe surface. Possibly $15 \mathrm{ft} / \mathrm{s}$ would be a reasonable maximum "landing" speed. Independent of this maximum landing speed, the worker should knot his line so that 2u will automatically stop before he reaches the surface below.

\subsubsection{Class III systems}

Class III systems, as exemplified by the lineman's body belt and pole strap, is basically a working tool used to support the worker in the desired location while he performs his duties. The body belt acts as a back rest and tool carrier while the pole strap provides him with the balance necessary to maintain his working position. However, it is possible for such a system to allow a worker to fall freely until the pole strap catches on a footrest or other structural member. Such a fall, if arrested, would not usually exceed $0.9 \mathrm{~m}(3 \mathrm{ft}$ ).

Lineman's pole straps and belts, the only class III system included in this study, are covered by the following regulations :

$$
\begin{aligned}
& \mathrm{AP}-2 \text { (1972) (Edison Electric Institute) [EE-1] } \\
& \text { KK-B-151G (ANSI) [NA-1] } \\
& 29 \text { CFR } 1926.959 \text { (OSHA) [CF-8] } \\
& 29 \text { CFR } 1910.268 \text { (OSHA) [CF-4] }
\end{aligned}
$$


Such a system normally consists of:

(1) A body belt with dee-rings positioned at left and right sides (i.e., at the 3 and 9 o'clock positions). The belt is usually padded for wearer comfort.

(2) A (pole) strap with snaphooks at both its ends and which may be adjustable in length.

In use, the strap is first snapped into one or the other dee-rings; it is then placed around a structural member and the strap is then secured to the remaining deering. These fall-safety systems are used in climbing poles; however, they also see service on high-voltage and microwave transmission towers as well as in construction work

involving re-bars.

The strap and belt must both be adjustable for comfort and utility as a positioning device. Furthermore, since Class III devices apply a constant pressure to the worker, they should be designed to do so in such a manner as to minimize worker discomfort. For this reason lineman's belts are trmically padded with a 75 to $100 \mathrm{~mm}$ ( 3 to 4 in) wide inner lining. Weight, bulkiness, and other qualities that affect worker acceptance must be considered since users of Class III systems must frequentIy wear these devices for hours at a time.

A pole strap repeatedly moved up and down poles and/or metal struts will abrade in time. It is important that the pole strap be thick enough so that even after significant abrasion there is sufficient strength remaining in the strap to arrest a worst-case fall. Similarly the strapping should have some built-in indicator that will let the worker know that a strap has been abraded beyond safe limits and, therefore, should be discarded.

The assumption is made that a lineman's safety strap and belt are not "married" and that, due to differential life expectancies and other factors, a strap or belt will possibly see more than one mate during its lifetime. It would appear reasonable that, whatever length belt is used, its length is adjusted so that the belt at the worker's waist never spaces him (at waist level) more than about 0.46 $m$ (18 in) from the pole or structural member. With the strap so adjusted, the worker is assumed to be able to vertically free fall no more than $0.9 \mathrm{~m}$ ( $3 \mathrm{ft}$ ) before being 
stopped. It is furthermore assumed that the lineman's pole strap is never used as a lanyard.

As was the case for Class IIa systems, a Class III system is typically used in a loaded (but not impacted) state. As such, the components should be designed to withstand constant loading without "creeping" or degradation of breaking strength or extensibility properties. The forces observed by the strap in a snubbed fall depend greatly on the angle developed between both sides of the strap. This angle depends on:

(1) the width of the user (assuming the strap is snapped on at 3 and 9 o'clock positions).

(2) the diameter of the snubbing obstruction (assumed to be a right cylinder).

(3) the length of the strap and its extension upon impact.

(4) the location of the dee-rings, relative to the buckle, and possibly the shape that the belt must conform to during impact.

If a lineman should fall, he is likely to suffer a $+a_{x}$ acceleration, performing a reverse jackknife (backbend) about his waist. This is a dangerous type of flexure and the opportunity for vertebral damage is high; therefore, it is recommended that the deceleration limit for lineman's body-belt/pole-strap systems be tentatively set at 4 or 5 gn.

Linemen appear to be more safety conscious, on the average, than is the typical steel construction or industry worker. As such, worker acceptance is probably less of a problem with class III than with Class V or VI systems.

\subsubsection{Class IV systems}

Class IV systems include, as part.of the system, rope grabbing and/or shock-absorbing devices that are designed to give the worker extensive horizontal or vertical mobility. These systems usually, but not always, include a lifeline (horizontal or vertical). A lanyard is usually used in conjunction with the rope grab or shock absorber, but a 
rope-grab may be used to connect a body belt directly to a dropline. In any case, the Class IV system is intended to:

(1) Reduce potential free fall distances;

(2) Absorb a significant part of acquired kinetic energy and, thereby, limit impact forces and accelerations imposed on a worker as the result of a fall;

(3) Limit fall-arrest system strength requirements by restricting fall distances, by absorbing fall energy, and by the use of couplings that do not result in a reduction in system strength.

Class IV systems frequently involve a mechanical grabbing component but some shock absorbers utilize energy absorbing tear-webbing. There are, basically, two types of rope-grabbing devices. These are described in [BE-2]:

"I) Static rope-grabbing device used with lanyard. The worker moves the device by hand up and down the dropline with relative ease. It is preferably nnsitioned above the work level. The device is actuated during a fall to squeeze the rope or tip in such a way as to lock onto the dropline by friction. The fall is thus halted. The lanyard is needed to provide freedom of movement from the fixed position rope-grabbing device.

"II) Mobile rope-grabbing device used without lanyard. INo lanyard is used, the safety belt is attached directly to the dropline. The connecting device floats freely on the dropline providing freedom of movement but locks instantly during a fall. The device is actuated in one system by inertia during a fall with a mechanism comprising three balls floating in a cage which are forced into a conical wedge and thus onto the rope. The fall is limited to a few inches. A second cam-operated lock in some models provides a further safety feature."

Class IV systems may be shock loaded, if only lightly, relative to Class V and VI systems; therefore, design (safety) factors should be introduced to compensate for component variability and degradation with age, environmental conditions, and usage. 
To quote from [CS-1]:

"In practice a lifeline is attached to a fixed anchorage at a point above the working platform; the rope grabbing device is then attached to this lifeline. In turn a lanyard is attached to the rope grab and run to a dee-ring attached to a body belt worn by the workman.

"If a fall then occurs the workman drops in free fall until the lanyard tightens. At this point the rope grab is actuated and made to "grab" the lifeline and thus arrest the worker's fall."

With regard to lifelines, a Class IV system (1) may not require one; (2) may be compatible with a great many lifeline materials, diameters and constructions; or (3) may require and be compatible with only one or a few type lifelines.

Mechanical devices such as rope grabs and shock absorbers may be more severely affected by environmental conditions than components such as lanyards. The possible effect: of moisture, grease, dust, grit, heat, cold, and ice should be considered in the use and testing of Class IV systems.

In a recent (1973) CSAO study [CS-1], seven ropegrabbing devices were evaluated. The wearer was represented by $91 \mathrm{~kg}$ (200 lb) rigid weight, M. Peak forces were measured with a transducer attached just above the weight. Falls were simulated using a bomb-drop-type quick-release mechanism. A six foot drop of the test weight was used by CSAO to represent a worst-case fall situation for each of the seven Class IV systems. The acceleration for each drop test was calculated from the measured force, Fobs' as

$$
\text { Acceleration }=\mathrm{F}_{\text {obs }} / \mathrm{M} \text {. }
$$

CSAO's conclusions and recommendations (explicit and implicit) and relevant IJBS project staff comments are presented in Table 10.

\subsubsection{Class V Systems}

A Class V fall-safety system typically consists of a body belt, a lanyard, and an anchorage. It may include a 
Table 10. CSAO's (a) Conclusions and Recommendations Regarding Fall-Safety Equipment with Rope Grabs

\begin{tabular}{|c|c|}
\hline CSAO'a Conclusions & NBS Project Staff Commente \\
\hline $\begin{array}{l}\text { The test program clearly Indicates that the use } \\
\text { of manila rope for the lifeline or lanyard } \\
\text { constitutes a potential hazard; affordingly, } \\
\text { it is recomended that only poly or nylon } \\
\text { rope be used in fleld situations. }\end{array}$ & $\begin{array}{l}\text { Agreed, that manila rope be proscribed from use } \\
\text { In fall-safety systems. Nylon, polypropylene and } \\
\text { polyester and admixtures thereof all appear to } \\
\text { be viable materials at this time. }\end{array}$ \\
\hline $\begin{array}{l}\text { It is necessary to have detailed installation } \\
\text { and operating instructions supplied with each } \\
\text { rope grabbing device. }\end{array}$ & Agreed. \\
\hline $\begin{array}{l}\text { Where a mechanical rope grab device was not } \\
\text { avallable, the triple hitch knot could be used. }\end{array}$ & Agreed \\
\hline $\begin{array}{l}\text { Too much slippage of a rope grab along a } \\
\text { lifeline is undesirable. }\end{array}$ & $\begin{array}{l}\text { Agreed. Set slippage } 11 \mathrm{mlt} \text { at } 3 \mathrm{ft} \text { for a worst- } \\
\text { case anticipated fall. }\end{array}$ \\
\hline $\begin{array}{l}\text { The actions required of a worker to effect a } \\
\text { change In the position of a rope grab on a drop } \\
\text { line may produce temporarlly unsafe conditions } \\
\text { (e.g., the need for two hands to move the } \\
\text { device was considered unsafe). }\end{array}$ & $\begin{array}{l}\text { Agreed. However, this is seen to be more of a } \\
\text { purchaser decision than a regulation requirement. }\end{array}$ \\
\hline $\begin{array}{l}\text { The device should function normally even if the } \\
\text { user grabs } 1 \text { t as he falls. }\end{array}$ & $\begin{array}{l}\text { This is again seen to be a desirable characteristic } \\
\text { but 1t } 1 \text { s not clear how critical this characteris- } \\
\text { t1c would be in actual accident situations. }\end{array}$ \\
\hline A bounce-type stopping action is undesirable. & $\begin{array}{l}\text { Agreed. It is suggested that each secondary } \\
\text { impact amplitude be less than } 1 / 2 \text { the (acceptable) } \\
\text { previous peak amplitude. }\end{array}$ \\
\hline $\begin{array}{l}\text { A device that can be coupled to a lifeline at } \\
\text { any point is to be preferred over a device } \\
\text { that must be threaded onto the line from a } \\
\text { free end. }\end{array}$ & $\begin{array}{l}\text { Agreed. The regulation need not insist upon this } \\
\text { condition, however. }\end{array}$ \\
\hline $\begin{array}{l}\text { The device should be clearly labeled as to which } \\
\text { side of it is "up" if it is unidirectional and } \\
\text { should also indicate which type lifeline } \\
\text { materials it is compatible with. }\end{array}$ & Agreed. \\
\hline $\begin{array}{l}\text { The grabbing action of the device should not } \\
\text { cut, abrade, crush, fuse or otherwlse so weaken } \\
\text { the lifeline as to reduce its strength below } \\
\text { the margin of safety. }\end{array}$ & Agreed. \\
\hline $\begin{array}{l}\text { A human faller would incur about half the g's } \\
\text { observed from a similar drop but with a rigld } \\
\text { weight. }\end{array}$ & Agreed. \\
\hline $\begin{array}{l}\text { A fall arrest system must be capable of limiting } \\
\text { Impact } \mathrm{g}^{\prime} \mathrm{s} \text { to below } 10 \text {. }\end{array}$ & $\begin{array}{l}\text { Agreed. However, a limit of } 8 \mathrm{~g} \text { (when used with } \\
\text { a body belt) is recommended. }\end{array}$ \\
\hline
\end{tabular}

a) $\operatorname{CSAO}=$ Construction Safety Association of Ontarto.

b) "Poly" = polypropylene. 
lifeline between the anchorage point and the lanyard if mobility greater than would be permitted by the lanyard alone is required. In any case, these systems are intended to save a worker after a significant free fall distance by absorbing the energy of the fall and reducing the forces and accelerations to tolerable levels.

For the Class $V$ system, it is assumed that all of the energy is absorbed by the lanyard. The lanyard must therefore be carefully selected and secured so as to limit the potential free fall distance, Table 9 proposes a maximum of $1.8 \mathrm{~m}(6 \mathrm{ft})$, to have adequate strength to withstand the peak force generated in arresting the fall and to elongate with the force in such a way that the peak acceleration is not excessive.

As was discussed earlier, a body belt exerts force on the human body in a way more likely to produce injury than a body harness, i.e. through the soft abdominal tissue rather than through the skeletal structure. To minimize the possibility of injury, the belt should be as wide as practical so as to distribute the force over a large area and care should be taken to attach the lanyard in the midback, six o'clock position, to limit the tendency for sideways or backward bending. In addition, the belt must have sufficient strength to withstand the force generated by the arrested fall and must not elongate to permit the body to be released. It should be noted that this elongation includes not only the stretch of the belt material but also any slipping or tearing at the buckle.

The anchorage and lifeline, if used, are also assumed to absorb none of the energy. They are, therefore, required only to have sufficient strength to withstand the maximum force generated in arresting the fall. The factors shown in Figure 5 and Table 5 must be considered if a horizontal lifeline is used.

Considering the physiological and operational factors involved with a class $\mathrm{V}$ system, the maximum acceleration should probably be limited to $8 \mathrm{~g}_{\mathrm{n}}$ and the peak force to $8900 \mathrm{~N}(2000 \mathrm{lbf})$. 


\subsubsection{Class VI systems}

A Class VI system differs from a Class V in use of a body harness instead of a body belt. Such harnesses transmit forces to the body through the skeletal structure and hence are less likely than a body belt to cause injury for the same fall conditions. Class VI devices are generally worn only in very hazardous work environments. The worker who elects to use such a system is likely to be safety conscious and motivated towards that end.

Much of the information applicable to the use of class VI systems comes from the use and testing of parachutes and ejection seats. The standard parachute has four riser straps coming up from the harness and linking with the parachute above the wearer. The usual Class VI body harness, however, secures to a lanyard by means of one of several dee-rings present on the harness. Since man is very susceptible to sideways, i.e. $t a_{y}$, and backward, i.e. $+a_{x}$, accelerations, the selection o $\bar{f}$ the point of attachment of the lanyard is important. A U.S. Navy document [AS-2] states:

"nnother important factor is the placement of the fixation point of lanyard on the belt (harness). This must be on the back and not the chest in order to avoid the quick movement of the head towards the back. It is important to place it as high as possible, so that the body is vertically suspended after a fall, this means that the fixation point should be at the point where the shoulder straps cross in the back at level of the shoulder bone in an eye provided for this purpose. The dynamic strain is thereby divided between the two shoulder straps, transmitted to the safety belt in 4 different places, which assures a good distribution of the pressure points on the thorax."

It is imperative that the connection between a Class VI harness and a lanyard only be made high in the back (between the shoulder blades) or from riser straps coupled to a deering above the head.

Body harnesses are generally adjustable to fit a large range of sizes. Military specifications call for parachute harnesses to be adjustable to fit users weighing from 63.5 $\mathrm{kg}(140 \mathrm{lbs})$ to $113.5 \mathrm{~kg}(250 \mathrm{lbs})$. It might be desirable to provide two sizes to cover the weight range of $59 \mathrm{~kg}$ (130 $1 \mathrm{bs})$ to $113.5 \mathrm{~kg}(250 \quad 1 \mathrm{bs})$. 
Navy policy [BO-3] limits the use of parachutes to 100 jumps unless it is damaged and retired sooner. Class VI harnesses may experience forces greater than usually seen with parachutes. Class VI harnesses and other components should be regularly checked to determine their serviceability.

Because of the possibility of a Class VI system being subjected to high impact loads, the lanyard should always be tied off in a nonstrength-reducing manner. This can be accomplished by limiting the length to $1.8 \mathrm{~m}$ ( $6 \mathrm{ft}$ ) with snaphooks on each end or by use of a two-part lanyard having a steel cable or heavy web strap in contact with any structural member. Such straps should have a wear indicator to show when abrasion sufficient to weaken the strap significantly has occurred.

\subsection{Descriptions and Functions of Components}

The successful performance of a fall-safety system depends upon each component functioning in an adequate manner. A number of components are common to several classes, while others are limited to use with one or two classes. For convenience and reference, a number of these components are described below and their functions are explained.

\subsubsection{Containment Devices}

A containment device serves to insure that the body of a person involved in a fall accident remains attached to fall arresting mechanisms, to position the victim's body so as to minimize the chance of injury, and to transmit the forces generated to the body. The three types of containment devices most commonly used are shown in Figure 6. Such devices include:

(1) Body Belt. Generally a wide, padded web belt having either a friction or tongue buckle so that it can be adjusted for a comfortably snug fit around the waist. These belts frequently have a dee-ring or other arrangement for attaching to a lanyard. With suitable attachments, these belts are sometimes used to carry tools. Body belts may be used with Class I, II, III, IV, and $V$ fall-safety systems. 
(2) Chest-Waist Harness. The combination of a belt around the chest and a waist belt connected by shoulder straps. A dee-ring for attaching to a lanyard is generally located in the back between the shoulder blades. This type of harness distributes the load over a larger area, but tends to pull up under the arms unless the waist belt is excessively tight. A chestwaist harness might be used with Class II and possibly Class IV fall-safety systems.

(3) Body Harness (Parachute Type). A harness similar to that used with parachutes. The force is applied to the body skeletal structure through straps around the upper thigh and pelvic region, a waist belt (primarily for positioning), and shoulder straps. A dee-ring for attaching to a lanyard is generally located high in the back, between the shoulder blades. Body harnesses may be used with Class II, IV, and VI systems. They are a definitive part of Class VI systems.

(4) Bosun's Chair. A seat attached to ropes for suspending over the side of a ship, building, etc. to provide support to a worker during inspection, päinting, repairing, etc. A bosun's chair might be used with a Class II fall-safety system.

(5) Other. A variety of special or impromptu arrangements might be used for particular purposes. These could vary from a simple rope tied around the waist to special harnesses for mountain climbers. The simple, impromptu arrangements should be discouraged except for emergency use in Class I systems.

\subsubsection{Lanyards}

A lanyard is a short, generally less than $4.6 \mathrm{~m}$ (15 ft), flexible line, rope or strap used to connect the containment device of a fall-safety system to anchorage or lifeline. Except for Class IV systems, the lanyard is assumed to absorb all of the energy of an arrested fall. Lanyards may be made of a number of materials, including spun nylon, filament nylon; polyester, polypropylene, and manila. A lanyard may have snaphooks attached to one or both ends or may be attached by knotting. Ianyards are used with all fall-safety systems except some class III systems 
and the few Class IV systems that connect directly onto'a lifeline.

\subsubsection{Lifelines}

A lifeline is a heavy line used to transfer an anchorage point to a more convenient or secure site and/or to give the user considerable horizontal or vertical freedom of movement. Since a lifeline may be used by several workers simultaneously and is not considered to be an energy absorbing component, it will be selected and installed based on strength considerations. In calculating strength requirements, the number of workers using the lifeline at one time and the geometric factors discussed in section 3.1 must be considered. Heavy fiber rope and steel cable are candidate materials for lifelines.

\subsubsection{Rope Grabs and Shock Absorbers}

Rope grabs and shock absorbers are definitive parts of Class IV systems. These components are intended to provide mobility along a lifeline while reducing the potential free fall distance and absorbing a significant part of the energy generated by the fall. The rope grabbing feature may be manually operated, requiring the user to deliberately move it along a lifeline and lock it in place with a cam or similar mechanical system, or it may be automatic, allowing free motion along the lifeline until activated by a falling motion to lock onto the lifeline, usually by an inertial device. In any case, the system should limit the total fall distance, including travel along the lifeline. Sweden [SW1] sets one meter (3.3 ft) as the allowable travel of the rope grab along the lifeline. In addition to the energy absorbed in the travel along the lifeline, additional energy absorption may be provided by a mechanical shock absorber or tear webbing.

\subsubsection{Ascent and Controlled Descent Devices}

These devices are intended to provide for the egress or rescue of workers, generally with the assistance of one or more co-workers. The ascent systems generally incorporate a manual or motorized winch. Such a winch should have controls, brakes, and/or stops to permit a disabled worker to be carefully maneuvered around obstacles and through 
openings. A controlled descent device may be automatic or manually controlled, but should limit the descent speed to less than $4.5 \mathrm{~m} / \mathrm{s}(15 \mathrm{ft} / \mathrm{s})$ to avoid injury from impact at the end of the descent. Other provisions, e.g. knotting of the line, should be made to prevent impact with the landing surface.

\subsubsection{Anchorage}

An anchorage is the means for attaching a lanyard, lifeline or other components to a structural member or other secure point. The anchorage point is frequently not a part of the working or walking surface. The anchorage is usually a beam or an eyehook attached to a beam. A lanyard may be looped around the beam and tied off with a bowline or snapped onto itself, or it may be snapped or tied to the eyehook. In general, the eyehook is preferable since beams may have cutting or abrading edges that will damage a fiber line. A portable anchorage consisting of a steel cable or heavy web strap that can withstand the cutting and abrasion of a beam can be used. A two-part lanyard, having a web strap attached to one end, could be considered as a portable anchorage.

\subsubsection{Other Components}

In addition to the principal components discussed above, fall-safety systems include a variety of components, generally solid metal or polymeric items, used to couple the systems together. These items include buckles, carabiniers, dee-rings, grommets, snaphooks, thimbles, and toggle bolts. Since these items generally couple to fiber components, it is important that they be free of sharp edges or burrs that could cut or abrade. Most of these items will carry some, if not the major, load during a fall accident, so they must have adequate strength and should not deteriorate through corrosion, weathering, or environmental conditions. They should be subjected to inspection, proof loading, and design and quality control testing as rigorously as the principal components.

\subsection{Components, Requirements, and Limitations}

In performing the function of preventing or arresting an accidental fall, the components of a fall-safety system 
must meet a number of requirements, specifically those requirements related to strength, energy absorption, force distribution on the body, and limiting fall distance. The requirements will vary for the different classes of fallsafety systems and, to some extent, they may differ depending upon the particular use. In establishing requirements that must be met during prototype and quality control tests, the effects of product variability (due to material and manufacturing tolerances), use conditions, and degradation with age, use, environment, etc. must be considered. Contingency factors are commonly applied for this purpose. Additional degradation factors may be needed when specific uses are known or suspected to affect performance; e.g. tie-off of a lanyard around a beam with sharp edges will reduce the strength of the lanyard.

\subsubsection{Mechanical Requirements}

Based upon the information gathered for this report, it is suggested that the criteria shown in Table 11 be used in developing the performance requirements for fall-safety equipment.

The values given in Table 11 consider that the acceleration pulse will generally have a duration of 0.1 second or less. This is based upon oscillograph traces from drop tests by two manufacturers of fall-safety equipment and computer synthesized drop tests using lanyard characteristics determined during this program. Pulse duration was taken as full-width-at-half-maximum amplitude of pulses that were fairly symmetric. It is also considered that, based upon information found in the literature, [AS-2, BI-1, MO-l, NS-1], a healthy, young male can sustain short-term accelerations of $+a_{z}>20 \mathrm{gn}^{\prime} \mathrm{a}_{\mathrm{y}}=15 \mathrm{gn},+\mathrm{a}_{\mathrm{x}}=15 \mathrm{gn}$ without substantial injury and that other standards [AN-1, $\mathrm{CS}-1, \mathrm{CS}-3$ ] have adopted $10 \mathrm{~g}$ as allowable, supposedly in the taz direction and presumably with the use of body belts. The values for Class $V$ systems recognize that the forces are transmitted to the body through the soft abdominal tissue rather than through the skeletal structure as for a Class VI system.

The contingency factors, $D_{S}$ and $D_{a}$, are meant to allow for variability and the effects of aging, use, environment, etc. on the strength and extensibility of the components, particularly lanyards. It is also noted that tests made using a rigid mass will produce higher force and 


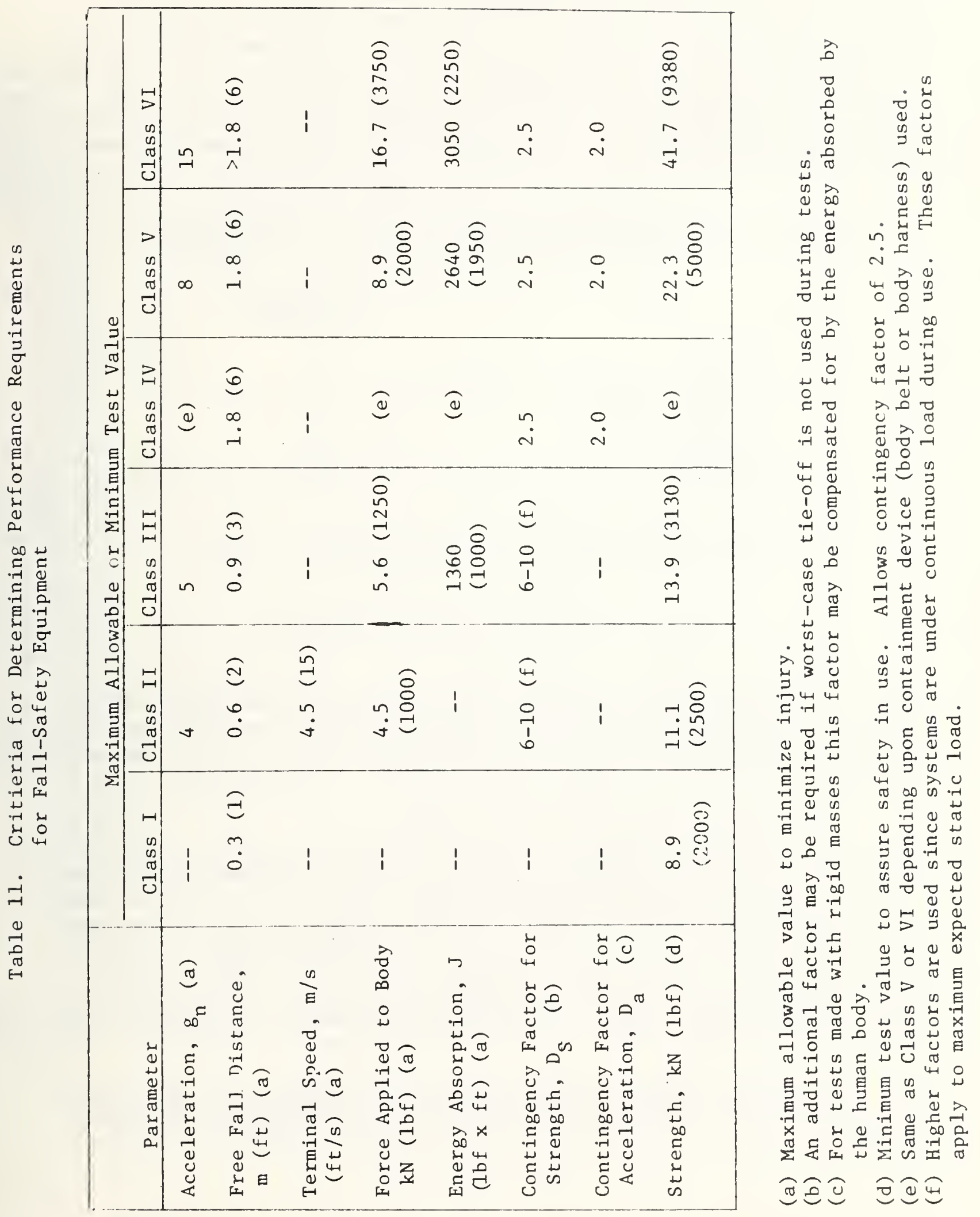


acceleration values than would be generated by a falling human because of the energy absorbing characteristics of the human body. In many cases, this energy absorption will essentially introduce a contingency factor, $D_{S}=2$. The use of a higher contingency factor, Ds, for Class II and III systems is based upon their sustained loading during use and the recommendations of the Cordage Group for working loads for various types of fiber ropes [CG-3], shown in Table 12.

Table 12. Recommended working load as a percentage of breaking strength for various fiber ropes [CG-3]

Fiber

Manila

Filament Nylon, Goldline

Filament Dacron

Polypropylene

$\mathrm{P} / \mathrm{D} 100$

$\mathrm{P} / \mathrm{D} 10$
\% Breaking

Strength

The energy absorption values are based upon a worst case full and estimated lanyard elongation.

\subsubsection{Electrical Requirements}

When fall-safety systems are used around electrical systems, they must not only provide protection from falls, but must also insure adequate electrical isolation for the worker. Although this is probably most common with class III systems, it may apply to all other classes depending upon the usage.

The dielectric properties of fall-safety equipment are covered in other regulations and standards [CF-4, CF-8, EE1, NA-1]. According to one of these [EE-I], all fabric used in the construction of safety straps shall withstand an $A C$ dielectric test of at least 82000 volts per meter (25 000 volts per foot) when dry for three minutes without visible deterioration, and leather, fabric, and rope components shall have leakage current of less than one milliampere for $3000 \mathrm{~V}$ AC on electrodes $0.3 \mathrm{~m}$ (l ft) apart.

The above requirements seem reasonable for fall-safety equipment to be used where significant electrical hazard exists. 


\subsubsection{Environmental}

Fall-safety equipment is used in a wide range of weather and environmental conditions, and fall accidents may be more likely in adverse environments. It is therefore appropriate and important that the various components be known to function properly over the full range of conditions that may be encountered. Environments of concern and ranges that might be encountered include:
(1) temperature: -18 to $43^{\circ} \mathrm{C}\left(0\right.$ to $\left.110^{\circ} \mathrm{F}\right)$
(2) humidity: 10 to 100 percent $\mathrm{RH}$
(3) ultraviolet radiation
(4) ice
(5) salt
(6) dust
(7) dirt and grit
(8) industrial solvents

In addition to possibilities under these conditions, components may be stored so as to have extended exposure to temperature up to $80^{\circ} \mathrm{C}\left(175^{\circ} \mathrm{F}\right)$, high humidity, low humidity, grease or industrial fumes. Each of these factors may reduce the strength, energy absorbing capability, reliability, or durability of some components. Unless available information shows that exposure to these environments will not affect the performance of a component, testing may be required.

Figure 8, taken from [DU-3], gives the comparative sunlight and weather resistance of $1 / 2$ in diameter ropes exposed to direct Florida sunshine. To quote from [DU-3]:

"NOTE. Exposure conditions for Florida outdoor exposure tests are extremely severe because the test items are continuously exposed to sunlight and to weather elements for prolonged periods of time. The deterioration observed during such tests is usually many times greater than that experienced during actual use of fiber products."

Pertinent information derived from a reading of [BR-2, $\mathrm{DU}-3, \mathrm{DU}-4, \mathrm{PA}-1]$ regarding the effects of sunlight and moisture includes:

(1) A Capracyl-dyed, 1/2 inch nylon lanyard should retain at least 80 percent of its original strength after. worst-case exposure to the elements (sun and rain 


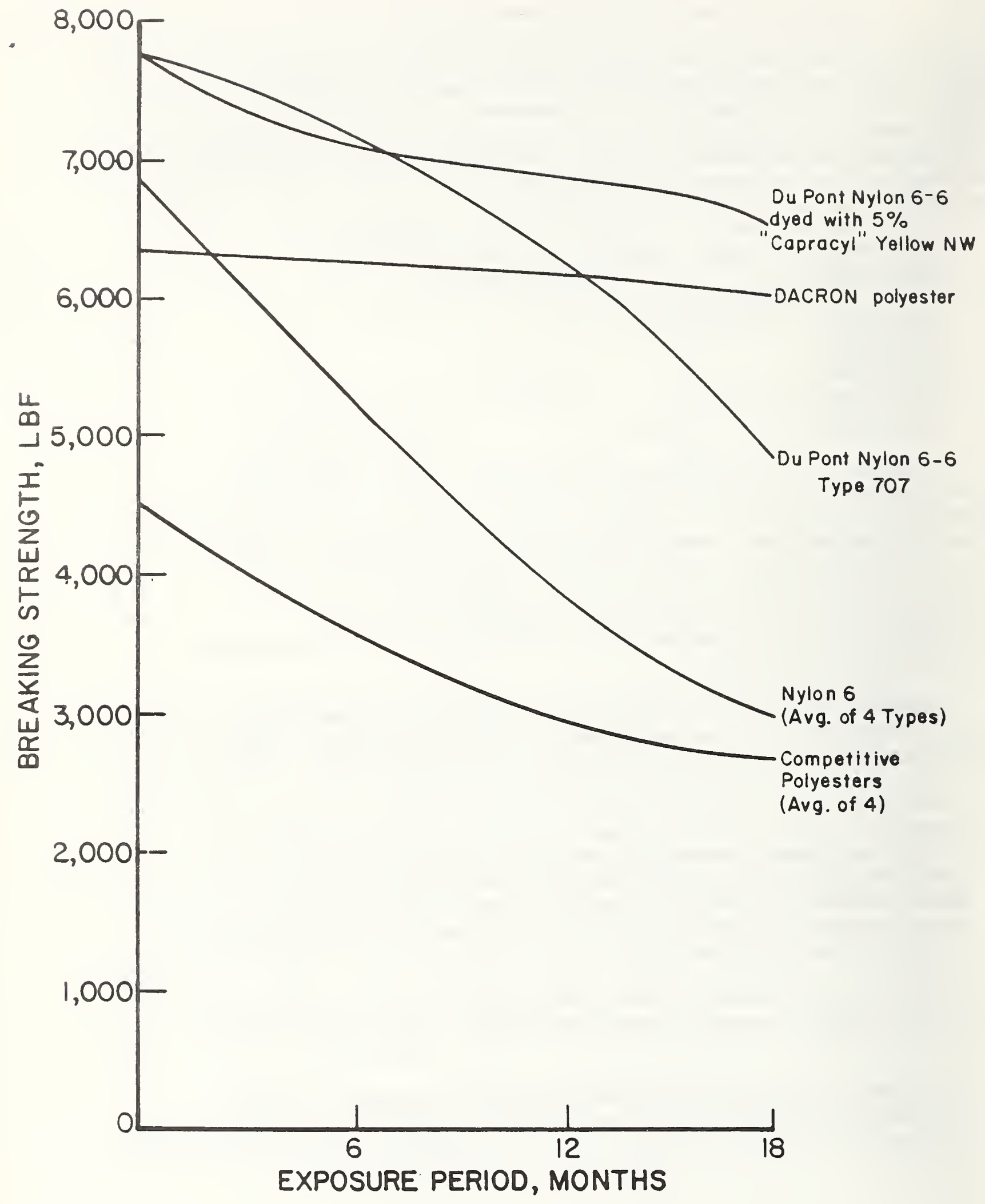

Fiqure 8. Comparative Sunlight and Weather Resistance of Commercial Ropes 
for three or more years). A larger diameter nylon lanyard will retain a proportionately higher percentage of its original strength.

(2) Surface grease and dirt probably act to still further attenuate the degradation effects of ultraviolet (UV) light on lanyards.

(3) Dupont Dacron polyester ropes will likely retain more than 90 percent of their original strength after two or three years of worst-case exposure to the elements.

(4) For rope diameters greater than $1 / 2$ inch, the curves in Figure 8 should tend to flatten out [BR-2].

(5) Various UV inhibiting chemicals can significantly retard the degrading effects of UV on nylon and polyester. (Most manufacturers of fall-safety equipment claimed they purchase nylon ropes so inhibited.)

(6) Polypropylene is quite light-sensitive and so must contain a UV inhibitor. In this regard polypropylene, containing a black, UV-absorbing pigment, will give the least UV degradation. However, slightly less effective yellow polypropylene is recommended since fiber damage is probably more easily detected than with the black. Stabilizers make the UV resistance of polypropylene ropes comparable to ropes of nylon and polyester [PA1].

(7) A carbon-arc tester (e.g., weatherometer) is no substitute for actual outdoor exposure since no consistent correlation between the two types of data has been observed. Furthermore, outdoor exposure (i.e., not under glass) combines the effects of sunlight, moisture, and heat in one test.

(8) Dry nylon rope can absorb about 4 percent more energy per unit length than its wet equivalent.

(9) Several sources of information indicate that nylon is slightly weakened by long-term exposure to moisture. It would appear, however, that degradation due to UV light is more significant. The instantaneous loss in strength of nylon that has been wetted down is estimated by various sources [DU-3, DU-4] at from 5 to 
15 percent. Nylon ropes can be stabilized against degradation due to moisture. Quoting from [PA-l]: "European rope standards now require stabilization of nylon ropes, while in the corresponding U.S. standards stabilization is expressly prohibited" (e.g. German std. UIN 83330 vs. U.S. stds. listed in Table 2-5 of $[P A-1])$.

(10) No synthetic cordage fiber other than nylon shows noticeable degradation in strength or extensibility properties with moisture since these fibers absorb little or no water. In fact polypropylene ropes may show from 2 to 5 percent higher breaking loads when wet than when dry due to the reduction in fiber friction in the rope by water around the fiber itself.

(11) Dacron's properties are essentially invariant between $0^{\circ} \mathrm{C}\left(30^{\circ} \mathrm{F}\right)$ and $32^{\circ} \mathrm{C}\left(90^{\circ} \mathrm{F}\right)$, and Dacron is quite resistant to UV degradation.

An experimental study performed at the National Parachute Test Range (NPTR) and completed in 1976 [TU-1] tested manila and various synthetic ropes by submitting them to a series of conditioning treatments, as formulated in MIL-STD-810B. Percentage difference, comparing post- and pre-conditioned breaking strengths, for averages representing, typically, three samples each are presented in Table 13. The salient findings given in [TU-l] include:

(1) None of the types of rope tested was significantly weakened after 24 hours exposure to high temperatures.

(2) Manila loses about $1 / 3$ of its strength and polypropylene about $1 / 5$ of its strength (when it is exposed to $71^{\circ} \mathrm{C}\left(160^{\circ} \mathrm{F}\right)$ ambient conditions for 200 hours). All the other ropes are essentially unaffected by exposure to these high temperatures for extended periods.

(3) Cold has little effect on rope breaking strength and this effect is to slightly strengthen lanyards of Dacron and nylon.

(4) Salt spray appears to have little short term bad effect on the breaking strength of the ropes tested.

(5) Extended exposure to moisture and UV appeared to weaken "poly-plus" and manila ropes by 10 percent or more relative to control averages. The other types of 


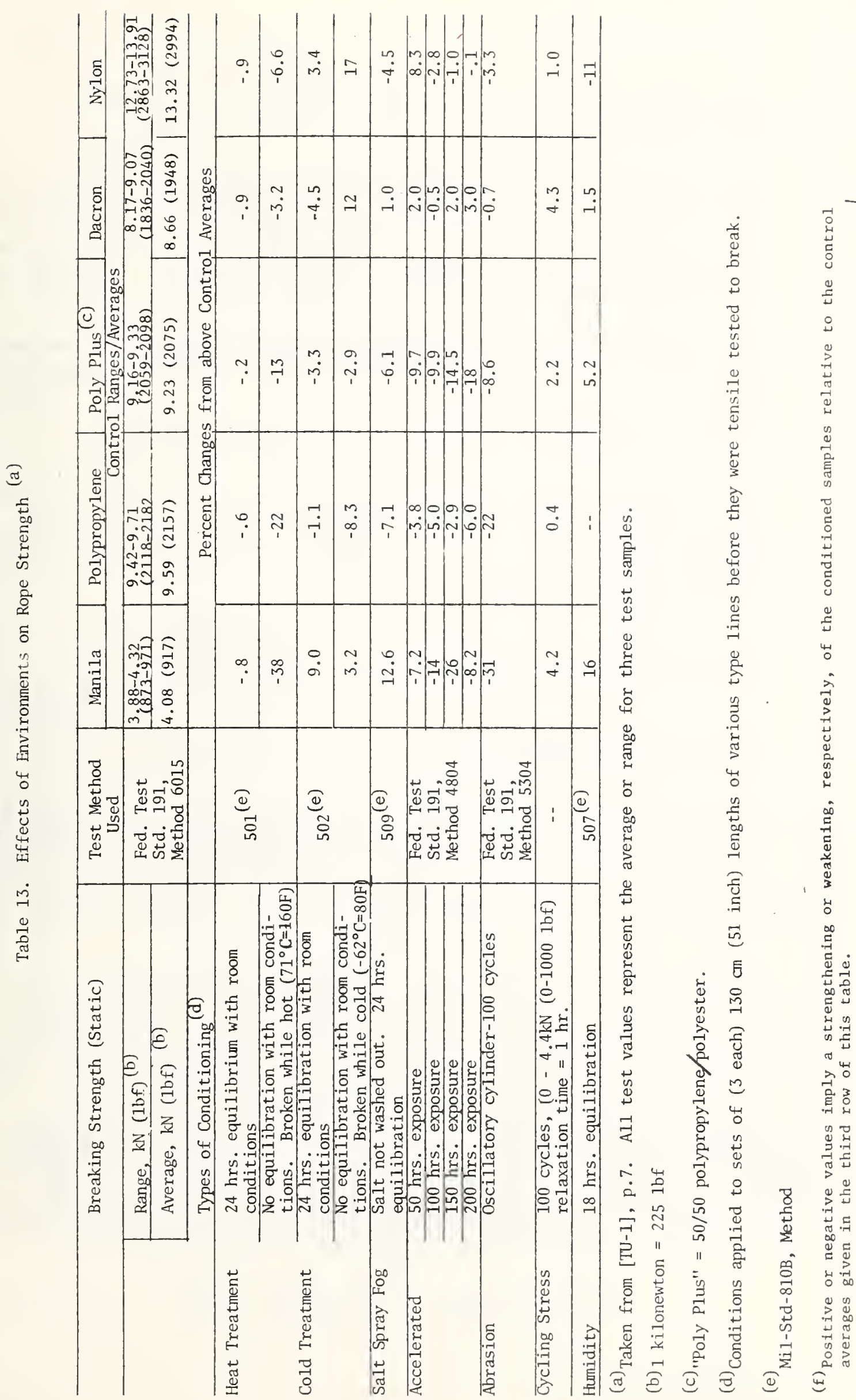


rope were significantly less affected by these environmental factors.

(6) Manila and polypropylene are readily abraded but the remaining ropes showed good resistance to abrasion.

(7) Breaking strengths of the type ropes tested were not significantly reduced by 100 cycles of loading to $4.45 \mathrm{kN}(1000 \mathrm{lbf})$.

(8) Manila is somewhat strengthened and nylon somewhat weakened by equilibration at a high relative humidity $(\mathrm{RH})$.

It is, therefore, reasonable to conclude that:

(1) The temperature at which ropes are conditioned is not a significant strength factor but, at least for manila and nylon, relative humidity can have a noticeable effect. Strength may be significantly lower at high temperature.

(2) Heat, cold, moisture, and salt spray do not significantly weaken the rope types tested, but possible combinatorial effects remain to be explored.

(3) Abrasion is not a serious problem except for manila and polypropylene.

Most hardware components are load-bearing. To quote from [HA-2]: "As the temperature drops from 27 to $-18^{\circ} \mathrm{C}(80$ to $\left.0^{\circ} \mathrm{F}\right)$, the carbon steel becomes increasingly brittle and the material can endure little impact at subzero temperatures. Alloy steels, such as 4140 , remain tough to temperatures as low as $-185^{\circ} \mathrm{C}\left(-300^{\circ} \mathrm{F}\right) . "$

Figure 9, taken from [HA-2] compares the impact strength of an alloy and a carbon steel from -73 to $65^{\circ} \mathrm{C}$ $\left(-100\right.$ to $\left.+150^{\circ} \mathrm{F}\right)$. Now fall-safety equipment is typically tested at from 18 to $27^{\circ} \mathrm{C}\left(50\right.$ to $\left.80^{\circ} \mathrm{F}\right)$, yet some units will probably see service at $-20^{\circ} \mathrm{C}\left(0^{\circ} \mathrm{F}\right)$ or slightly below. Due to adverse conditions at low temperatures, falls are probably more likely than, say, at $20^{\circ} \mathrm{C}\left(70^{\circ} \mathrm{F}\right)$. Thus, it is imperative that the strength of all fall-safety equipment components remain above the required minimum limits in at least the temperature range from -20 to $+45^{\circ} \mathrm{C}\left(0\right.$ to $\left.110^{\circ} \mathrm{F}\right)$. Nylon and Dacron are seen [PA-l] to retain their strengths in this range and, in fact, they become stronger at low 


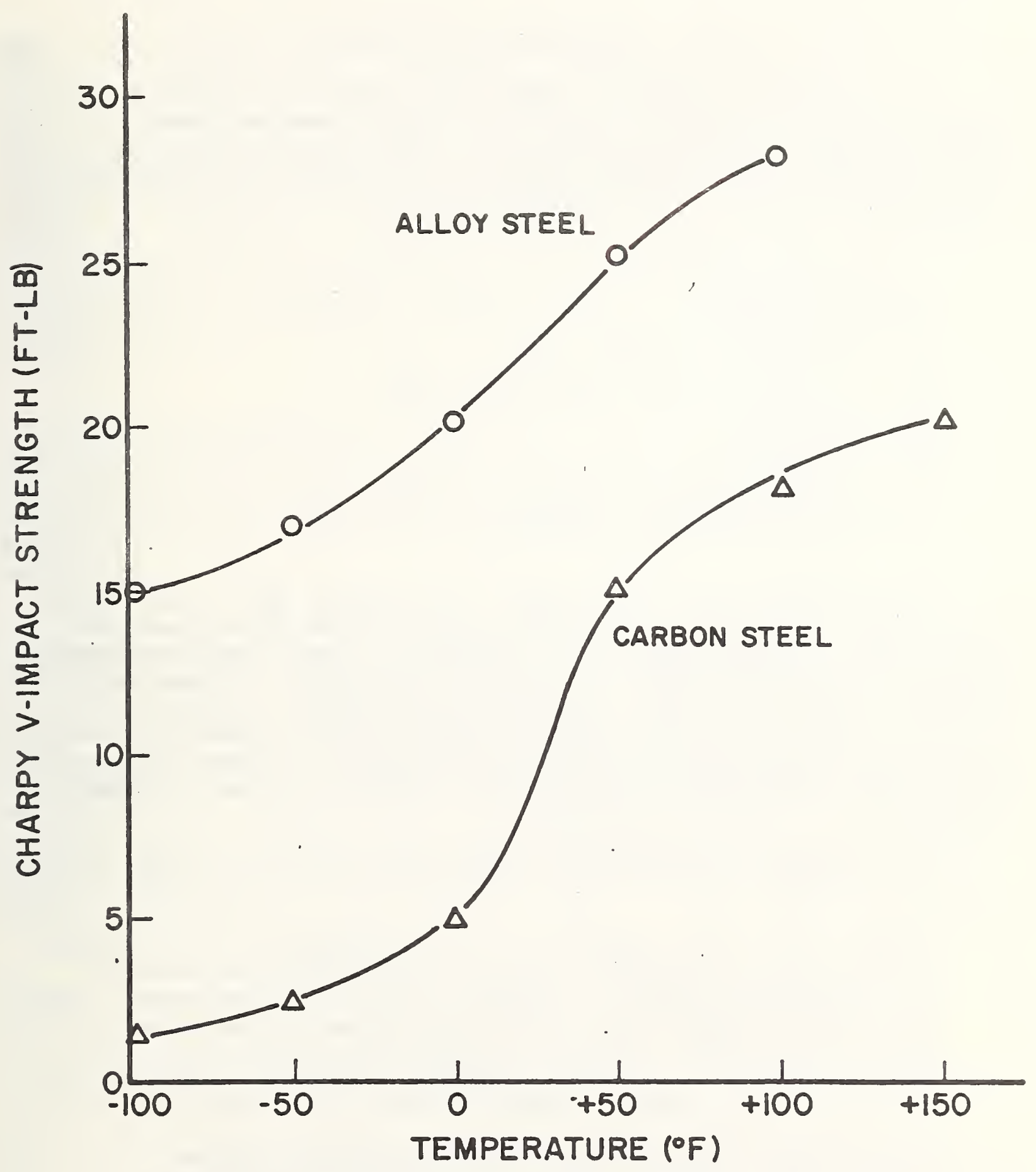

Figure 9. Impact Strength vs. Temperature Curves for Carbon and an Alloy Steel 
temperatures. These synthetic materials do not become brittle until well below $-20^{\circ} \mathrm{C}\left(0^{\circ} \mathrm{F}\right)$.

\subsubsection{Deterioration in Use}

As a result of normal usage, fall-safety equipment will deteriorate and may be damaged. Periodic inspections, including daily checks by the user, are essential to insure that equipment is replaced before it would fail if involved in a fall accident. Factors that would be of concern include:
(1) normal wear
(2) abrasion
(3) cutting
(4) fraying, hackles, etc.
(5) repeated loads and shock loads
(6) bending
(7) cracking
(8) corrosion
(9) failure of protective coatings
(10) environmental exposure
(11) age

Wear indicators can be built into belts and straps that are subject to wear or abrasion. Components should be discarded when such indicators appear. Items that pass over edges or rough surfaces, e.g. structural beams, should be examined frequently for abrasion and cutting. Lifelines that are used with rope grabs should also be inspected frequently for signs of abrasion, crushing, or other damage. Manila and polypropylene have been found to be particularly susceptible to abrasion [TU-l].

In a study of fall-safety equipment [BO-1], Boeing engineers found that:

"Nylon line will stretch up to 40 percent of its length under impulse loading. However, once shock loaded, this material does not recover its full elasticity. It was found, that, for a series of three successive drops, the shock absorbing characteristics continually deteriorated. The shock load for the third drop was as much as $2 \mathrm{~g}_{\mathrm{n}}$ 's greater than for the first drop."

A paper by Jay Boine [BO-3] also indicates that repeated, static loading of ropes tends to reduce their 
shock absorbing capability even though their strength is not significantly affected.

Corrosion not only weakens the metal part affected, but may also degrade synthetic fibers such as nylon. Metal parts can be corrosion-proofed by plating with corrosion resistant materials such as cadmium. However, cadmium plating is brittle and may crack and possibly peel thereby exposing the base metal. In such cases, the corrosion may be underneath the plating and not readily visible. The bending of plated parts, such as thimbles, during assembly should be minimized, and corrosion testing should be done after such parts are assembled. The plating may also wear off with use so that the base metal becomes exposed and susceptible to corrosion. High strength, low alloy steels are generally more resistant to corrosion than plain carbon steel.

Through numerous conversations with scientists and rope engineers, the belief was acquired that as a rope aged not only did its strength decrease but it became stiffer (i.e., its extensibility decreased). In fact it is generally believed that the embrittlement process proceeds at a greatc. rate than does the reduction in rope breaking strength.

However, a recent study by Kosmath and Kaminger [KO-2] included strength tests of 21 nylon climbing ropes. These ropes varied from 7 months to 8 years old and had seen from 0 to 400 hours of service. Loads and extensions at rope failure (breaking point) were observed and compared to new ropes. The results were ambiguous and showed no strong correlation with age or use. Two ropes (the oldest and one of the newest) showed higher extensibility while nine showed significantly reduced extensions, though frequently associated with reduced strengths. The remaining samples showed extension that varied from nine percent higher to eight percent lower than the new ropes.

On the other hand, in the course of this study the elongation of eight new and 17 used spun nylon lanyards was measured as a function of load. The used lanyards had been in service from three months to four years and ranged in conditions from "good" to "quite dirty, greasy, and abraded." At $4.45 \mathrm{kiv}(1000$ lbf) the new lanyards showed an average extension of about 20 percent and the used ones showed an average of 26 percent. At $13.34 \mathrm{kN}$ (3000 lbf), the new lanyards averaged about 34 percent elongation and 
the used ones averaged 41 percent. In this case, for spun nylon, the extensibility seemed to definitely increase with age or use. However, in these same tests, the breaking strength of the used lanyards averaged 80 to 86 percent of that for new lanyards, depending upon rope diameter.

Although parachute harnesses do not typically experience impact forces as great as might be imposed on a Class VI fall-- safety system, U.S. Navy policy [BO-3] limits the use of parachutes to 100 jumps, or less if damage is evident.

\subsubsection{Other Use Factors}

In addition to the possible deterioration of fallsafety equipment with use, some factors inherent in the use of these systems may affect their performance.

As was shown in Section 3.1, a horizontal lifeline and its anchorage must be of higher strength than a vertical line, the amount depending upon the geometry of the system.

It has been observed [CS-1, CS-3] that short lanyards with free ends will generally be tied off onto eyehooks or anchor bolts, and that longer lanyards with snaphooks or free ends are likely to be secured around structural angles, "H" or "I" beams. It was also shown [CS-3] that securing a lanyard around a beam reduces its strength by 42 to 71 percent (an average of 60 percent) due to the shearing action of the beam edges. Heat generated as the lanyard passes rapidly over the metal flange may also melt or embrittle the fibers. It has also been found [CG-3] that securing a lanyard with commonly used knots can reduce its strength by up to 50 percent. It should also be noted that the nature of these tie-off effects, e.g., cutting, is such that compensation by use of a larger diameter rope may not be effective. A more effective procedure might be the use of a length of steel cable or an abrasion resistant strap to secure to the beam.

In contrast to the strength reduction when a knot is used to secure a lanyard, rope engineers claim that a properly made eye-splice should result in less than 5 percent reduction in rope strength [CG-3]. This agrees with results from Canadian tests [CS-3]. Therefore, a lanyard's strength should remain relatively intact if a snaphook, 
correctly spliced onto its anchor end, is secured to an eyebolt.

The knot-holding ability of various lanyard materials was evaluated at the National Parachute Test Range [TU-1]. A bowline knot was tied in each of 10 one-half inch diameter rope sections of each material. The knotted sections were then tumbled for 24 or 48 hours and the quality of the knots was evaluated. The results of these tests are shown in Table 14. These tests indicate that Dacron and polypropylene have reasonably good knot-holding ability while filament nylon and poly-plus (a 50/50 blend of polypropylene and polyester) are poor in this respect. Construction workers indicate that spun nylon is superior to filament nylon in this respect.

\subsection{Test Procedures}

When examining the various Federal, military, state, manufacturer, user, and foreign regulations for standards concerning fall-safety equipment, one is struck with the widely divergent test parameters, test conditions, and certification criteria. In some cases components must just satisfy tensile strength criteria; in other cases, these components must pass a dynamic test; and in still other cases, equipment must pass both static and dynamic criteria. The diversity of requirements for drop tests is evident in the following tabulation.

Test Weights

- $200 \mathrm{lb}(100 \mathrm{~kg})$, rigid weight

- 250 lb, sand-filled canvas bag

- 250 lb, rigid simulated torso

- 300 lb, rigid cylinder or torso

- 300 lb, simulated torso

- 350 lb, rigid weight

$[\mathrm{SW}-1]$
$[\mathrm{CF}-4, \mathrm{EE}-1, \mathrm{FE}-3$,
$\mathrm{NA}-4, \mathrm{NI}-1, \mathrm{US}-1]$
$[\mathrm{AN}-1, \mathrm{X}-1]$
$[\mathrm{OS}-1]$
$[\mathrm{BS}-4, \mathrm{MI}-4]$
$[\mathrm{CA}-5, \mathrm{NA}-2]$

Drop Height

- $2 \mathrm{ft}$ (body belt or pole strap)

- 4 ft (body belt and attachments)

- 4 ft (safety straps)

- $5 \mathrm{ft}$ (body belt and lanyard)

- $6 \mathrm{ft}$ (body belt, lanyard, rope line, tail line)

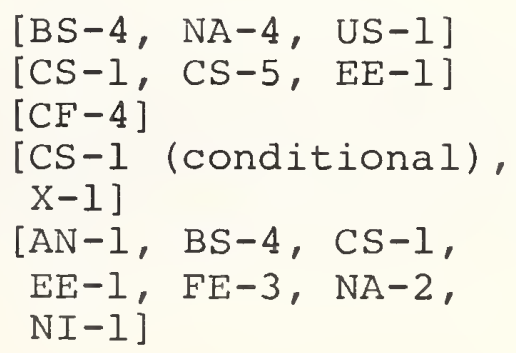


Table 14. NPTR knot test data [TU-1]

Bowline Knot, 24 Hours(a)

\begin{tabular}{|c|c|c|c|c|c|}
\hline $\begin{array}{c}\text { Final Knot } \\
\text { Status }\end{array}$ & Manila & Polypropylene & Poly Plus & Dacron & Nylon \\
\hline Tight & 2 & 6 & 0 & 8 & 0 \\
\hline Slack & 8 & 2 & 0 & 1 & 0 \\
\hline $\begin{array}{l}\text { Partially } \\
\text { Undone }\end{array}$ & 0 & 1 & 0 & 1 & 1 \\
\hline Undone & 0 & 1 & 10 & 0 & $?$ \\
\hline
\end{tabular}

Bowline Knot, 48 Hours(a)

\begin{tabular}{|c|c|c|c|c|c|}
\hline $\begin{array}{c}\text { Final Knot } \\
\text { Status }\end{array}$ & Manila & Polypropylene & Poly Plus & Dacron & Nylon \\
\hline Tight & 0 & 6 & 0 & 8 & 0 \\
\hline Slack & 6 & 1 & 0 & 1 & 0 \\
\hline $\begin{array}{l}\text { Partially } \\
\text { Undone }\end{array}$ & 2 & 1 & 0 & 1 & $n$ \\
\hline Undone & 2 & 2 & 10 & 0 & 10 \\
\hline
\end{tabular}

(a)A bowline knot was tied in $10,1 / 2$ in diameter rope sections of each listed fiber (see column headings). The knotted sections were then tumbled for either 24 or 48 hours. Tabled elements represent the frequency with which each fiber type rope section was found in the state specified in column 1 . 


$$
\begin{aligned}
& \text { - } 6 \mathrm{ft} \text { (lanyard) } \\
& \text { - } 2 \mathrm{~m}(6.6 \mathrm{ft}) \text { (Ianyard) }
\end{aligned}
$$

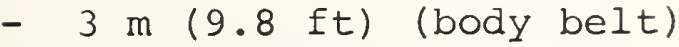

$$
\begin{aligned}
& \text { - } 3 \mathrm{ft}+\text { lanyard length or } 1.5 \mathrm{x} \text { [OS-1] } \\
& \text { lanyard length }
\end{aligned}
$$

Number of Required Drops Without Failure

$$
\begin{array}{ll}
\text { - One } & {[\mathrm{BS}-4, \mathrm{CA}-5, \mathrm{CS}-1, \mathrm{NA}-2, \mathrm{OS}-1]} \\
\text { - Two } & {[\mathrm{NA}-4, \mathrm{US}-1]} \\
\text { - Three } & {[\mathrm{AN}-1, \mathrm{FE}-3, \mathrm{SW}-1]} \\
\text { - Four } & {[\mathrm{X}-1]}
\end{array}
$$

How Unit Tested

- By itself (lanyard and/or belt) [BS-4, CA-5, CF-4,

- Belt + Lanyard

- Belt + Pole Strap

Anchorage

- Anchor- or toggle-bolt into which a snaphook is snapped [most]

- "I" or "L" beam around which a lanyard is tied off [CS-1]

Test criteria (one or more of the following)

- No breakage

- No release of test weight

- Keeper of snaphook not released

[all]

[all]

$[\mathrm{CS}-1]$

- Peak force $\leq 2500$ lbf (body [X-1] belt)

Peak force $\leq 8750$ lbf (body [ $x-1]$ harness)

- Impact force $\leq 50$ percent of [OS-1] tensile BS

- Force on torso $\leq 700$ lbf [MI-4]

- Tongue buckle mō̄ing grommets [BS-4, NA-2]

- Ripping of belt >3 in

- Follow-up tensile pull of 4000 [FE-3] lbf without failure

The variability in tensile test requirements is seen from the following: 


$$
\begin{aligned}
& \text { - } 4000 \mathrm{lbf} \\
& \text { - } 5000 \text { lbf } \\
& \text { - } 5000 \text { lbf (dee-rings) } \\
& \text { - } 50 \text { percent proof load of } \\
& \text { ultimate tensile strength up } \\
& \text { to } 2000 \text { lbf } \\
& {[\mathrm{CF}-2, \mathrm{CF}-6, \mathrm{CS}-1 \text {, }} \\
& \mathrm{FE}-3, \mathrm{NA}-2] \\
& \text { [MI-4] } \\
& {[\mathrm{AN}-1, \mathrm{NA}-2, \mathrm{US}-1]} \\
& \text { [BS-4] }
\end{aligned}
$$

Lanyard (Strength Reguirements)

$$
\begin{aligned}
& \text { - } 4000 \text { lbf } \\
& \text { - } 5400 \text { lbf (rope) } \\
& \text { - } 6000 \text { lbf (rope) } \\
& \text { - } 9000 \text { lbf (strap) }
\end{aligned}
$$

$$
\begin{aligned}
& {[\mathrm{CF}-2]} \\
& {[\mathrm{CF}-6, \mathrm{US}-1]} \\
& {[\mathrm{MI}-4]} \\
& {[\mathrm{US}-1]}
\end{aligned}
$$

Lifeline

$$
\begin{aligned}
& \text { - } 4000 \text { lbf } \\
& \text { - } 5400 \text { lbf } \\
& \text { cable) } \\
& \text { cableraft }
\end{aligned}
$$

[ $\mathrm{CF}-2]$

$[\mathrm{AN}-1, \mathrm{CA}-5, \mathrm{CF}-6]$ [US-1]

Safety Lines

$$
\text { - } 20001 \mathrm{bf}
$$

Belt Buckles

- 2000 lbf (with no slippage)

- 2000 lbf (max. deform.< $1 / 64$ in)

[MI-1]

- 4000 lbf

$[\mathrm{EE}-1]$

$[A N-1, M I-4, N A-2$, US-1]

Snaphooks

- 1500 lbf (pole strap)

- 1500 lbf (positioning line straps)

- 5000 lbf (break, distort, or release keeper)

- 750 lbf side load on keeper

[US-1]

$[\mathrm{AN}-1]$

$[A N-1, E E-1, U S-1]$

[EE-1]

Body Belt, Body Harness

- 4000 lbf (body belt)

- 5000 lbf (harness)

- 10000 lbf (webbing itself)
[CF-2, $\mathrm{FE}-3]$

[MI-4]

[US-1] 


$$
-3400 \mathrm{lbf} \quad[\mathrm{AN}-1, \mathrm{CF}-6]
$$

Since the test procedures and performance requirements that now exist are so diverse and sometimes inadequately described, it is suggested that fall-safety system components be required to meet the performance criteria of Table 11 when tested as described below.

\subsubsection{Static Strength Tests}

Although most fall-safety devices are primarily intended to withstand a dynamic (impact) load in arresting a fall, it is frequently more convenient and reliable to determine their strength under static or quasi-static conditions. Considering the materials and rates of loading involved, strengths for dynamic and static loading are probably comparable, and the results of static tests should be acceptable [CF-9, NE-1]. Dynamic effects may be significant when lanyards are tied-off around a beam [CS-3].

Static strength tests would usually be conducted by applying force to the component with a testing machine. The testing machine should meet the accuracy requirements of ASTM Method E4 [AS-4]. Fixtures should be provided for the testing machine so that the component being tested is mounted in the same manner as it will be in use and so that the method of applying the load closely simulates use conditions. The load should be applied smoothly until failure occurs. The maximum force applied during the test is the strength value to be reported. Strain and/or elongation measurements as a function of force may be desirable during some tests when information in addition to strength is being sought.

For some tests, particular care must be taken to insure that the loading conditions and procedures insure validity and repeatability of the results. Factors to be considered include:

(1) For lanyard tests, the tie-off must simulate the worst-case anticipated in use as proposed by CSAO [CS3 ] and stipulated in the Canadian Safety Regulation [CS-1]. It is suggested that tie-offs be made as 
listed in Table 15. The same types of anchorages should be used in testing lifelines.

(2) For consistency, all strength tests of lanyards, ropes, etc. should be carried out in uniform atmospheric conditions and on specimens that are in temperature and humidity equilibrium with the test environment. The specimens should be exposed to the test environment for at least 24 hours prior to test. It is suggested that preconditioning and testing be carried out in the temperature ranges of 10 to $30^{\circ} \mathrm{C}(50$ to $85^{\circ} \mathrm{F}$ ) and at a relative humidity of 40 to 60 percent. It is noted, however, that Federal Test Method Standard No. 191 [FE-2] calls for a temperature of $21.1 \pm 1.1^{\circ} \mathrm{C}\left(70 \pm 2^{\circ} \mathrm{F}\right)$ and a relative humidity of $65 \pm 2$ perrcent.

(3) Since the synthetic fibers generally have large elongations before failure, the testing machine must have a long stroke. For test specimens up to $1.8 \mathrm{~m}$ (6 $\mathrm{ft}$ ) in length, a stroke of at least $0.9 \mathrm{~m}$ ( $3 \mathrm{ft}$ ) is required.

(1) Because of the large elongation and the use of quasi-static data to predict dynamic performance, a testing speed of at least $0.1 \mathrm{~m} / \mathrm{min}(4 \mathrm{in} / \mathrm{min})$, and preferably $0.25 \mathrm{~m} / \mathrm{min}(10 \mathrm{in} / \mathrm{min})$ or more, should be used.

(5) The effective strength of a lineman's pole strap, Class III system, is related to the geometry of its use. Test fixtures such as those shown in Figure 10 are suggested where the major diameter of the mandrel is $345 \mathrm{~mm}(13.5 \mathrm{in})$ and diameter of the rod loading the strap is $13 \mathrm{~mm}(0.5 \mathrm{in})$.

(6) The fixturing shown in Figure 11 is suggested as simulating use conditions for a body belt. The mandrel should have an elliptical form with a major diameter of $345 \mathrm{~mm}$ ( $13.5 \mathrm{in}$ ) and a minor diameter of $265 \mathrm{~mm}$ (10.5 in). This gives a circumference of $965 \mathrm{~mm}$ (38 in).

\subsubsection{Elongation (Extensibility) Tests}

The load Vs. elongation ( $\mathrm{L} / \mathrm{E}$ ) relationship for a lanyard type is used in predicting the force and acceleration levels that will be generated under a variety 
Table 15. Anchorages and anchor linkages to be used when strength testing lanyards

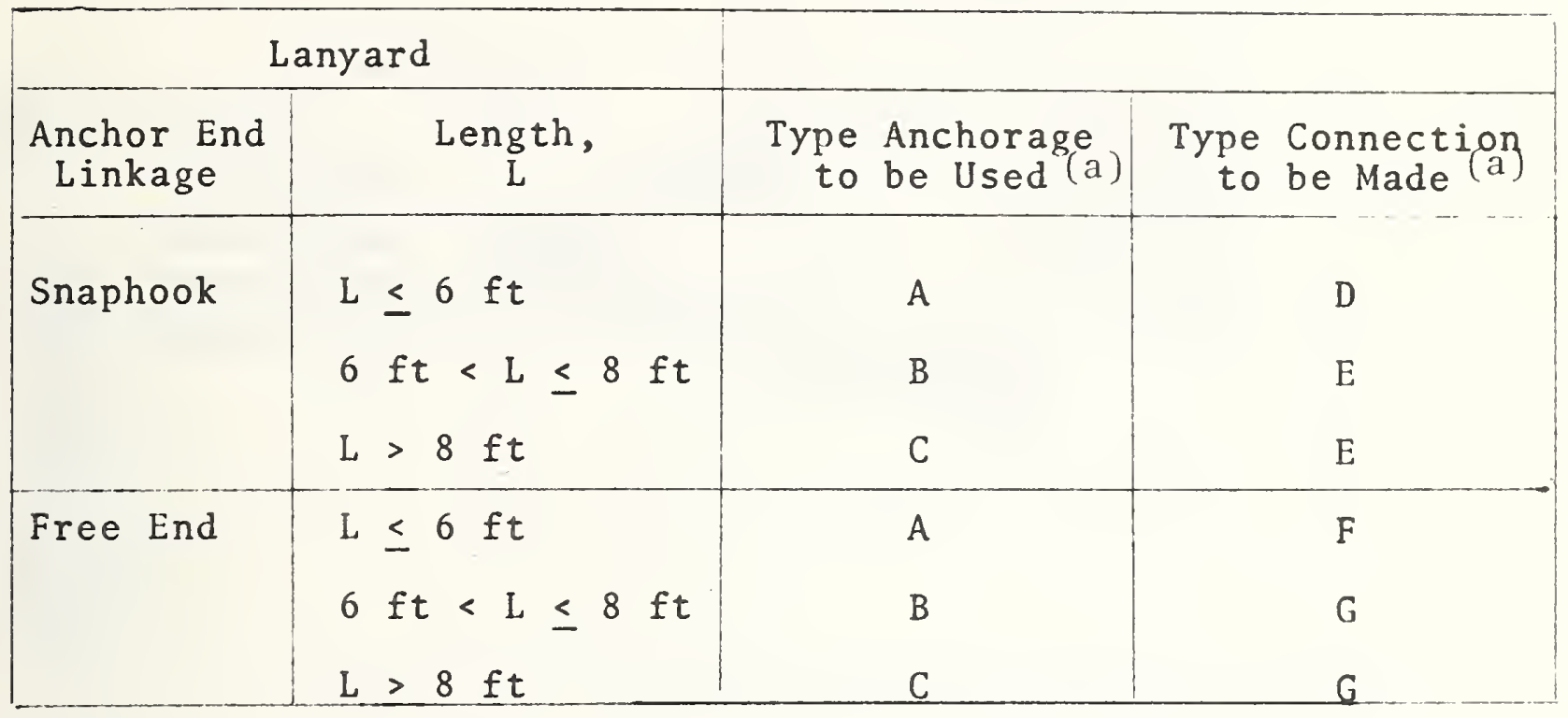

(a) Where:
$A=$ eye bolt or the like
$B=3 " \times 3 " \times 3 / 8 "$ angle iron
$C=10$ WF 33 I-beam
$\mathrm{D}=$ snap onto eye bolt
$E=100 p$ lanyard around beam once and snap into line
$F=$ tie bowline knot directly to a heavy-duty eye bolt
$\mathrm{G}=$ loop lanyard around beam once and tie off with bowline 


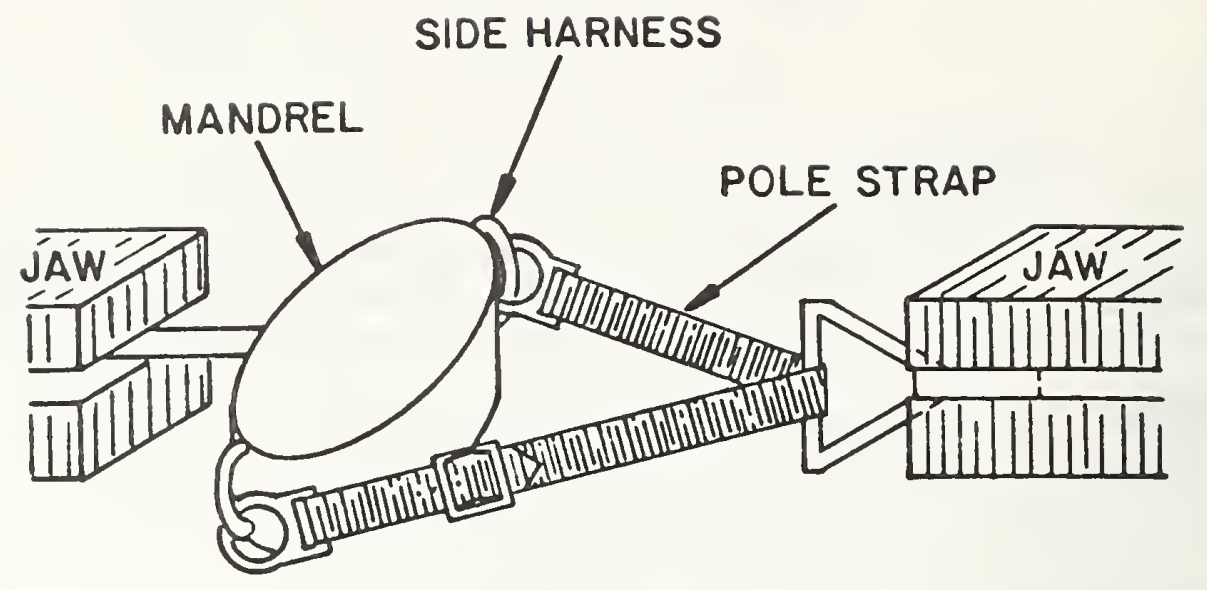

Figure 10. A Possible Setup for Tensile Testing of Lineren's Pole Straps

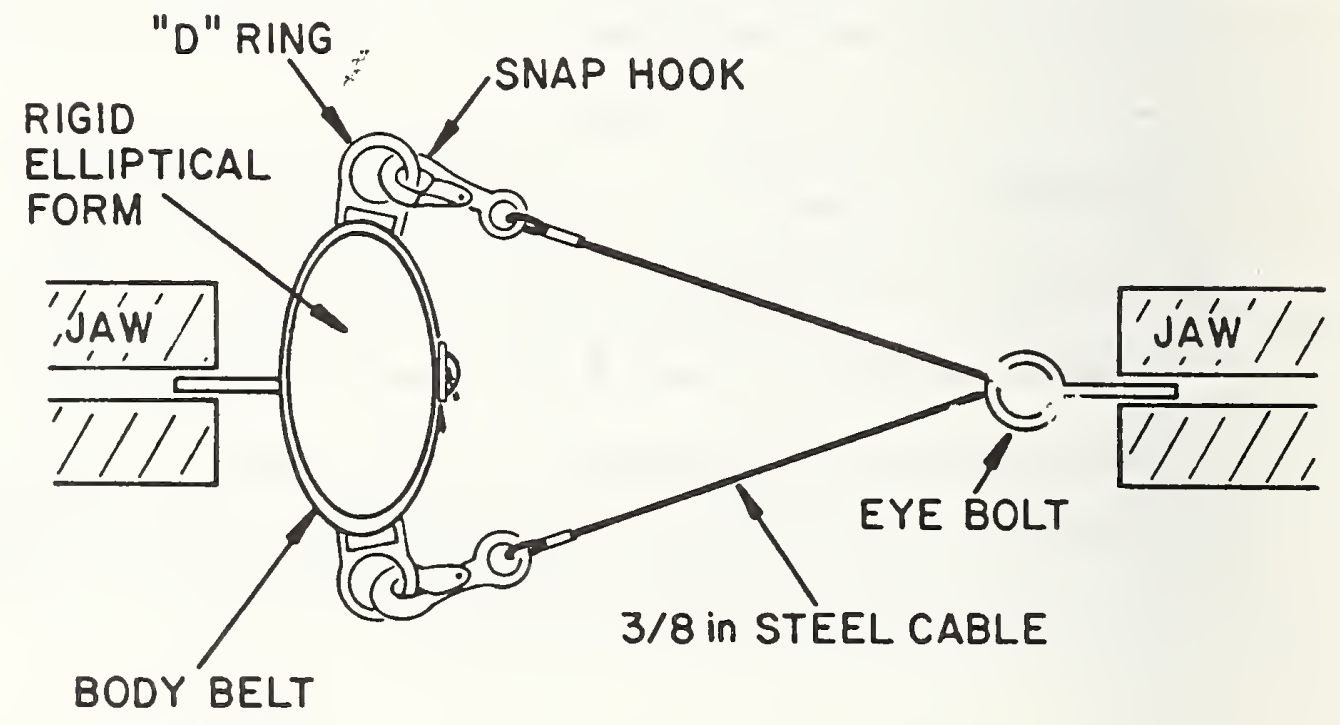

Figure 11. A Possible Setup for Tensile Testing of Linemen's Pole Belts 
of fall conditions. The data required to determine this relationship can be obtained at the same time that the static strength test is being made. For this purpose, it is suggested that a lanyard of $1.8 \mathrm{~m}$ ( $6 \mathrm{ft}$ ) length with snaphooks spliced onto each end be used. For test, the snaphooks would attach to eyebolts as shown in Table 15.

When possible, it is desirable for the load and elongation to be automatically plotted on an $x-y$ recorder. This can be readily done when the testing machine has an electrical output proportional to load and an electrical signal proportional to the motion of the moving head can be obtained. In this case, the signal leads are connected to the $y$ and $x$ axes of the recorder, respectively. The axes are scaled to provide nearly full scale records for anticipated maximum values, and the test is made. Care must be taken to determine the zero elongation point to coincide with the first indication of load.

Where autographic recording is not practical, data can be obtained by observers simultaneously reading the load and the elongation or position of the moving head. It is suggested that at least 15 data points, including one at the first indication of load, be taken to define the I/E curve.

Since the ends of the lanyard (snaphooks, thimbles, and splices) will not have the same L/E characteristics as the center (pure rope) section, the results of the above tests will only represent the length of lanyard tested. However, if a second set of elongation data for a center section of the lanyard is taken, the $\mathrm{L} / \mathrm{E}$ curve for any length of lanyard can be calculated. This second set of data can be obtained manually as described in [FE-2], using a tape to measure the change in length between two points on the lanyard. A more convenient method when autographic recording is used was developed during the study and is described in Appendix $A$.

Using the extension of the entire lanyard, $\Delta I$, the relative extension of the pure rope section, $\Delta l / l$ and defining the length of the lanyard of interest as $\lambda=I+p$, the relative extension of the new lanyard, $\Delta / \lambda$, can be found for any force, $\mathrm{F}_{i}$, as follows:

$$
\Delta \lambda=\Delta \mathrm{I}+\Delta \mathrm{p}
$$

But $\Delta_{\mathrm{p}}=\mathrm{p} \Delta \mathrm{l} / \mathrm{l}$

$$
\left.\left.\Delta \lambda / \lambda]_{F_{i}}=\Delta L / \lambda\right]_{F_{i}}+p / \lambda(\Delta \lambda / \lambda)\right]_{F_{i}}
$$


where all quantities on the right hand side of Equation 9 are known by definition or experimental measurement. By calculating a number of such values for various forces an $\mathrm{L} / \mathrm{E}$ curve for the new length lanyard can be described.

In conducting elongation tests, factors that must be given consideration include:

(1) The initial length must be determined under reproducible conditions. This is generally aone by applying a small load, frequently with weights, to insure that the rope is straight. The load is generally based upon the diameter of the rope; for example [FE-2] calls for a load, in $1 \mathrm{bf}$, of $100 \mathrm{~d}^{2}$, where " $d$ " is the nomijnal rope diameter in inches (approximately $0.7 \mathrm{~d}^{2}$ for force in newtons and diameter in millimeters). The procedure followed for this report, and suggested for general use, was to condition the lanyard with a $100 \mathrm{~d}^{2}$ lbf load, remove this load and allow recovery for at least 30 minutes, and then measure the length under a $22 \mathrm{~N}$ (5 lbf) load.

(2) The length of the entire lanyard should be measured between the inside surfaces of the snaphooks.

(3) Pure rope values should not include sections of the lanyard closer than $0.1 \mathrm{~m}$ ( 4 in) to a splice.

(4) If data is taken by an observer, care must be taken to avoid injury from possible whip-like action of the lanyard when it fails.

\subsubsection{Dynamic (Drop) Tests}

The ability of a lanyard, body belt, or other components to withstand the force generated in arresting a fall and to limit the acceleration to a tolerable level can be determined through dynamic drop tests. Static tests are easier to conduct, less subject to experimental variables, and provide more information for each test, but the prediction of dynamic performance from static tests has not been completely verified.

Drop tests are frequently used as pass/fail specification tests in which a given weight is allowed to fall freely a specified distance before its fall is arrested by the lanyard being tested. The lanyard would be judged to 
pass the test, and hence indicate that similar lanyards are acceptable for use, unless:

(1) one or more rope strands or hardware components broke or deformed excessively;

(2) a peak force greater than specified was generated; or

(3) a peak acceleration greater than specjeied was generated.

Tests must be made using both maximum and minimum weights to check for (2) and (3). The same tests would, of course, test other components of a fall-safety system involved (e.g., anchorages, containment devices, and hardware). Results from a series of drop tests of different severity can be used to predict the performance of a lanyard over a range of tests or use parameters.

A schematic diagram of a drop test is shown in Figure 12. In general either a load cell or accelerometer would be used, but usually not both. A test is conducted as follows:

(1) The length of the lanyard is measured under a small load ( 5 lbf or 22 newtons is suggested as for static tests) and recorded.

(2) The weight is raised to the desired drop point, and the lanyard is connected to the anchorage and the weight. The two eyebolts and the center of gravity of the weight should be a vertical line. The free fall distance is recorded.

(3) The instrumentation is adjusted and triggering circuits are set.

(4) The weight is released by a quick release mechanism that imparts no motion to the weight upon release.

(5) The peak force and/or acceleration indicated by the instrumentation is recorded.

(6) When only force or acceleration has been measured, the other is calculated from the relationship $F=$ Ma. 


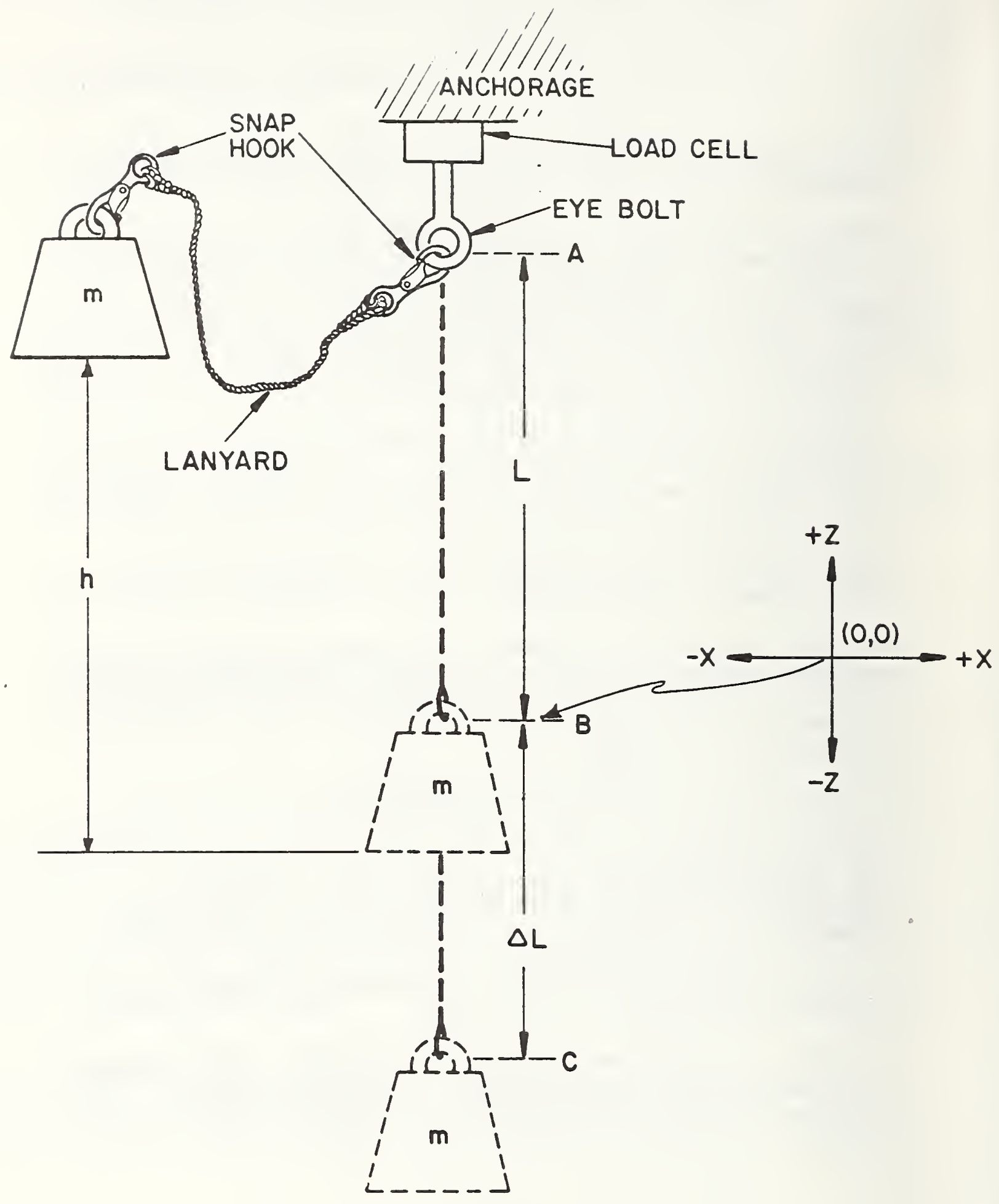

Figure 12. Schematic Diagram of a Drop Test 

include:

Factors that must be considered for this type of test

(1) Provision should be made to catch the weight in case a component breaks.

(2) The test area should be enclosed to prevent injuries to personnel in case of a component failure.

(3) The weight should not rotate or swing excessively. If there is significant motion of this type, the test should be voided.

(4). The supporting structure must be rigid so as not to absorb significant energy.

(5) The geometry of the test weight is important when testing pole straps, body belts, and other containment devices. A possible test weight configuration is shown in Figure 13. Possible setups for testing linemen's pole straps and body belts are shown in Figures 14 and 15 .

(o) The load cell can be mounted on the weight instead of on the supporting structure. This is not

recommended because of problems with the leads and possible damage to the load cell if a component breaks. With the arrangement of Figure 12, the measured force includes that required to accelerate the lanyard. This effect is considered to be negligibly small.

(7) The length of a lanyard should be measured under consistent load conditions. Five lbf $(22 \mathrm{lN})$ is suggested.

(8) For strength tests, a worst case tie-off condition, Table 15, should be used. Tests for acceleration levels should use optimum tie-off conditions.

For pass/fail specification testing for strength, the following tests are suggested:

(1) For Class III systems, a $115 \mathrm{~kg}$ (250 lb) mass with a free fall of $1.2 \mathrm{~m}$ (4 ft)

(2) For Class $\mathrm{V}$ systems, a $136 \mathrm{~kg}$ (300 lb) mass with a free fall of $2.7 \mathrm{~m}$ (9 ft). 


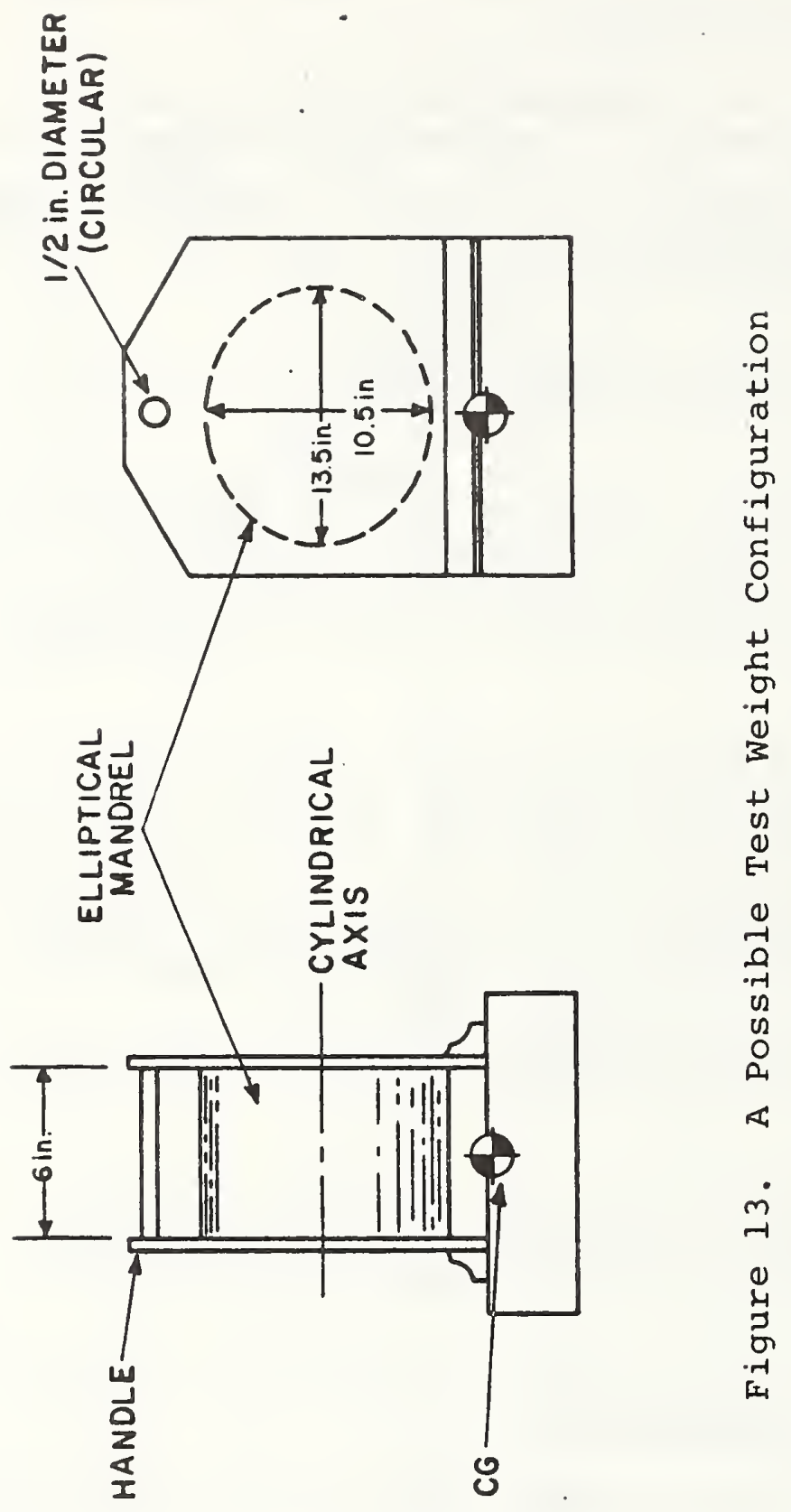




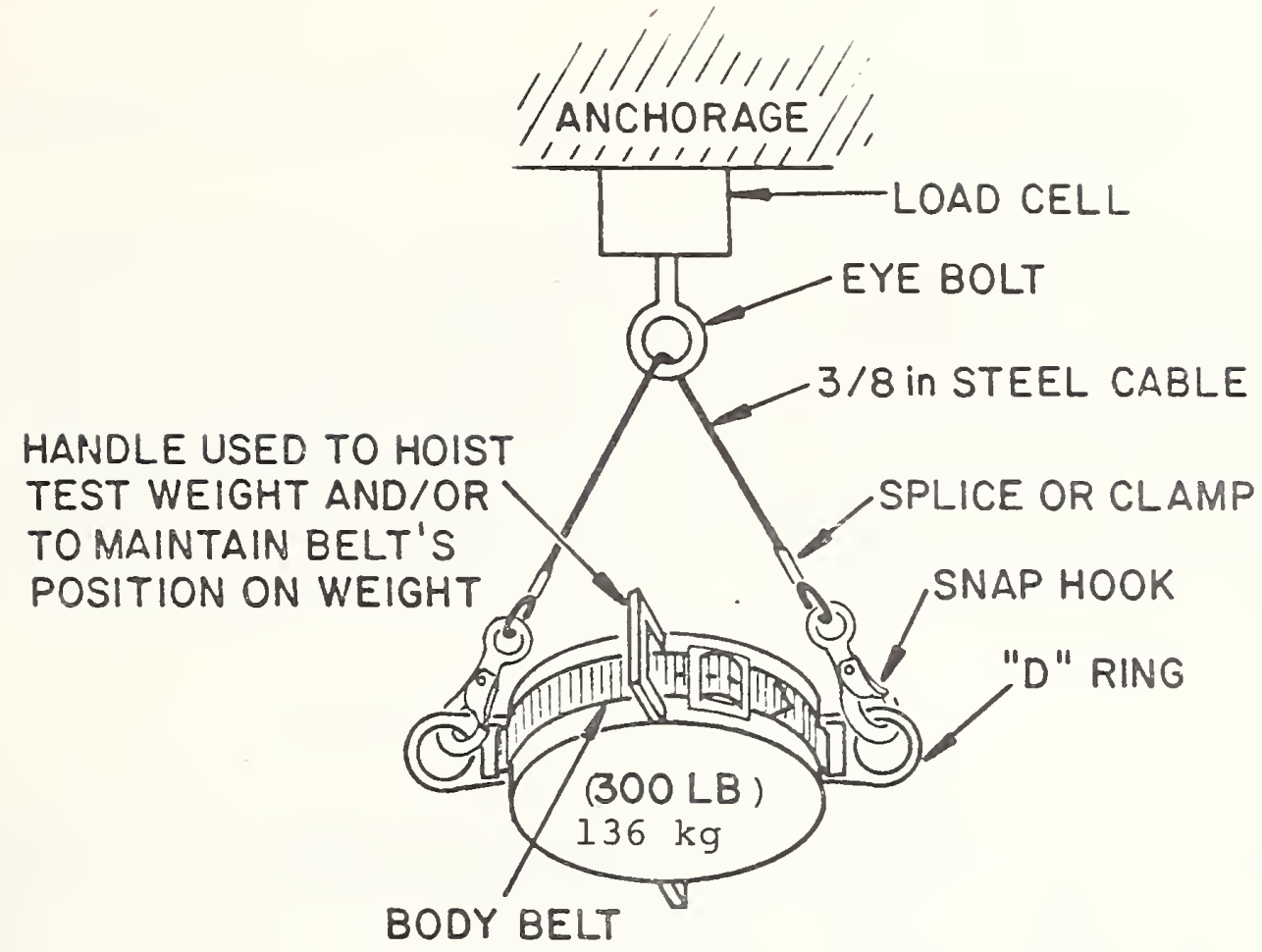

Fiqure 14. A Possible Setup for Dynamic Testing of Isinemen's Body Belts

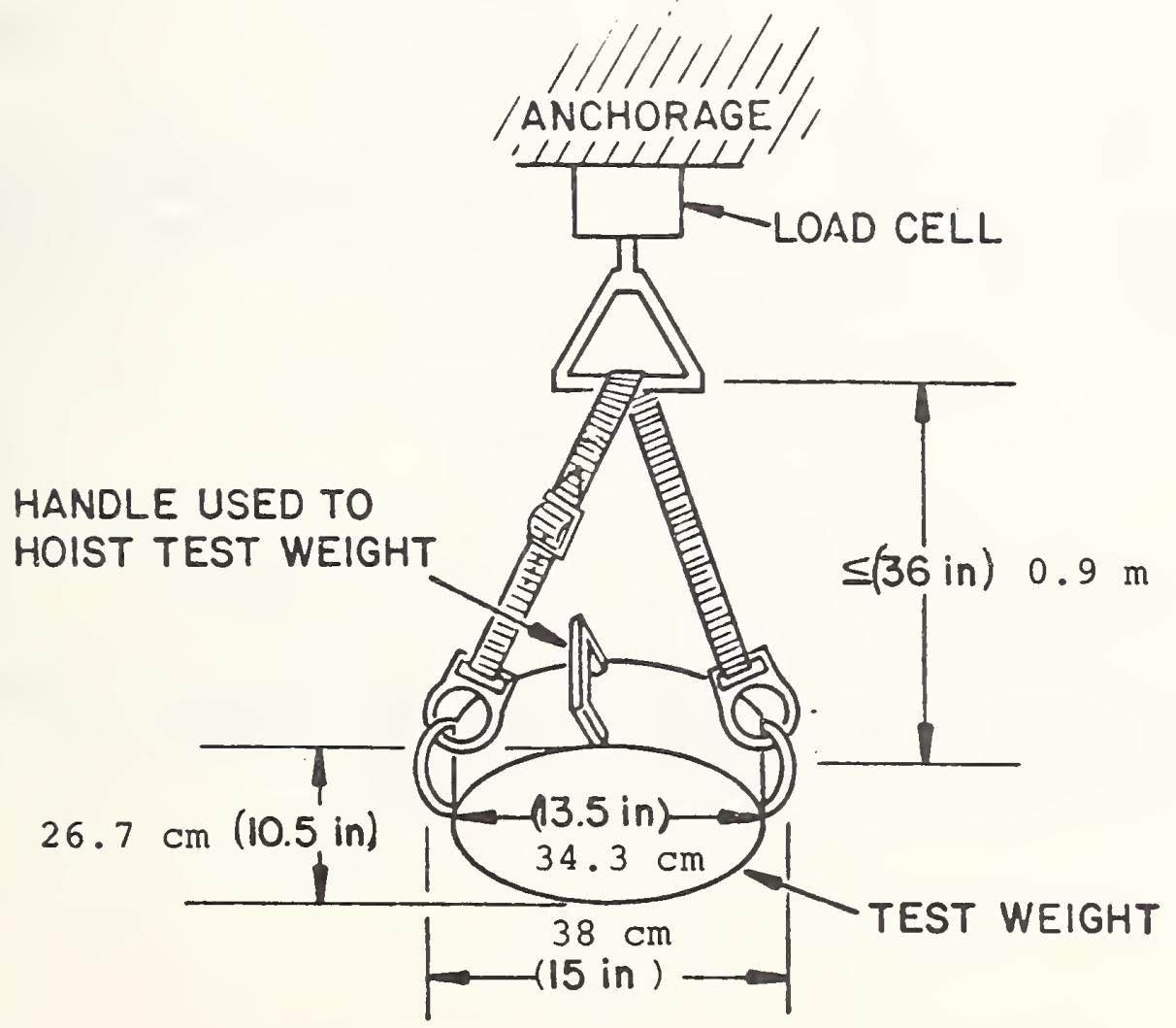

Figure. 15. A Possible Setup for Dynamic Testing of Linemen's Body Straps. 
(3) For Class VI systems, a $160 \mathrm{~kg}$ (350 1b) mass with

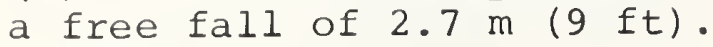

For acceleration level testing, a $60 \mathrm{~kg}$ (130 lb) mass should be allowed to fall the maximum possible free fall distance anticipated for the lanyards' use. The peak acceleration measured by an accelerometer or calculated from force measurements should not exceed $2 a_{\max } / D_{a}$, where $a_{\max }$ is the allowable acceleration level for the class of system being tested (Table 11 ), $\mathrm{D}_{\mathrm{a}}$ is a contingency (safety) factor ( 2 is suggested), and the factor of 2 accounts for the energy absorption of a human body compared to a rigid mass.

\subsubsection{Electrical Tests}

Existing documents [CF-4, $\mathrm{CF}-8, \mathrm{EE}-1, \mathrm{NA}-1]$ include dielectric and leakage current requirements for linemen's fall-safety equipment. An AC dielectric test of $82000 \mathrm{~V} / \mathrm{m}$ (25000 V/ft) on dry components for three minutes without visible deterioration and a leakage current of less than 1 $\mathrm{mA}$ with $3000 \mathrm{~V}$ AC imposed on electrodes $0.3 \mathrm{~m} \mathrm{(} 1 \mathrm{ft}$ ) apart are typical requirements. Procedures for testing dielectric and leakage current properties of wet and dry rope are contained in parts 1910.268 and 1926.959 of Code of Federal Regulations, Title 29.

In making the electrical tests, it is important that good electrical contact be made on the rope or strap under test. This can be done with narrow strips of clean, heavyduty aluminum foil placed snugly about the test item. The test length is the free space between the foil strips. This arrangement is shown in Figure 16.

\subsubsection{Other Tests}

It is suggested that sunlight and weather resistance tests be made by direct exposure to Florida weather conditions for extended periods, up to two years, with strength, extensibility and electrical property tests being made at intervals. The use of a carbon-arc tester (e.g. weatherometer) is not recommended until correlation with actual outdoor exposure tests can be shown. 


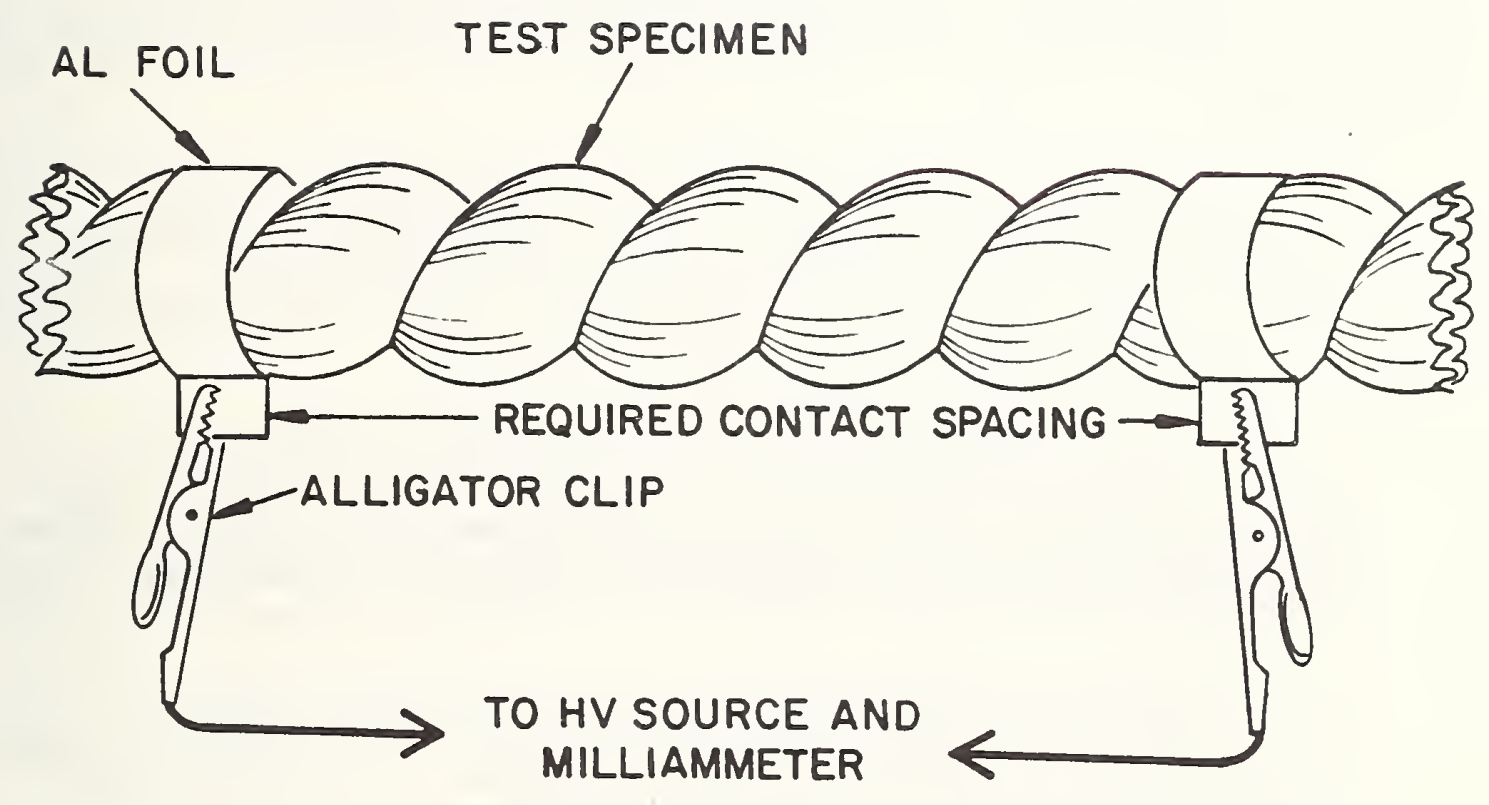

Figure 16. Electric Contact Configuration for Dielectric Testing of Ropes 
All hardware components should be either inherently corrosion resistant or made with a corrosion resistant finish in accordance with Federal Test Methods QQ-P-416 or QQ-Z-325, ASTM Methods Al43 or Al53, or Military Specification MS 22042 , 3, or 6. These hardware components should be exposed to a salt spray for 50 hours in accordance with ASTM Method B117, and then be examined for corrosion and tested for strength. Thimbles or other parts that are bent during assembly should be tested after such bending to detect possible chipping or cracking of protective coatings.

To determine whether strength and extensibility deteriorate during storage in extreme environmental conditions, samples of fibrous materials (lanyards, lifelines, belts, straps, etc.) should be exposed to adverse temperature and humidity conditions. It is suggested that these storage tests include at least 200 hours at $80^{\circ} \mathrm{C}$ $\left(175^{\circ} \mathrm{F}\right), 10$ percent relative humidity and 100 percent relative humidity. The storage periods would be followed by strength and elongation tests using normal testing conditions.

\subsection{Prototype, Production Line, and Field Testing}

There are, basically, three types of inspections that must be performed on fall-safety equipment:

(1) Before any system or component is marketed, prototype specimens must be tested to determine if design features meet performance requirements. This initial inspectional phase is called "prototype testing."

(2) Since raw materials, workmanship and the fabrication process vary with time, a production line's output must be periodically sampled to ensure that performance criteria continue to be met. This is "quality control" or "production-line testing."

(3) When a fall-safety device is first put into service and at regular intervals thereafter, it should be carefully inspected for defects that could cause unsatisfactory behavior or failure. This is called "field inspection."

Prototype and production line testing are the responsibility of the manufacturer or assembler of the 
component or system. Field testing is the concern and responsibility of the user and using organization.

\subsubsection{Prototype Testing}

During the design and development of new fall-safety equipment, comprehensive analysis must be done to assure adequate strength and energy absorbing properties. To verify the design and analysis, tests should be conducted upon custom-made, prototype models of the device. These tests are frequently more comprehensive than subsequent testing and may include the measurement of strains, etc. to permit stress analysis, determination of load distribution, and interactions between the various components and the user. These tests are generally designed, conducted, and evaluated by trained engineering personnel. Where certification of a device is required, the results of such tests should be submitted to the certifying agency for review and evaluation.

Guidance on the quantity and selection of test specimens, the assignment of measurement uncertainty values, and judging the satisfactory or unsatisfactory nature of the test results can be obtained from statistical handbooks, e.g. $[\mathrm{NA}-3]$.

\subsubsection{Production Line Testing}

Production line testing at the proper level will minimize the chance of faulty products being furnished because of factors such as:

(1) variability of the materials and purchased components;

(2) variability in production line labor; and

(3) variability in the production and assembly process.

The testing program must be designed to continuously monitor critical parameters such as strength, elongation or energy absorption, and resistance to salt spray. Other factors, such as weather and ultraviolet resistance, should be determined for types or lots of materials. 
Guidance on the method and rate of sampling can be obtained from statistical handbooks, e.g. [NA-3], military specifications, etc. Mil-Spec MIL-H-24460, "Harness, Safety" [MI-4] recommends the following:

\begin{tabular}{cc}
$\begin{array}{c}\text { Units in the } \\
\text { Production Lot }\end{array}$ & $\begin{array}{c}\text { Units in } \\
\text { Sample }\end{array}$ \\
\cline { 2 - 2 } $\begin{array}{c}\leq 40 \\
41 \text { to } 110\end{array}$ & 2 \\
111 to 300 & 3 \\
$>300$ & 4 \\
& 5
\end{tabular}

Under this sampling procedure, the lot would be rejected if any sample failed to meet the requirements of the test.

The ultimate responsibility for production line testing rests with the manufacturer or assembler of the final product, even though components have been tested by their producers. Complete records of production line test procedures and results should be available to the purchaser and the regulatory agency.

A large purchaser of fall-safety equipment may also decide to perform test samplings of delivered lots. This process is independent of the manufacturer's test program and might be considered part of a field test program.

\subsubsection{Field Testing}

In order to provide the best possible continuing assurance that faulty fall-safety equipment is not being used, two levels of field inspection are suggested. These are:

(1) A visual inspection by the user, supervisor, or delegated inspector before each day's use, and

(2) A thorough inspection by a knowledgeable, authorized person at some regular, designated interval. This may be a strictly visual inspection, but it could also include some nondestructive test procedures. The inspection date, inspector's name, and signature should be recorded in a company log book along with the results of each thorough inspection. 
Any device found to have a serious defect should be immediately removed from service. If the defect is not remediable, the device must be discarded.

Miller and MSA (two manufacturers of safety equipment) both put out well illustrated booklets giving inspection and maintenance procedures. U.S. Steel makes available a slide show on the care and maintenance of fall-safety equipment and points out ten principal defects in fall-safety equipment that a worker or inspector should be mindful of:

(1) cuts or tears of any size

(2) abrasions

(3) burned or melted fibers

(4) molten metal burns or scars

(5) acid, alkali or other chemical burns

(6) dryness

(7) punctures

(8) tar or similar products that penetrate and harden in the fibers

(9) cracks in or distortions of hardware

(10) loss of flexibility or elasticity (in lanyards and lifelines)

In addition to these factors, the inspector should be alert for:

(1) Sand and grit in a belt which can cause internal breakage of fibers. If a fabric component is excessively sandy, it should be inspected for fuzziness of inner fibers. (Fuzziness on a rope lanyards'

exterior will occur with use but is not necessarily a sign that the lanyard is no longer satisfactory.

Fuzziness on inner fibers is stronger evidence that a lanyard has been weakened and should be replaced.) $[\mathrm{CG}-2$ ]

(2) Deformed thimbles and buckle tongues and grommets. Such deformation could be evidence of an unreported shock load, perhaps from a "near miss." Normal wear on thimbles, grommets, and buckles will not generally cause significant deformation.

Toward the end of ensuring that these periodic inspections are made and within the specified interval, each system and/or major interchangeable or replaceable component thereof should contain a permanently affixed tag on which the next inspection date should be stamped after each 
periodic inspection. If the item has a finite life expectancy then the date by which the device or component must be removed from service should also be indicated on the inspection dating tag.

Unfortunately, according to the ARL tests performed for U.S. Steel on well used and old devices, except for obvious defects, the appearance of a belt and/or lanyard generally bears little relationship to its performance under test. Nondestructive field test methods are needed to sort out those fall-arrest components which no longer meet breaking strengths or energy-absorption requirements. These field tests should not require either elaborate equipment or time. Since nylon lanyards are relatively inexpensive, any test that requires more than a few minutes of company time may not prove cost effective since it could be less expensive to replace the lanyard than to conduct the test.

A possible nondestructive field test method for estimating the shock absorbing capability of a lanyard involves a comparison of the extensibility of a lanyard at a load of $200 \mathrm{~d}^{2}$ lbf $\left(1.4 \mathrm{~d}^{2} \mathrm{~N}\right)$ with its extensibility at a relatively large load, $15 \mathrm{klJ}$ or 3000 lbf for example. Such a comparison is shown in Figure 17. There appears to be some correlation of these two factors, and further investigation of such a method for estimating energy absorption capability should be considered.

In any event, daily inspection of fall-safety equipment and periodic in-depth inspections should be part of every company's safety program, and all outdated or rejected devices should be disposed of so that they cannot be reused. 


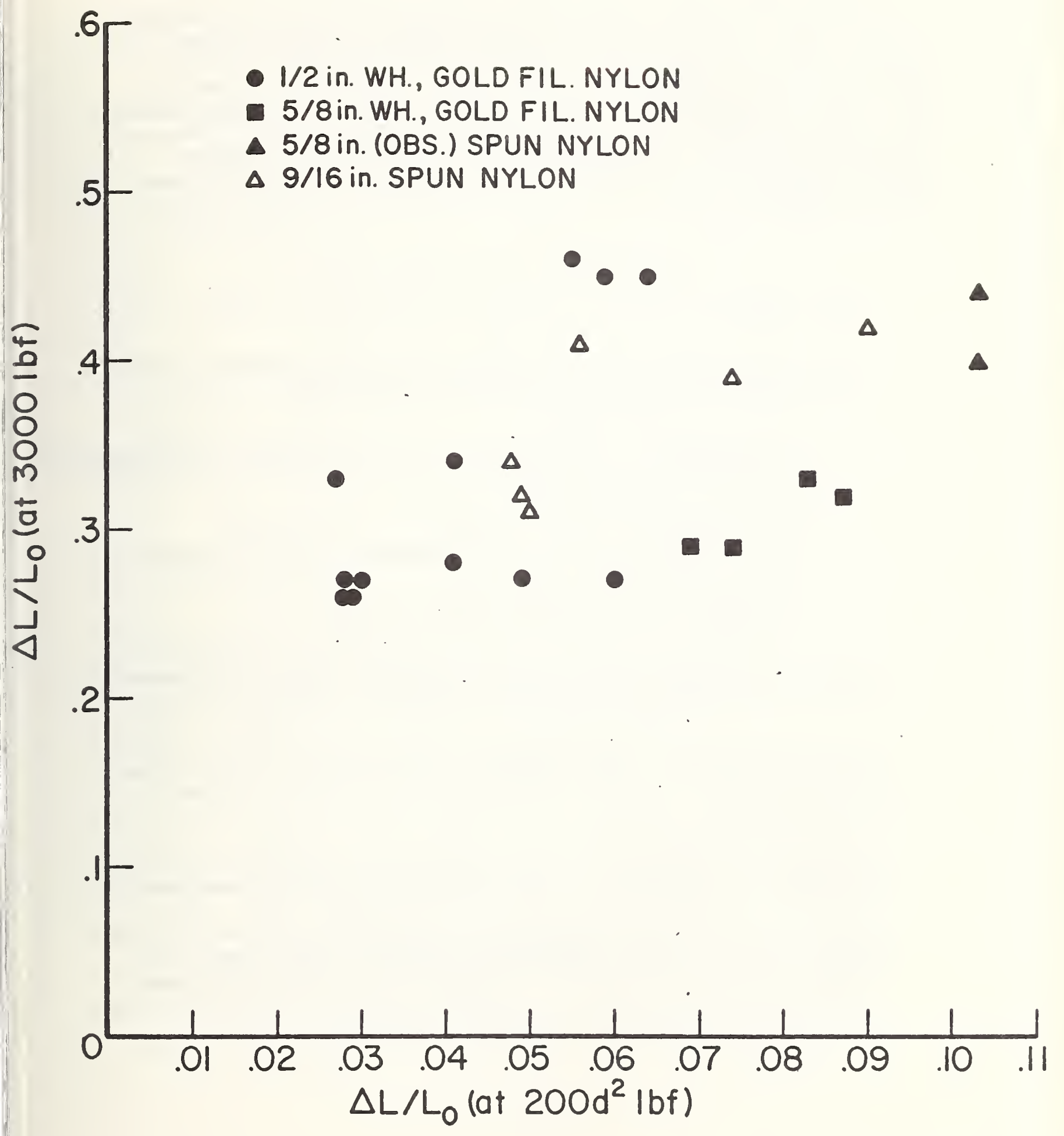

Figure 17. Correlation Between Lanyard Extensibility at Two Loads. 
Based upon the information gathered from the literature search, site visits, and in-house testing that made up this study, it is recommended that the factors given in this section be considered in preparing a regulation governing fall-safety equipment. For convenience, the recommendations have been grouped as to whether they pertain to (1) design and fabrication, (2) performance, (3) use, (4) testing, (5) information to be provided, or (6) areas where additional work is needed.

\subsection{General Considerations}

Some general considerations are:

(1) Each requirement of the regulation should involve a consideration of the following factors:

- safety of the user

- reasonable anticipated worst-case usage, environmental and storage factors

- worker acceptance/convenience

- worker efficiency

- cost effectiveness (anticipated impact on worker safety vs. cost)

- technological feasibility

- reliability under reasonable abuse

(2) To the degree that it is possible, the addressed regulation should be of a performance nature.

(3) Any regulation 'should be written in both SI and customary units. The intent to eventually convert to metric units should be explicitly stated in the regulation.

(4) The classification of fall-safety systems into six classes as proposed in this report should be adopted.

(5) If it is accepted that a lineman's pole strap and belt are used as a positioning device, backrest, and tool carrier, then Class III devices may be excluded from 29 CFR 1910.132a. In this case, 29 CFR 1910.260g and 29 CFR 1926.959 should be revised. 


\subsection{Design and Fabrication}

Recommendations relating to the design and fabrication of fall-safety systems and components include:

(1) Contingency factors should be used to allow for anticipated degradation with time and/or usage.

(2) Manila rope and leather should be prohibited from use as a load-bearing member of any class of fallsafety system. These materials can, however, be used in non-load bearing applications such as padding, tags, and tool pouches.

(3) The use of hard- or soft-lay ropes in lanyards should be discouraged.

(4) Although the acceleration imparted to the falling worker is related to the ratio of the free fall distance to the lanyard length, longer falls are more likely to cause injury from contact with other objects. Lanyard length should therefore be such as to limit free fall distance to the values shown in Table 9.

(5) Lanyards for use with a body harness (e.g. Class VI systems) should have snaphooks spliced to both ends and be limited to $1.8 \mathrm{~m} \mathrm{(6} \mathrm{ft)} \mathrm{in} \mathrm{length.}$

(6) To minimize abrasion of lines or straps, thimbles or rollers (sleeves) should be used wherever a synthetic fiber, load-bearing, line or strap is coupled to metal, load-bearing hardware and the two parts are free to move with respect to each other.

(7) All stranded lanyard and lifeline splices should be made with at least four full tucks. Tapered splices beyond the four-tuck limit can be encouraged but need not be required. Splices made with clamping devices, such as those clamps used on wire cables, can be used if the component so constructed passes all requisite tests. All stranded endings, whether free or spliced should be seized, whipped, taped, seared, glued or otherwise treated to prevent unraveling of the ending for the life of the lanyard.

(8) Splices should be seized or tightened so that thimbles cannot be hand turned within the splice. 
(9) A rope lanyard can be spliced around the loadbearing webbing of a body belt by means of a direct splice (no thimble) or to a load-bearing dee-ring. Webbing lanyards used on belts without dee-rings should terminate in a sewn eye of suitable size to accommodate only the width of the belt.

(10) Any load-bearing or potential load-bearing rope or strap passing over a shearing edge (e.g., flange or roof ledge) should be abrasion resistant or padded at the shearing edge. Use of a sheath that slides up and down on a line, so as to provide a cushion at the required point, may be permitted so long as the sheath does not degrade the operating characteristics of the line nor significantly abrade the line when moved along it.

(11) Adjustable lanyards should be permitted, but only if their maximum length is not greater than six feet (See Section 4.2 (4)).

(12) All synthetic fiber lanyards and lifelines should contain UV inhibitors where UV degradation is known to significantly affect the fiber in question.

(13) iJylon ropes and strapping should be stabilized against the undesirable effect of moisture. Such stabilization is especially in order with regard to lifelines used in conjunction with Class II or IV systems where dimensional changes brought upon by water absorption could affect the operational characteristics of a rope grab or controlled-descent device.

(14) Belt sizing should conform to conventional sizing as follows:

Belt Sizes

Small

Medium

Large

Extra Large
(S)

$(\mathrm{XL})$
To Fit Waist irange

81 to $102 \mathrm{~cm}$ (32 to $40 \mathrm{in})$

91 to $112 \mathrm{~cm}$ (36 to $44 \mathrm{in}$ )

102 to $122 \mathrm{~cm}$ ( 40 to 48 in)

112 to $132 \mathrm{~cm}$ (44 to $52 \mathrm{in}$ )

(15) Class IV and $\mathrm{V}$ body belt load-bearing webbings should be at least $50 \mathrm{~mm}$ ( 2 in) and no more than $100 \mathrm{~mm}$ (4 in) wide with a manufacturing tolerance of $2 \mathrm{~mm}$ (1/16 in). 
(16) No more than four tool loops should be permitted per belt, and these loops should not be placed in the front half of the belt.

(17) The cushion part of the lineman's body belt should:

(a) contain no exposed rivets on the inside;

(b) be at least three inches in width;

(c) be at least $4 \mathrm{~mm}$ ( $5 / 32$ in) thick;

(d) have pocket tabs that extend at least one and one-half inches down and three inches back of the inside of the circle of each dee-ring for riveting of plier or tool pockets. On shifting dee-ring belts, this measurement for pocket tabs should be taken when the dee-ring section is centered.

(18) The inner core of the pole strap should be of a different color than both outer surface layers (to flag excessive wear). The thickness of the surface layers should comprise, in total, less than $1 / 4$ of the belt thlckness (exclusive of padding).

(19) A dee-ring intended for use with a lanyard should not be located outside the 4 to $80^{\prime} \mathrm{clock}$ zone of a belt. If dee-rings are located outside this zone they should be clearly labeled as not safe for use with a lanyard. A belt intended for use with a directly (soft) coupled lanyard should have a loop placed on the belt to receive the lanyard. This loop should contain the strength member of the belt (not the padding, if any) and should restrain the lanyard from locating itself outside the 4 to 8 o'clock zone.

(20) Dee-ring spacing (heel-to-heel) on lineman's belts should be as in [EE-I].

(21) The use of a liner (sleeve) between dee-rings and belt webbing should be required to prevent wear between these components. These sleeves can be made of any durable, smooth surfaced, metal or synthetic material.

(22) It is suggested that grommets be used on all tongue buckle holes, and that they be inserted by spreading the belt weave--not by punching. A similar 
suggestion is made for rivets used to attach tags or labels onto strapping. These need not be requirements, however, as long as the belt or strap is capable of passing the prerequisite drop and/or tensile test.

(23) 'Tongue buckle holes for body belts and lineman's pole straps should be only large enough to accommodate the tongue and should be placed no closer than $25 \mathrm{~mm}$ (one inch) apart and no further than $38 \mathrm{~mm}(1-1 / 2 \mathrm{in}$ ) apart.

(24) The construction of a body harness system with regard to strap and harness dimensioning, strength, and location should be equivalent to that for a militarytype parachute. These harnesses should be designed to distribute the impact forces, due to an arrested fall, over the buttocks, waist, chest, and shoulders.

(25) The coupling dee-ring of a body harness should be located between the shoulder blades and high up on the back. Alternatively, four riser straps, each coming off a shoulder strap as in conventional parachute systems, shall be joined into a dee-ring above the wearer's head level. This dee will then serve as a coupling point for the associated lanyard.

(26) Two size, adjustable body harnesses might be made available: $60-90 \mathrm{~kg}(130-200 \mathrm{lb})$ and $80-115 \mathrm{~kg}$ (180250 1b). Alternatively, a single adjustable size could be employed that fits 60-115 kg (130-250 1b) users.

(27) Body harnesses should be designed to avoid undue stresses in the crotch area (resulting from arrested falls) even if these stresses will not cause serious injuries.

(28) All hardware components (snaps, dees, sleeves, carabiniers, thimbles, and buckles) and anchorages should be smooth and without sharp or pointed edges where they contact a fiber line. Snaphooks should be round-nosed.

(29) All metal components (hardware, anchorages, rope grabs, etc.) should be of a corrosion-resistant material or, if corrodible metal, should be made with a corrosion-resistant finish as specified in:

$$
\begin{aligned}
& \text { Federal Specification - QQ-P-416 (Cd plating) } \\
& Q Q-Z-325(\mathrm{Zn})
\end{aligned}
$$




ASTM Method $\begin{aligned} & \text { A-165-71 (Cu) } \\ & \text { A-153-73 ( } \mathrm{Zn})\end{aligned}$
Military Specification- MS 22042, 3, 6

(30) Snaphooks or carabiniers and their mating anchorages (e.g. anchor bolts or eye hooks) should be of such configuration and dimension as to eliminate the possibility of rollout. Unless specifically designed and so designated, snaphooks and carabiniers shall not be coupled to one another.

(31) If thimbles are to be required in eye splices, their inside diameters should be not less than $1.75 \mathrm{x}$ the rope diameter (a larger ratio is preferred). Thimbles should have deep, smooth ridges to prevent separation of rope from thimble. Thimbles, other than round-shaped (e.g. pear-shaped), that meet these requirements should be acceptable.

(32) Where metal thimbles with corrosion-resistant platings are used, they should be mounted so as to be able to pass the salt-spray test after mounting (to insure that the mounting process does not chip or crack the deposited coating). It is recommended, therefore, that thimbles be plated in the open position so they need only be pressed closed to complete a linkage.

(33) The nose of a snaphook should override the keeper by at least $3 \mathrm{~mm}(1 / 8 \mathrm{in})$.

(34) The construction of an anchorage should, preferably, be such as to retain the strength of the lines that will be secured to it. Towards this end, eye bolt type anchorages are recommended.

(35) Portable anchorages should be readily transportable, easy to attach and remove, and should also withstand reasonable abuse.

(36) Whatever body container device is used in conjunction with a tether line (Class I system) should be designed so that it couples to the tether line above the worker's center-of-gravity.

(37) The body-restraint component of a Class IIa system should be so designed as to maintain the worker in an upright position so that he may be readily extracted through a narrow orifice. 
(38) The body-restraint component of a Class IIa system should be so designed as to render it impossible for a worker to become separated from the system except by deliberate effort on his part.

(39) A winch-type mechanism used as part of a Class IIa safety system should be so geared as to be operable by one man, even where loads of 113 to $136 \mathrm{~kg}$ (250 to 300 Ib) are involved.

(40) A Class IIa system should be designed so as to minimize potential jolts or impacts to users. Such a system should limit the descent rate to about $4.6 \mathrm{~m} / \mathrm{s}$ (15 ft/s). The ascent rate can be ungoverned, however. The hoist should contain an easily-activated locking (braking) mechanism.

(41) Class IIb systems, when designed as a rescue device, should be capable of descent at a slow constant speed that will not injure the worker when it is stopped.

(42) If a rope grab controlled descent device is to be used with a lanyard then the device should be lockable so linat it will not ride down its line during nonactive use intervals. This "locking" action must be readily effected; yet deliberate repositioning should also be easily accomplished.

(43) A locked device should not travel down a dropline under dead-weight load of $1.3 \mathrm{kiv}$ (300 lbf) until it is manually released.

\subsection{Performance}

The following performance criteria and related factors are suggested:

(1) All load-bearing components of a fall-safety system should have the demonstrated capability to withstand, without failure, the worst-case peak forces that they can be expected to encounter. Environmental factors should be considered.

(2) Components that can be separated should have their pertinent performance characteristics determined independently. Even where a belt or harness is spliced 
directly to a lanyard, the two should be tested separately.

(3) Components of fall-safety systems should meet the performance criteria set forth in Table 16.

(4) When a component (e.g. anchorage or lifeline) may be used by two or more persons simultaneously, the minimum strength values should be multiplied by the maximum number of users. Horizontal lifelines must also consider geometric effects.

(5) The principal peak force is equal to or greater than $2 \mathrm{Ma}_{\max } / \mathrm{D}_{\mathrm{a}}$, where $\mathrm{a}_{\max }$ is the peak deceleration limit for the highest class system the component is intended for use with and $\mathrm{D}_{a}$ is the established $\mathrm{g}_{\mathrm{n}}$ 's contingency factor for that system. The factor of 2 is introduced to adjust the impact force to that force a real person (as opposed to a rigid mass) would experience.

(6) Droplines intended for use with Class II or IV systems should also satisfy the criterion:

$\mathrm{BS}_{\text {min }}=100 \mathrm{Mg}_{\mathrm{n}} / \mathrm{P}_{\mathrm{BS}}$

where $P_{B S}$ is the percent of breaking strength shown in Table 12 .

(7) Bounce (secondary impacts) for worst-case falls (as measured with extreme value weights) should not be in excess of $4.5 \mathrm{kN}$ (1000 lbf).

(8) Where electrical hazards may be present, fibrous components should meet dielectric criteria of section $3.6 .2[\mathrm{AP}-2]$.

(9) To allow for degradation of the extensibility of lanyard materials with time and use, a contingency factor for acceleration, $D_{a}$, of two is suggested.

(10) A fall-safety system or system component should be considered to have failed a strength test if any of the following occur below the specified load:

(a) breaking of one or more strands of a lanyard or lifeline; 


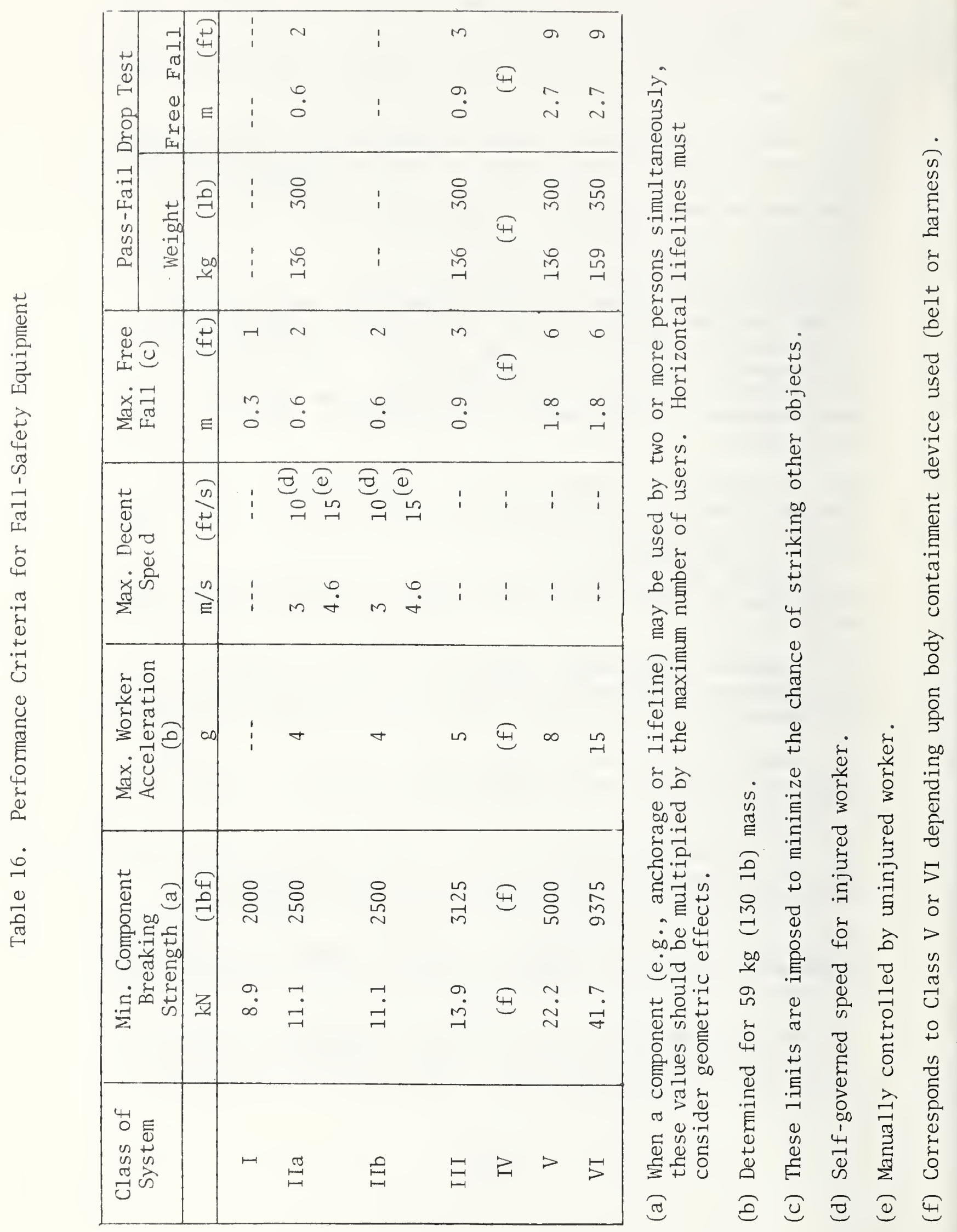


(b) slipping of one or more strands from a splice;

(c) breaking or cracking of any hardware component;

(d) deformation of any hardware component sufficient to release a keeper or belt tongue or to allow a hook to uncouple from an anchor point;

(e) a buckle tongue cutting through a belt webbing for more than $25 \mathrm{~mm}$ (1 inch);

(f) a friction buckle belt slipping more than 25 mm (1 inch);

(g) body belt elongating more than $100 \mathrm{~mm}$ (4 in);

(h) in a drop test, a secondary force peak exceeding $4.5 \mathrm{kN}(1000 \mathrm{lbf})$ or 50 percent of primary peak, whichever is least; or

(i) in a drop test, lanyard elongation of more than $0.9 \mathrm{~m}$ ( $3 \mathrm{ft}$ ) with a weight equal to or less than $115 \mathrm{~kg}(250 \mathrm{lb})$ or more than $1.2 \mathrm{~m} \mathrm{(4 \textrm {ft } )}$ with a weight greater than $136 \mathrm{~kg}(300 \mathrm{lb})$.

(11) For all test requirements involving a binary-type result (i.e., fail or pass, as in a drop test) all units comprising a sample (for a sample size of six or less) should pass the test in order for the system or component to remain an active candidate for certification, or for a production lot to be accepted.

(12) For tests involving continuous results (e.g. loadcell tensile test, or dielectric current measurement) a device, design or lot is acceptable if:

(a) the average sample value for the measured quantity is in the acceptable range;

(b) for prototype evaluation all test specimens give acceptable responses or for production line testing fewer than an established percentage (e.g. five percent) of the test specimens give unsatisfactory readings; and 
(c) no single unsatisfactory test unit deviates from acceptability by more than 10 percent.

(13) Assume a test is properly conducted, there are two types of statistical inference errors possible. These can:

(a) reject a design or lot although it does in fact meet all requirements (an "error of the first kind" or a "Type I error") or

(b) accept a design or lot although it does not meet all requirements (an "error of the seconà kind" or a "Type II error"). Since the introduction of a defective component into the market could convert a "near miss" into a tragedy, it is imperative that Type II errors be guarded against in all statistical analyses and by proper sampling design.

(14) Lanyards and lifelines used with Class II or III systems should not show significant creep after 8 hours exposure to loads of up to $1.3 \mathrm{kN}(300 \mathrm{lb})$. Preconditioning of a line by loading it with, say 1.3 $\mathrm{kN}(300 \mathrm{lb})$, for one hour prior to the creep test should be permitted. Permanent line extension (measured under a nominal load) resulting from the preconditioning should not exceed 5 percent.

(15) The dropline that the device travels along should be impervious to moisture to the degree that system behavior is not altered significantly by changes in temperature or relative humidity or upon being wetted.

(16) The extensibility of droplines should not exceed the values given in Table 17 to minimize the chance of a falling worker striking another object or surface.

Table 17. Recommended Maximum Permissible urop Line Extensibilities (a)

Ioad

Percent Extension

$4.5 \mathrm{kiJ}(1000 \quad 1 \mathrm{bf})$

$8.9 \mathrm{kN} \mathrm{(2000)}$

8

$13.4 \mathrm{kN}(3000)$

10

$17.8 \mathrm{~kJ}(4000)$

14 
(17) All load-bearing snaphooks, carabiniers, deerings, buckle frames and other load-bearing hardware components should be proof-loaded to a substantial fraction of the required system breaking strength. For hardware destined for use in Class IV and $V$ systems $17.8 \mathrm{kN}(4000 \mathrm{lbf})$, and for Class VI hardware $33.4 \mathrm{kN}$ (7500 lbf) are the tentatively suggested proof loads.

(18) All hardware components should pass a 50-hour salt spray test as per ASTM Bl17-73.

(19) Snaphooks and carabiniers should not open at ll N (2.5 lbf) load, but should begin to open by a force of $18 \mathrm{~N}$ (4 lbf) applied to the keeper latch. The use of double-locking snaps and self-locking carabiniers should be encouraged, but their requirement in fallsafety equipment may be premature.

(20) Snaphook and carabinier keeper latches should withstand $3.4 \mathrm{kiv}$ (750 lbf) of applied side load without suffering a permanent deformation of more than $0.4 \mathrm{~mm}$ $(1 / 64$ in).

(21) Sudden impact forces experienced by a winch should not cause the systern to unlock or to unwind at a rate exceeding $3 \mathrm{~m}$ (10 ft) per second. In any event, the shock should not be transferred directly to the turning crank in such a manner that a winch operator could suffer a significant injury.

(22) Repeated operation of an ascending/descending system under $113 \mathrm{~kg}$ (250 lb) loading should not significantly abrade the lifeline or cause significant wear to the mechanical components of the system.

(23) The mechanical action of rope grabs and shock absorbers upon impaction should not be affected to any significant degree by the presence of moisture, ice, dirt, grit, or greasy or oily surface contaminants.

(24) An unlocked rope grab should lock upon impact. It shall be capable of locking in response to a $59 \mathrm{~kg}$ (130 lb) man falling $0.3 \mathrm{~m}$ ( $1 \mathrm{ft}$ ) into the device as well as from a $113 \mathrm{~kg}(250 \mathrm{lb})$ man falling up to $1.8 \mathrm{~m}$ (6 ft) (depending on the free fall linits imposed by the system). A locked rope grab should remain locked upon impaction. 
(25) A rope grab or shock absorber, upon impaction, should activate and arrest the fall within $0.9 \mathrm{~m} \mathrm{(3} \mathrm{ft)}$ of travel along the dropline (exclusive of dropline elongation). Rope grab slippage, lanyard extension and/or tear webbing extension should not, in total,

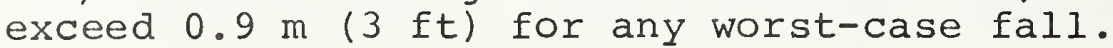

(26) Each rope grab test sample should show only nominal wear after sliding over 100000 linear feet of cable in both the up and down directions.

(27) Each rope grab test sample should be moved up and down a dropline 10000 times over a distance of not less than one foot for each movement without significantly abrading the line. This could be quantified by the breaking strength of the dropline after these tests being reduced from the new line values by less than an average of 10 percent. On the last 1000 operations, each test sample should correctly activate without a single failure.

\section{4 Use}

Recommendations pertaining to the use of fall-safety equipment include the following:

(1) All fall-safety system components should be visually inspected by the user or by an authorized company inspector before each day's use. Every six months (more frequently for severe usage) each fallsafety system and/or component should be thoroughly examined by an authorized inspector. Items to be so inspected include:

(a) Ianyards, Iifelines, tether Iines;

(b) body belts, safety belts;

(c) body and chest harnesses;

(d) pole straps;

(e) rope grabs and shock absorbers.

The inspection date, inspector's name, inspection findings and the inspector's initials alongside these findings should be recorded in a company log and should be available for review upon legitimate request. Each system, or component that can be separated from the system, should have a permanent tag affixed to it, and the date of the next inspection and the life expectancy expiration date (if any) should be stamped on this tag. Any system component that exceeds the life expectancy limit, whatever its apparent condition, should be discarded. 
(2) Any component of a fall-safety system with one or more of the following defects should be withdrawn from service immediately:

(a) cuts or tears of any size

(b) abrasions

(c) burned or melted fibers

(d) molten metal burns or scars

(e) acid, alkali, or other chemical burns

(f) dryness

(g) punctures

(h) tar or similar products that penetrate and harden in the fibers

(i) cracks in or distortions of hardware

(j) loss of flexibility or elasticity

(k) fuzziness on inner fibers

(I) deformed thimbles, buckle tongues, or grommets

(m) mold

(n) hackles or loose rope strands

(o) permanent deformation or elongation

(p) faulty snaphook retainer springs

(q) alterations or additions that could impair functioning or efficiency.

(3) If possible, the methods used to couple a lifeline to an anchorage and/or to a lanyard should minimize reduction in system strength. If a coupling method is used that is known to reduce system strength (e.g. use of knots), then the system (or affected component) strength may have to be increased so as to stay within acceptable limits.

(4) Workers requiring the services of fall-safety equipment frequently wear heavy gloves in the course of their duties. Frequently such workers are called upon to perform their duties at ambient temperatures at which fine manipulations become difficult. The design of fall-safety equipment, especially rope grabs, shock absorbers, controlled descent devices, and the like, must take into account the potential awkwardness of their users.

(5) Lanyard pouches should state explicitly that they should not be used for extended storage of strandedtype lanyards or lifelines since stranded rope may hackle and be weakened by this method of storage. Rather stranded rope should be carefully coiled or 
stored in the form of a "hank" as is commonly worn by construction/steel workers.

(6) A lanyard should, by design, or by the method of securing to an anchorage or lifeline, never permit a free fall of more than $1.8 \mathrm{~m}$ ( $6 \mathrm{ft}$ ) nor a total fall distance (free fall + lanyard elongation + rope grab or shock absorber slippage) greater than $2.7 \mathrm{~m}$ (9 ft).

(7) The use of two-part lanyards, as described in Section 3.8, should be encouraged as a substitute for the long, free-ended lanyards commonly used by steel workers.

(8) Synthetic and natural fiber lanyards in, essentially, daily use should be discarded after four years of service, or sooner, if observed defects warrant such action. Natural fiber lanyards more than five years old and synthetic fiber lanyards more than eight years old, independent of use level, should be removed from service.

(9) Class I tether lines in frequent use should be discarded at or before their sixth service year. No tether line used or unused should be retained beyond the 8 th anniversary of its date of manufacture. For Class I belts/harnesses, these respective retirement dates should be seven and ten years.

(10) Since Class IIa lines are frequently loaded and may be abraded by repeated ups and downs, their life expectancy should be set at four years. Any Class IIa line more than four years old should be discarded. The control mechanism need be removed from service only if it fails a visual inspection or a nondestructive test.

(11) Any fiber lanyard impacted by a force considered to be in excess of its recommended working load limit (obtained by multiplying $B S \times P_{B S}$ ) should be discarded. Fall parameters that are estimated to be capable of generating these limiting forces are presented in Table 18. Alternatively, severity of impact force can be estimated from distortion of thimbles, permanent line elongation, or other distortions. When in doubt, the device should be discarded.

(12) A lifeline should be removed from service if subjected to shock loading more than 1.5 times that 


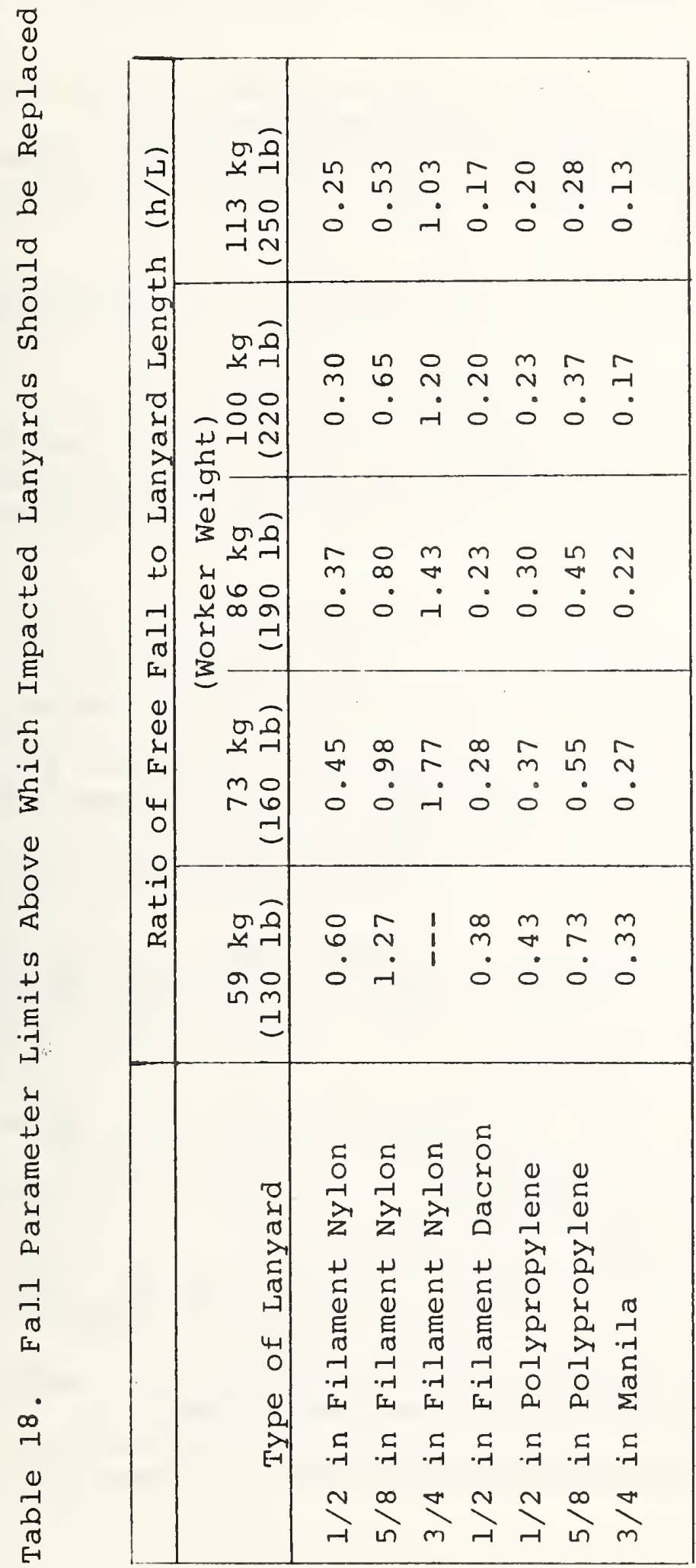


impact force implied by the drop parameters given in Table 18, since such an impaction would probably not reduce the strength of the line.

(13) A body belt or harness that has been loaded (or is suspected of having been loaded) to more than 70

percent of its rated strength should be removed from service. Visual evidence of impact damage is also good cause for replacement of a belt.

(14) If an $\mathrm{N}+\mathrm{N}$ half-hitch (rope grab) is used to secure a lanyard to a lifeline $\mathrm{N}$ should be 2 or 3 , preferably 3 .

(15) When a lanyard or lifeline must pass over a jagged, rough surface or a shearing edge, some means should be provided to protect the line. A sheath or saddle-type padding may be used. Alternatively, the line should be of such construction as to resist abrasion or shear forces.

(16) When possible, a lanyard should secure to an anchorage or lifeline attached to an independent, secure walk or work surface or structural member of appropriate strength. In the case of scaffolding work, a lanyard must secure to an independent surface, or better yet, to an independently secured lifeline. The coupling point should, preferably, be above the worker's waist level, but it must be such that a free fall of more than six feet is not possible.

(17) Tether lines should be of fixed length and should have nominal extensibility. These lines should be as short as possible and should not be longer than $10 \mathrm{ft}$ under most circumstances.

(18) A minimum of 12 ft of dropline should always be allowed below the securing point of a rope grab or shock absorber. For added security, a knot should be made at the end of the dropline.

(19) A Class VI lanyard should be no longer than $6 \mathrm{ft}$ in length and should contain an eye-spliced snaphook fitting at its anchor end. These criteria are to preclude its being tied off around a beam. The anchor snap should secure directly to an anchor bolt.

(20) A lineman's pole strap should never be used as a lanyard. 


\subsection{Testing}

The following are recommendations regarding testing of fall-safety equipment:

(1) Equipment test criteria must measure quantities that actually bear on the anticipated behavior of a system when put to its intended use.

(2) For drop tests, a rigid weight should be used instead of a sandbag.

(3) Prototype sample lots should consist of at least six units of each item to be certified.

(4) In addition to regular sampling of each distinct unit, samples should be taken whenever raw material suppliers, subcontractors, or personnel changes occur.

(5) Proof-loading, dielectric, and corrosionresistance testing can be performed by secondary suppliers. The responsibility for the validity of these tests, however, should reside with the manufacturer of the ultimate product.

(6) If a manufacturer has more than one factory that produces a given item one prototype sample will suffice for all, but each factory should determine production line (quality control) sampling rates independently of the remaining factories.

(7) All test samples should be new and previously unused.

(8) The sample size for Class VI systems should be augmented since these devices tend to be used when the danger of a fall is greater.

(9) The entire test drop apparatus should be fenced or caged off during tests to avoid injuries in cases of failure. All test personnel should wear safety hats and glasses and/or should keep clear of the test area during each drop.

(10) If body belts are similarly constructed, except for length of belt and dee-ring location, it is recommended that only one size (preferably $M$ ) be tested in order to certificate all size belts. In the case of 
body (or chest) harnesses, only one or two sizes are indicated. In this case, evaluation of each size harness is recommended.

(11) Each potential load-bearing component of a fallsafety system that can be interchanged, that is sold separately, or for which a unique test is prescribed, must be so tested. However, only medium size body belts in a line containing various size belts need be prototype tested.

(12) If a Class II ascent or descent control device or a Class IV rope grab or shock absorber is permanently affixed to the lanyard so that if either becomes defective both must be discarded then lanyard and device should be tested as a unit.

(13) When measuring the strength of a Class IIa system, the lifting mechanism and the line should be tested as a unit.

(14) A Class IIb dropline and an associated controlled descent device should be tested as a unit.

(15) Prototype units must in every way be equivalent to units that will eventually be marketed. If the design of a unit is modified in a way that could conceivably modify its intended behavior under load or impact, the modified unit should be "prototype" tested.

(16) A test weight can be similar in construction to that form given in CSA 2249.1 [CS-1] but preferably with an elliptical core. A torso-type weight or weights can be used to statistically or dynamically test body belts and/or harnesses.

(17) Multiple drop testing should not be used as a means of evaluating the aging of lanyards.

(18) In making dynamic (drop) tests of lanyards, a number of new, untested lanyards are selected. Half of them are drop tested for strength and the remaining half for their energy-absorbing capability.

(19) For either static or dynamic strength testing the anticipated worst-case tie-off configuration should be used. For energy absorption testing optimum tie-off procedures should be followed. 
(20) A tumble-type test could be employed to evaluate the permanency of knots and splices.

(21) Testing and/or preconditioning of all load-bearing natural and synthetic fiber components should be done within ambient ranges of 10 to $30^{\circ} \mathrm{C}\left(50\right.$ to $\left.85^{\circ} \mathrm{F}\right)$ and 40 to 60 percent relative humidity. The test procedure should also determine the strength and, where applicable, energy absorption at anticipated operatingtemperature extremes. An operating temperature range of -18 to $38^{\circ} \mathrm{C}\left(0\right.$ to $\left.100^{\circ} \mathrm{F}\right)$ would appear to be reasonable.

(22) When a lanyard of specific material, type, size and design is manufactured in a range of lengths, the range should be specified by the manufacturer. Six samples of the minimum length in the range and six samples of the maximum length in the range, should be tested.

(23) In cases where the lanyard length is adjustable, 12 samples of that lanyard should be submitted for test, six of which should be tested at minimum lanyard length.

(24) Friction buckles should be strength tested under anticipated usage conditions such as grease, moisture, and ice.

(25) A drop test for a Class IIa system could consist of dropping a rigid test weight of $136 \mathrm{~kg}$ (300 lb) 0.6 $\mathrm{m}$ (2 ft) into a winch-line combination. An effective line length of $6 \mathrm{ft}$ should be used. The impact force generated by such a drop should not cause a system failure (as defined in item 10 of Section 4.3).

(26) Each pole strap size to be certified should be tested at both outermost and innermost tongue buckle hole settings.

(27) Testing of a harness (static, dynamic, force or acceleration level) requires the services of a torso shaped dummy or weight. For dynamic strength testing, allow a $160 \mathrm{~kg}(350 \mathrm{lb})$ torso-shaped dummy with harness snugly affixed to free fall $2.7 \mathrm{~m}$ (9 ft) into a lanyard. For dynamic testing of a lanyard's energyabsorbing ability a $60 \mathrm{~kg}(130 \mathrm{lb})$ weight is allowed to free fall $1.8 \mathrm{~m}$ ( $6 \mathrm{ft})$. 


\subsection{Information to be Furnished}

Information and instructions that should accompany a fall-safety system or component throughout its lifetime should be permanently printed, embossed, or affixed to the item it pertains to. In addition each fall-safety system or purchasable component may also require written information or instructions that need not (or, due to their extensiveness, cannot) permanently accompany the equipment. This type of literature should be attached to the equipment so that the unpacker cannot avoid seeing it. The recipient should keep this literature on file to be read or reviewed by appropriate personnel. Recommendations pertaining to such labels and literature information are given below:

(1) Advertisement-type literature should state the environmental and usage limitations of such systems where such limitations are not self-evident.

(2) All prototype certification test data should be kept on hand by the manufacturer and made available to legitimate requesters. This data should be available a minimum of seven years beyond the date at which the item is taken off sale.

(3) The manufacturer (or assembler) of fall-safety equipment should keep on hand all required productionline test results. These results should be made available upon written request.

(4) The maker of each component should be readily determined from unique labeling, markings, or tagging done by the manufacturer. "Labeling" can be accomplished using indelible print, embossing, or imprinting or by means of affixed cloth, leather, metal, or plastic labels containing the requisite information. Labeling can also be accomplished by the use of unique markers or trademarks. However, when labeling is done it should be readily legible through the lifetime of the unit and the label should not impair the operational characteristics of the equipment it is affixed to.

(5) Instructions and information that should accompany fall-safety equipment are listed below. In some cases, these listings can be included on labels; in other cases, the information is too lengthy or the device too small to conveniently display the requisite writing. 
(a) Acceptable and preferred methods of use, including preferred tie-off and coupling procedures and recommended system components mates.

(b) Methods of abuse to be avoided, including application limits.

(c) Preferred and unsatisfactory use and storage environments.

(d) Recommended field inspection procedure and schedule.

(e) Recommended cleaning and maintenance procedures, if any.

(f) The breaking strength of the system or component when used in the normal manner.

(6) All fibrous items (lanyards, lifelines, belts, straps, and harnesses) should be labeled with the following:

(a) manufacturer's name, city, and state;

(b) model number of component;

(c) date of manufacture or assembly;

(d) Recommended maximum life expectancy or date by which equipment should be replaced;

(e) Regulation against which a device is certified; and

(f) Tensile strength and/or highest fall-safety system class for which the equipment is certified.

(7) Each component should be labeled with the environmental conditions which will adversely affect its performance. Possible deleterious environments include temperature, moisture, grease, oil, dirt, sand, and organic, or other liquids or vapors.

(8) Since components for Class I sytems are not designed to withstand any significant impact, these 

only."

(9) To insure that lanyards are not tied-off leaving excessive length, any lanyard longer than six feet should have a permanent mark at the anchorage end (or at both ends if the device is symmetric), indicating the six-foot point from snaphook or belt splice.

(10) Lifelines should state on them the maximum number of persons that can tie onto them at one time and the highest class system for which they are certified.

(11) Body belts and harnesses should state the waist dimensions that they are designed to be used with.

(12) Body belts should state that the associated lanyard should be positioned within the 4 to $80^{\prime} \mathrm{clock}$ region at the small of the back. Where a body belt contains more than one dee-ring, all dee-rings outside the 4 to 8 o'clock region must be noted as unsatisfactory as tie-off points for the lanyard.

(13) If conditions such as grease, moisture, ice, etc. reduce the strength of a belt with friction buckle below an acceptable level, then this fact must be stated on the belt tag and on all accompanying literature and advertisements.

(14) Snaphooks, carabiniers, dee-rings, and the like should be color, letter, or number coded so that only compatible components are linked together.

(15) Where a friction buckle is required to be double passed for the system to achieve its rated strength or integrity, this fact must be clearly printed on the belt.

(16) Except where a carabinier is self-closing, it must be stated in advertisements, on the device itself and in literature accompanying the device that the rated strength of the device depends on the loop being completed by the user.

(17) Load bearing hardware should be clearly labeled with the proof load value they were subjected to, if proof loading is required or was performed optionally by the manufacturer. 
(18) When they are unidirectional, mechanical rope grabs and shock absorbers that fit onto lifelines should have an arrow and the word "UP" clearly and legibly printed on them.

(19) Where a rope grab or shock absorber will, upon impaction, move down a dropline some distance before locking, the mechanical device should state the minimum amount of dropline that must always be present below the working position of the device.

(20) Where a shock absorber is intended for use by a specific weight range population, it should so state on the device.

\subsection{Suggested Areas for Additional Work}

In conducting this study, a number of areas were noted where additional or better validated information would assist in specifying, producing, selecting, and using fallsafety equipment. Suggestions of areas for further work include the following:

(1) A definitive study should be conducted to determine the feasibility and limitations of using static load/elongation tests to predict the performance of fall-safety equipment under dynamic (impact) conditions.

(2) It is recommended that manufacturers and users periodically subject fall-safety equipment to destructive tests for the purpose of increasing the understanding of equipment characteristics as functions of use, age, and environment. Such sampling could be coordinated by the manufacturer or by a Federal or private organization.

(3) Contingency (safety) factors for use with various fall-safety components should be evaluated and updated as new materials become available, the accident data base is developed and data regarding the extensibility of synthetic-fiber ropes with age and/or use becomes available.

(4) Some means of nondestructively strength testing anchorages, lanyards, and lifelines should be developed. 
(5) Kern mantel rope, a material that has become popular in mountaineering, should be evaluated for possible use with fall-safety systems.

(6) The effects of light, moisture, heat, age, and usage level on body belts, lanyards, and lineman's equipment as a function of exposure time should be studied.

(7) Samples of fall-arrest components with known use histories should be collected and tested to determine how strength and extensibility vary with usage, age, and ambient factors.

(8) A data base for arrested fall case histories is needed to show how safe such devices are and what are the problems with their use.

(9) How much impact energy is absorbed by belts and harnesses relative to lanyards should be evaluated and how this information might affect regulations for safety equipment should be determined.

(10) The correlation between lanyard type, composition, diameter, and tie-off procedure on system strength should be determined when a lanyard is tied-off around an L-beam, I-beam, or wide flange for static and dynamic loadiny conditions.

(11) I'he shock-absorbing and strength properties of Class V systems where the lanyard is spliced.directly to the body belt should be correlated with systems where coupling is by means of dee-ring and snaphook.

(12) The maximum safe descent and/or arresting speeds for both conscious and unconscious descenders should be evaluated.

(13) Tests should be made to determine the correlation between lanyard or lifeline length and line strength and extensibility.

(14) The need for and cost-effectiveness of stabilizing nylon ropes against moisture should be investigated.

(15) Modifications to fall-safety equipment regulations that would be required by the entry of women into 
trades that require fall-safety equipment should be determined.

(16) An extensive comparative analysis should be made of new and used safety equipment relative to both strength and extensibility.

(17) The effects of preboiling nylon lanyards in terms of their work-to-break ability should be studied.

(18) The psychological and physiological effects of the suspension of humans as a function of body-containment system and duration of suspension should be studied.

(19) A realistic test for abrasion resistance of fibrous components should be developed. 
AA-1 "Dynamic Tests on Nylon Rope." (All American Aviation, Inc. (All American Engineering), February 1942).

AF-1 U.S. Parachute Handbook. (U.S. Air Force, 1963.)

AN-1 "Requirements for Safety Belts, Harnesses, Lanyards, Lifelines, and Drop Lines for Constructive and Industrial Use." ANSI, Al0.14, (April 1975).

AR-1 Ardouin, G., "Experimental Studies on Safety Belts, Part I." CIS 75-195, (Centre Fixperimentaux de Recherches Des Batiments et Travaux Publics, Paris, August 1975).

AR-2 Ardouin, G., "Experimental Studies on Safety Belts, Part II." CIS 684-1973, (Centre Experimentaux de Recherches Des Batiments et Travaux Publics, Paris, August 1975).

AR-3 Armstrong, R. W. and Waters, H. P., "Testing Programs and Research on Restraint Systems." 1969 SAE Transactions, pp. 1023-70 (Soc. of Auto. Engineers, Inc., May 1972).

AR-4 "Dynamic Testing of Webbed Nylon Safety Belts and Assemblies." (A 1 ab report and report summary) 17 and 11 pages, respectively (Applied Research Laboratory, Pitts., PA, 1968).

AR-5 Aerospace Medicine, Armstrong, H. G., ed., The Wilkins

AS-1 "Safety Belts, Harnesses and Accessories." ASSE, (National Safety Council, Chicago, I11., 1952).

AS-2 "Air Standardization Agreement on Ejection Acceleration Limits." Air Standardization Co-ordinating Committee, Air Std. 61/1, (Navy Department, September 5, 1975 ).

AS-3 "Standard method of Salt Spray (Fog) Testing." ASTM, B117-73, (March 1973). 
AS-4 "Standard Method of Verification of Testing Machines." ASTM, E4-72, (September 1972).

AS-5 "Standard Metric Practice Guide." E380-75, (ASTM, Phila., Pa., 1975).

BE-1 Beeding, E. B. and Mosely, J. D., "Human Deceleration Tests." AFMDC-TN-60-2 (Jan. 1960).

BE-2 "Guidelines for Fall Prevention and High Worker Safety Equipment." Best's Safety Directory, (1976).

BI-1 Bioastronautics Data Book. Parker, J. F. and West, V. R., eds., 2nd ed. Washington Scientific and Technical Information Office, National Aeronautics and Space Administration, 1973).

BI-2 Bierman, H. R., "Distribution of Impact Forces on the Human Through Restraint Devices." ND491-763, (National Technical Information Service, 1971).

BI-3 Bierman, H. R. and Larsen, B. R., "Reaction of the Human to Impact Forces." (Navy Research Institute, October 1946.)

BO-1 "Evaluation of Safety Belts, Lanyards, and Shock Absorbers, Report No. 2, 1886-09." Safety Engineering Department, (The Boeing Co., Aerospace Division, September 15, 1967).

BO-2 "Aerospace Applications of Energy Absorption and Peak Force Reduction Devices." Tech. Document No. 102-73, (NPTR, E1 Centro, Calif., October 1973).

BO-3 Boone, Jay, "Fatigue Effects in Webbing, Chord and Fabric." U.S. Naval Parachute Facility, TR4-61, (Auxiliary Landing Field, El Centro, Calif., July 17, 1961).

BR-1 Brabin, E. J., "The Dynamic Properties of Seat Belt Webbing and End Fixings as Tested on the Pneumatic Accelerator." MIRA Bulletin 4, pp. 4-11 (July/August $1970)$. 
BR-2 Bringgardner, MCCarty and Ditrulsky, "Light and Weather Resistance of Fibers." Textile Industries, CXXX, 4, pp. 125-, (1966).

BS-1 "Specification for Self-Locking Safety Anchorages in Industrial Use." British Standards Institute, BS 5062:1973, (1973).

BS-2 "Specification for Safety llarnesses and Safety Lines for "Use by Children in Yachts." British Standards Institutes, BS4474:1969, (1969).

13S-3 "Code of Practice for the Use of Safety ivets on Constructional Works." British Standards Institute, CP 93:1972, (1972).

BS-4 "Specification for Industrial Safety Belts and llarnesses." British Standards Institute, BS 97:1967, (1967).

BS-5 "Specification for Industrial Safety Nets." British Standards Institute, BS 3913:1965, (1965).

BS-6 "Specification for Safety llarnesses and Safety Lines." British Standards Institute, BS 4224:1976, (1976).

BS-7 "Specification for Seat Belt Assemblies for Motor Vehicles." British Standards Institute, BS 3254:1968, (1968).

BS-8 "Specification for Suspended Safety Chair and Cradles for Use in the Construction Industry." British Standards Institute, BS 2830:1973,

CA-1 "Personal Safety levices and Safeguards." Industrial Relations, Article 10, (State of California, Department of Industrial Relations, July 13, 1974).

CA-2 "Safety Belts and Nets." Industrial Relations, Nrticle 24, (State of California, !)epartment of Industrial Relations, July 13, 1974). 
CF-1 "Safety Requirements for Scaffolding." Code of Federal Regulations, Title 29, Part 1910, Subpart D, par. 28 (July 1,1975 ).

CF-2 "Power Platforms for Exterior Building Maintenance." Code of Federal Regulations, Title 29, Part 1910, Subpart D, Par. 66 (July 1, 1975).

CF-3 "Safety Nets." Code of Federal Regulations, Title 29, Part 1926, Subpart E, Par. 105 (July 1, 1975).

CF-4 "Telecommunications." Code of Federal Regulations, Title 29, Part 1910, Subpart R, Par. 268 (July 1, 1975).

CF-5 "Scaffolding." Code of Federal Regulations, Title 29, Part 1926, Subpart L, Par. 451 (July 1, 1975).

CF-6 "Safety Belts, Lifelines and Lanyards." Code of Federal Regulations, Title 29, Part 1926, Subpart E, Par. 104, (July 1, 1975).

CF-7 "Definitions Applicable to this Subpart." Code of Federal Regulations, Title 29, Part 1926, Subpart E, Par. 107 (July 1, 1975).

CF-8 "Linemen's, Body Belts, Safety Straps, Lanyards."

Federal Register, Title 29, Part 1926, Subpart E, Par. 959 (June 24, 1974).

CF-9 "Motor Vehicle Safety Standard, No. 209." (Code of Federal Regulations, Title 49, Part 571, Subpart A, Par. 209 (Jan. 24, 1974).

CG-1 "Bend Tests Made on Natural and Synthetic Fiber Ropes." Technical Communications, (Cordage Institute, January 1971).

CG-2 "Haas, Frank J., "Knowing the Ropes." Cordage Group, Auburn, N.Y. 13021).

(The

CG-3 "Rope Technical Data." (The Cordage Group, Auburn, N.Y. 13021, August 1973). 
CG-4 Koon, A. W., "Environmental Degradation of Ropes." Prod. Bul1., (The Cordage Group, Auburn, N.Y., August 1973).

CG-5 "Standard Test Methods for Stranded and Plaited Ropes." (The Cordage Institute, Washington, D.C. 20008, April 1974 ).

CG-6 "Rope Knowledge for Riggers." Group, Auburn, N.Y. 13021).

(The Cordage

CG-7 "Fiber Data." (The Cordage Group, Auburn, N.Y. $13021)$.

CS-1 "Fall Arresting Safety Belts and Lanyards for the Construction and Mining Industries." Canadian Standards Association, Standard 2259.1,

CS-2 "Rope Grabbing Device." Research Publication No. 13, May 1973). (Construction Safety Association of Ontario,

CS-3 "Current Research on Safety Belts, Lanyards, and Lifelines." Research Publication No. 30, (Construction Safety Association of Ontario, Toronto 1, Ontario, 1975).

DA-1 Dahnke, J. W., Palmer, J. F., and Ewing, C. L., "Results of Parachute Opening Force Test Program." TR 2-76 (Naval Air Systems Command, Washington, D.C., April 1976).

DA-2 Damon, A., "Effect of Flying Clothing on Body Measurments of Army Air Force Flyers." Engineering Report 49-645-32 (Aero Medical Lab., Wright-Patterson $A F B$, Ohio, 1943).

DU-1 "The Effect of Loading on the Extension and Recovery of Ropes of Nylon and Dacron." DuPont Technical Information Bulletin X-92, (October 1958).

IU-2 "Tensile Recovery Properties of fibers." DuPont Technical Information Bulletin X-142, (September 1961). 
DU-3 "Light and Weather Resistance of Fibers." DuPont Technical Information Bulletin X-203, 1966).

DU-4 "Properties of Ropes of Dacron and DuPont Nylon." DuPont Technical Information Bulletin X-225, (February 1969).

DU-5 "Impact Resistance or Energy Absorbing Properties of Ropes of Nylon, and Dacron." DuPont Technical

Information Bulletin X-99, (February 1959).

EE-1 "Linemen's Climbing Equipment." Standard AP-2, (Edison Electric Institute, Accident Prevention Committee, 1972).

EV-1 Evans, Ayde L. and Plumb, F. E., "Industrial Safety Belts and Lanyards Evaluated, Draft 4." ASSE Journal, Tech. Section X, 2, pp. 11-16 (February 1965).

FA-1 Fatta1, S. G., Cattaneo, L. E., Turner, G. E. and Robinson, S. N., "A Model Performance Standard for Guardrails," NBSIR 76-1131, National Bureau of Standards, Washington, D.C. 20234 (Ju1y 1976).

FA-2 Fattal, S. G., Cattaneo, L. E., Turner, G. E. and Robinson, S. N., "Personnel Guardrails for the Prevention of Occupational Accidents," NBSIR 76-1132, National Bureau of Standards, Washington, D.C. 20234 (July 1976).

FA-3 Fattal, S. G. and Cattaneo, L. E., "Investigation of Guardrails for the Protection of Employees from Occupational Hazards," NBSIR 76-1139, National Bureau of Standards, Washington, D.C. 20234 (July 1976).

FE-1 Ferry, J. D., Viscoelastic Properties of Polymers. (Wiley and Co., New York, N.Y., 1961).

FE-2 "Strength, Breaking, Heavy Cordage (Rope)." Federal Test Method Standard 191 , (General Services Administration, Business Service Center, Boston, Mass., December 31, 1968).

FE-3 "Belts, Safety, Industrial, Safety-Body-Pad-Harness." Federal Specification JJ-13-160, Services Administration, April 6, 1956).

GL-1 Medical Physics, G1asser, O., ed., The Year Book Publishers, Inc., Chicago (1950).

HA-1 Haas, Frank J., "Natural and Synthetic Cordage in the Field of Oceanography," New Thrust Seaward, pp. 617629 (Marine Tech. Soc., 3rd Annual Conference, June 5$7,1976)$. 
HA-2 Hauser, R. L. and Frieber V., "Critique of Steels for Safety Hardware." Hauser Labs., Report \#5346-72-3, (Boulder, Colorado, January 24, 1972).

HI-1 Himme1farb, David, Technology of Cordage, Fibers and Rope. (Textile Book Publisher, 1957).

IS-1 "Safety Belts, Body llarnesses, Lanyards, Lifelines, and Safety Lines." (Industrial Safety Equipment Assoc., December 1975).

KI-1 King, W. R. and Mertz, H. J., "Human Impact Response: Measurement and Simulation." Research Labs., pp. 181199, (Plenum Press, New York, N. Y., 1973).

KI-2 Kingsley, Norman, "The Swami Be1t: A Neadly Tie-In?" Summit, 21 (No.6), pp. 12-13 (August 1975).

K0-1 Kourouklis, G., Gloney, J. and DesJardins, S., "The Design Development and Testing of an Air Crew Restraint System for Army Aircraft." USAAMRDL, Tech. Report 72-26, pp. 64-65 (Ft. Eustis, Va., June 1972).

KO- 2 Kosmath, E. and Kaminger, P., "Ageing of Ropes, Report of the Safety Committee of the Austrian Mountaineering Club." Narrow Fabric and Braiding Industry (Ger.),

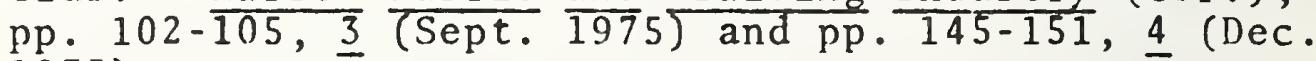
$1975)$.

KR-1 Krizik, J. G., et al., "Dynamic Testing of Small Textile Structures and Assemblies." MIT Publication AD 684 $948,(1969 ?)$.

KR-2 Kroel1, C. K., Schneider, D. C. and Nakum, A. M., "Impact Tolerance and Response of the Human Thorax." Research Publication No. GMR-1167, pp. 31E (GMC, Warren, Mich., November 1971).

KR-3 Kroel1, C. K., Schneider, D. C. and Nakum, A. M., "Impact Tolerance and Response of the Human Thorax, Part II," Research Publication No. GMR-1167 (GMC, Warren, $.4 i c h .$, December 1974), and paper 741187 presented at 18 th Stapp Car Crash Conference.

MC-1 McCormick, Y. Y., "Physical Characteristics of the 1946 Airline Transport Pilot Population." (Civil Aeronautics Admin., Washington, D.C., 1947.)

ME-1 Melvin, J. W., Stalnaker, R. L. and Roberts, V. L., "Impact Injury Mechanism in Abdominal Organs." (paper \#730968 presented at the 16th Stapp Car Crash Conference) pp. 115-126 (Soc.Auto. Engineers, Inc., New York, N.Y., 1972). 
ME-2 Handbook of Ocean and Underwater Engineering, Meyers, Holm and McAll ister, eds. (McGraw Hill Book Co., New York, N.Y., 1967).

MI-1 "Rope, Nylon." Mi1-Spec. R17343(D), (Department of Defense, June 2, 1969).

MI-2 "Military Testing Standard for Personnel Parachutes." Mil-Std. 858 , 1969).

(Department of Defense, June 26,

MI-3 "Environmental Test Methods." MIL-STD 910C (Department of Defense, March 10, 1975).

MI-4 "Harness Safety." Mil-Spec.H-24460, (Bureau of Ships, March 8, 1972).

MO-1 Human Engineering Guide to Equipment Design, Morgan, C. T. et al, eds., (McGraw Hil1, New York, N.Y., 1963).

MU-1 Mosacchio, Car1, "The Construction Industry's Struggle for Safety." Occupational Hazards, pp. 33-35 (October 1975).

MY-1 Meyers, Holm and McAllister, Handbook of Ocean and Underwater Engineering. Chapter 4 (McGraw Hi $\overline{11}$, New York, N.Y., 1969).

NA-1 "Don't You Fall." Lifeline Magazine, pp. 26-27 (September/October 1975).

NA-2 "Kenedy Space Center Practices Handbook." pp. 11-14 (J. F. Kennedy Space Center, Florida, June 30, 1975).

NA-3 Natrella, Mary G., Experimental Statistics. Nat. Bur. Stand. (U.S.), Handbook 91, (October 1966).

NA-4 "Belt, Lineman's; and Strap, Pole, Lineman's Type." Federal Specification KK-B-151G, Services Administration, February 5, 1975).

NC-1 "Skinfolds, Body Girths, Biacromial Diameter, and Selected Anthropometric Indices of Adults, United States, 1960-62." Series 11, No. 35, (National Center for Health Statistics, PHS, Washington, D.C., February 1970). 
NC-2 "Weight, Height, and Selected Body Dimensions of Adults, United States, 1960-1962." Series 11, 35 (National Center for Health Statistics, PHS, Washington, D.C., June 1965).

NE-1 Newman, S. B. and Wheeler, H. G., "Impact Strength of Nylon and of Sisal Ropes." J. Res. Nat. Bur. Stand. (U.S.) 35, pp. 417-431 (November 1945).

NE- 2 Neathery, R. F., Kroe11, C. K. and Mertz, H. J., "Prediction of Thoracic Injury From Dummy Responses." Research Publication No. GMR-1918 (GMC, Warren, Mich., November 1975), and Paper 751151 presented at 19 th Stapp Car Crash Conference.

NE-3 Neathery, R. F. and Lobde11, T. E., "A Mechanical Simulation of the Human Thorax Under Impact." Research Publication No. GMR-1420 (GMC, Warren, Mich., November 12, 13, 1973), and Paper 730982 presented at 17 th Stapp Car Crash Conference.

NI-1 "Linemen's Climbing Equipment." Systems Spec. E-1042 (Niagara Mohawk Power Corp., Syracuse, N.Y., November 1,1968$)$.

N0-1 Noe1, Georges, "Study to Standardize Safety Equipment Used in Buildings and Public Works, Part 11." CIS598, (Center Experimentaux de Recterches Des Batiments et Travaux Publics, Paris, August 1975).

NS-1 Hirsch, Tom, "Rescue Devices and Fall Protection." National Safety News, pp. 28-30 (September 1956).

NS-3 "Belly Whopping and Chest Injuries." National Safety News, (January 1976). 1976).

OS-1 "Safety Belts, Body Harnesses, Lanyards, Lifelines and Safety Lines, Draft 6," OSHA (Department of Labor, Washington, D.C., March 4, 1976).

PA-1 Paul, Walter, "Review of Synthetic Fiber Ropes." (USCG Academy Research Project, August 1970).

RE-I Reid, D. H. and Doerr, J. E., et al., "Acceleration and Opening Shock Forces During Free Fall Parachuting." Aerospace Medical Bulletin, 42, pp. 1207-1210 (1971). 
R0-1 Roebuck, Kraemer and Thomson, Engineering Anthropometry Methods. (Wiley and Sons, New York, N.Y. 1975).

SA-1 "Mathematical Modeling Biodynamic Response to Impacts," SP-42, Society of Automotive Engineers (1976).

SH-1 Shand, T. G., "The Design of Modern Safety Belts and Their Uses." Br. J. of Ind. Safety V, 51 (Roy, Soc. for the Prevention of Accidents, London, 1960).

SM-1 Smith, J. C., et al., "Stress-Strain Relationships in Yarns Subjected to Rigid Impact Loading, Part VII: Stress-Strain Curves and Breaking-Energy Data for Textile Yarns." Textile Res. J. XXI, 8, pp. 721-734 (August 1961).

SN-1 Snyder, R. G., "Human Impact Tolerance." (paper \#700398 1970 Internat. Auto. Safety Conf.) pp. 712-755 (Soc. of Auto. Engineers, Inc., 1970).

SW-1 "Safety Belt with Lifeline." National Workers Protection Board Directive 45: 8-VIII, 199200 (Sweden, 1961).

TE-1 Elastic and Creep Properties of Filamentous Materials and Other High polymers. (Textile Foundation, Washington, D.C.)

TU-1 Tubis, Richard I., "Comparison Testing of Synthetic Fiber Lines Versus Manilla Lines." TR 1-76, (Nat. Parachute Test Range, El Centro, Calif., $\Lambda$ pril 1976).

US-1 "Specifications for Safety Belts, Lanyards, Linemen's Body Belts and Pole Straps." NO 900-569, Steel Corp., Pittshurgh, Pa., May 1969).

VA-1 Human Engineering Guide to Equipment Design. Van Cott, H. P., and Kinkade, R. G., eds., pp. 508-509 (Am. Inst. for Research, Washington, D.C., 1972).

VI-1 Viano, D. C. and Gadd, C. W., "Significance of Rate of Onset in Impact Injury Evaluation." Research Lahs GMR-1910, pp. 807-819 (GiC, Warren, Mich., November 1975 ). 
WA-1 Walker, C. R., "Comparison of Natural Fiber and Synthetic Fiber Ropes." Transmission and Distribution, pp. 48-53 (September 1969).

WE-1 Wexler, A., "The Theory of Belaying." American Alpine Journa1, VII, 7, pp. 379-405 (1950).

X-1 "Drop Test Procedure for Belts and Harnesses, Spec. 1192." A test procedure is used by a major manufacturer of fall safety equipment. (This test procedure was current as of March 3, 1975.) Private communication. 
Experimental Program

\section{A.1 Introduction}

\section{A.1.1 Purpose}

During the course of this study, it became evident that there was insufficient data available on the performance characteristics of components of fall-safety systems, in particular as pertains to energy absorption. In addition, there seemed to be no generally accepted, convenient method for using test data to predict the performance of fallsafety equipment under use conditions. It was therefore decided to conduct a limited experimental program to demonstrate how the needed data could be readily obtained, to show how such data could be used to predict performance and to develop some data on more commonly used items. The work was primarily on rope type lanyards although some tests were made on web straps, body belts, and pole straps. The results of these tests were compared to other data that was availabie.

\section{A.1.2 Scope}

This experimental work was supplemental to principal aspects of the study and was not intended to be comprehensive. Strength and load/elongation data were gathered from 12 types of lanyards, and the data were. processed to predict the performance of lanyards of various lengths under a variety of fall conditions. Tables and graphs were prepared to present the data in a readily usable form. A mathematical model was developed to assist in processing the test results. The test methods and analytical methods used should be useful in developing a more adequate data base on the strength and energy absorbing properties of fall-safety equipment. 


\section{A.2.1 Rationale for Testing Components Separately}

To date most standards and regulations concerned with fall-safety equipment require that body belts or harnesses be tested together with their lanyards. In their 1974 report [CS-3], however, the Construction Safety Association of Ontario recommends that these components be tested independently of each other. The basic reasons given in [CS-3] are:

(1) In actual usage lanyards are replaced far more frequently than belts. It is possible for the owner of the belt, in replacing his lanyard, to choose one having a different length or material and, by doing so, to create a completely different fall arresting system for which no certification exists. If, on the other hand, the belt and lanyard are tested and certified independently of each other then his new lanyard will, regardless of length and material, be a certified product.

(2) The lanyard, being in essence a large spring and shock absorber, substantially affects the load transmitted to the safety belt during a fall arrest. Variations in lanyard size, length and material produce significant differences in belt loadings. Thus, when testing belts and lanyards together, the load experienced by the belt is controlled by whatever lanyard the manufacturer wishes to use. There was, in effect, no common standard that a belt had to meet. A change to separate component tests ensures that all belts are subjected to the same test criteria.

(3) Conversely, the loading of the lanyard is influenced to a degree by the belt and its degree of stretch during a fall arrest. The belt material, width, thickness, and stitching vary from product to product, introducing a variable into the lanyard load. Separate tests for belts and lanyards removes this variable.

In addition to the above, the following factors support the separate testing of fall-safety system components: 
(1) It is impractical, if not impossible, to insist that a user continue to purchase lanyards with as good or better energy absorbing properties than the

discarded ones. Similarly it is unreasonable to expect a user to throw out a good body belt or harness because its mate has become defective.

(2) Depending on particular use, a fall-arrest system may or may not secure to an anchorage through an intermediate lifeline. The basic system, therefore, cannot depend on the presence of the lifeline for meeting performance criteria.

(3) Similarly a fall-arrest system may secure to a variety of anchorages some having modest energy absorbing ability while others nay be quite rigid. Again the system must meet fall impact force criteria set down in the regulation independent of anchorage.

(4) A worker should be able to combine only worst-case certified components and still come up with a satisfactory system.

(5) Simpler test procedures can be used when components are tested separately.

(6) Separate testing will allow manufacturers to sell separate components each of which can be certified as meeting OSHA requirements.

If the premise that all of the energy of an arrested fall will be absorbed by the lanyard and the body of the falling person is accepted, the systems will be conservatively rated, i.e., the accident victim will be less severely impacted, as a result of energy absorbed by other components. This provides an additional safety factor for the worker. We have calculated that various combinations of body belts and rigid masses having a $1.8 \mathrm{~m}$ ( $6 \mathrm{ft}$ ) fall arrested by a $1.8 \mathrm{~m}$ ( $6 \mathrm{ft}$ ) lanyards of $1 / 2$ inch nylon will be exposed to impact forces 5 to 25 percent lower than predicted for the lanyard alone. These values were based upon the difference in energy absorbed by a belt lanyard combination and lanyard alone at $8.9 \mathrm{kN}(2000 \mathrm{lbf})$ and 13.3 $\mathrm{kN}(3000 \mathrm{lbf})$. Since these would be relatively severe impacts, the actual reduction in impact force due to the belt would probably be 5 to 10 percent. 
The effect of testing the components separately and assuming that all energy absorption is by the lanyard is seen to introduce a modest additional margin of safety for the worker. This, in addition to the factors listed above, seem to justify this approach to testing fall-safety equipment.

\section{A.2.2 Rationale for Using static Test Results to Predict Impact Parameters}

In the interest of worker safety, the use of data gathered from static tests should be used to predict dynamic performance only if it can be assured that the predictions will not increase the danger to the worker. Such increased danger could come from the probability of equipment failure or from higher impact loads being imposed upon a fall victim.

With regard to the effect of loading rate on breaking strength of fibrous materials, the literature generally indicates higher strength for impact loading [BR-1, $\mathrm{KO}-1$ ] . Impact strength 20 to 25 percent greater than static strength was reported in $[\mathrm{PA}-1]$. According to [BO-3] an increase in strain rate from 2 percent per minute to 200 percent per minute was accompanied by more than 25 percent increase in breaking strength. This trend towards higher breaking strengths associated with higher loading rates was confirmed by a representative of the Cordage Institute for ropes commonly used in construction of lanyards.

On the other hand, the evidence is that extensibility decreases with increasing loading rates [BO-3, $\mathrm{BR}-1, \mathrm{KO}-1$, $\mathrm{PA}-1, \mathrm{SM}-1]$. A 1961 experimental study on tubular rayon webbing [BO-3] showed a decrease in extensibility at intermediate loads of about 10 and 20 percent as the elongation rate was increased from 2 percent per minute to 20 and 200 percent per minute. Newman and Wheeler [NE-1] concluded that, for 7/16 inch nylon rope, "the energy required to produce a given stretch in nylon specimens was greater for impact loading than for static loading."

Support for the use of static data to predict dynamic performance is found in several places. For example, a 1972 study on braided and twisted ropes [AA-1] concluded that "velocity of action or impact timing generally seems to have little effect on the action of nylon rope within cycle limits of from 7 seconds to 60 seconds." Dr. Bralin [BR-1] 
concludes that "static testing of webbing material gives a good indication of the dynamic properties up to strain rates of $40 \mathrm{ft} / \mathrm{s} . "$ Dr. Frank MCCrackin of the Polymer Division, NBS, in a private communication, expressed the opinion that, at the impact velocities involved, our static-based

predictions are probably a satisfactory representation of the dynamic L/E behavior for the ropes in question.

Newman and Wheeler [NE-1] concludes that:

(1) the load-extension curve for impact loading is different from the curve for static loading and lies above it, and,

(2) ". . the energy computed from static-test loadstretch data may also be used to obtain a safe estimate of the impact energy capacity of a nylon rope of the length used in these tests."

Motor Vehicle Safety Standard No. 209 [CF-9] calls for the static testing of (adult) lap/shoulder seat belts (including most associated, load-bearing hardware). This promulgation of this standard implies either that:

(1) DoT is satisfied that the static test requirements of this standard are valid indicators of the performance of seat belts in impact, or

(2) The extensive research on auto occupant protective systems (overwhelming compared to the research done on fall-safety systems) has yet to uncover evidence that static tests do not provide valid measures of the dynamic behavior of restraint equipment.

In actual comparisons impact force peaks generated in our study from static L/E data (for lanyards alone and with body belts) were typically greater by from 0 to $30 \%$ than equivalent peak data from manufacturer drop tests. This observation is contrary to expectations.

In the course of the present work, reasonable agreement has been obtained in two specific cases between statically obtained L/E curves and oscillographic traces with comparable components under dynamic conditions. There is obviously a requirement to confirm such tests with a wide variety of cases. However, because of the relatively good agreement of the comparative records obtained in the project at hand, it is tentatively proposed to accept the general equivalence of static-based predictions and dynamic measurement of arrested fall parameters pending further investigation of this issue. 
The static tensile tests were primarily intended to determine breaking strengths and load/elongation data for lanyards and body belts. Therefore, the test procedures differed in some respects from test methods of the cordage Institute [CG-5] and Federal Test Method Standard iNo. 191 [FE-2]. The procedures used may be relevant to other rope testing situations.

A flow diagram of the testing and analysis procedure is shown in Figure $A-1$.

\section{A.3.1 Test Specimens}

\section{A.3.1.1 Lanyards}

The lanyards tested included new ones donated by manufacturers, old ones donated by users, and a group assembled from miscellaneous parts provided by manufacturers. The specimens were made from spun and filament nylon, polyester, polypropylene, and manila. The nominal diameter of the rope specimens varied from $13 \mathrm{~mm}$ $(0.5 \mathrm{in})$ to $19 \mathrm{~mm}(0.75 \mathrm{in})$.

All lanyards had snaphooks spliced or sewn on at both ends. Most lanyards tested were of stranded rope; however, about a dozen were of strap nylon. All rope lanyards had deeply grooved plastic or metal thimbles inserted into the splice eyes. For all but a few $3 / 8$ in and $3 / 4$ in ropelanyards tested, inner thimble diameters were about 1 in. All rope splices contained at least four full tucks except for two ropes that had only three tucks.

These specimens differ from conventional rope-test samples in that: (1) they contained snaphooks at both ends, (2) the thimbles had one inch diameters rather than equivalent rope test pins or mandrels ranging from twice the rope diameter to $15 \mathrm{~cm}$ ( 6 in), (3) most splices contained four full tucks while rope test samples frequently are made with tapered four or six tuck splices.

About a dozen new and used strap lanyards were also tested. These also had snaphooks at each end but these were secured to the lanyard by means of stitched splices. 


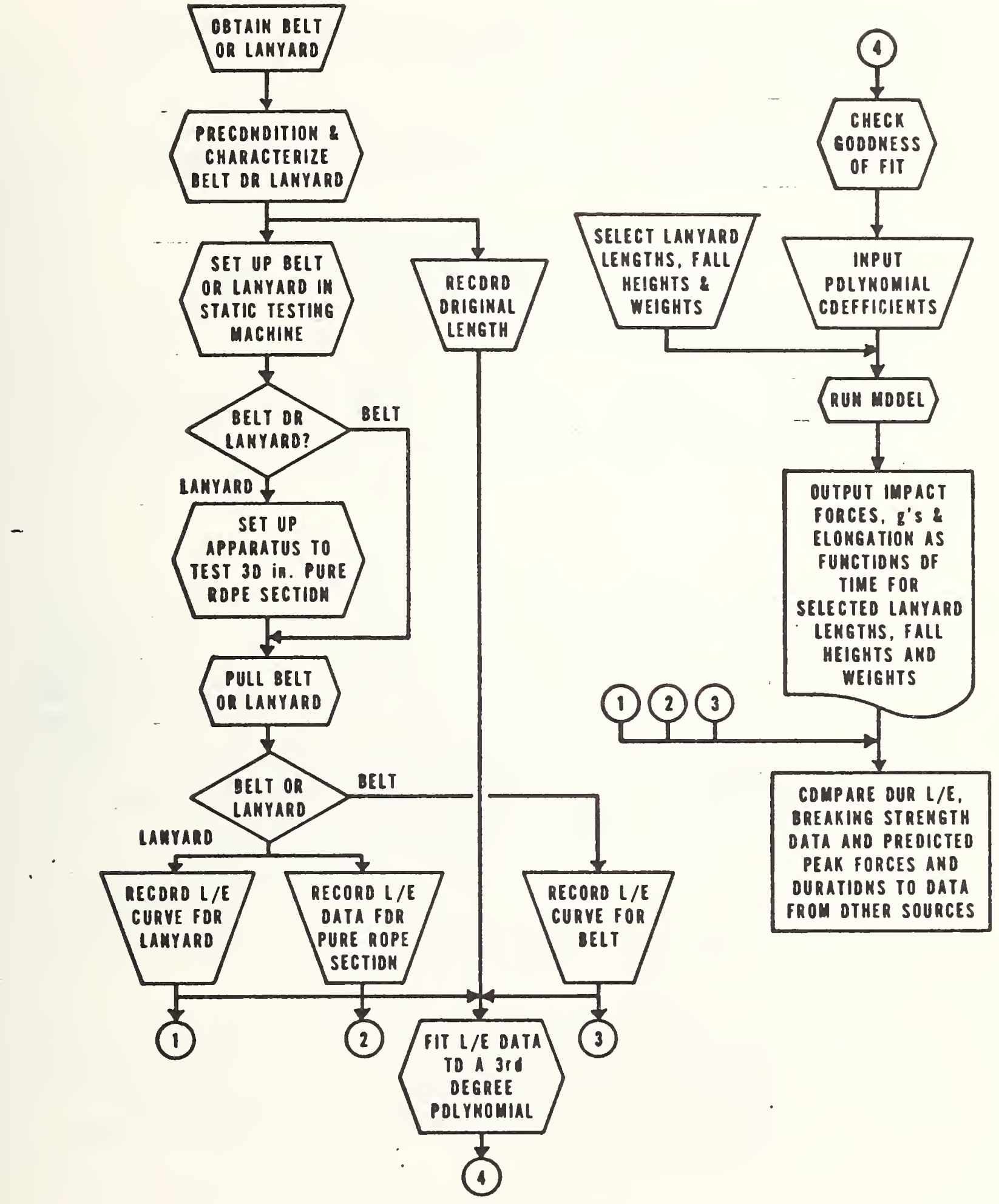

Figure A-1. Flow Diagram of Experimental Procedures 
Although a few of these had leather inserts most contained no sleeves.

As a result of these lanyard configurations, most lanyards tested (that did not exhibit hardware failures) broke at or in their splice zones.

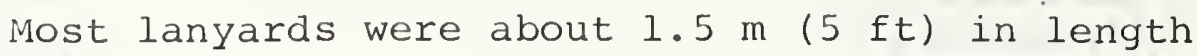
(bearing to bearing), although a few were approximately 1.8 $\mathrm{m}$ ( $6 \mathrm{ft})$ in length.

\section{A.3.1.2 Body Belts}

All six body belt test specimens were unused belts donated by various manufacturers.

Tongue buckle belts tested were buckled at the fourth hole in from the tip of the belt. Friction buckles were fastened so as to leave approximately 10 to $12.5 \mathrm{~cm}$ (4 to 5 in) extended beyond the buckle after double passing the belt.

\section{A.3.2 Testing Apparatus}

The tests were conducted using a horizontal ropetesting machine located at the National Bureau of Standards. This machine has a capacity of 100000 lbf (450 klj), but its lowest range of 10 000. Ibf full scale (about $45 \mathrm{~kJ}$ ) was used for all tests. The load reading dial has markings at 50 lbf intervals and can generally be read to about $\pm 5 \mathrm{lbf}$. The dial was equipped with a pointer follower system that provided an electrical signal corresponding to the dial reading. The testing machine had been calibrated in accordance with ASTM Method E4-72 shortly prior to this program and found to have the errors shown in Table A-1. The load is applied by a hydraulic piston having a maximum stroke of about $0.9 \mathrm{~m}$ (36 in). The rate of motion of the piston varies under load, but rates of 13 to $16.5 \mathrm{~cm} / \mathrm{min}$ ( 5 to $6.5 \mathrm{in} / \mathrm{min}$ ) were used for these tests.

The movement of the piston controlled jaw of the testing machine, and hence the elongation of the lanyard was sensed by a potentiometer-type extensometer attached to the bed of the machine and the movable jaw. The electrical output of this extensometer was connected directly to the $\mathrm{x}$ axis of an $\mathrm{X}-\mathrm{Y}$ recorder. 
Table A-1. Calibration of Rope Testing Machine

\begin{tabular}{|cc|}
\hline \multicolumn{2}{|c|}{ Scale Range $(0-10000$ lbf $)$} \\
\hline Machine Reading $(1 \mathrm{bf})$ & Error $\left(\frac{\circ}{0}\right)$ \\
\hline 1000 & -0.42 \\
2000 & -0.42 \\
3000 & -0.56 \\
4000 & -0.34 \\
5000 & -0.42 \\
6000 & -0.45 \\
7000 & -0.32 \\
8000 & -0.47 \\
9000 & -0.40 \\
10000 & -0.86 \\
\hline
\end{tabular}

(a) This calibration was performed May 6 , 1975 in accordance with ASTM Method E4-72. Note that a negative error indicated that the machine reading is less than the applied load. 
The potentiometer-type extensometer measured the total, bearing to bearing, elongation of the lanyard. In order to adjust this data to represent the total elongation of lanyards of other length and to compare to data on rope performance from other sources, the unit elongation of the center, pure rope portion was desired. Initially this center section elongation was measured visually using a technique similar to that used by rope engineers [FE-2].

The experimental setup used here is pictured in Figure A-2. A rubber band was looped several times over one of the circles marking off the 30 inch section. This was looped so as to be snug but not cutting. A measuring tape was fastened to this band by sliding it between about half of the loops and taping it back on itself. The other end of the tape was brought down towards the other marked circle and tied with elastic thread to an anchorage point so as to keep it taut. Masking tape loops were loosely placed over the measuring tape-rope pair to facilitate reading of the 30 inch mark with respect to the tape rilings. Readings were taken at predetermined load increments; but this was an inconvenient method and readings were inadvertently missed.

A more satisfactory method for measuring the center section elongation utilized an "incremental extensometer" developed at NBS to provide automated measurements for these tests. This instrument, pictured in Figure A-3, consists of a tape with narrow metallic strips deposited perpendicular to its length at precise intervals. The tape passes through a slot in an insulating block and under two small "finger" contacts. As each metallic strip passes under the fingers, an electrical circuit is closed and the resulting electrical signal is used to place a pip on the load/elongation curve being generated for the total lanyard length. An example of the resulting curve is shown in Figure $A-4$.

These extensometers (about a dozen 'was fabricated at the NBS shops) worked quite well although several were broken when ropes or hardware destructed. As is evident from their design, these extensometers were made for use with ropes; nevertheless, they function equally well with strap lanyards. The need to rotate these devices about the rope axis occasionally, as stretched ropes unwound, remained as problematic for these automated tests, however, as when measuring tapes were used.

The electrical signals from the pointer follower (load) and potentiometer-type extensometer were connected to a 


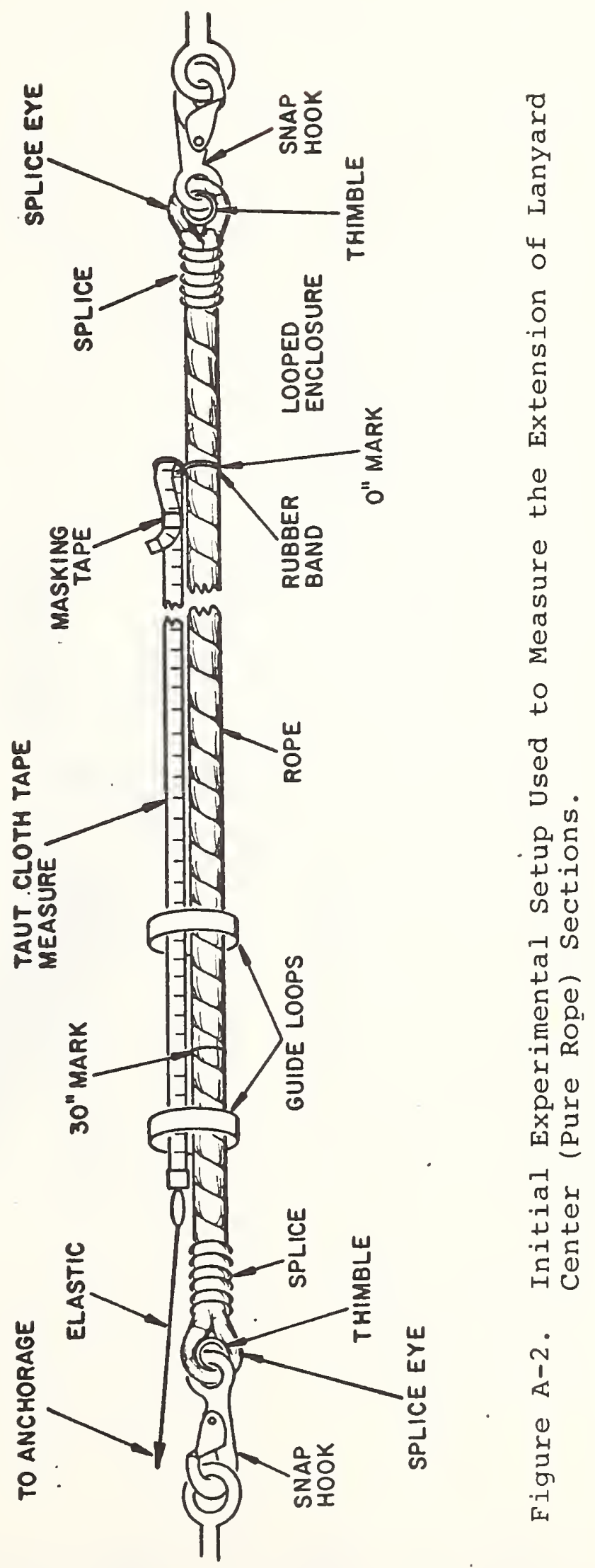




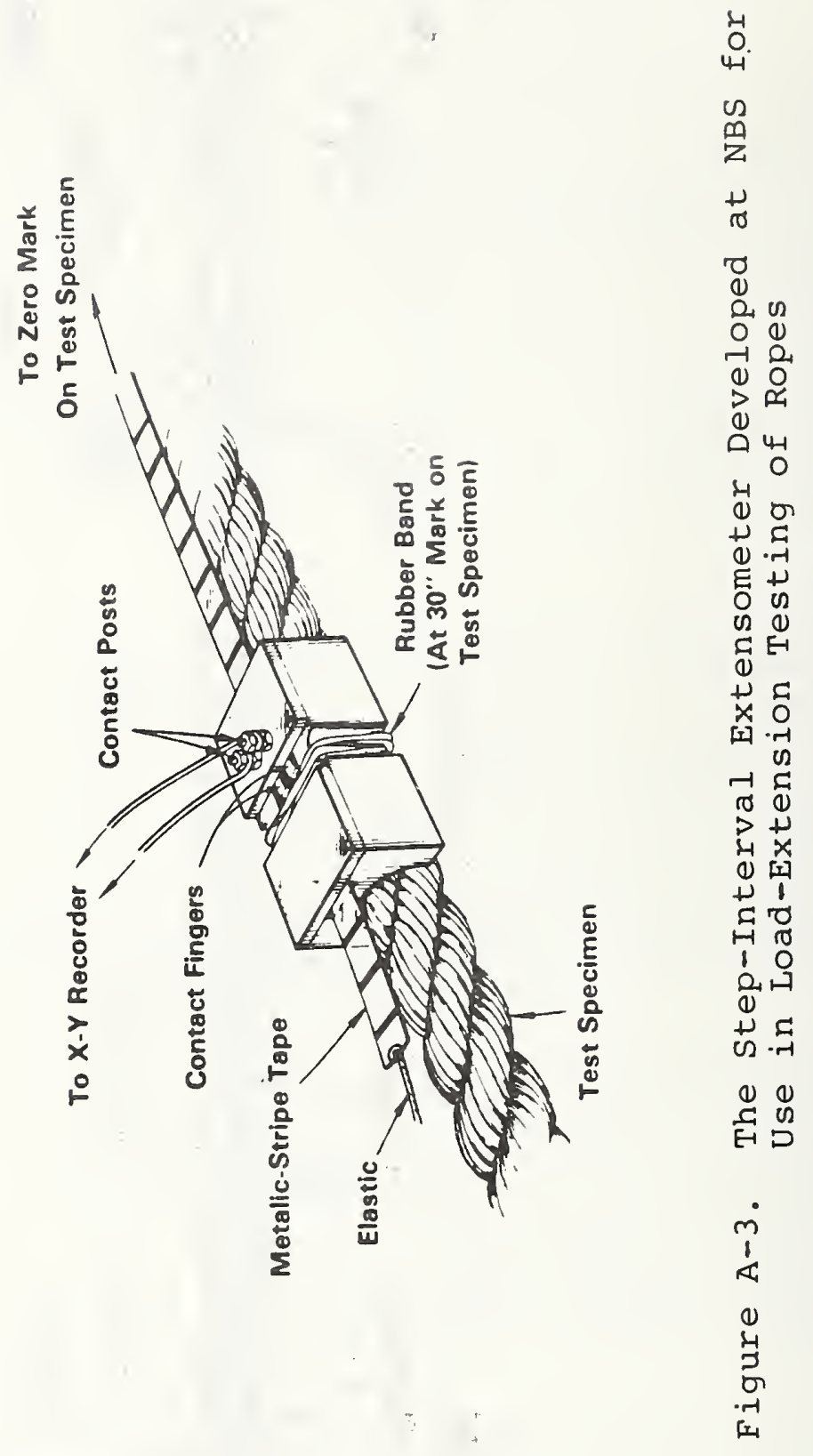




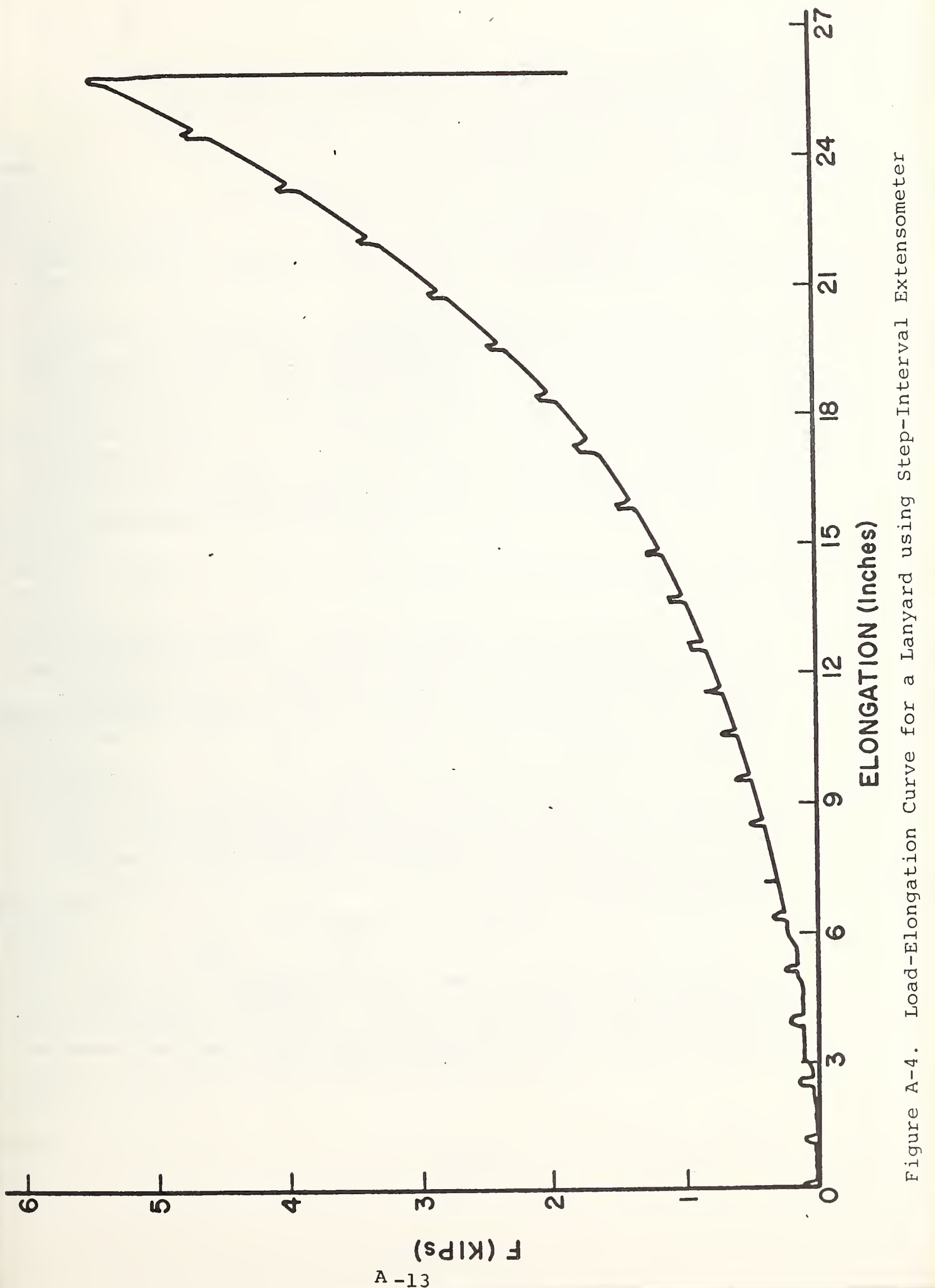


conventional $\mathrm{X}-\mathrm{Y}$ recorder. The signal from the incremental extensometer was connected and adjusted to put a small offset onto the load signal. The recorder has a span adjustment for each axis that permits nearly full "scale for any anticipated load or elongation.

\section{A.3.3 Lanyard Tests}

A record sheet for a lanyard test is shown in Figure

Rope testing procedures [FE-2] call for preconditioning of test samples in a standard atmosphere, typically for 72 hours, preceding the test. However, since a conditioning chamber was not readily available, the specimens for these tests were stored at about $21^{\circ} \mathrm{C}\left(70^{\circ} \mathrm{F}\right)$ and $50 \pm 10$ percent relative humidity. The effect of this lack of standardized preconditioning is not known. The temperature effects were probably small, particularly for nylon, but there is some evidence [DU-3, DU-4, TU-1] that nylon and manila are weakened and polyester is strengthened by exposure to high humidity.

Each lanyard specimen was prepared for test in the following way:

(1) One snaphook was fastened onto a crane hook and was tensed by means of a $5 \mathrm{lb}$ weight (suspended from the other snaphook) for about one minute. During this time a bearing-to-bearing length was measured. This step was to determine the effect of step 2 on the lanyard length.

(2) After removing the $5 \mathrm{lb}$ load a $200 \mathrm{~d}^{2} \mathrm{lbf}$ load was suspended from the lanyard. (Conventionally, the diameter (d) 2 of a rope is supposed to be defermined with a $200 \mathrm{~d}^{2}$ weight in place.) The "200 $\mathrm{d}^{2}$ value for strap lanyards was determined by converting to crosssectional area, i.e.,

$$
200 \mathrm{~d}^{2}(\mathrm{lbf})=\frac{800 \mathrm{~A}}{\pi}
$$

where $A$, the cross-sectional area, is determined from the width and thickness for strap lanyards. Suspension time for each $200 \mathrm{~d}^{2}$. load was at least 5 minutes in order to condition the tensed rope. The length of each lanyard under a $200 \mathrm{~d}^{2}$ load was obtained. 
SAMPLE " ; SPLICED ; TAGGED ; BROKEN ; DATE BROKEN

TYPE DEVICE - Rope ( ), Strap ( ), Adjustable Rope ( ), Other ( ), describe

BASIC LANYARI) PROPERTIES:

Composition

Filament/Spun

Color , Lay

IF ROPE:

Diameter, Given in Obs.

* Strands

IF STRAP:

Width

Thickness Rope/Strap Cross-Sectional Area Pitch ANYARD ORIGIN \& ORIGINAL CONDITION (as received):

Donated by , Date Received at NBS

Length of Service (by user) Type of Service Seen Condition of Lanyard as Received Rope/Strap/Webbing Manufacturer Comments Accompanying Device

PRECONDITIONING OF THE LAVYARD: Original Snap-to-Snap Length (Lanyard wt with 5 1b) $200 d^{2}=$ lbf. Weight Added to Lanyard (>1 min.) Snap-to-Snap Length of Lanyard + Conditioning wt Final Pre-Test Lanyard Length, Snap-to-Snap, after $>5$ minute SPLICES/THIMLRLES/SNAP-HOOKS LEFT (Moving Side)

" Tucks.........

Splicer..........

Thimble Compo/... Manufacturer

Snap Manuf'rer... Ident. on Snap...

Final Snap Dis-. position in $^{2}$

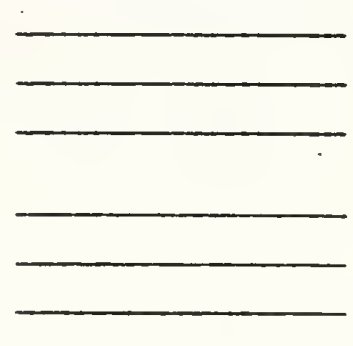
in; 1b; in;

RIGT (Stationary Side)

\footnotetext{
'Relaxation'Period (Lanyard wtd with 5 lbs) (L)___ in;

Increase in Length Due to Preconditioning in. ;
}

STATIC TENSILE TEST RESULTS:

Date of Test ; APPROXIMATE SPEED OF PULL $5^{\prime \prime} / \mathrm{MI}$

Length of Free-Standing Rope Test Zone (l) Method Used in Mcasuring Extension of this Zone Breaking Load Ibf Comments

Where Failure Occurred

Final Free-Standing Section ( $\Delta l)$

Final Snap-to-Snap Length $(L+\Delta L)$ $(\Delta l / l)$

Ratio of Above Ratios $(\Delta \mathrm{L} / \mathrm{L})$

ADDITIONAL COMMNTS 
The observed diameter of each rope lanyard was also obtained with the $200 \mathrm{~d}^{2}$ weight in place. Some

disagreements between given and observed rope diameters were found, almost invariably involving used, spunnylon lanyards. Observed values were used in subsequent analyses.

(3) The $200 \mathrm{~d}^{2}$ weight was removed and the lanyard left in an unloaded state. It was soon observed that there was still significant contraction of some lanyards after 5 minutes. This rest interval was therefore increased to 30 minutes or longer. After this rest interval each conditioned lanyard was loaded with a 5 lb weight and its new length, $L$, obtained. Relative lanyard extension ( $\Delta L / L)$ values for each load-extension curve were calculated using this L value.

(4) While the lanyard was loaded with a 5 lb weight for the second time, a 30-inch, free-standing, centrally-located rope section was marked off on the lightly stressed lanyard and the spine of the lanyard (if it was made of stranded rope) was delineated. After removing the $5 \mathrm{lb}$ weight (for the second time), the lanyard was mounted in the tensile testing machine so as to keep its spine straight.

(5) A sample to be pulled was mounted between the machine jaws by securing each snaphook to a mating eyebolt. The jaws were originally set at some spacing less than $L$ (so the lanyard would not be strained during mounting) and the lanyard length was then adjusted to $L$ by manually increasing the jaw spacing. The $X-Y$ recorder was then set and checked for a $(0,0)$ setting .

(6) For central section extension ( $\Delta l$ ) measurements, the original position of the measuring tape with regard to the 30-inch mark on the lanyard was noted before the test was begun. Alternatively, if central section measurements were automatic, the extensometer tape was set so that the contacts rested on a metallic strip (note the origin peak in the $\mathrm{L} / \mathrm{E}$ curve presented in Figure $\mathrm{A}-3$ ) at the inception of the test pull.

A typical data sheet obtained during an early run when the tape measure method was being used to measure $\triangle \mathrm{L}$ VS. $\mathrm{F}$ values is represented in Table $\mathrm{A}-2$. To obtain $\Delta \mathrm{L}$ values 
Table A-2. Typical Data for Manually Obtained

Lanyard-Central-Section L/E Measurements

Sample \#14, 1/2 in Dacron Lanyard

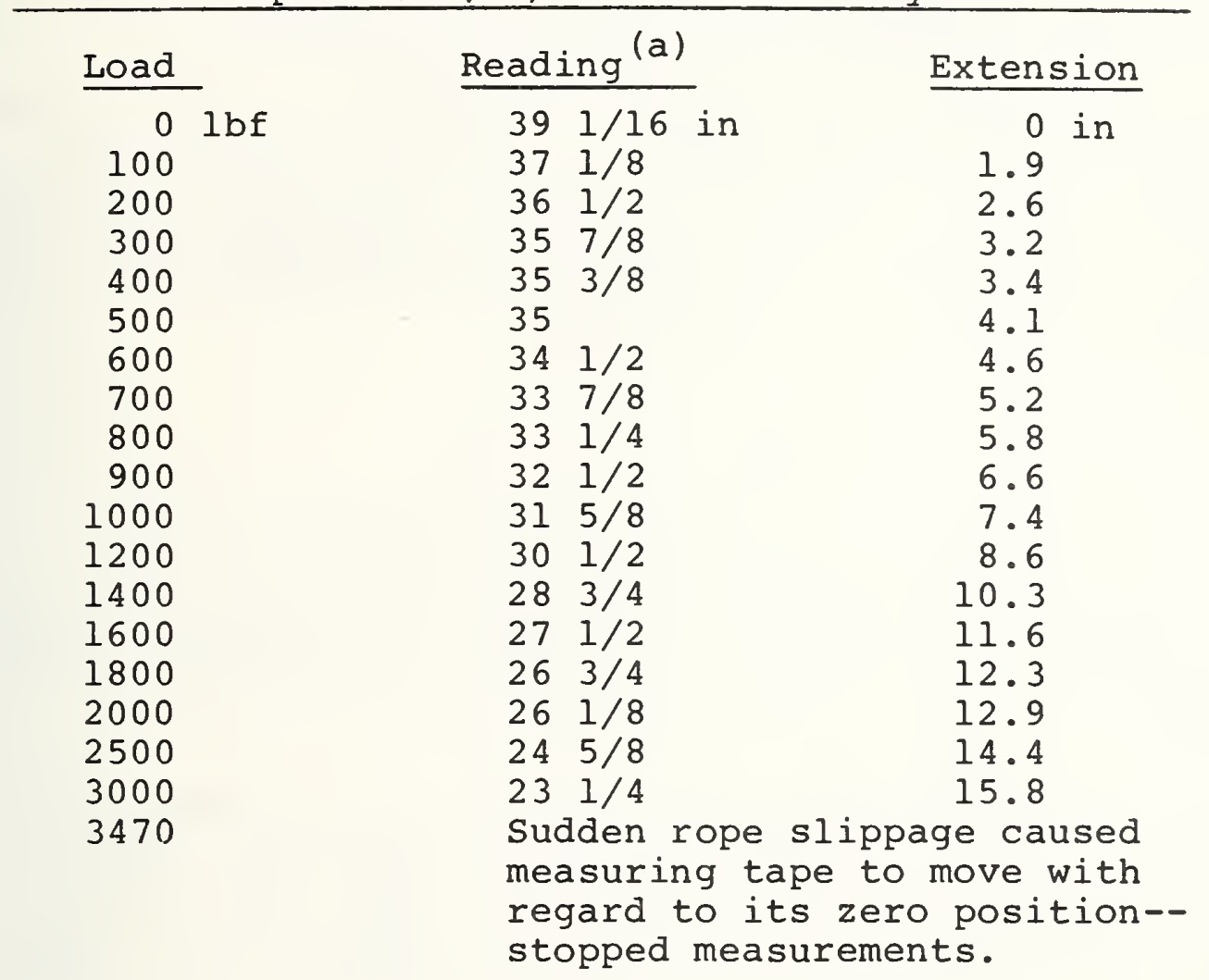

Original snap-to-snap length, $5 \mathrm{lb}$ weight, 63 in Length with $50 \mathrm{lb}\left(200 \mathrm{~d}^{2}\right.$ wt) for $>1 \mathrm{~min}, 653 / 4$ in Removed $50 \mathrm{lb}$ and waited for $>5 \mathrm{~min}$

Final length (L) with $5 \mathrm{lb}$ weight, $631 / 16$ in

(a) Due to the mounting configuration of the tape measure in this run the rope appears to be contracting when, in fact, it is being stretched. Test specimen extensions were obtained by taking the absolute magnitude of the differences between the first and subsequent readings. 
from "readings" each reading was subtracted from the initial length $(39-1 / 16$ in).

With the specimen and extensometers installed and adjusted to the proper initial position and the recorder set to $(0,0)$, the loading control value of the testing machine was an amount that had been predetermined to produce a head motion of about $15 \mathrm{~cm}$ ( 6 in) per minute. When the measuring tape was used to measure center section elongation, the machine operator called out "read" signals to the tape observer. The test continued until one or more rope strands broke or disengaged from a splice, or snaphook failed so that the lanyard was released, or a stitched splice opened to release a strap lanyard. A typical load/elongation curve is shown in Figure $A-6$ and center section extension data are presented in Table $A-2$. Data using the incremental extensometer is shown in Figure A-4.

\section{A.3.4 Body Belt Tests}

As with lanyards, the body belt specimens were not exposed to a special preconditioning environment. The general test procedures were the same as for lanyards except for the method of measuring belt length, the mounting in the machine, and the use of only the potentiometer type extensometer.

The method of measuring the belt length is shown in Figure A-7. The heavy metal mandrel was used as a spacer and also as a weight to tense the belt. The same mandrel was used as a test fixture as shown in Figure A-8. In the test setup, the dee-ring of the belt is attached to a heavy hook clamped in the jaw of the testing machine. The deering used was the one furtherest from the buckle. Tongue buckle belts were buckled at the fourth hole in from the tip of the belt. Friction buckles were fastened so as to leave 10 to $12.5 \mathrm{~cm}$ ( 4 to 5 inches) beyond the buckle after double passing the belt.

After mounting the specimen in the testing machine, the movable jaw was spaced to give the same length, $L$, as during the pretest measurement. The $X-Y$ recorder was adjusted to $(0,0)$ at this point. The loading control value of the machine was then opened to provide a head motion of about 15 $\mathrm{cm}$ ( 6 in) per minute. The test was terminated when the belt broke or uncoupled from either end constraint. Such failure occurred due to: 


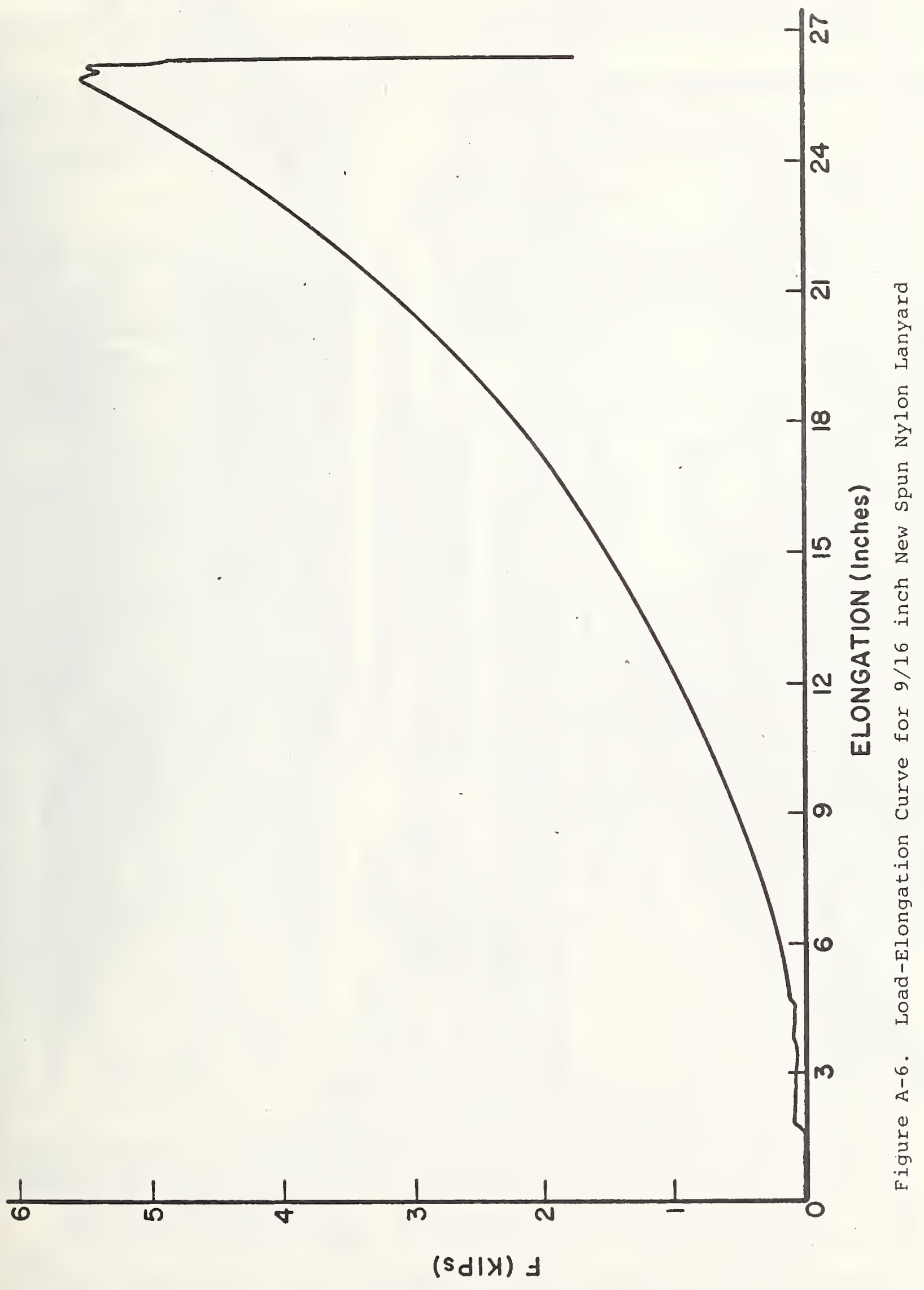

A -19 


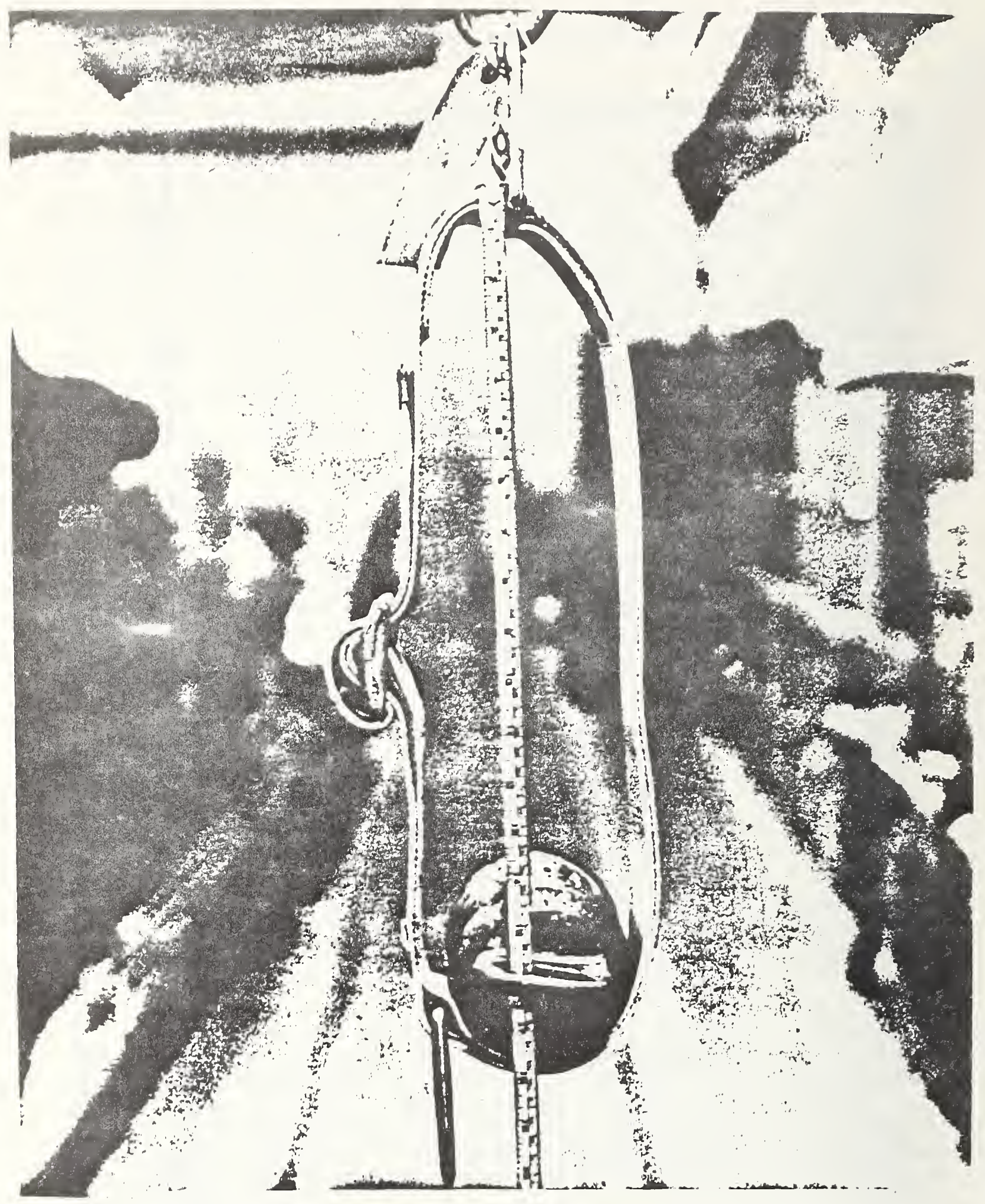

Figure A-7. Length-Measurement Configuration for Body Belts 





(1) webbing breaking;

(2) a dee-ring splitting or deforming to release the hook;

(3) a tongue tearing completely through the belt webbing; and/or

(4) a belt end sliding completely through a friction buckle.

Typical load vs. elongation curves for tongue and friction buckle belts are shown in Figures $A-9$ and $A-10$ respectively. 


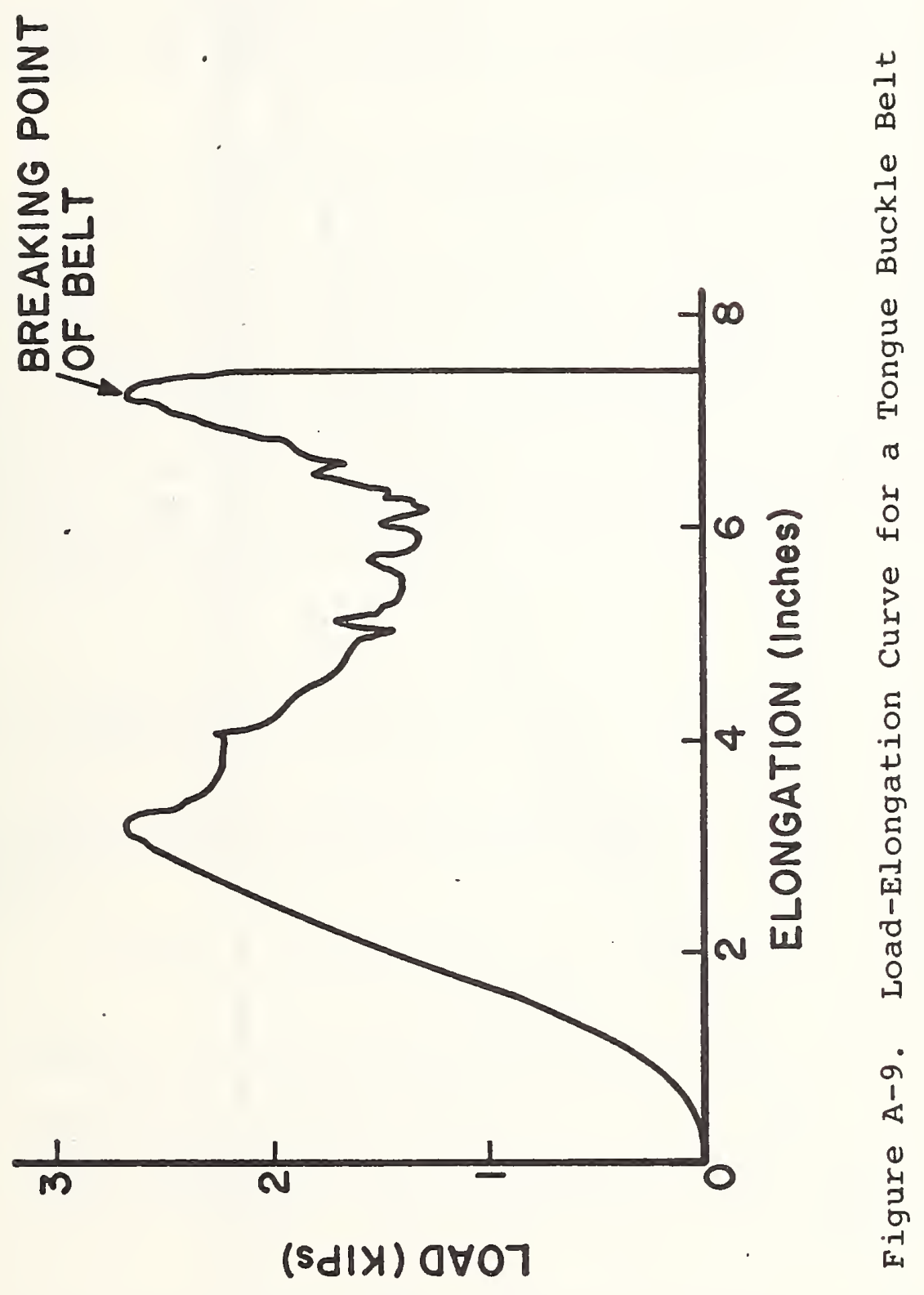

A -23 




Figure A-10. Load-Elongation Curve for a Friction Buckle Beit 


\section{A. 4 Data Analysis}

The objective of these tests was to provide static test data that could be used to predict the performance of fallsafety systems, in particular lanyards and lanyard body belt combinations, under impact loading conditions such as might be involved in arresting a fall. Such predictions should be possible for all reasonable combinations of fall distance, lanyard length, and worker weight. The data analysis techniques used for this purpose are described below.

\section{A.4.1 Reduction of Experimental Data}

In order for our data to be readily used in the computer model, third degree polynomial curves were fitted to the load vs. elongation data for the total lanyard and the pure rope center section. This was done by computer using least square techniques. The total lanyard data was taken from the recorded curve at frequent load intervals. The pure rope data was taken from the recorded curves at equal elongation intervals indicated by the pips, Figure A4, or directly from the data taken visually by the observer using the measuring tape technique, Table $\mathrm{A}-2$. The resulting equation had the form

$$
\text { Load }=A+B \Delta L+C \Delta L^{2}+D \Delta I^{3}
$$

where $\Delta L=$ elongation; and $A, B, C, D=$ coefficients obtained from the curve fitting process.

Equations of this form were obtained for lanyards of several lengths of possible interest by using the relationship,

$$
\left.\left.\left.\frac{\Delta \lambda}{\lambda}\right]_{i}=\frac{\Delta L}{\lambda}\right]_{i}+\frac{p}{\bar{\lambda}}\left(\frac{\Delta l}{l}\right)\right]_{F_{i}}
$$

where $\lambda=$ length of lanyard of interest

$L=$ length of lanyard tested

$\ell=$ length of pure rope (center) section, and

$\mathrm{p}=\lambda-\mathrm{L}$

The output from the computer program using relative elongation, $\Delta \lambda / \lambda$, and load as inputs included: 
(1) the coefficients $A, B, C$, and D;

(2): predicted (curve) values of load for each elongation entry;

(3) the differences between the experimental and predicted (curve) values of load (residuals);

(4) the standard deviations for these quantities;

(5) the total lanyard extension, $\Delta \lambda$ and

(6) the instantaneous lanyard length, $\lambda+\Delta \lambda$.

An example of the computer output is shown in Tables A$3(\mathrm{a}, \mathrm{b}$, and $\mathrm{c})$.

Since the load sustained by the lanyard at zero elongation is, by definition, zero, the zeroth order coefficient (A) should be zero. Although this was not generally the case, an analysis weighting the zero load point $(0,0)$ by 100 changed the average computed peak force and acceleration values by less than one percent (less than 3 percent maximum) and the average peak duration values by less than two percent (less than five percent maximum). These differences are considered to be within acceptable limits and not warranting the introduction of a heavily weighted $(0,0)$ point.

Figures $A-11$ and $A-12$ show the average load vs. elongation curves for 13 lanyard types and their pure rope (center) sections respectively. The curves can be identified as follows:

$\begin{array}{ll}\text { Curve 201 } & 9 / 16 \text { inch used spun nylon } \\ \text { Curve 202 } & 9 / 16 \text { inch new spun nylon } \\ \text { Curve } 203 & 1 / 2 \text { inch filament nylon } \\ \text { Curve } 204 & 5 / 8 \text { inch filament nylon } \\ \text { Curve } 205 & 3 / 4 \text { inch filament nylon } \\ \text { Curve } 206 & 1 / 2 \text { inch gold filament nylon (I) } \\ \text { Curve } 207 & 1 / 2 \text { inch gold filament nylon (II) } \\ \text { Curve 208 } & 5 / 8 \text { inch gold filament nylon } \\ \text { Curve 209 } & 1 / 2 \text { inch single-ply polyester } \\ \text { Curve 210 } & 1 / 2 \text { inch three-ply polyester } \\ \text { Curve 211 } & 1 / 2 \text { inch polypropylene } \\ \text { Curve } 212 & 5 / 8 \text { inch polypropylene } \\ \text { Curve } 213 & 3 / 4 \text { inch manila }\end{array}$

The prediction of the response of any length of lanyard to various loading conditions would be straightforward if full lanyards and pure rope sections had the same response. unfortunately, this is not the case, and, contrary to expectations, the vercent elongation of the pure rope sections was generally less than that for the full lanyard at any given load. 


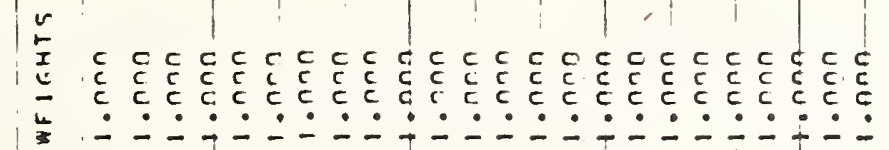

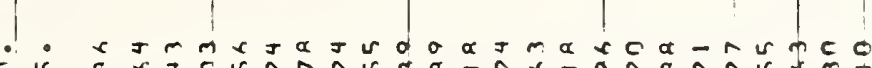
c s

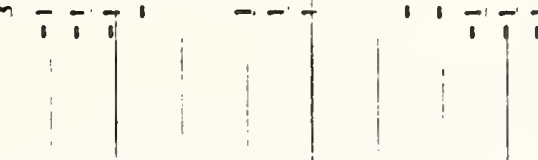

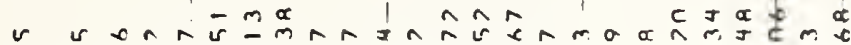

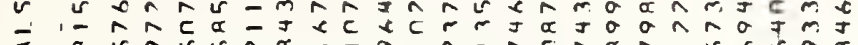

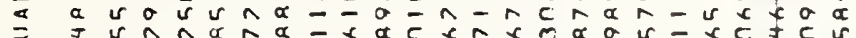

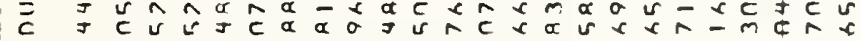

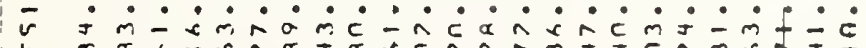

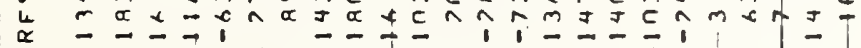

$\sum^{-1}$ $4=$ $\begin{array}{lll}4 & 4 \\ 0 & 4\end{array}$

$-2 \stackrel{n}{n}$

.

\section{.}

.

Ð

D. $c=c$

ช⿺⿻一𠃋十

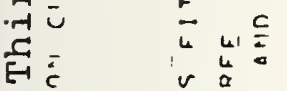

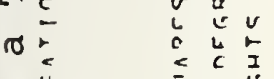

हू

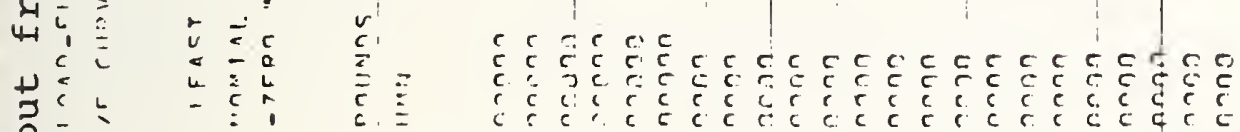

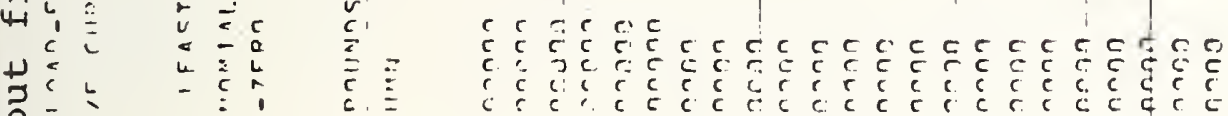

c)

r.

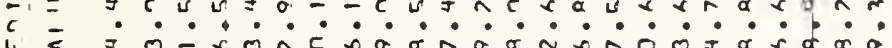

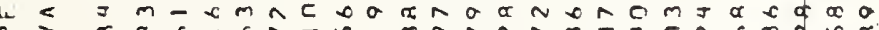

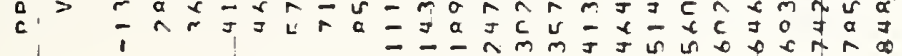

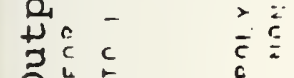

o.

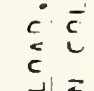

$\dot{r} \dot{r} \dot{c} \dot{c} \dot{c} \dot{c} \dot{c} \dot{c} \dot{c} \dot{c} \dot{c} \dot{c} \dot{c} \dot{c} \dot{c} \dot{c} \dot{c}$

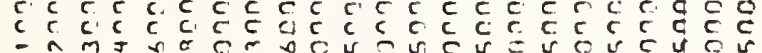

त्र

U $-\vec{H}=$

足

$-2$

.$\dot{c} \bar{c}$

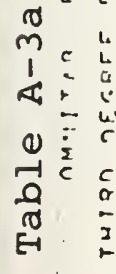

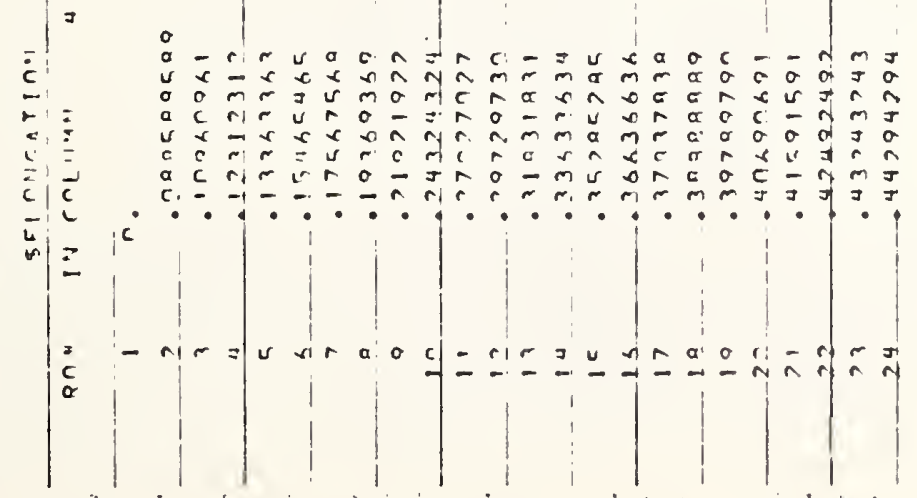




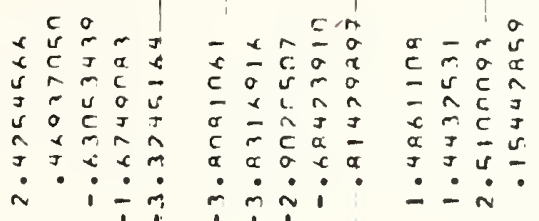

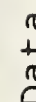

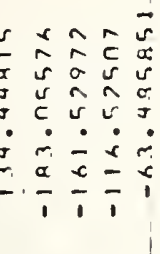

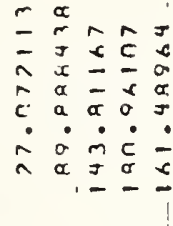

$\hat{\hat{n}} \hat{\sim} \hat{s}$

$c_{i} ;$

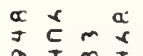

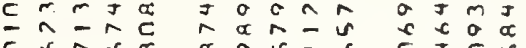

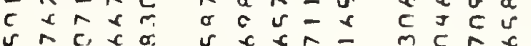
. 0.0 .0 .0

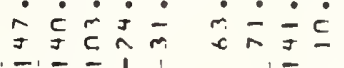
$\hat{c} \Sigma \hat{n} x$ $\stackrel{\text { II }}{\mapsto}$

r.

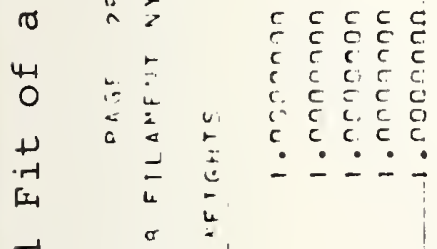

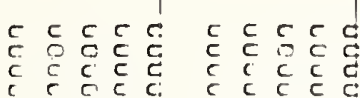

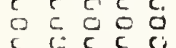

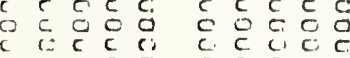

ᄃ. . . . . :

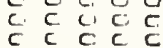

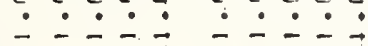

Ti:

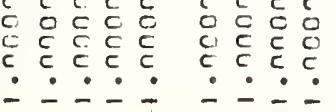

r

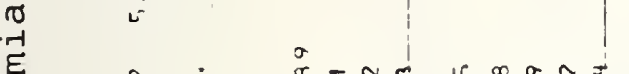

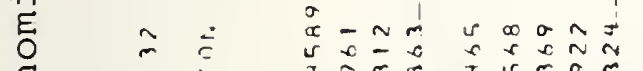

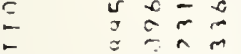

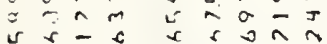

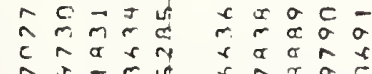

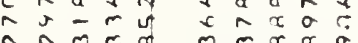

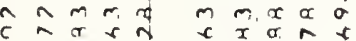

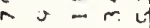

$\vec{c} \quad \dot{c} \div \vec{c}$

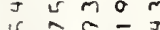

$\overline{-\div} \div$

c $x$ a

ก.?

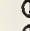

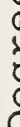

\section{r

.

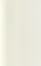

4

(n)



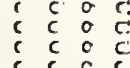

$\begin{array}{llll}c & c & c & c \\ c & c & c & c \\ c & 0 & 0 & 0 \\ 0 & 0 & 0\end{array}$

$\therefore \div$

$\begin{array}{lllll}r & c & c & c & d \\ c & c & c & c & c \\ c & c & c & c & c \\ c & c & c & c & c \\ c & c\end{array}$

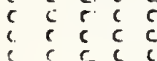

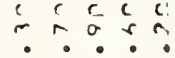

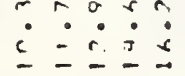

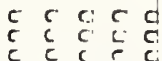

$\begin{array}{lllll}c & c \\ c & c & c & c & c \\ c & c & c & c & c \\ c & c\end{array}$

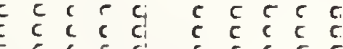

c a $a$ a

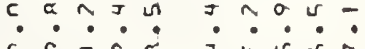

$\dot{2} \dot{2} \dot{\sim} \dot{n}$

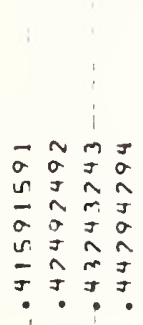

- $-4 \pi v$



$\circ: 000$

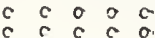

$\therefore 000$ c o o o

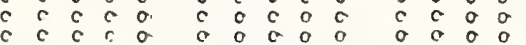

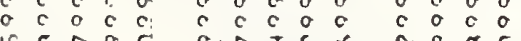

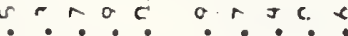

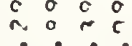

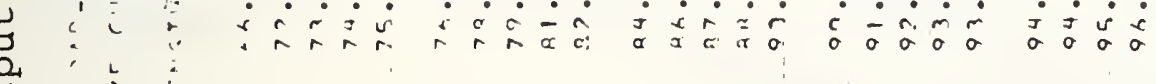

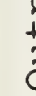

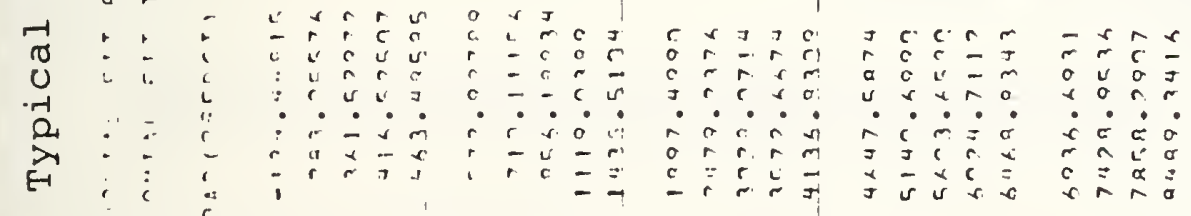

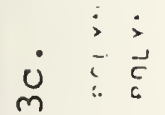

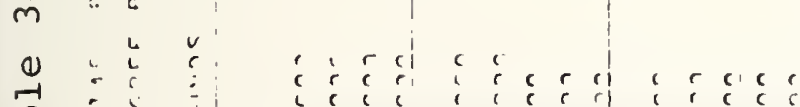

,
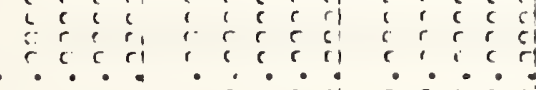

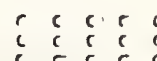

c. c c c c i c

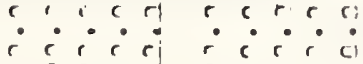

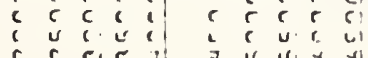
c. ' c ? ? $\therefore<\dot{0}$ i तो

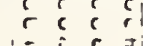

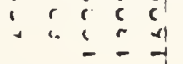
c i 


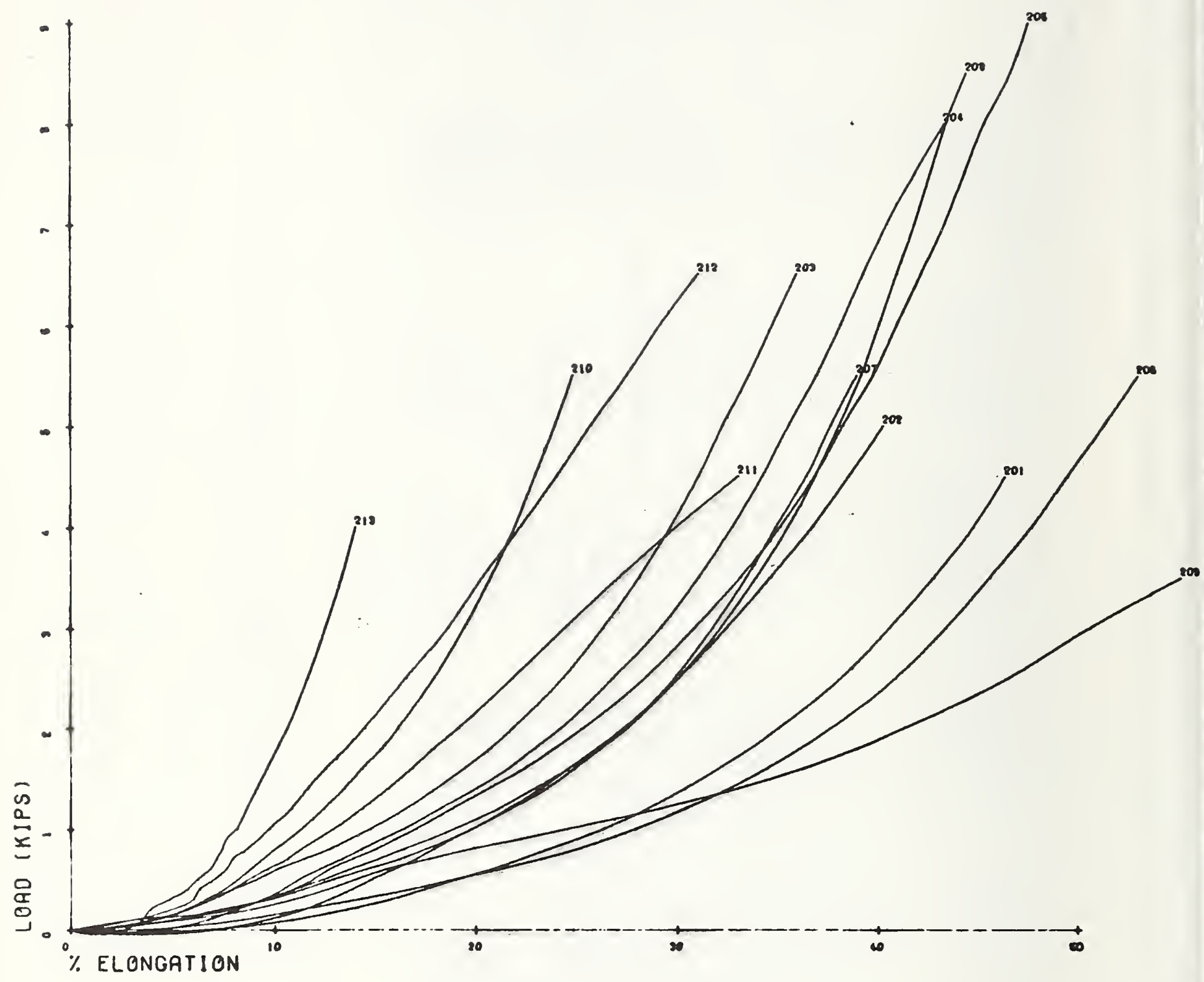

No. 400

Figure A-11. Load/Relative Extension Curves Obtained for 13 Lanyard Types 


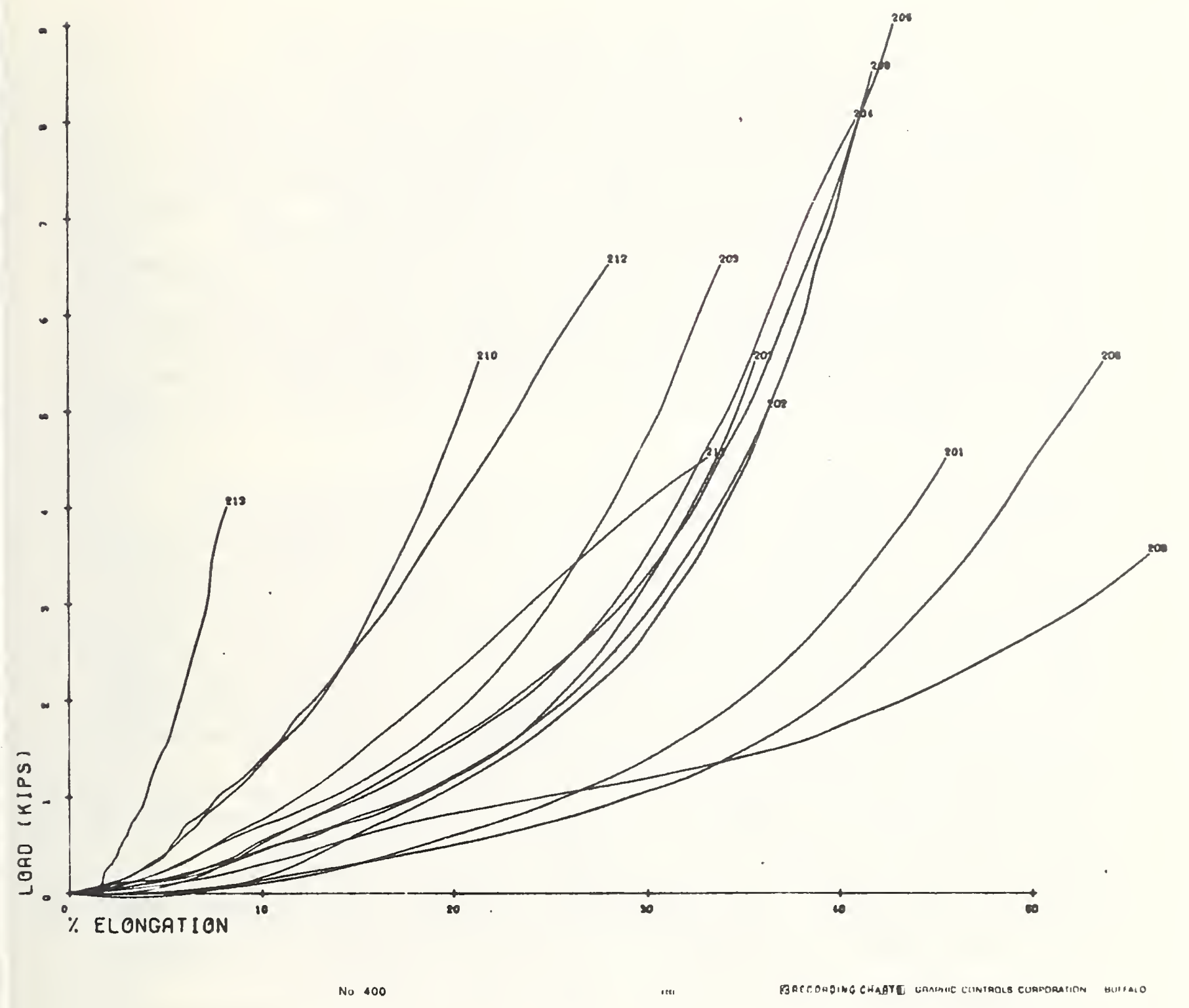

Figure A-12. Load/Relative Extension Curves Obtained for 13 Lanyard Types-- Center Rope Sections

$$
\text { A }-31
$$


Figure A-13 shows results that were in good agreement while Figure A-14 shows considerable variation between specimens of the same type.

\section{A.4.2 Computations Using Analytical Model}

In order to predict the performance of fall-safety systems under impact conditions, forces, accelerations, elongations, and velocities were computed as a function of time after impact for a variety of lanyard lengths, test weights (rigid masses) and free fall distances. The times at which these factors were computed were themselves determined by a feedback type internal routine and averaged approximately $0.01 \mathrm{~s}$. Peak values were estimated using still finer time gradations; nevertheless, this time scale "graininess" generated slight additional uncertainties in computed peak values. The magnitudes of these peak value errors (induced by time graininess) are estimated to be less than $1 / 2$ percent.

An effort was made to extend the versatility of our computerized model to complete (body belt plus lanyard) fall-arrest systems. This was an attempt to ascertain the contributions of body belt to various critical arrested fall parameters. In order to simulate the behavior of lanyardbody belt systems the elongation of each belt at specified loads was added to the appropriate lanyard elongation at the same loads. Note that the L/E data used here were obtained from lanyards similar to those used in the actual drop tests (i.e., same manufacturers, configurations, compositions and diameters). The one difference--lanyard length-necessitated adjusting our L/E data to the length used by the manufacturer. These modified load-elongation data were then fitted to third degree polynomials and the four coefficients from each fit entered into the main program, which was then run. Oscillograph load vs. time or peak load data was available, for comparison purposes, from the same two manufacturers who supplied us with the belts.

Examples of the computer output are given in Tables $\mathrm{A}-4$ $a$ and $b$.

Using the peak values from the above computations, tables of peak force and acceleration for a variety of lanyard types, lanyard lengths, free fall distances, and mass of test weight or worker were compiled. Examples are shown in Tables $A-5$ and $A-6$. 


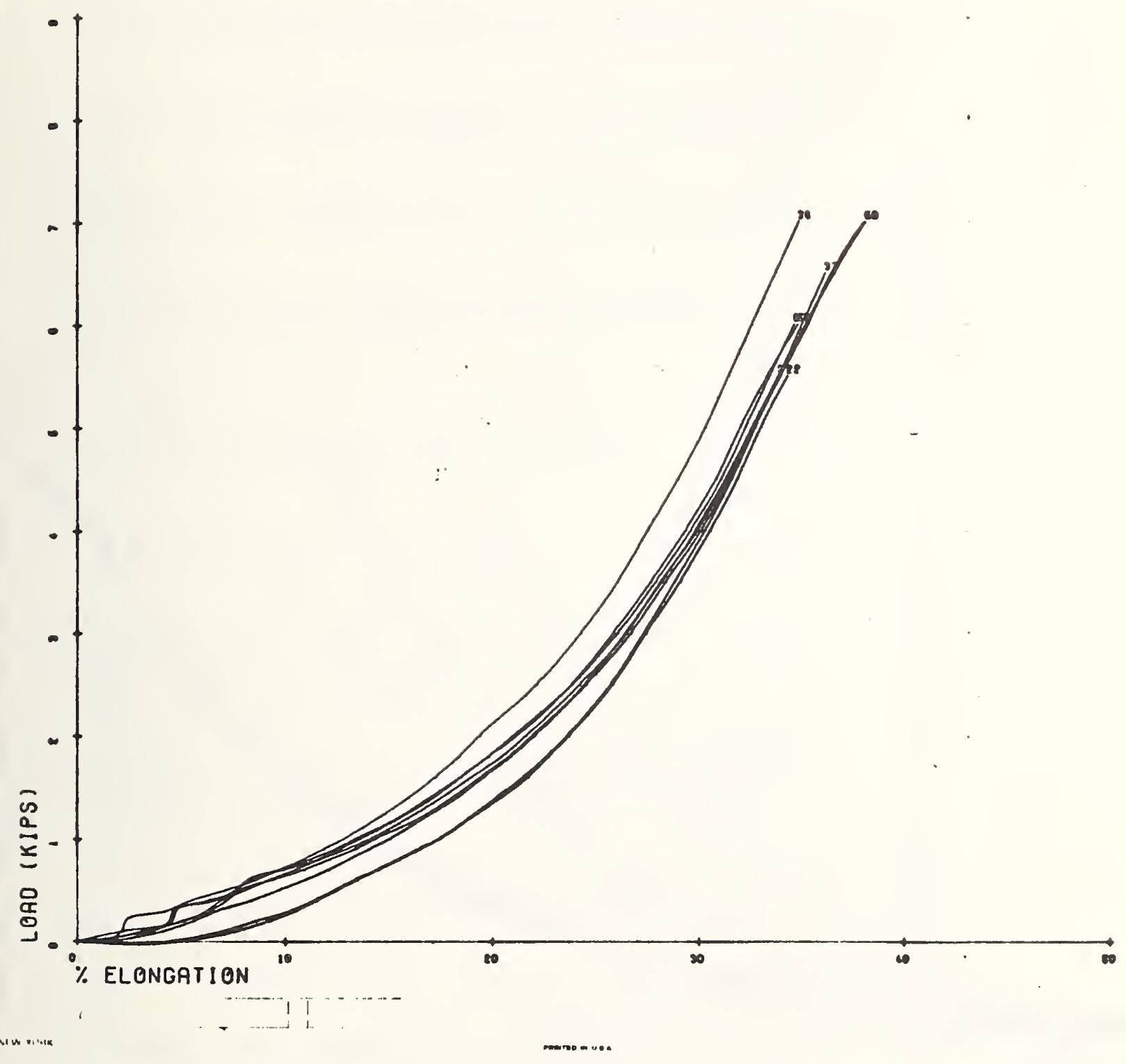

Figure A-13. Load/Relative Extension Curves Obtained for $1 / 2$ inch , Filament Nylon Lanyards.

$$
\text { A }-33^{\circ}
$$




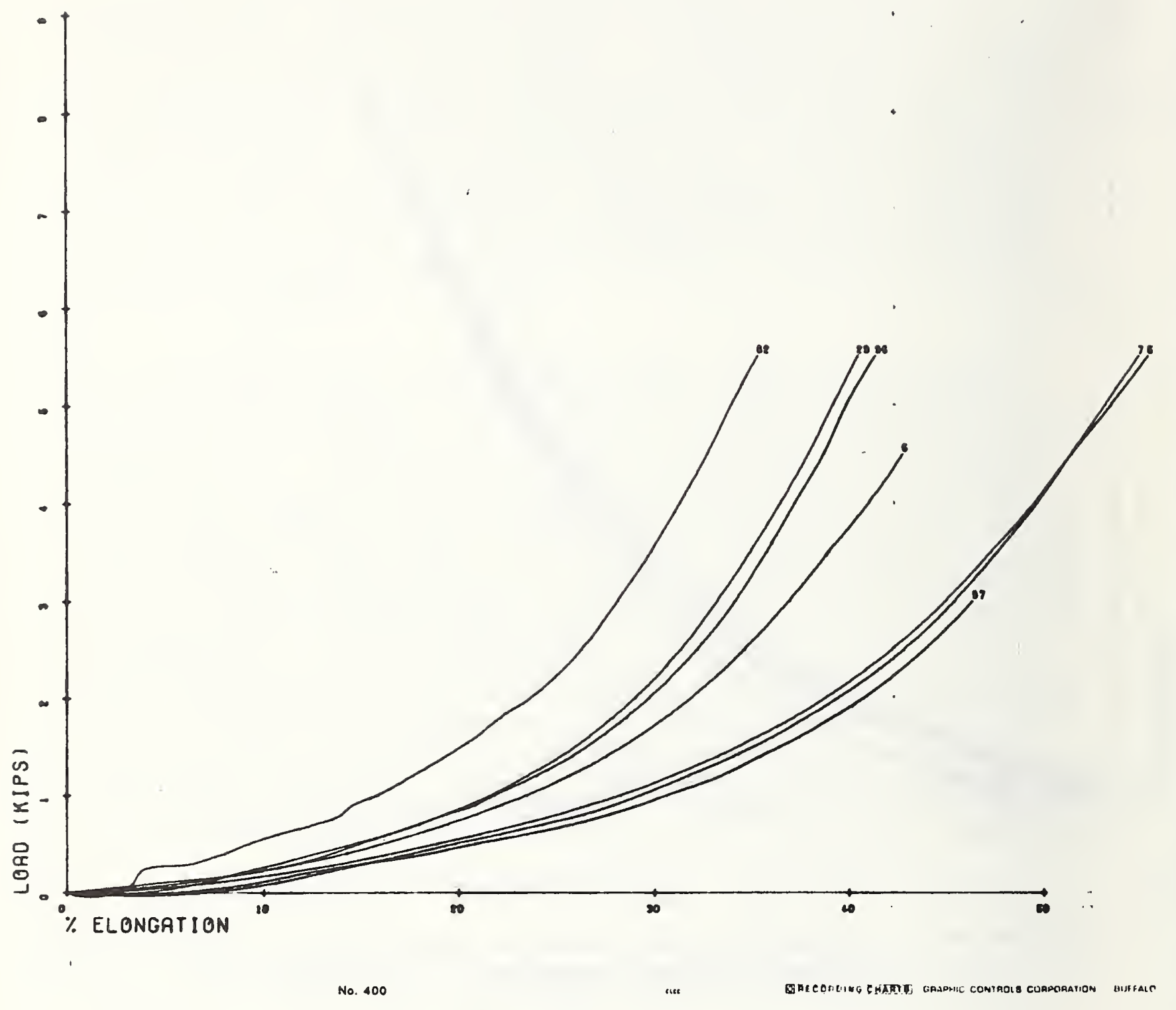

Figure A-14. Load/Relative Extension Curves Obtained for $1 / 2$ inch Gold Filament Nylon Lanyards 
*

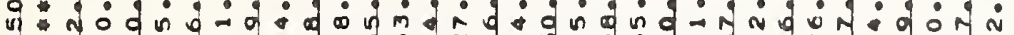

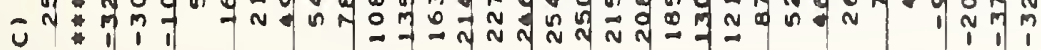

㠺

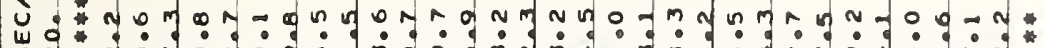
ท

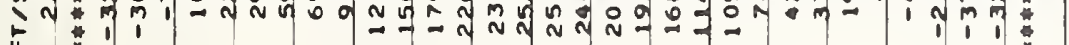

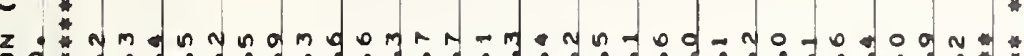

z: E- 군 : 1 -

出 $:$ *

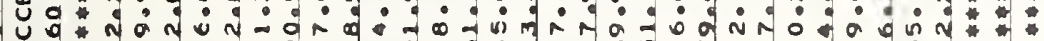
- - i n

$\rightarrow$. -

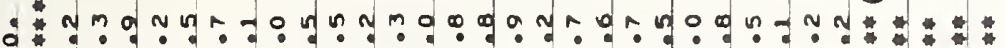

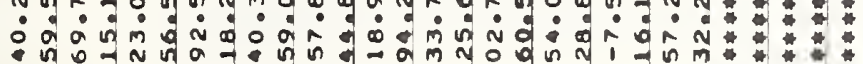

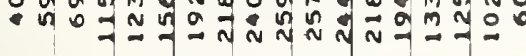

*

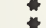

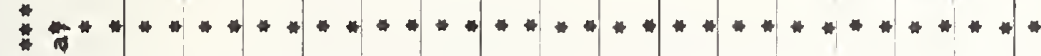

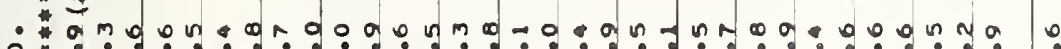

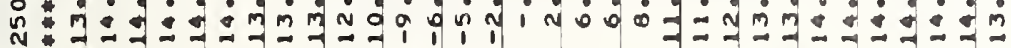
*

ư -

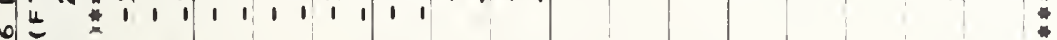

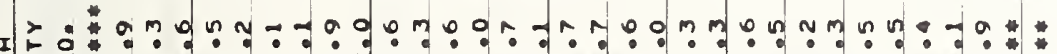
I

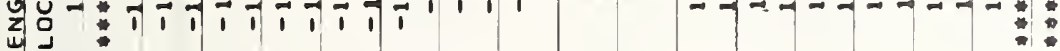
แ

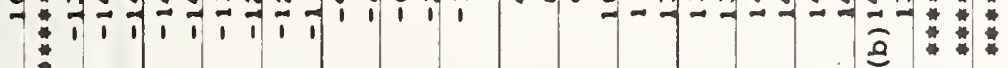
ตั

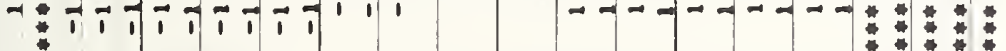
-

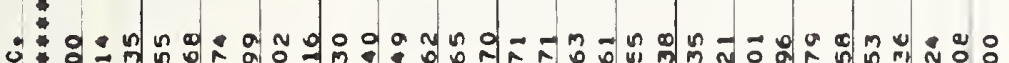
* oาm n ㄴ.

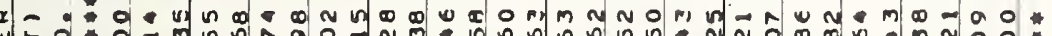
เ 茨


으의 a 5 a

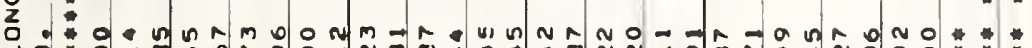
J.: 0 - m n

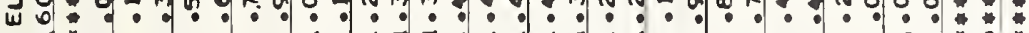
* on n m ñago

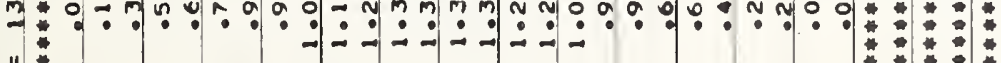

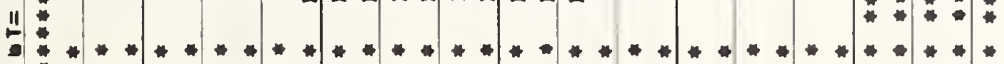
-

U. แ w.

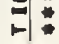

4.

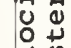

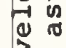

弪

건

击式

둥 


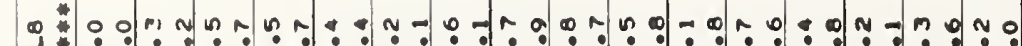

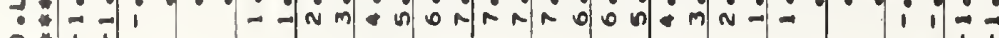
0.11

.

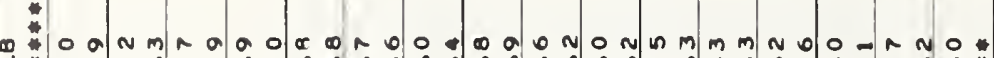

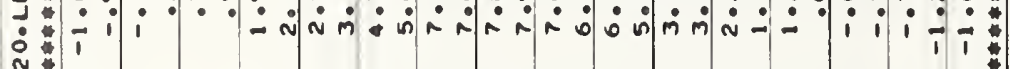
N

บํ.

$\therefore$

$\dot{0}$

(1)

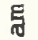
⿶凵

落

崩

(1)

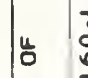

$\div$

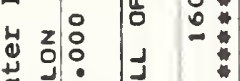

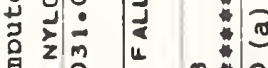

(2)



$1 \div \div \div$

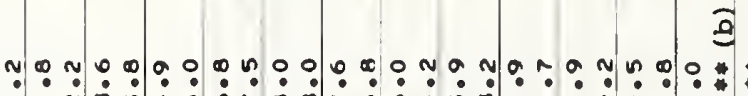

放:

崖

:

离

垔

㟧

형

年

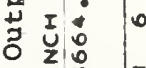

㟧

o :

总

药

$\ddot{\alpha}$

I

$\infty$

.

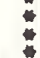

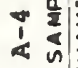

a n I

है

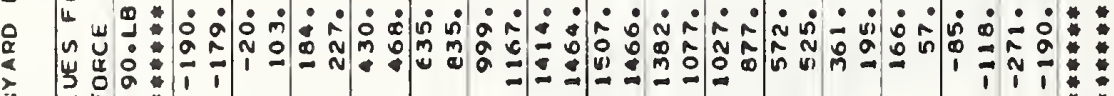

- $\alpha$

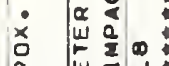

(a)

a

은

岂

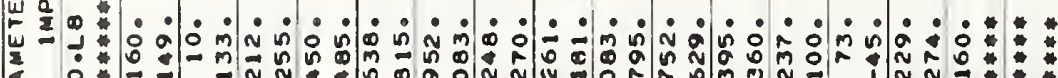

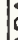
a

.

-

을

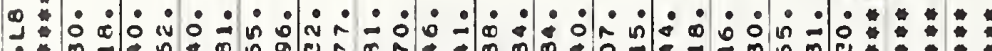

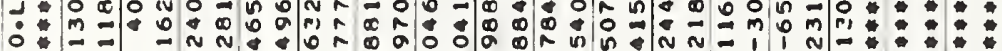

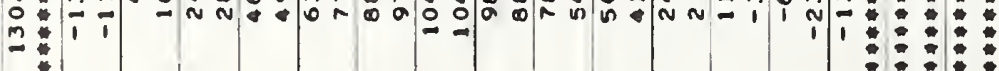

".

5

u.

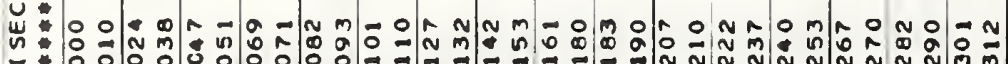

w

: 
Table A-5 Summary of calculated peak impact forces for selected fall parameters

IMPACI FURCES IIN LMFI FOH A 130 LB WEITHT LANYARU LENGIH AND TYPE _ DKUP $=$

2F1 $x 9 / 161 \mathrm{~N}$ USED SPUI NYLUN

4FI $X 9 / 16 I N$ USLU SHIIN NYLUN 6F $T$ T $9 / 16 I N$ USED SPUN NYLON BFI $X 9 / 161 N$ ISLU SPUN NYLON IUFT $X 9 / 16 I N$ ISEEU SPUN MYLON

2F $T$ \% $161 N$ IIEN SPUN INYLON

4FT $X$ Y/16IN FEA SPUN INYLUN

6FI $X 9 / 16 I N$ NEN SHUN NYLON

BFT $X 9 / 16 I N$ IJ $N$ SPUN NYLON

IUFI $X 9 / 16 I N$ INE WPIIN NYLON

2\& $\quad x 1 / 2 I \|$ FILAMENT NYLON

4FT $X 1 / 2$ IN FILAMFNT NYLUN

GFI $X I / 2 I N$ FILAMFNT IIYLON

HFI $X 1 / 2 I \|$ FILAMENT NYLON

IUII $X 1 / 2$ IN FILAMFNT IIYLON

2f $1 \times 13 / B I N+I L A M F N T$ NYLON

4F $X 5 / R I N$ FILAMENT NYLON

6FT $X 5 / 8111+I L A M E N T$ NYLUN

\&F $X$ I $X I N F I L A M F N T$ NYLON

IJHI $X$ S/BIN FILAMENT NYLUN

2FT $\times 3 / 4 I N$ FILAMENT NYLOH

4F I $X 3 / 41 N+$ ILAMENT IJYLON

6FT $X 3 / 4 I N$ FILAMENT NYLUN

8FT $X 3 / 4 I H$ FILAMENT NYLON

IUFT $X 3 / 4 I N$ F ILAMENT NYLON

2F $X 1 / 2$ IN GOLL NYLON FILANENT (I)

4FI $x 1 / 2 I M G O L D$ NYLON FILAMENT 11 ,

GFI $X 1 / 21 N G() L D$ NYLON FILAMENT $(1)$

8F $T$ I/ZIN GULU NYLON FILAMENT (1)

IUFI $X 1 / 2$ IN $(O L L N Y L D N$ FILAMENT $(I)$

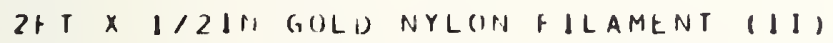

4F $T$ 1/2IN GOLD NYLON FILAMENT (11)

6H $x 1 / 21 N G O L U$ NYLON FILAMENT (II)

BF $X 1 / 21 N G O L D N Y L O N$ P ILAMENT 1111

IUFT $X 1 / 21 N G O L U$ NYLON FILAMENT 1111

2FI $X 5 / 8$ IN GULD NYLOH FILAMENT $4 F T \times 5 / H I N G O L D N Y L O N$ FILAMENT 6F $X 5 / 8 I N G$ GLD NYLON FILAMENT BFI $X 5 / A I H G O L U$ NYLON FILAMENT IOFT $X 5 / B I N G O L U$ NYLON FILAMENT

2FT $X$ I/ZIN SINGLE PLY POLYESTER 4FI $X$ I/2IN SINGLE PLY POLYESTER 6FI $X 1 / 21 \mathrm{~N}$ SINGLF PLY POLYESTER OF $X 1 / 2 I N$ SINGLE PLY POLYESTER IUF $1 \times 1 / 2 I N$ SINGLE PLY PULYESTEK

\begin{tabular}{|c|c|c|c|}
\hline 3 F T & $6 F T$ & Y FT & $12+1$ \\
\hline 322 . & $\cdots \cdots$ & $\cdots \cdots$ & $\cdots \cdots$ \\
\hline 1464 . & 2278 . & $\cdots \cdots$ & $\ldots \ldots$ \\
\hline 1124. & 1729. & 2265 . & $27 \circ 3$. \\
\hline 948. & 1428 & 1859 & 2260 \\
\hline 835. & 1236. & 1598. & 1436. \\
\hline 2256 . & $\cdots \cdots$ & $\cdots \cdots$ & $\cdots \cdots$ \\
\hline 1491. & 2316 & $\cdots \cdots$ & $\cdots \cdots$ \\
\hline 1166. & 1786. & 2340 & 2835. \\
\hline 985 & 1482 & 1931. & 2514. \\
\hline A68. & 1286 & 1665. & 2014. \\
\hline 2627 & $\ldots \cdots$ & $\cdots \cdots$ & $\ldots \ldots$ \\
\hline 1645 . & 2616. & $\cdots \cdots$ & $\cdots \cdots$ \\
\hline 1276 & I 475. & 2614. & 3211. \\
\hline 1079. & 1621. & 2133 & 2613. \\
\hline 955. & 1409. & 1828 & 2227 \\
\hline 2661. & $\ldots \ldots$ & $\cdots \cdots$ & $\ldots$ \\
\hline 1664. & $2 b 78$. & $\cdots \cdots$ & $\cdots \cdots$ \\
\hline 1289. & 1460. & 2559 . & $311 b$. \\
\hline 1086 & 1613. & 2097. & 2547. \\
\hline 961. & 1404. & 1806. & 2181. \\
\hline 2346 . & $\cdots \cdots \cdots$ & $\cdots \cdots$ & $\cdots \cdots$ \\
\hline 1495. & 2337 . & $\cdots \cdots$ & $\ldots+\cdots$ \\
\hline 1169. & 1771. & 2332 . & 2863. \\
\hline I งU 2 . & 1469. & 1909. & 2328 . \\
\hline 901 & 1285 & 1644 & 1940. \\
\hline $2 J 7 R$. & $\cdots \cdots$ & $\cdots \cdots$ & $\cdots \cdots$ \\
\hline 1268 & 2043. & $\cdots \cdots$ & $\cdots \cdots$ \\
\hline 956. & 1519. & 2038 . & $25<8$ \\
\hline 792 . & 1232 . & 1643. & 2027 . \\
\hline 697. & 105,2 & 1390. & 1714. \\
\hline 2395. & $\cdots \cdots$ & $\cdots \cdots$ & $\ldots \ldots$ \\
\hline 1489. & 2452 . & $\cdots \cdots$ & $\ldots$ \\
\hline 1123. & 1876. & 2479 . & $3 \cup 46$. \\
\hline 431. & 1478. & 1997 & 2443. \\
\hline 814. & 1259. & 1689. & 2143. \\
\hline 2557 . & $\cdots \cdots$ & $\cdots \cdots$ & $\cdots \cdots$ \\
\hline 1561. & 2562. & $\cdots \cdots$ & $\cdots \cdots$ \\
\hline $1|6|$. & 1890 & 2569. & 3211. \\
\hline 951. & 1518. & 2059 . & $256 \mathrm{~J}$. \\
\hline 825. & 1283. & 1731. & 2163. \\
\hline 1764 & $\cdots \cdots$ & $\cdots \cdots$ & $\cdots \cdots$ \\
\hline 1168. & 10101 & $\cdots \cdots$ & $\ldots \ldots$ \\
\hline 896. & 1248 & 1558. & 1856. \\
\hline 789. & $1 \cup 65$ & 1308. & 1538. \\
\hline 723. & 454. & 1155. & 1343. \\
\hline
\end{tabular}


Table ${ }^{A-5}$ (continued)

$2 \mathrm{ft} x \quad 1 / 2$ in three ply polyester 4FT $X$ I/ZIM TIIRTE PLY PULYESTER OF $X 1 / 21 N$ THKEE PLY PULYESTER AF $T$ I/ZIN THKLE PLY PULYESTER IUF $T$ I/ZIN IHREE PLY POLYESTER IFT $\times 1 / 2 I N$ HISHRKOHYLENE 4F $\mathrm{F} \times 1 / 2111$ POLYPROPYLENF 6H $1 \times 1 / 211$ POLYPROPYLENE HF $T$ X 1/2IN PULYPROPYLEHF ILFI $X I / 2 I N$ POL YPROPYLENE

2H T X 5/RIH ROLYPROPYLLNF. 4F $1 \times$ S/RIN POLYPHOPYLENE OF $T$ S/AIN PILYPRIIPYLENE BI $T$ S $X$ /BIN PULYPEOIPLLNE IUF $T$ G/BIN POLYPROPYLENI

$$
\begin{aligned}
& 2+T \times 3 / 4 I N \text { MANILA } \\
& 4+1 \times 3 / 41 N \text { MANILA } \\
& \text { 6H } \mathrm{T} \times 3 / 4 I N \text { MANILA } \\
& \text { BH } \mathrm{T} \times 3 / 4 I N \text { MANILA } \\
& \text { IUF } \times 3 / 4 I N \text { MANILA }
\end{aligned}
$$

\begin{tabular}{|c|c|c|c|}
\hline 3289 & 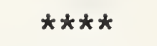 & $\star * * * * *$ & 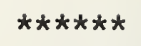 \\
\hline 2164. & 3387 . & $\ldots \ldots$ & $\cdots$ \\
\hline $17110^{\circ}$ & 2615 & 3420 . & 4103. \\
\hline 1457. & 2192 & 2848 . & • כد4د \\
\hline 1292. & 1914. & 2472 & $299 \mathrm{~J}$ \\
\hline 2831. & $\cdots \cdots$ & $\cdots \cdots$ & $\cdots \cdots$ \\
\hline 1884. & 2715 & $\cdots \cdots$ & $\ldots \ldots$ \\
\hline 1509. & 2155 & 2676 . & 3110. \\
\hline 1295. & 1835 & 2278 . & 2030. \\
\hline 1153. & 1677 & 2009 & $\angle 348$. \\
\hline 3126. & $\cdots \cdots$ & $\cdots \cdots$ & $\cdots \cdots$ \\
\hline 2158. & 3148. & $\ldots \ldots$ & $\ldots \ldots$ \\
\hline 1746. & 2525 . & 3141. & $300<$. \\
\hline 1518. & 2164. & 2704. & 3100. \\
\hline 1358. & 1919. & 2364. & $\angle 816$. \\
\hline 3896. & $\cdots \cdots$ & $\cdots \cdots$ & $\cdots \cdots$ \\
\hline 3007. & 4748. & $\cdots \cdots$ & $\cdots \ldots$ \\
\hline 2333. & 3906. & 5099. & 6141. \\
\hline 2213. & 3389. & 4402 & $b s<4$. \\
\hline 1989. & 3039 . & 3935 . & 4727. \\
\hline
\end{tabular}


Table A-6. Summary of calculated peak impact decelerations for selected fall parameters

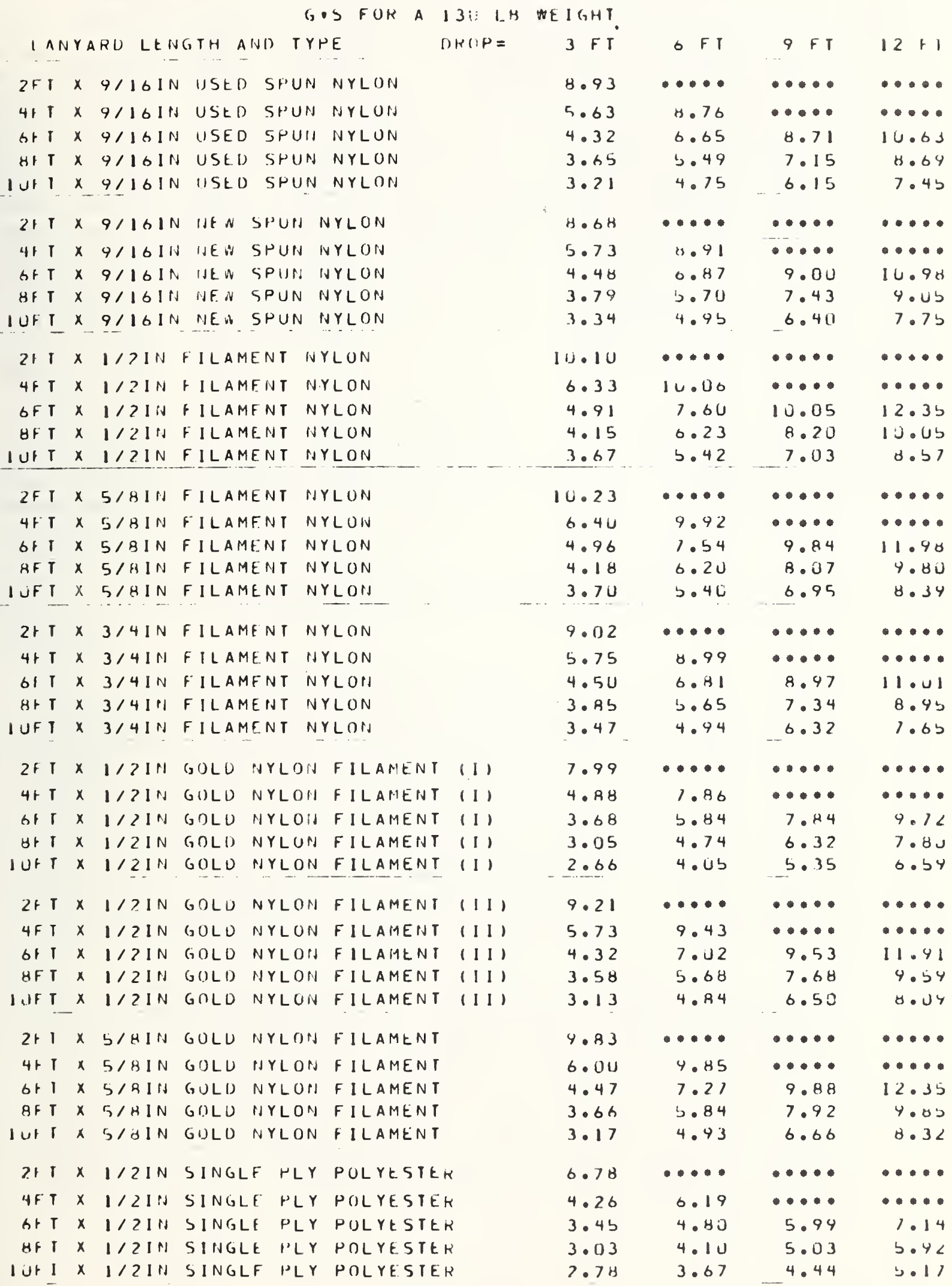


Table A-6 (Continued)

\begin{tabular}{|c|c|c|c|c|c|c|c|}
\hline${ }_{4 \mathrm{FT}}^{2 \mathrm{Ft}} \times$ & & $\begin{array}{l}1 / 2 \text { in } \\
1 / 7 \text { i } N\end{array}$ & $\begin{array}{l}\text { three ply polyester } \\
\text { THKEE PLY POLYESTER }\end{array}$ & $\begin{array}{l}12.65 \\
8.32\end{array}$ & $\begin{array}{l}\star \star \star \star \star \star ~ \\
13.03\end{array}$ &  & 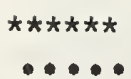 \\
\hline $6+1$ & $x$ & $1 / 21 \mathrm{~N}$ & PHKE PLY HOLYESTER & $6.5 \dot{8}$ & 10.06 & 13.15 & 16.01 \\
\hline $8+1$ & $x$ & $1 / 21 \mathrm{M}$ & THREE PLy POLYESTER & 5.60 & 0.43 & 10.95 & 13.24 \\
\hline $10+1$ & $x$ & $1 / 21 \mathrm{~N}$ & TWKEE PLY PULYESTEK & 4.97 & 7.36 & 9.51 & נد' 111 \\
\hline $2 \mathrm{~F} \mathrm{~T}$ & $x$ & $1 / 2111$ & PULYPPOHYLENE & 10.89 & $\bullet \bullet \bullet$ & $\cdots \cdots$ & $\cdots \cdots$ \\
\hline $41 \mathrm{~T}$ & $x$ & $1 / 2111$ & PIILYPKOPYLENE. & $7 \cdot 25$ & 10.44 & $\cdots \cdots$ & $\ldots \ldots$ \\
\hline $6+1$ & $x$ & $1 / 21 \mathrm{~N}$ & POLYPROPYLENE & 5.80 & 8.29 & 16.29 & 11.90 \\
\hline HF T & $x$ & $1 / 211$ & PIILYPROHYLENE & $4.9 H$ & 7.06 & 8.76 & 10.22 \\
\hline lut $r$ & $x$ & $1 / 21 \mathrm{~N}$ & POLYPKOHYLENE & 4.43 & 6.26 & 7.73 & y.us \\
\hline $2+1$ & $x$ & $5 / 31 N$ & PULYPRUPYI.ENE & 12.02 & $\cdots \cdots$ & $\cdots \cdots$ & $\cdots \cdots$ \\
\hline $4+1$ & $x$ & $5 / 8111$ & PILLYPROPYLENE & $8 \cdot 3 v$ & 12.11 & $\cdots \cdots$ & $\cdots \cdots$ \\
\hline $6+1$ & $x$ & $5 / H \backslash N$ & PULYPROPYLLNL & 6.72 & 4.71 & 12.08 & 14.10 \\
\hline Hit 1 & $x$ & $5 / H I N$ & POLYPROPYLENE & $5 \cdot 84$ & 8.32 & 10.40 & 12.15 \\
\hline $10+1$ & $x$ & $5 / 41 N$ & POLYPROPYLENE & 5.22 & 7.38 & 9.17 & 10.83 \\
\hline $2+1$ & $x$ & $3 / 41 N$ & MANILA & 14.98 & $\cdots \cdots$ & $\cdots \cdots$ & $\cdots \cdots$ \\
\hline $4 \mathrm{Fr}$ & $x$ & $3 / 41 N$ & MANILA & 11.57 & 18.26 & $\cdots \cdots$ & $\cdots \cdots$ \\
\hline hF 1 & $x$ & $3 / 41 N$ & MANILA & 9.74 & 15.02 & 19.61 & $\angle 3 . \forall s$ \\
\hline$B F T$ & $x$ & $3 / 41 \mathrm{~N}$ & MANILA & R. 51 & $13 \cdot 43$ & 16.93 & $2 u \cdot 5 u$ \\
\hline 1011 & $x$ & $3 / 41 \mathrm{~N}$ & MANILA & 7.65 & 11.69 & 15.13 & 18.10 \\
\hline
\end{tabular}


For simplicity in presentation and conveniences of use, these ciata are presented in terms of peak force and acceleration as a function of lanyard type, mass of test weight or worker, and ratio of free fall distance to lanyard length $(\mathrm{h} / \mathrm{L})$. These data are presented in Tables $\mathrm{A}-7$ and $\mathrm{A}-$ 8. The peak acceleration values for the extreme values of worker weight, $59 \mathrm{~kg}(130 \mathrm{lb})$ and $113 \mathrm{~kg} \mathrm{(250} \mathrm{lb),} \mathrm{are}$ plotted in Figures A-15 (a through $\mathrm{m}$ ). It will be noted that in nearly all cases the points are reasonably represented by a straight line function of acceleration as a function of the ratio $\mathrm{h} / \mathrm{L}$. The data presented are representative of lanyard length of 0.6 to $3 \mathrm{~m}$ (2 to 10 ft) and free fall distance of 0.9 to $3.7 \mathrm{~m}$ ( 3 to $12 \mathrm{ft}$ ).

\section{A.4.3 Model Validation and Comparison with Other Results}

Attempts were made to validate our static-to-dynamic impact parameter-prediction model. Steps (1) through (4) below represent checks of the basic L/E data obtained and the general methodology by which the data were converted to polynomial coefficients and then to arrested fall impact predictions. Steps (5) and (6) represent comparison of our impact parameter predictions (based on static L/E data) with actual, dynamic drop test results performed on similar equipment.

(1) Relative L/E data calculated from our L/E data for pure rope sections of lanyards were compared to industrial and research generated data on similar type ropes. Some such comparisons are shown in Figure A-16. The comparisons are considered to be generally satisfactory (i.e., not indicating serious disagreements), considering the high variability in rope behavior--a fact verified in our experimental program. Some observed differences may be due to variations between the project method for measuring and the methods used by others.

(2) Another check of our output was made as follows. The energy involved in a fall begins as potential energy, PE, which is measured from the point at which free fall begins to the point at which the test weight bottoms out and starts back up again. For a mass, M, and a fall distance, $h, P E=M g h$. Now $\mathrm{PE}$ so calculated is equivalent to the area under an $\mathrm{L} / \mathrm{E}$ curve from zero up to the peak impact force, Fpeak. Thus the area under an $L / E$ curve up to the peak impact force 


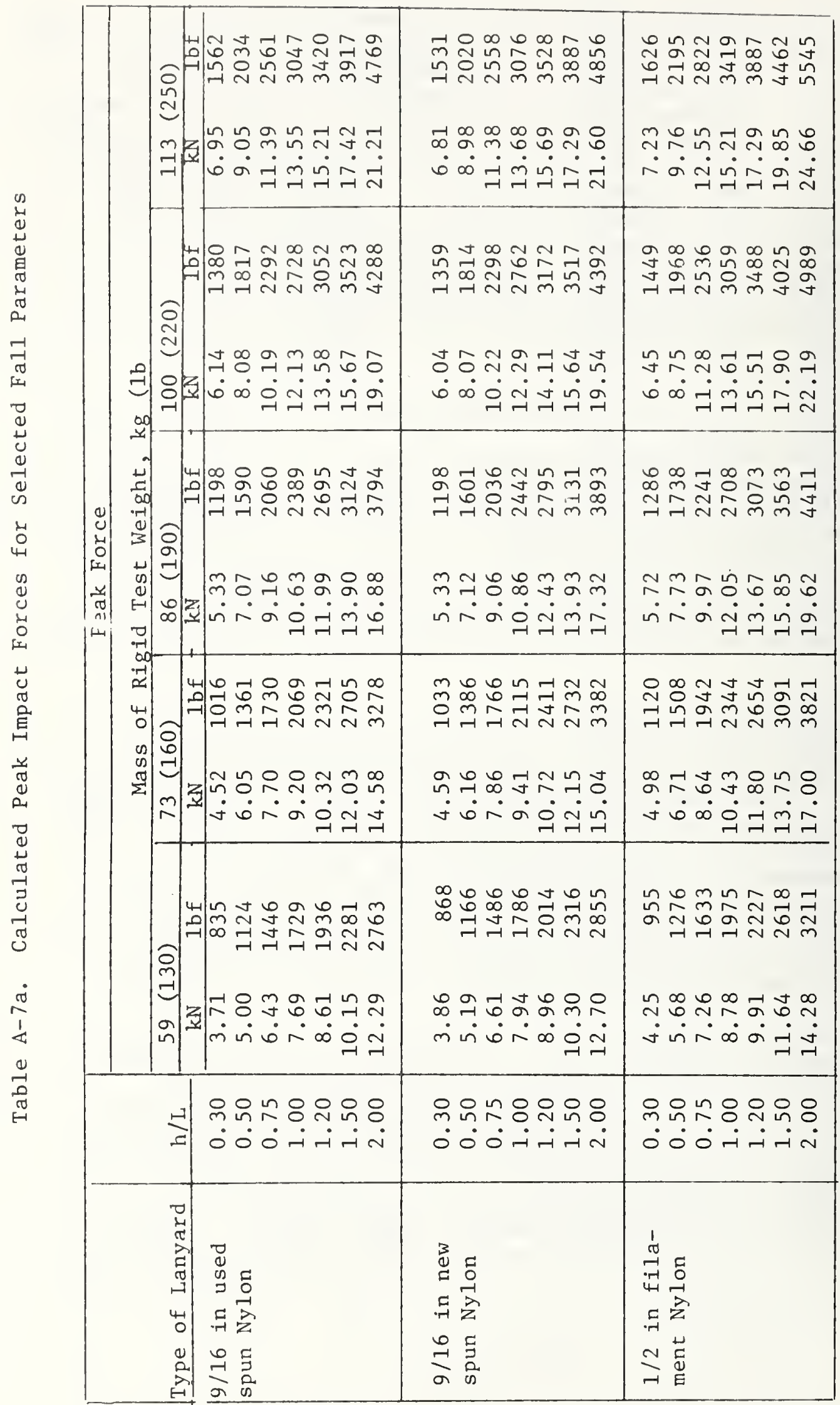









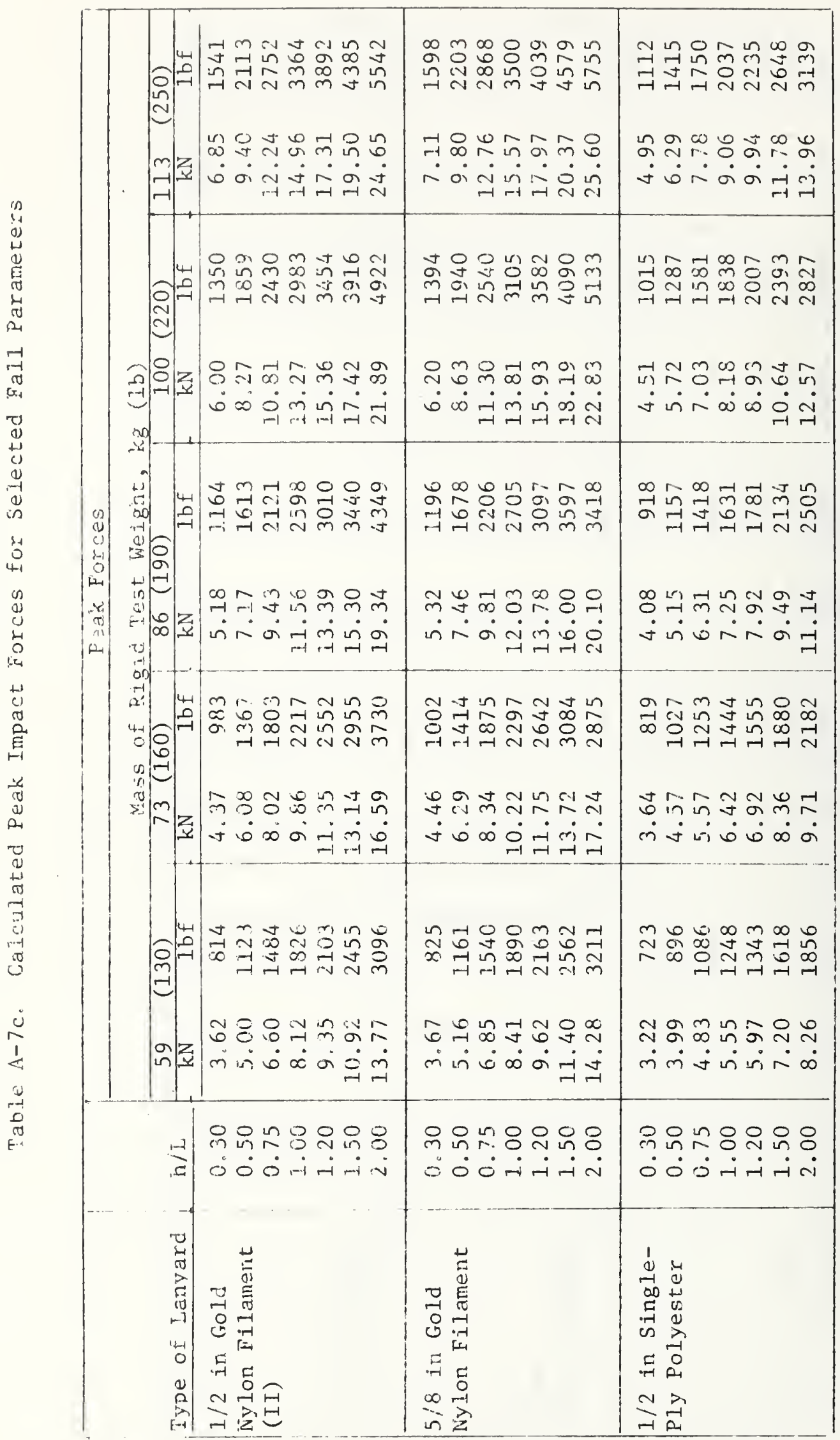














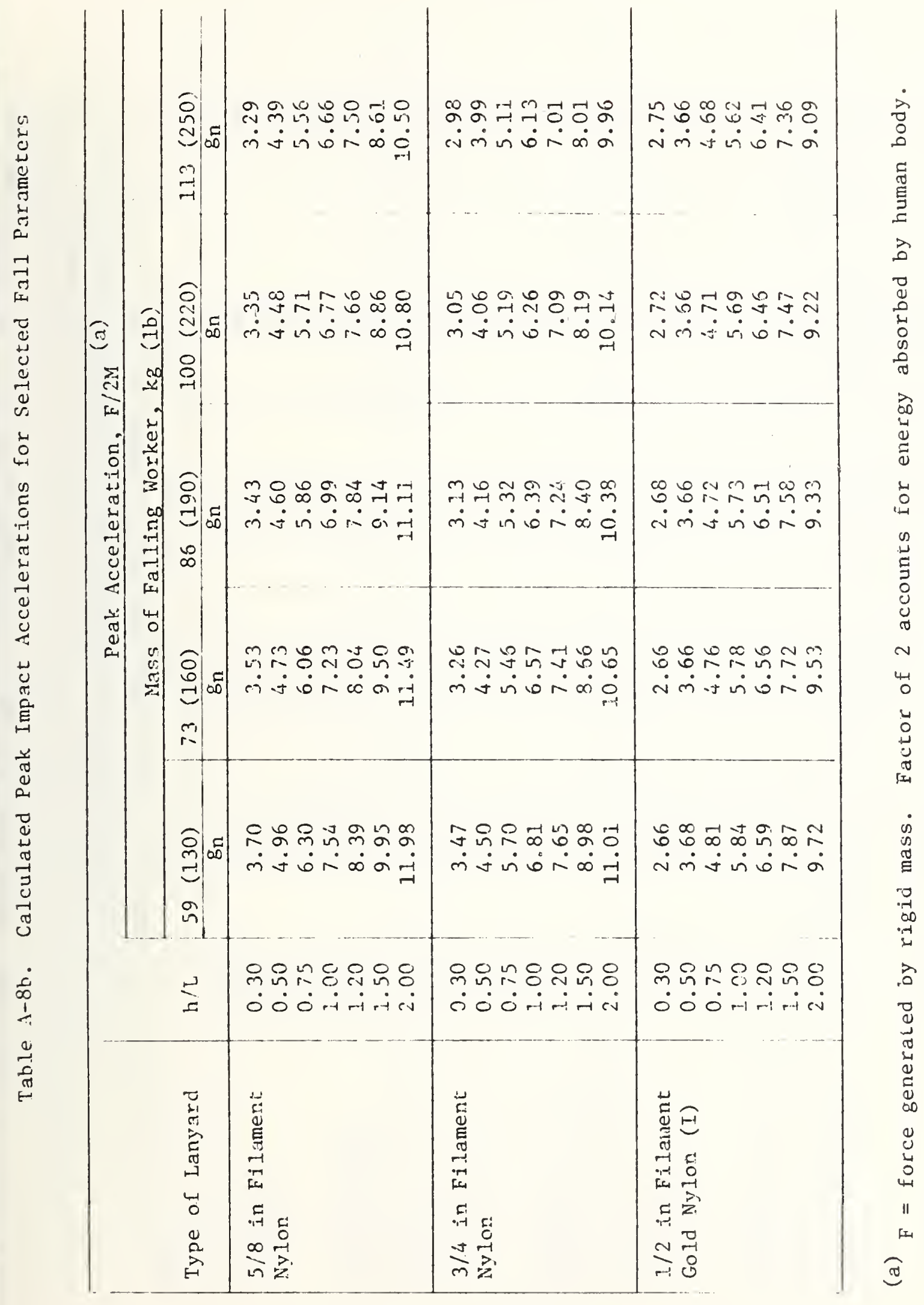




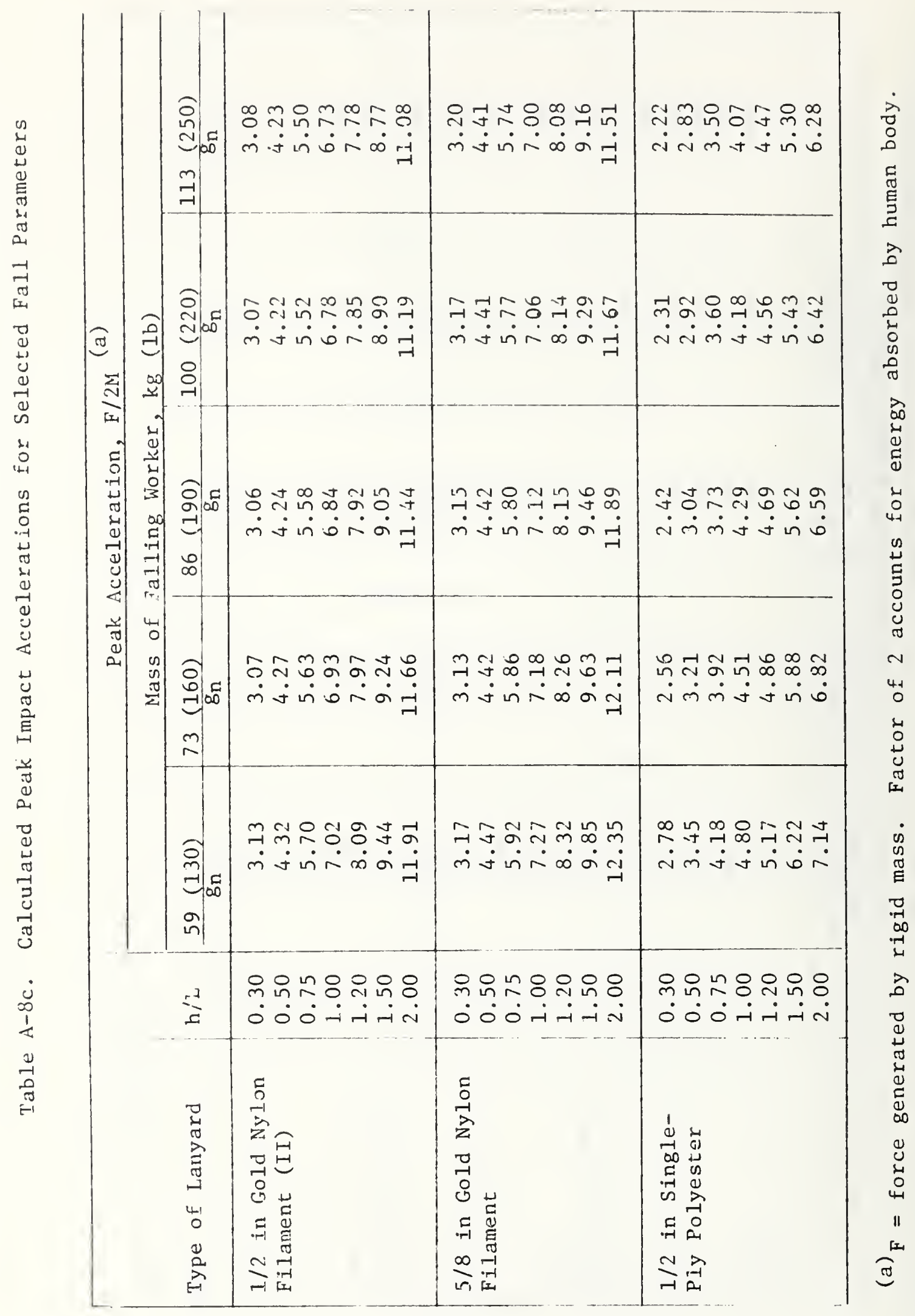




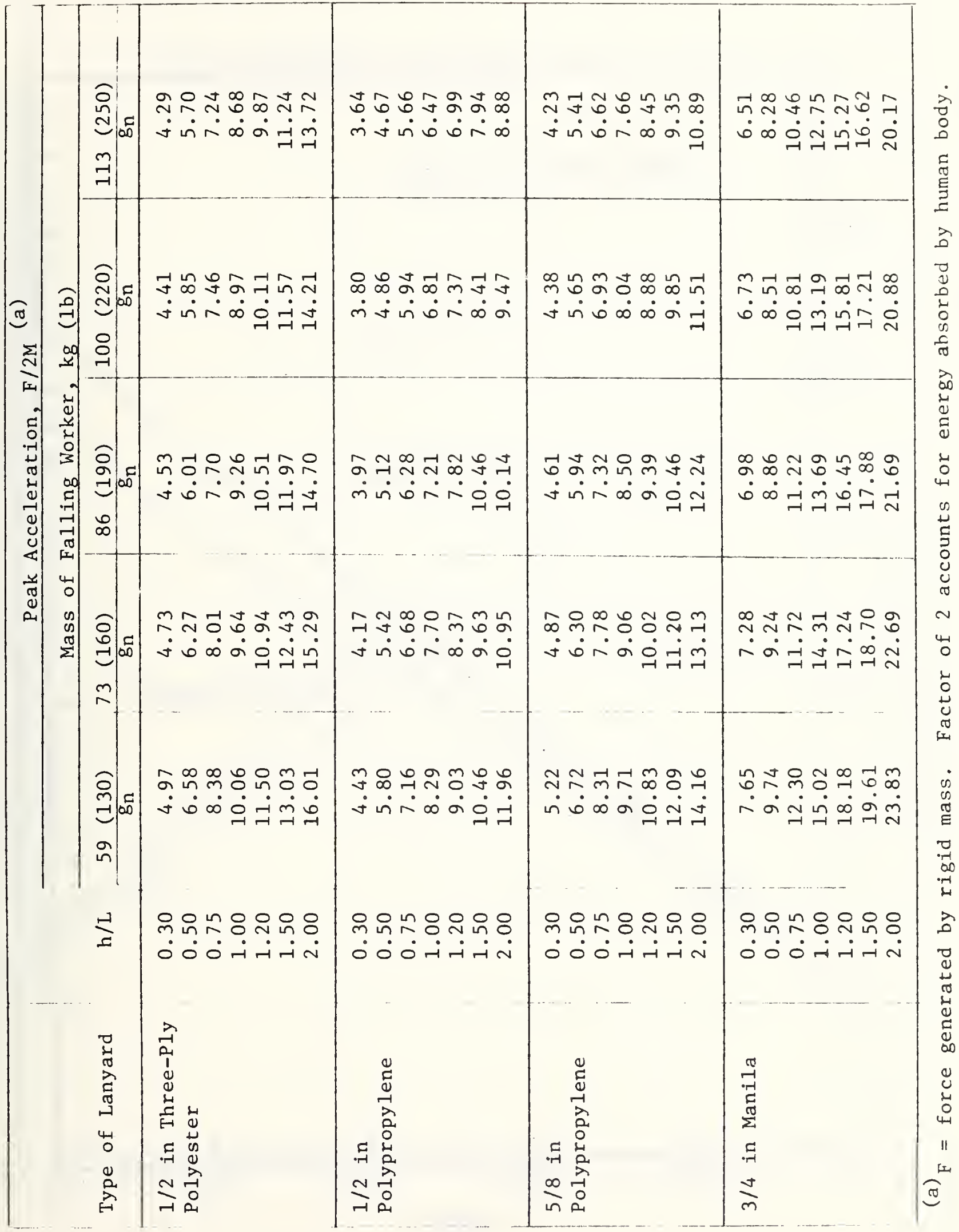


Figures Al5a-m. Calculated Peak Impact Acceleration as a Function of the Ratio of Free Fall Distance, $h$, to Lanyard Length, L.

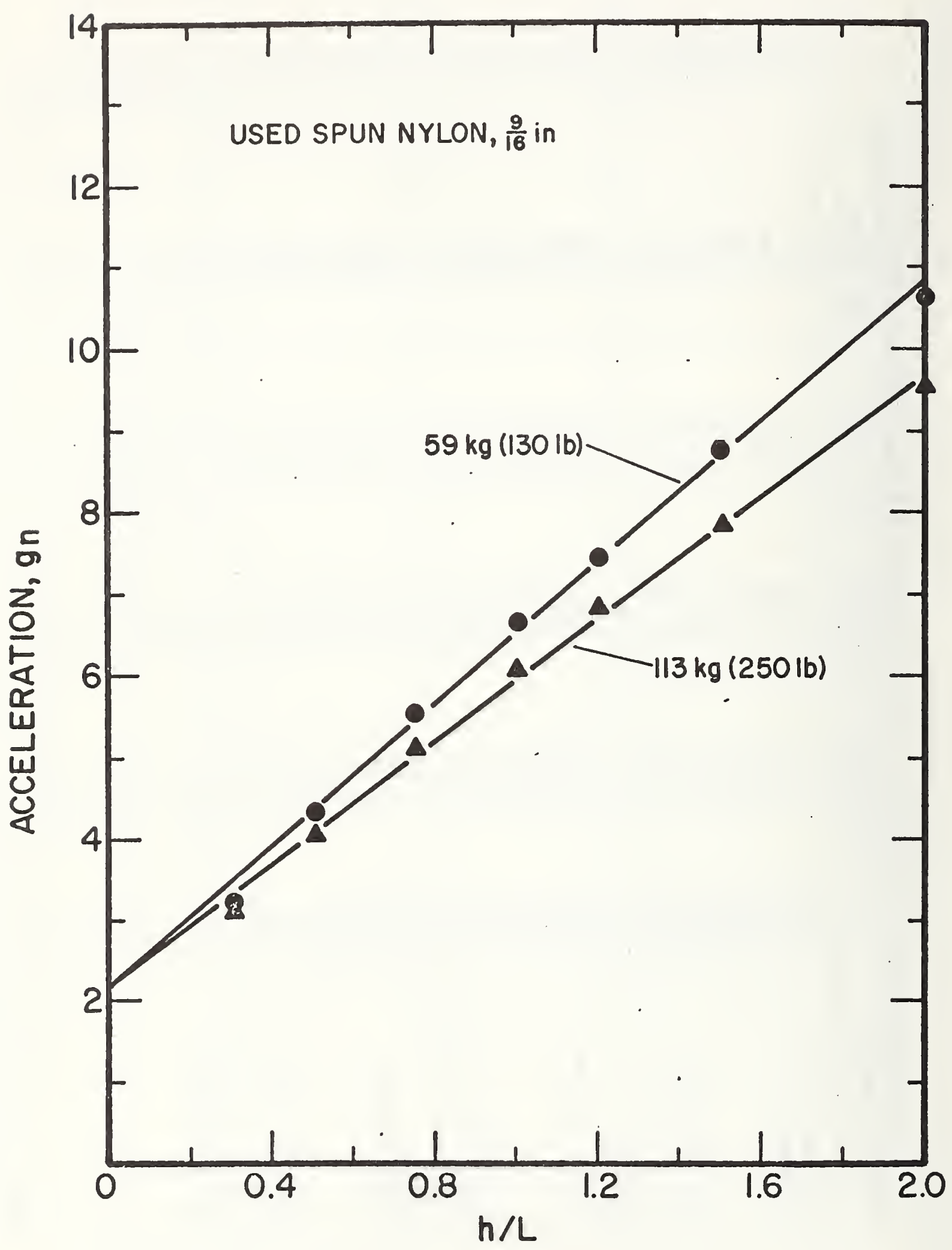

Figure $\mathrm{A}-15 \mathrm{a}$

A -50 


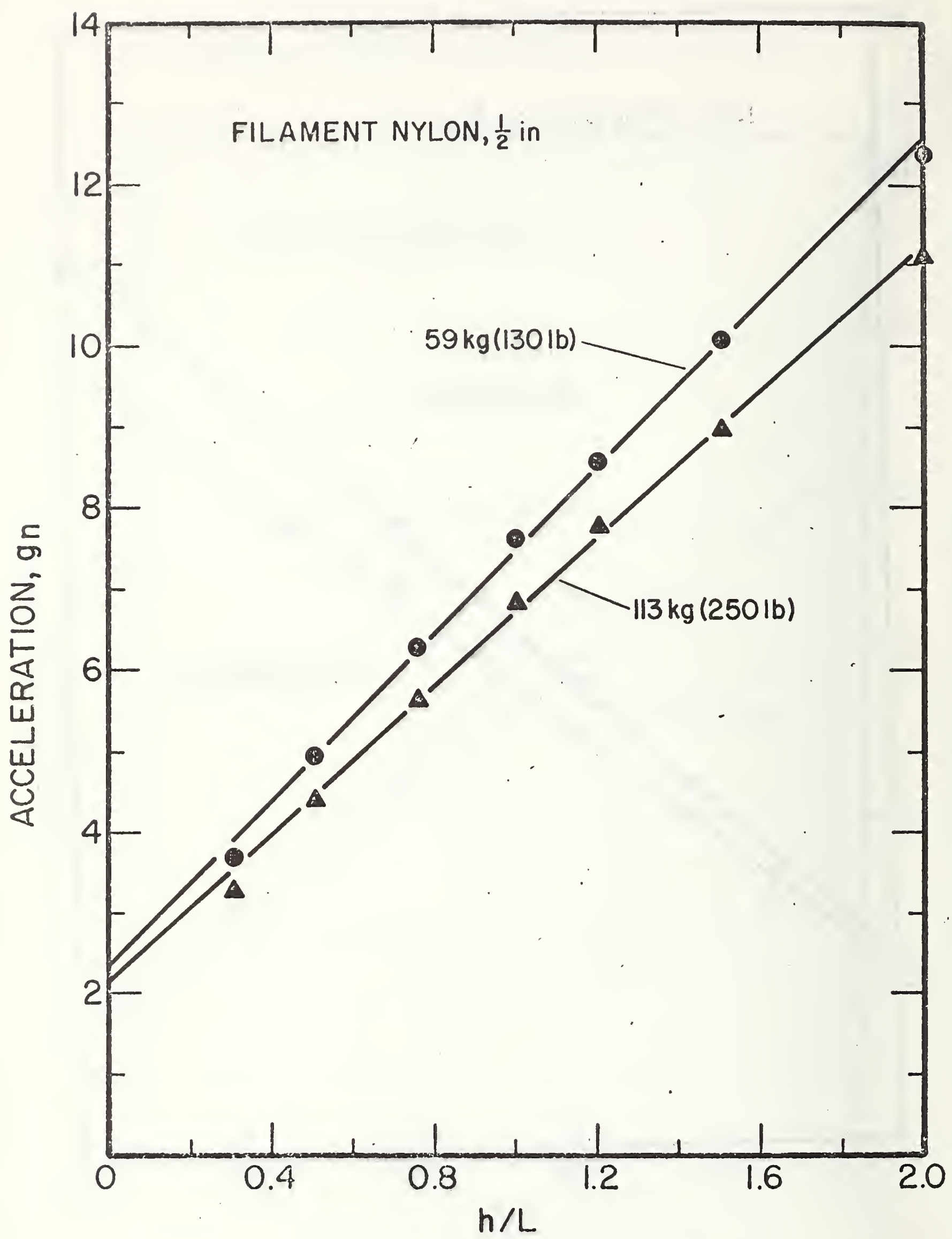

Figure $A-15 c$ 


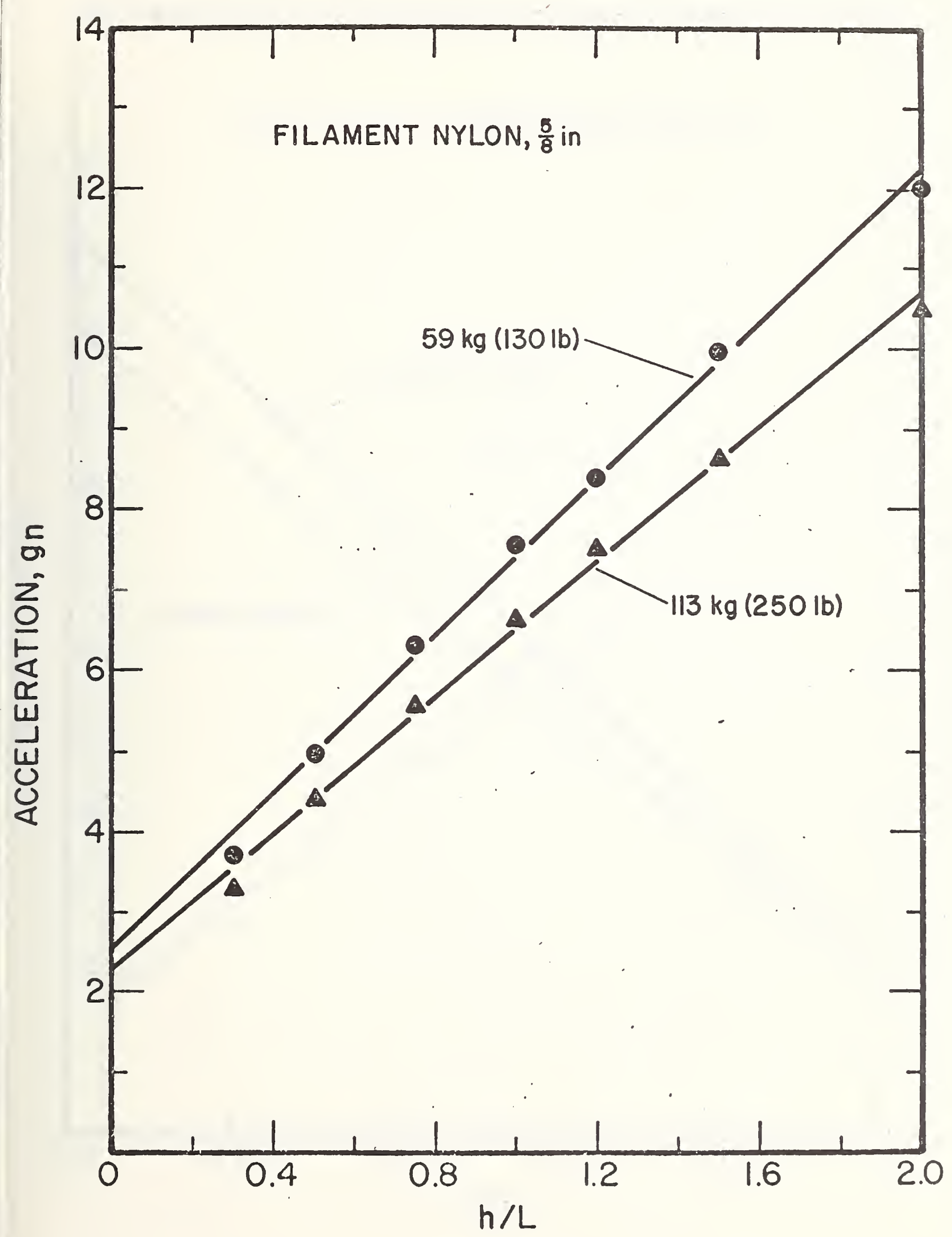

Figure A-15d

$$
\text { A }-53
$$




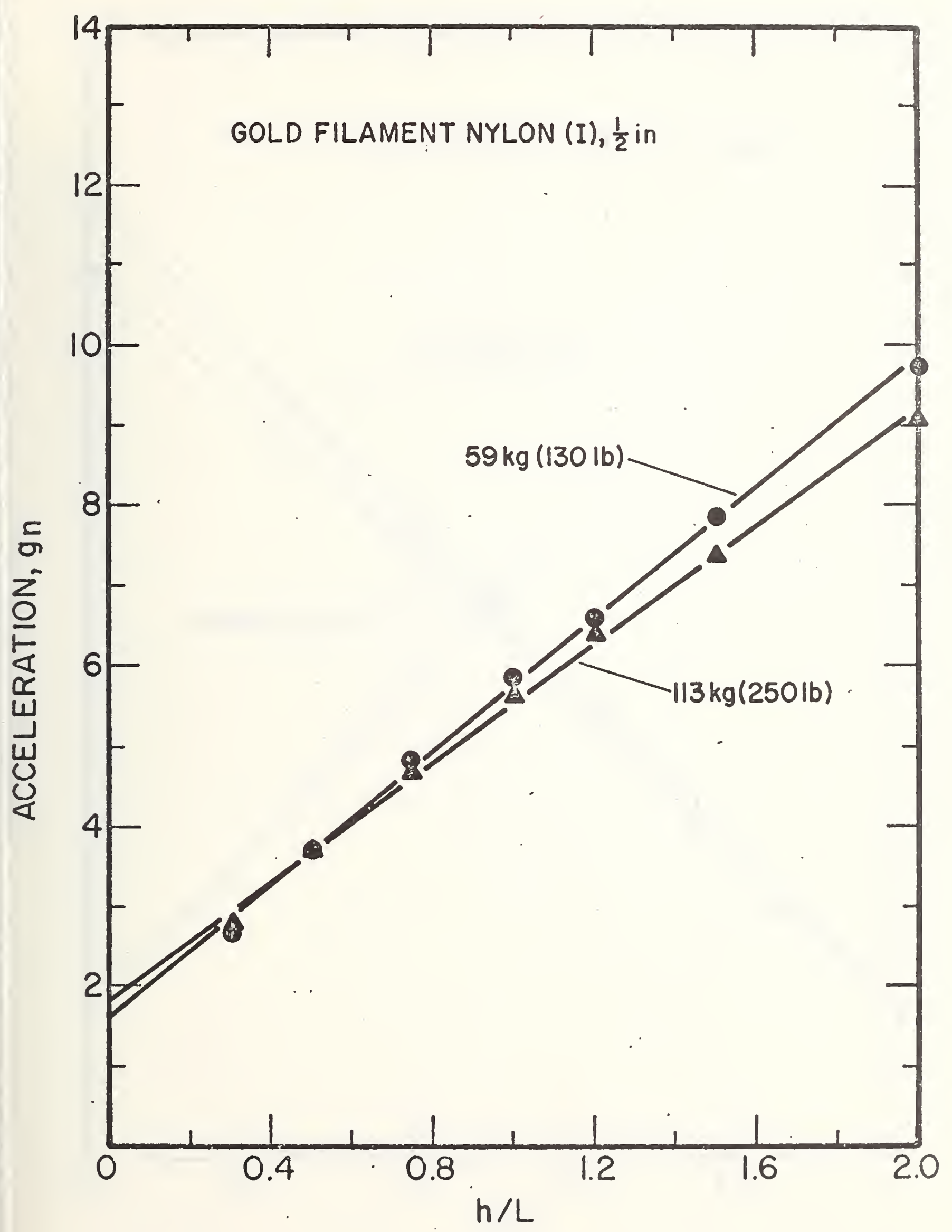

Figure $A-15 f$ 


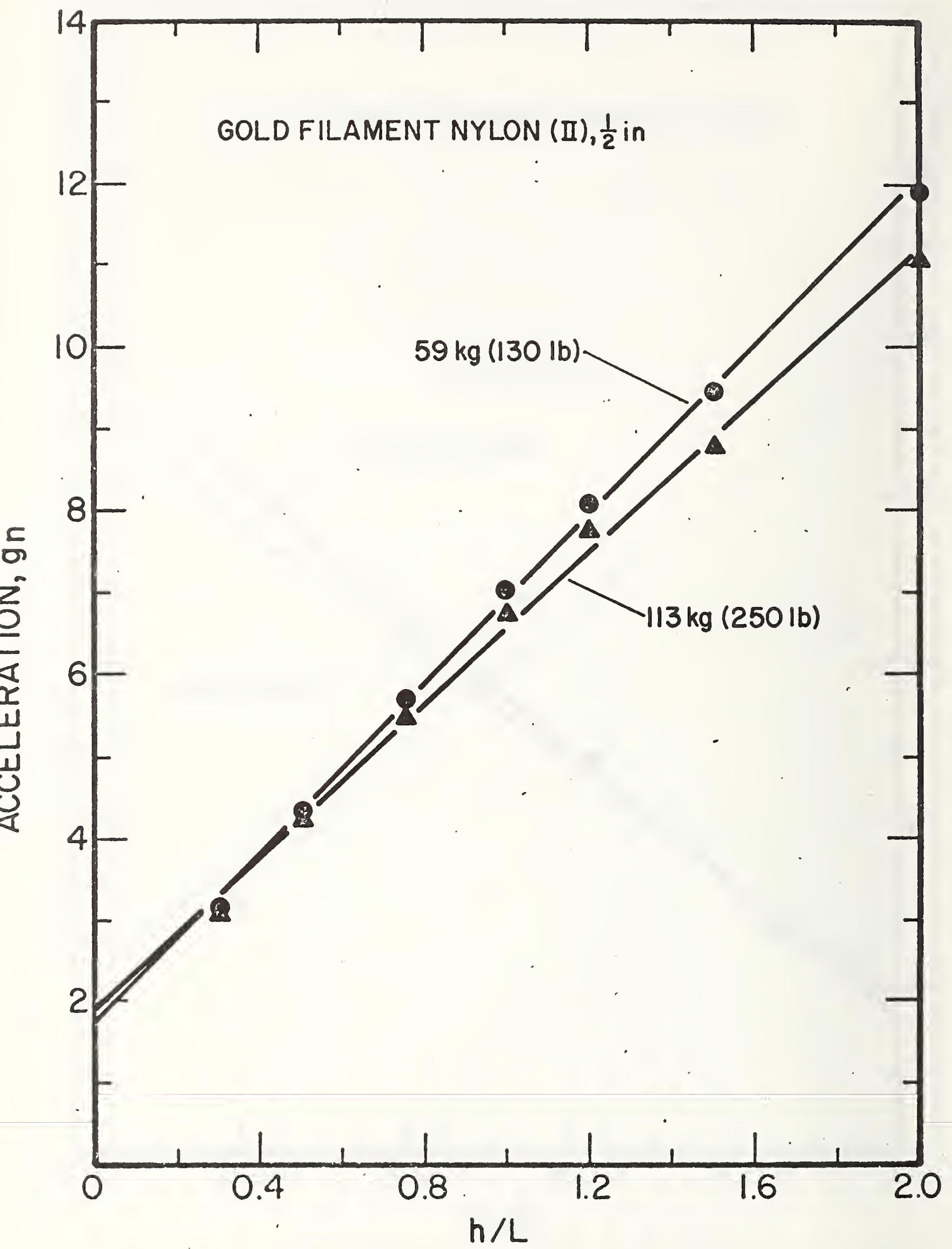

Figure $A-15 g$ 


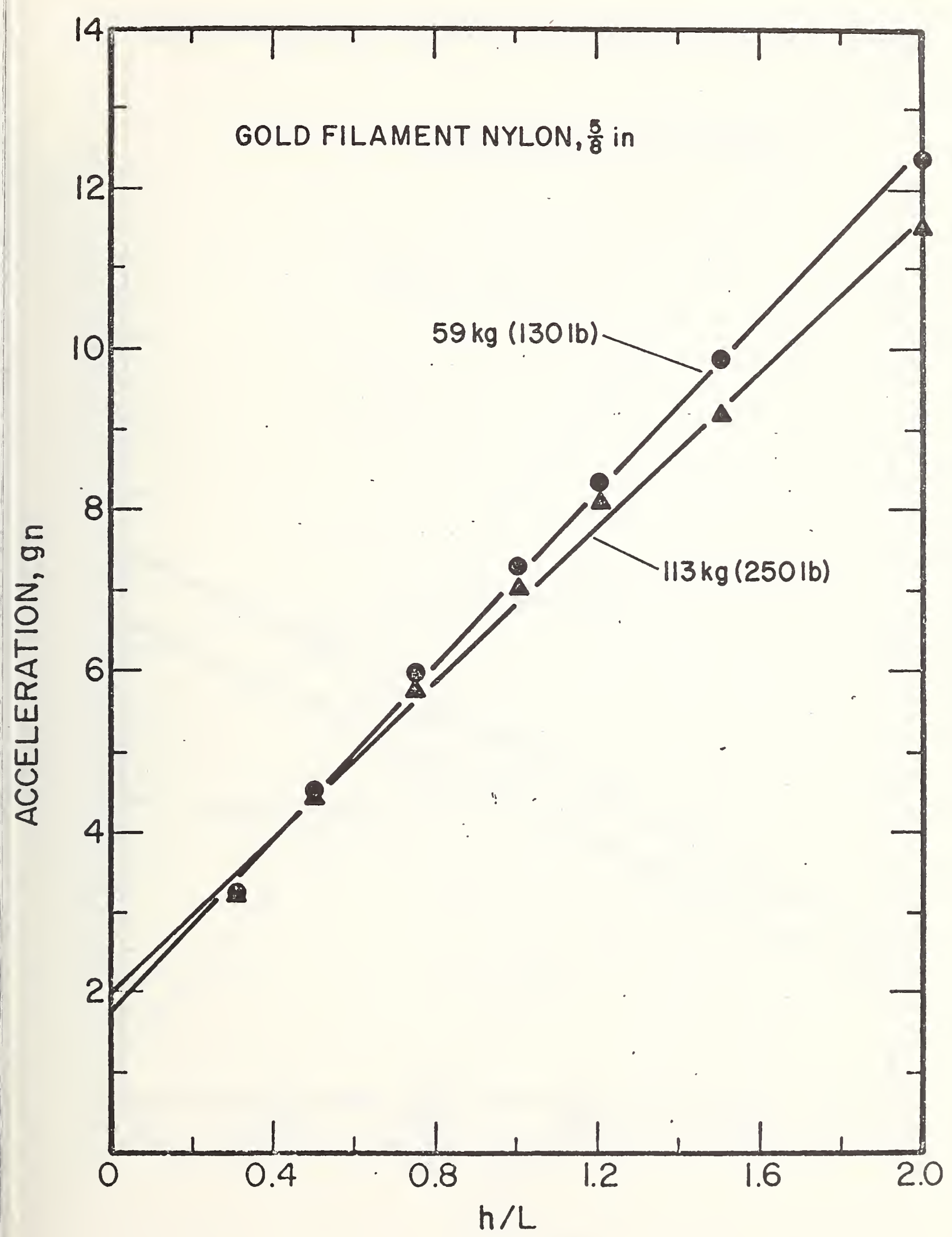

Figure $A-1.5 h$ 


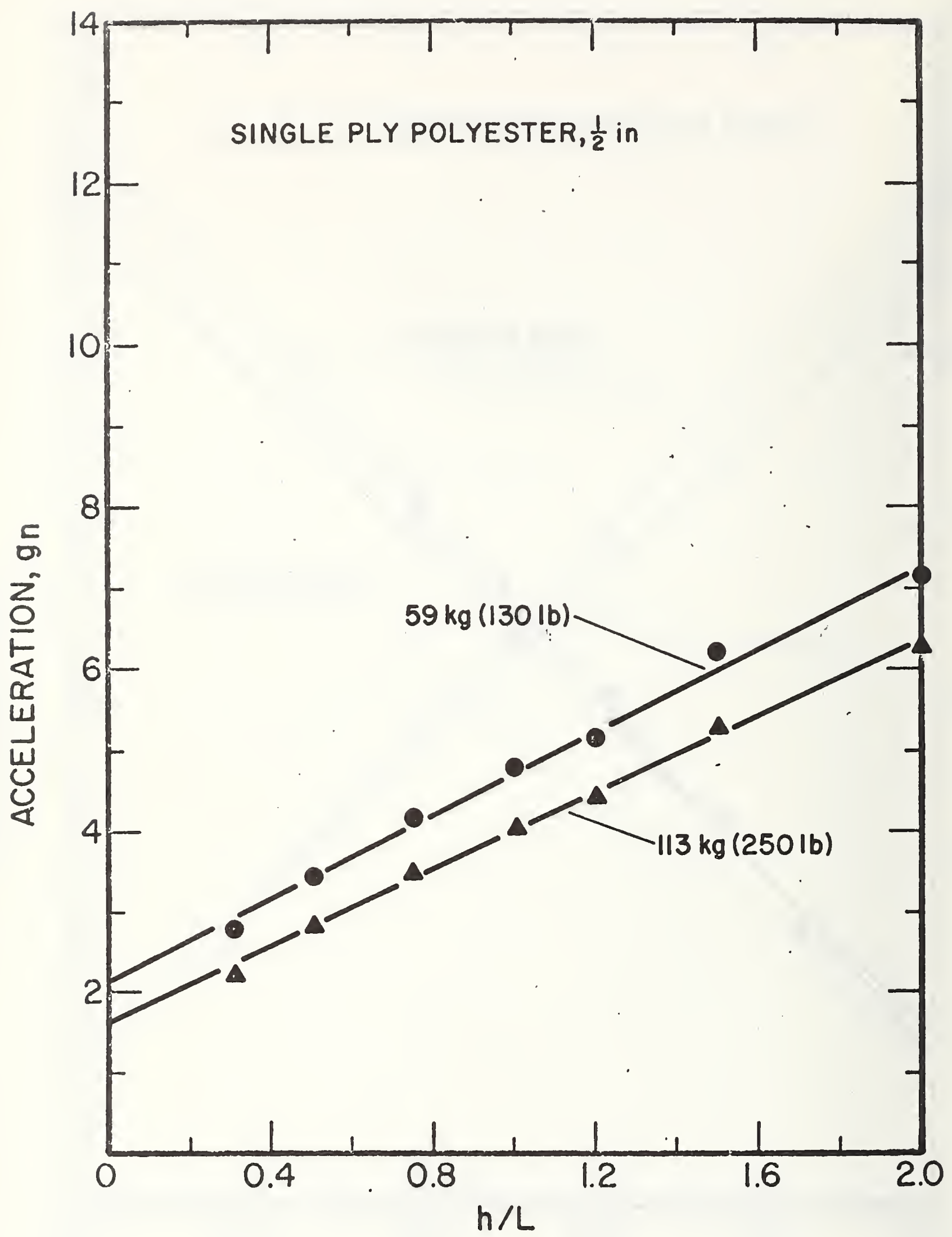

Figure $A-15 i$ 


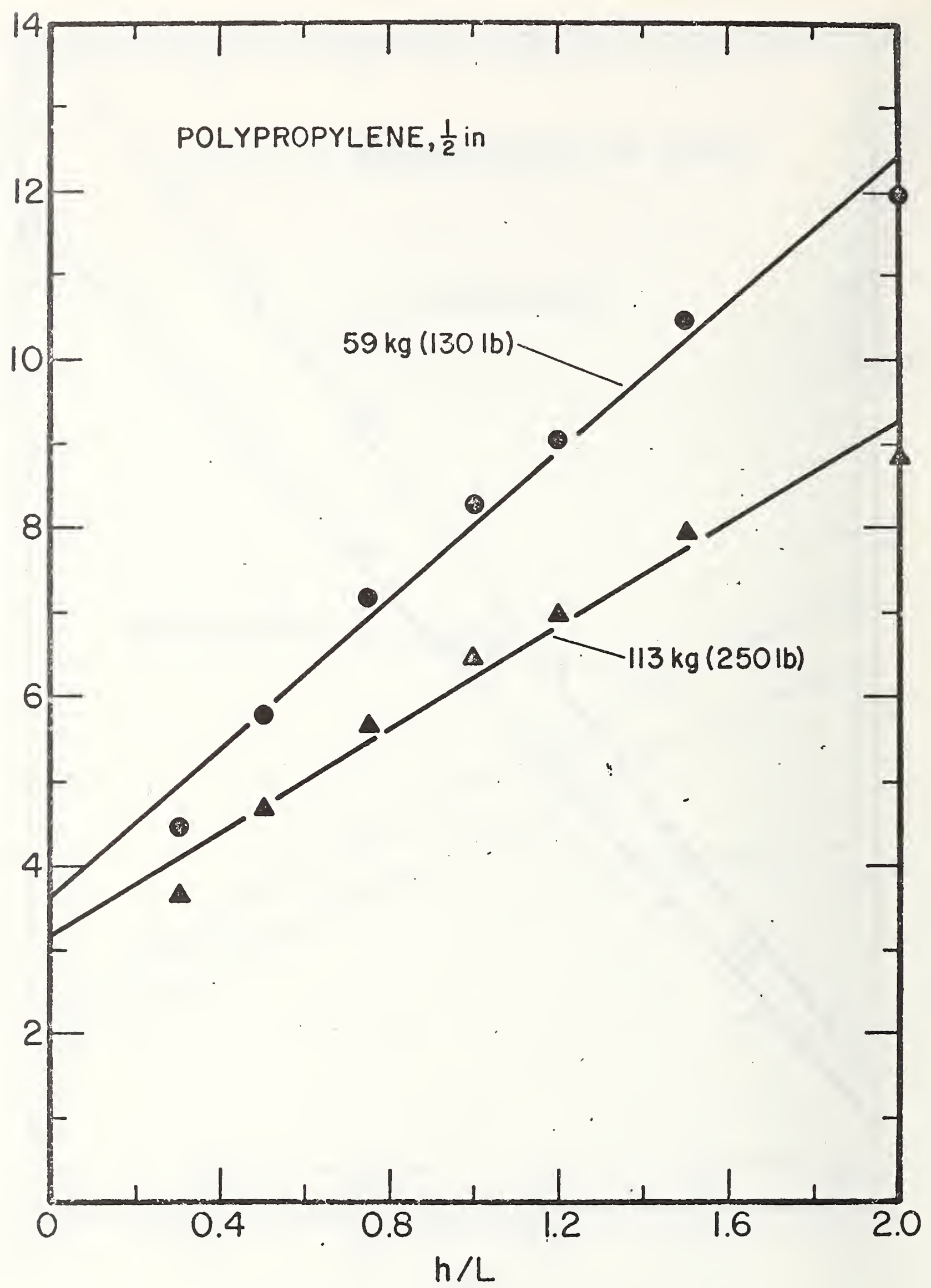

Figure $A-15 k$ 


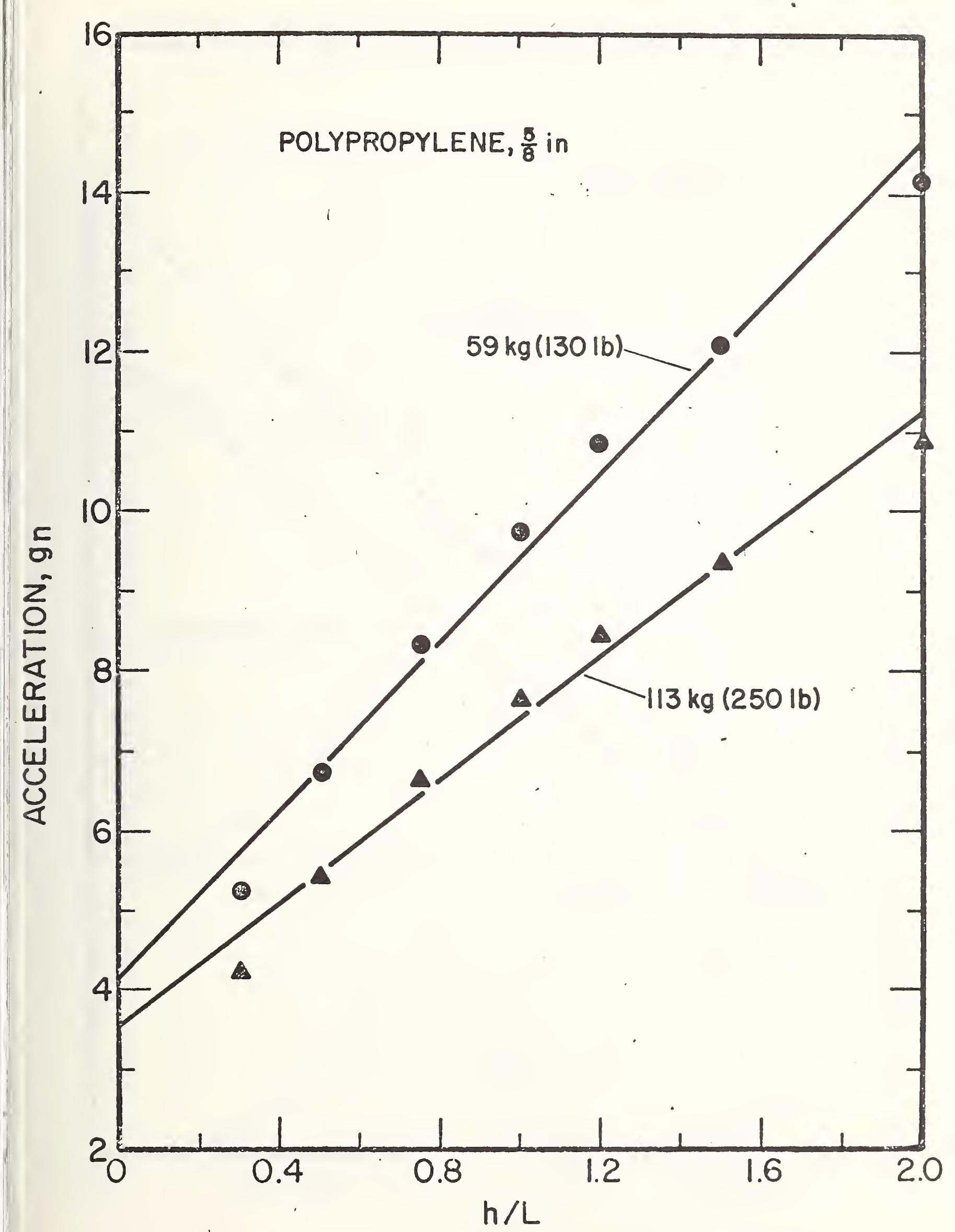

Figure A-i5(1) 


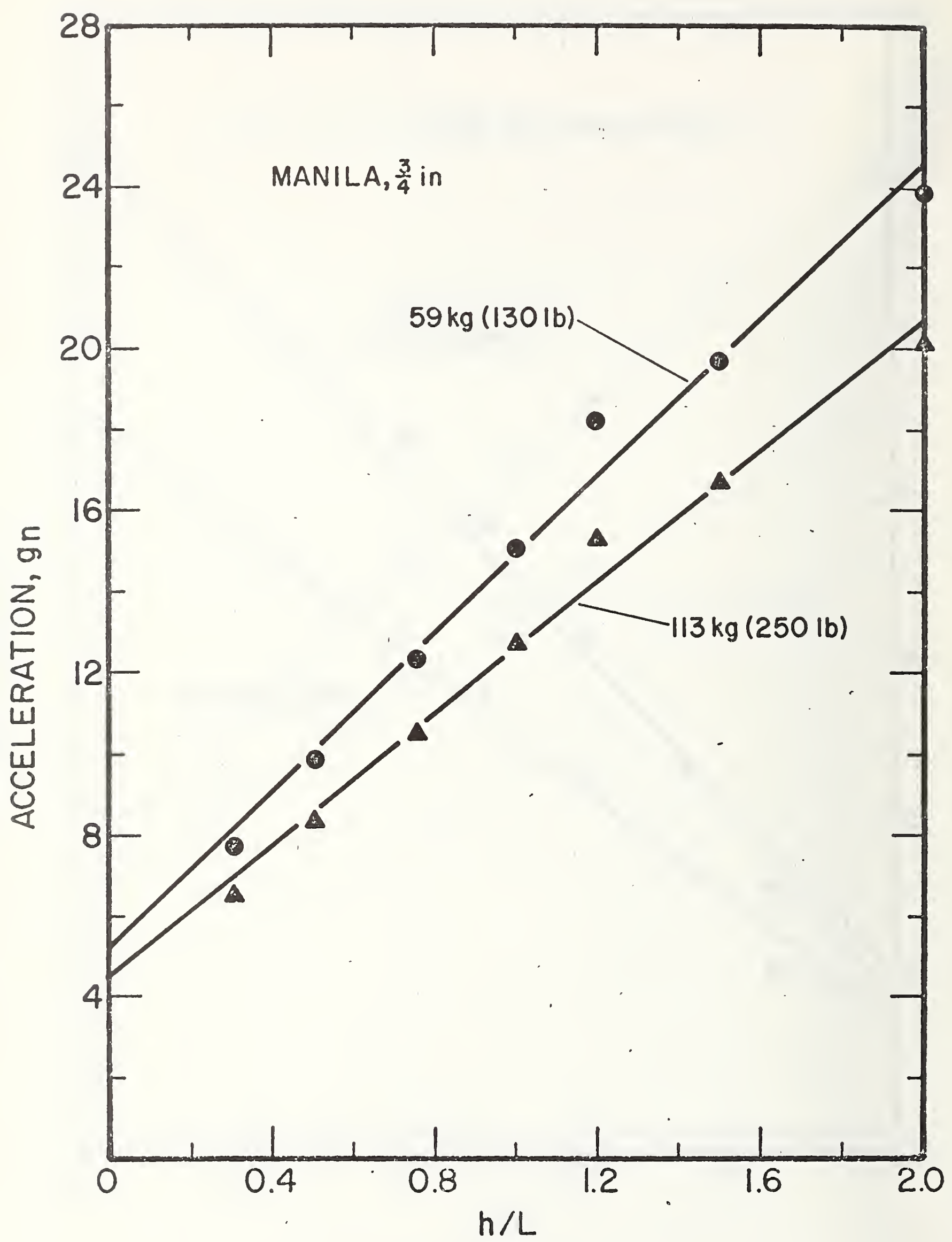

Figure $A-15 m$ 

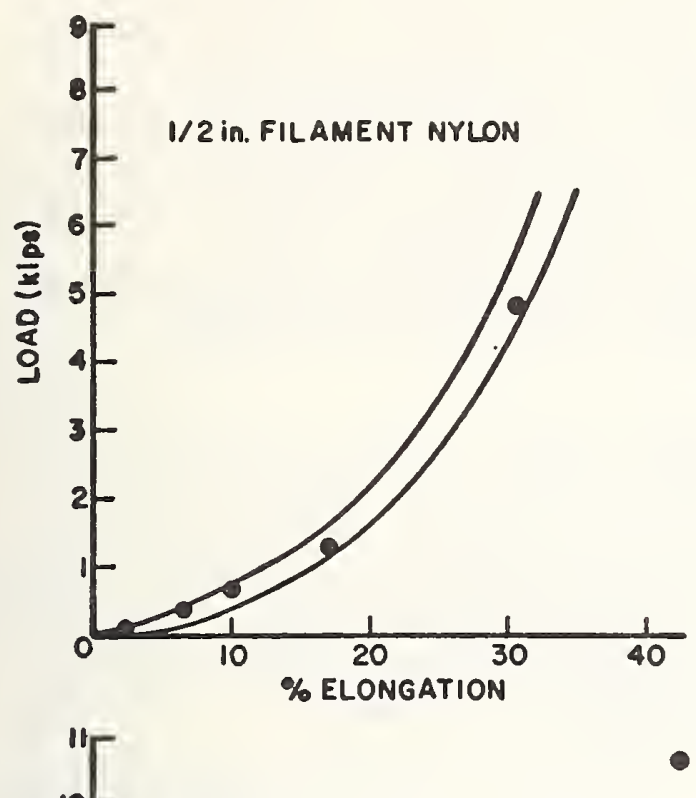

$3 / 4$ in. FILAMENT NYLON
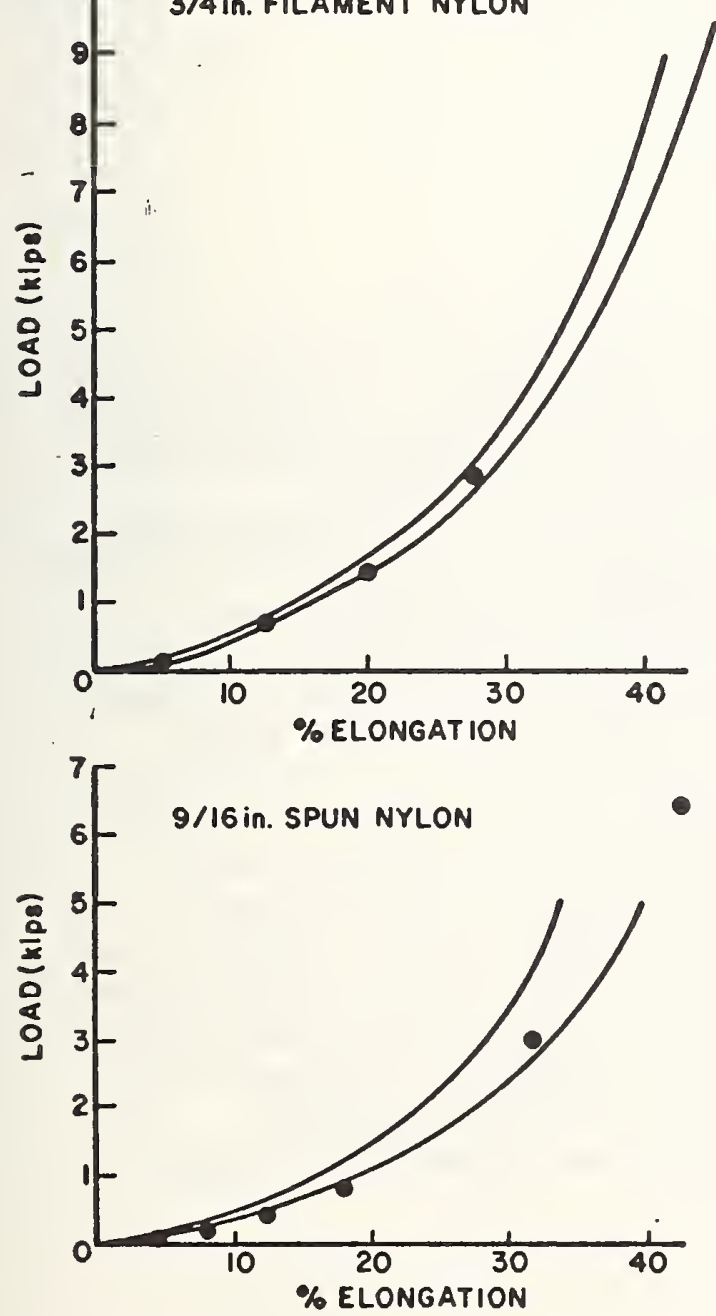
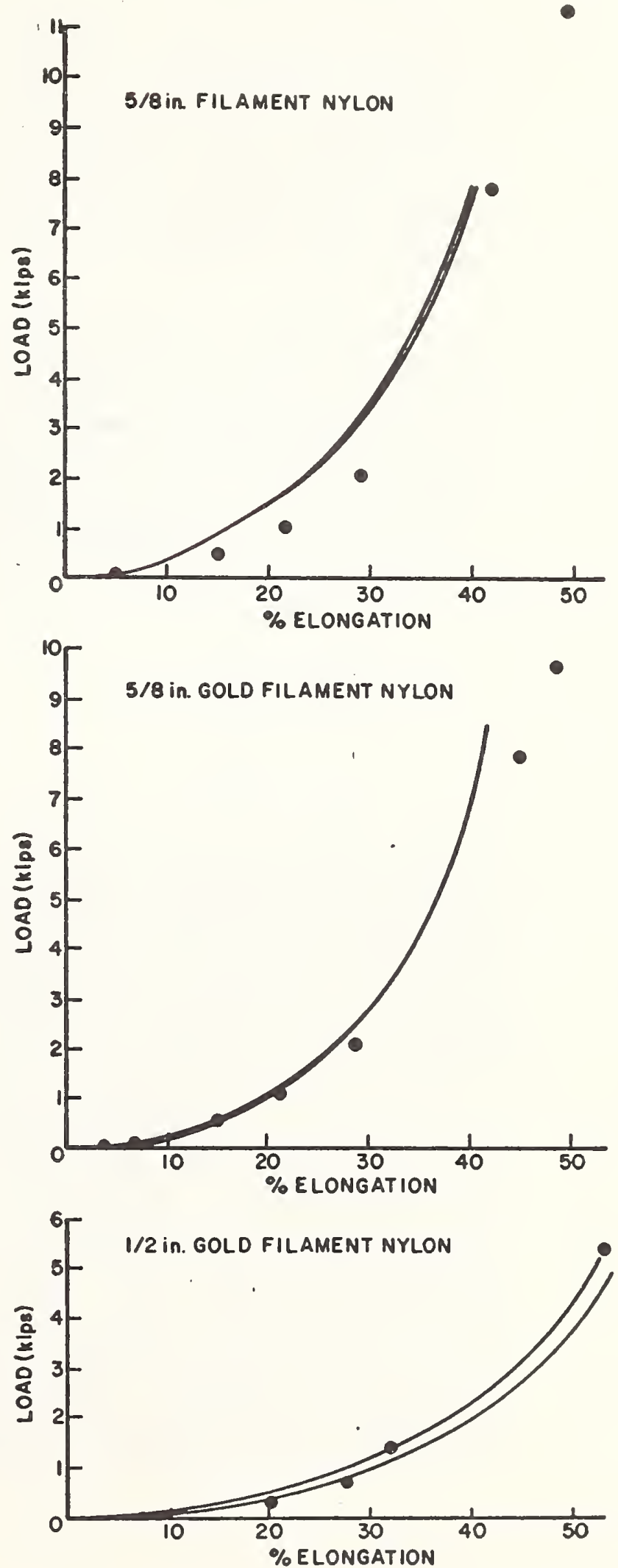

Figure A-16. Comparison of Test Results with Cordage Institute L/E Data 
the area under an L/E curve up to the peak impact force should be identical to the quantity $M g n$ ( $h+\Delta L$ ), where $h$ is the free fall distance and $\Delta L$ is the maximum lanyard elongation. Areas under $\mathrm{L} / \mathrm{E}$ curves up to Fpeak for various type lanyards were measured by means of a planimeter. This comparison, as given in Table A-9, is quite favorable. However, it merely checks the internal consistency of our model/analysis and does not confer any validity on our basic static-to-dynamic assumption.

(3) Another internal type check that was made was to test our entire analysis process using an imaginary spring that obeyed Hooke's law. A spring constant of 12500 lbf was assumed and a straight-line load vs. relative-extension curve was drawn. Load-elongation points were visually interpolated from the curve and a third degree polynomial fit performed. Quite reasonably the coefficients of this fit were:

$$
\begin{aligned}
& k_{0}=0.00006 \\
& k_{1}=12500 \\
& k_{2}=0.0004 \\
& k_{3}=0.0008
\end{aligned}
$$

These coefficients were then input into the main program and impact forces were computed. A comparison of generated impact forces with those computed from Hooke's law is given in Table $\mathrm{A}-10$. Again the agreement, while excellent, is merely a check of the static validity of our basic model and does not purport to confer a blessing on our dynamic predictions.

(4) Observed lanyard breaking strengthis were compared to the respective strengths as given for pure ropes. This comparison is detailed in Table A-11. Although differences were expected (due to rope variability and test condition differences), these differences are generally within the inherent variabilities of the materials themselves. That commercial rope testing is done using large diameter mandrels and tapered splices (in an attempt to determine the strength of pure rope) should have produced specified strengths higher than our measured forces. That many of our measured strengths were actually greater than specified values 
Table A-9. Comparison of Absorbed Energy as Measured with a Planimeter and Calculated Using a Computerized Model (a)

\begin{tabular}{|c|rcccc|}
\hline \multirow{2}{*}{ Rigid Weight, $\mathrm{W}$} & \multicolumn{5}{|c|}{ Free fall distance, $\mathrm{h}$} \\
\hline $150 \mathrm{ft}$ & $6 \mathrm{ft}$ & $9 \mathrm{ft}$ & $12 \mathrm{ft}$ \\
200 & $10^{(\mathrm{b})}$ & 1 & $<1$ & $<1$ \\
250 & 4 & $<1$ & $<1$ & 2 \\
300 & $<1$ & $<1$ & 2 & 3 \\
350 & $<1$ & 1 & 3 & NA \\
\hline
\end{tabular}

(a) These data are for a 6 ft lanyard. The computerized model essentially uses the $\mathrm{L} / \mathrm{E}$ curve as input data.

(b) Each element in matrix represents a quantity, $100\left[\frac{\text { (Area under curve to appropriate elongation) }-\mathrm{W}(\mathrm{h}+\Delta \mathrm{L})}{\text { (Area under curve to appropriate elongation) }}\right]$ 
0
0
0
4
0

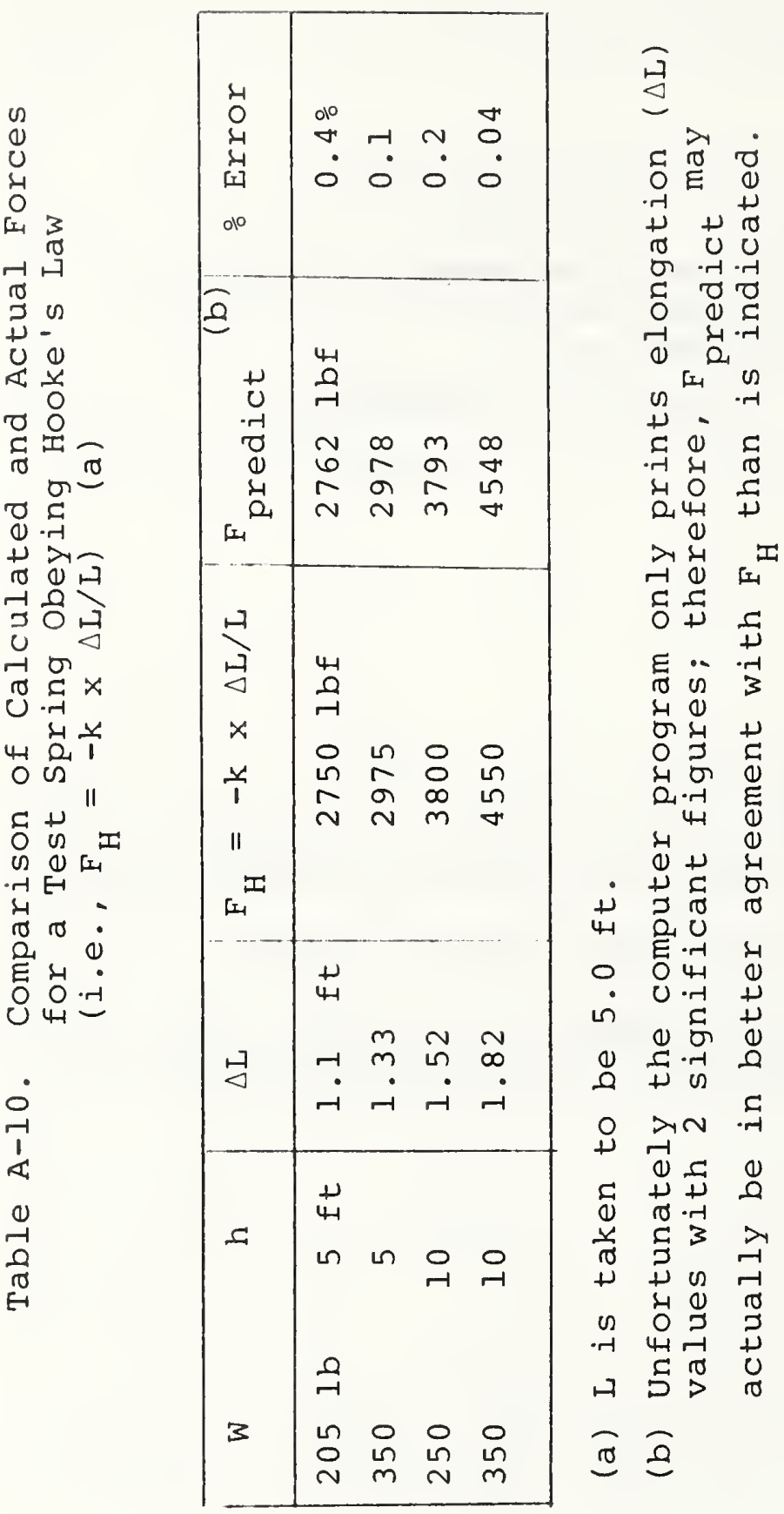




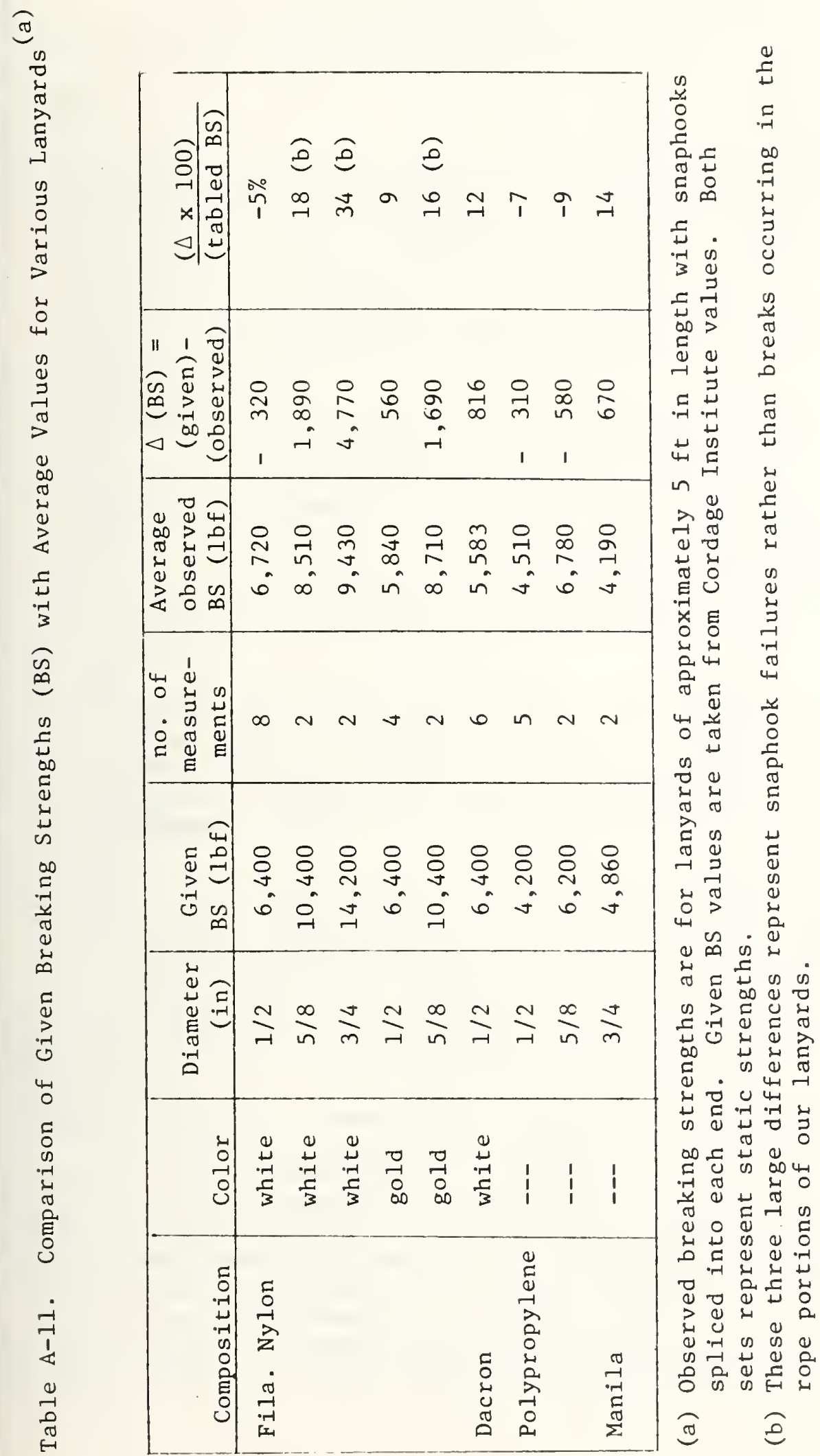


indicate that the use of small thimbles in commercial lanyaxds does not result in a significant reduction in breaking strengths. Note that our interest is in the characterization of real lanyards and not with rope strengths, per se.

(5) Several sets of dynamic drop test data, involving unused lanyards of varying lengths, were made available to us by two safety equipment manufacturers. These data included either peak impact forces or peak force oscillograph traces. Components of these data sets for which we could generate comparable data were used to check our model. These comparisons, presented in Tables $\mathrm{A}-12$ and $\mathrm{A}-13$, indicate that:

(a) Calculated peak forces for impacted lanyards are, typically, slightly higher than those generated by actual impacts and observed as oscillograph traces of load cell measurements. These differences are attributed, in part, to real sample variations, energy absorption by one or more elements in the experimental setup or to approximations and assumptions that went into the model.

(b) As is evident from Table A-13, peak duration calculations appear to give quite good comparisons with the experimental data. These durations are of use in validating the model, of course, but are also required to evaluate potential injury levels.

(c) If peak force calculations are acceptable then their counterpart peak deceleration

calculations should also be accepted. Similarly if peak forces and times are valid then lanyard elongation calculations, for which no comparable real world data were found, can also be assumed to be valid.

(6) Several impact force calculations made for $1.8 \mathrm{~m}$ ( $6 \mathrm{ft}$ ) falls of 68 and $113 \mathrm{~kg}(150$ and $250 \mathrm{lb}) \mathrm{rigid}$ weights into $1.8 \mathrm{~m}$ ( $6 \mathrm{ft}$ ) lanyards of $1 / 2$ inch nylon were compared with similar parameter calculations for lanyard-plus-belt (friction and buckle) combinations. These comparisons indicated that peak impact forces for lanyard plus body belts were about 5 to $25 \%$ lower than for the respective forces for lanyards alone. For a $1.8 \mathrm{~m}$ ( $6 \mathrm{ft}), 3 / 4$ inch manila rope inclusion of a body belt will reduce impact forces by about half. 
Table A-12. Comparison of calculated peak impact forces with comparable values as experimentally determined by equipment manufacturers

\begin{tabular}{|c|c|c|c|c|c|c|c|c|c|}
\hline \multirow[b]{2}{*}{$\begin{array}{l}\text { Manufac- } \\
\text { turer }\end{array}$} & \multirow[b]{2}{*}{$\begin{array}{c}\text { Type } \\
\text { lanyard }\end{array}$} & \multirow[b]{2}{*}{$\begin{array}{l}\text { Type } \\
\text { bolt }\end{array}$} & \multirow[b]{2}{*}{$\begin{array}{l}\text { Lanyard } \\
\text { length }\end{array}$} & \multirow[b]{2}{*}{$\begin{array}{l}\text { Drop } \\
\text { height }\end{array}$} & \multirow[b]{2}{*}{$\begin{array}{l}\text { Drop } \\
\text { weight }\end{array}$} & \multicolumn{4}{|c|}{ Peak Impact Forces $g$} \\
\hline & & & & & & $\begin{array}{l}\text { Manufac- } \\
\text { turer }\end{array}$ & $\begin{array}{l}\text { Sample } \\
1 \text { peak }\end{array}$ & $\begin{array}{l}\text { Sample } \\
2 \text { peak }\end{array}$ & $\begin{array}{r}\text { Percent } \\
\text { differenfe }\end{array}$ \\
\hline \multirow[t]{7}{*}{$x$} & $1 / 2$ in nylon & None & $\begin{array}{r}6 \mathrm{ft} \\
6 \mathrm{ft} \\
8 \\
8 \\
10 \\
10 \\
-10\end{array}$ & $6 \mathrm{ft}$ & $\begin{array}{l}250 \quad 1 \mathrm{~b} \\
350 \\
250 \\
350 \\
250 \\
350\end{array}$ & $\begin{array}{ll}2597 & \text { lbf } \\
3896 & \\
2277 & \\
3130 & \\
1910 & \\
3143 & \end{array}$ & $\begin{array}{l}3319 \text { lbf } \\
4560 \\
2754 \\
3823 \\
2371 \\
3322\end{array}$ & $\begin{array}{l}2729 \text { 1bf } \\
3726 \\
2287 \\
3152 \\
1999 \\
2786\end{array}$ & $\begin{array}{r}17_{\mathrm{b}}^{\mathrm{b}} \\
6 \mathrm{~b} \\
11 \mathrm{~b} \\
11_{\mathrm{b}}^{\mathrm{b}} \\
14 \mathrm{~b} \\
-3\end{array}$ \\
\hline & $5 / 8$ in nylon & None & $\begin{array}{r}6 \\
6 \\
8 \\
8 \\
10 \\
10 \\
-\end{array}$ & 6 & $\begin{array}{l}250 \\
350 \\
250 \\
350 \\
250 \\
350\end{array}$ & $\begin{array}{r}2565 \\
3410 \\
2465 \\
3145 \\
2330 \\
2930\end{array}$ & $\begin{array}{l}3314 \\
4429 \\
2737 \\
3692 \\
2359 \\
3212\end{array}$ & $\begin{array}{l}3363 \\
4341 \\
2826 \\
3698 \\
2474 \\
3257\end{array}$ & $\begin{array}{r}30 \\
29 \\
13 \\
17 \\
4 \\
10 \\
-10\end{array}$ \\
\hline & $1 / 2$ in polyester & None & $\begin{array}{r}6 \\
6 \\
8 \\
8 \\
10 \\
10 \\
-\end{array}$ & 6 & $\begin{array}{l}250 \\
350 \\
250 \\
350 \\
250 \\
350 \\
-\end{array}$ & $\begin{array}{r}4130 \mathrm{~d} \\
\leq 5330^{\circ} \\
-3762 \mathrm{~d} \\
\leq 5060^{\circ} \\
\\
3483 \\
4582 \\
\end{array}$ & $\begin{array}{l}4302 \\
5620 \\
3610 \\
4736 \\
3154 \\
4147\end{array}$ & $\begin{array}{l}4286 \\
5581 \\
3617 \\
4830 \\
3176 \\
4163 \\
\end{array}$ & $\begin{array}{r}4 \\
5 \\
-4 \\
-5 \\
-9 \\
-9 \\
-\end{array}$ \\
\hline & $3 / 4$ in manila & None & $\begin{array}{r}6 \\
6 \\
8 \\
8 \\
10 \\
10 \\
-10\end{array}$ & 6 & $\begin{array}{r}250 \\
350 \\
250 \\
359 \\
250 \\
350 \\
-3 .\end{array}$ & $\begin{array}{c}<4460^{\mathrm{d}} \\
3915^{\mathrm{a}} \\
4062 \mathrm{a} \\
2930^{\mathrm{a}} \\
3962 \\
-\end{array}$ & $\begin{array}{l}6334^{\mathrm{a}} \\
8181^{\mathrm{a}} \\
5470^{\mathrm{a}} \\
7082^{\mathrm{a}} \\
4855^{\mathrm{a}} \\
6393^{\mathrm{a}}\end{array}$ & $\begin{array}{l}6417^{\mathrm{a}} \\
8348^{\mathrm{a}} \\
5548^{\mathrm{a}} \\
7060^{\mathrm{a}} \\
4951^{\mathrm{a}} \\
6267^{\mathrm{a}}\end{array}$ & $\begin{array}{l}43 \\
-- \\
36 \\
-- \\
24 \\
- \\
-\end{array}$ \\
\hline & \multirow[t]{2}{*}{$1 / 2$ in nylon } & Friction & 6 & $\begin{array}{r}6 \\
-12 \\
-2\end{array}$ & 212 & $\begin{array}{r}1770 \mathrm{~d} \\
\sim 2990 .\end{array}$ & $\begin{array}{r}2168 \\
3423 \\
-\end{array}$ & $\begin{array}{r}2120 \\
3324 \\
-\end{array}$ & $\begin{array}{r}21 \\
\simeq 13 \\
-1\end{array}$ \\
\hline & & Tongue & 6 & $\begin{array}{r}6 \\
6 \\
12 \\
12 \\
12 \\
-12\end{array}$ & $\begin{array}{l}212 \\
150^{c}\end{array}$ & $\begin{array}{c}1770 \\
2100 \\
22830 \mathrm{~d} \\
3100 \\
1465\end{array}$ & $\begin{array}{l}1894 \\
2784 \\
2153\end{array}$ & $\begin{array}{l}1815 \\
2806^{\mathrm{a}} \\
2095\end{array}$ & $\begin{array}{r}-4 \\
\\
\sim-6 \\
45\end{array}$ \\
\hline & $3 / 4$ in manila & Tongue & 6 & $\begin{array}{r}6 \\
12\end{array}$ & $\begin{array}{l}212 \\
212\end{array}$ & $\begin{array}{r}2664^{d} \\
2750 \\
\sim 3205^{d} \\
4075\end{array}$ & $\begin{array}{l}2938^{\mathrm{a}} \\
4891^{\mathrm{a}}\end{array}$ & $\ldots$ & $\sim 54$ \\
\hline \multirow[t]{2}{*}{$Y$} & $1 / 2$ in nylon & $\begin{array}{l}\text { Friction } \\
\text { Tongue }\end{array}$ & 6 & 5 & $250^{\mathrm{C}}$ & $\begin{array}{r}1830 \\
1660 \\
-\end{array}$ & $\begin{array}{r}2923 \\
2661 \\
-\end{array}$ & -- & $\begin{array}{l}60 \\
60 \\
-\end{array}$ \\
\hline & $1 / 2$ in polyprop. & Tongue & 6 & 5 & 250 & 2250 & 2619 & -- & 16 \\
\hline
\end{tabular}

${ }^{\mathrm{a}}$ Rope failed. For co. $\mathrm{X}$ or $\mathrm{Y}$ force represents observed force at the break point. An "a" by NBS force indicates computed peak force above NBS observed breaking strength.

$b_{\text {The }} \mathrm{L} / \mathrm{E}$ curves for samples 1 and 2 differed considerably for $1 / 2$ in gold nylon. Were the percent differences given in colum 10 based on sample $\# 2$ only better agreement (i.e., smaller peak force differences) would have been obtained.

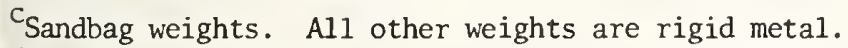

Measurements superscripted with $d$ went off oscillograph chart scale. Where $<$ sign appears limits were estimated by experimenters; where $\sim$ sign appears peak forces were extrapolated from existing parts of curves.

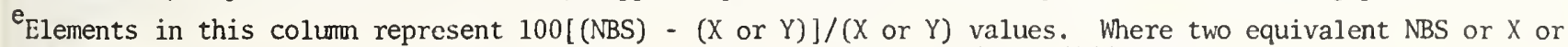
$Y$ measurements are listed, they have been averaged to produce the final difference.

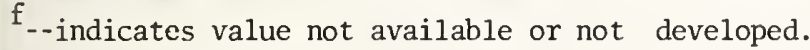

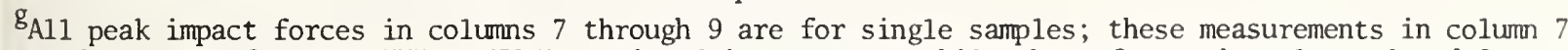
are due to manufacturer "X" or "Y," as listed in colunm 1, while those forces in columns 8 and 9 represent model calculations based on L/E data developed by this study. 
Table A-13. Comparison of calculated peak impact durations with comparable values as determined by equipment manufacturers

\begin{tabular}{|c|c|c|c|c|c|c|c|c|c|}
\hline \multirow[b]{3}{*}{$\begin{array}{l}\text { Manufac- } \\
\text { turer }\end{array}$} & \multirow{3}{*}{$\begin{array}{c}\text { Type } \\
\text { lanyard }\end{array}$} & \multirow[b]{3}{*}{$\begin{array}{l}\text { Type } \\
\text { belt }\end{array}$} & \multirow{3}{*}{$\begin{array}{l}\text { Lanyard } \\
\text { length }\end{array}$} & \multirow[b]{3}{*}{$\begin{array}{l}\text { Drop } \\
\text { height }\end{array}$} & \multirow[b]{3}{*}{$\begin{array}{l}\text { Drop } \\
\text { weight }\end{array}$} & \multicolumn{4}{|c|}{ Peak Widths, FWMM ${ }^{2}$} \\
\hline & & & & & & \multirow[b]{2}{*}{$\begin{array}{l}\text { Manufad } \\
\text { turer }\end{array}$} & \multicolumn{2}{|c|}{ NBS } & \multirow[b]{2}{*}{$\begin{array}{l}\text { Percent } \\
\text { ditference }\end{array}$} \\
\hline & & & & & & & Sample 1 & Sample 2 & \\
\hline \multirow[t]{8}{*}{$x$} & $1 / 2$ in nylon & None & $\begin{array}{r}6 \mathrm{ft} \\
6 \\
8 \\
8 \\
10 \\
10 \\
\end{array}$ & $6 \mathrm{ft}$ & $\begin{array}{l}250 \quad l b \\
350 \\
250 \\
350 \\
250 \\
350 \\
\end{array}$ & $\begin{array}{l}.12 \mathrm{~s} \\
.11 \\
.14 \\
.15 \\
.18 \\
.16\end{array}$ & $\begin{array}{r}.09 \mathrm{~s} \\
.09 \\
.11 \\
.11 \\
.12 \\
.13 \\
-.13\end{array}$ & $\begin{array}{r}.11 \mathrm{~s} \\
.12 \\
.13 \\
.14 \\
.16 \\
.16\end{array}$ & $\begin{array}{l}-17 \\
-5 \\
-14 \\
-17 \\
-22 \\
-\quad 9 \\
---1\end{array}$ \\
\hline & $5 / 8$ in nylon & None & $\begin{array}{r}6 \\
6 \\
8 \\
8 \\
10 \\
10 \\
-10\end{array}$ & 6 & $\begin{array}{l}250 \\
350 \\
250 \\
350 \\
250 \\
350 \\
-\end{array}$ & $\begin{array}{r}.13 \\
.13 \\
.14 \\
.15 \\
.16 \\
.17\end{array}$ & $\begin{array}{r}.09 \\
.10 \\
.11 \\
.12 \\
.13 \\
.14 \\
. .1\end{array}$ & $\begin{array}{r}.10 \\
.10 \\
.11 \\
.12 \\
.12 \\
.14 \\
. .1\end{array}$ & $\begin{array}{l}-27 \\
-23 \\
-21 \\
-20 \\
-22 \\
-18\end{array}$ \\
\hline &  & None & $\begin{array}{r}6 \\
6 \\
8 \\
8 \\
10 \\
-10 \\
-\end{array}$ & 6 & $\begin{array}{r}250 \\
350 \\
250 \\
350 \\
250 \\
350 \\
-\end{array}$ & $\begin{array}{r}.07 \\
\leq .09 \\
-.08 \\
<.08 \mathrm{~d} \\
-.08 \\
.10 \\
-.10\end{array}$ & $\begin{array}{r}.07 \\
.07 \\
.09 \\
.09 \\
.10 \\
.11 \\
\end{array}$ & $\begin{array}{r}.07 \\
.08 \\
.09 \\
.09 \\
.10 \\
. .11\end{array}$ & $\begin{array}{c}0 \\
-17 \\
13 \\
13 \\
0 \\
10 \\
\end{array}$ \\
\hline & $3 / 4$ in manila & None & $\begin{array}{r}6 \\
6 \\
8 \\
8 \\
10 \\
10 \\
-10\end{array}$ & 6 & $\begin{array}{r}250 \\
350 \\
250 \\
350 \\
250 \\
350 \\
-\end{array}$ & $\begin{array}{c}\leq .06^{\mathrm{d}} \\
-.05^{\mathrm{c}} \\
.07 \\
.05^{\mathrm{c}} \\
.07 \\
.\end{array}$ & $\begin{array}{r}.05^{c} \\
.05^{c} \\
.06^{c} \\
.06^{c} \\
.07^{c} \\
.07^{c}\end{array}$ & $\begin{array}{l}.05^{c} \\
.05^{c} \\
.06^{c} \\
.06^{c} \\
.06^{c} \\
.07^{c}\end{array}$ & $\begin{array}{c}-17 \mathrm{f} \\
--14 \\
-- \\
-7 \\
- \\
-\end{array}$ \\
\hline & 1,2 in nylon & Friction & 6 & $\begin{array}{r}6 \\
12 \\
-\end{array}$ & 212 & $\begin{array}{c}.13 \\
\sim .11^{d}\end{array}$ & $\begin{array}{r}.12 \\
.10 \\
-.10\end{array}$ & $\begin{array}{l}.12 \\
.11 \\
-1\end{array}$ & $\begin{array}{r}-8 \\
-5 \\
-\end{array}$ \\
\hline & 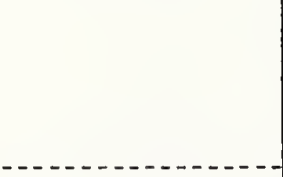 & Tongue & 6 & $\begin{array}{r}6 \\
6 \\
12 \\
12 \\
-12 \\
-\end{array}$ & $150^{\mathrm{b}}$ & $\begin{array}{c}.13 \\
.13 \\
.12 \\
.11 \\
. .16\end{array}$ & $\begin{array}{r}.15 \\
.14 \\
. .13\end{array}$ & $\begin{array}{c}.14 \\
.13^{c} \\
. .12\end{array}$ & $\begin{array}{r}12 \\
17 \\
-22 \\
-2\end{array}$ \\
\hline & $3 / 4$ in manila & Tongue & 6 & 6 & 212 & $\sim .07^{\mathrm{d}}$ & $.10^{\mathrm{C}}$ & -- & 43 \\
\hline & & & & 12 & 212 & $\sim .10^{\mathrm{d}}$ & $.07^{\mathrm{C}}$ & -- & -30 \\
\hline \multirow[t]{2}{*}{ Y } & $1 / 2$ in nylon & $\begin{array}{l}\text { Friction } \\
\text { Tongue }\end{array}$ & 6 & 5 & $250^{b}$ & .11 & $\begin{array}{r}.10 \\
. .11 \\
\end{array}$ & -- & $\begin{array}{l}-9 \\
=8\end{array}$ \\
\hline & $1 / 2$ in polyprop. & Tongue & 6 & 5 & 250 & .10 & .11 & -- & 10 \\
\hline
\end{tabular}

$\mathrm{a}_{\mathrm{All}}$ peak durations, computed as full-width-at-half-maximum (FWHM) times are based on single sample measurements; those measurements in column 7 are due to manufacturer "X" or "Y," as 1 isted in column 1 , while those times in columns 8 and 9 represent project staff data.

${ }^{b}$ Sandbag weights. All other weights are rigid metal.

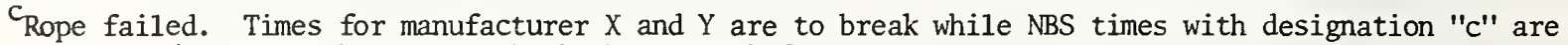
based on L/E curves where ropes broke below peak force.

Measurements superscripted with d went off oscillograph chart scale. Where < sign appears limits were estimated by experimenters; where $\sim$ sign appears peak durations were extrapoläted from existing parts of curves.

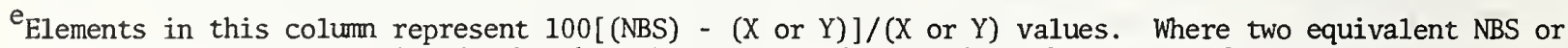
$X$ or $Y$ measurements are listed, they have been averaged to produce the final difference.

$f_{1 \text {-- }}$ indicates element not available or was not developed due to uncertainties in subordinate values. 
Peak impact forces for lanyards secured to body belts which, in turn, were wrapped snugly about rigid cylindrical weights represent the combined action of lanyard and belt in absorbing impact energies. The versatility of our model would be extended if, by appropriately combining $\mathrm{L} / \mathrm{E}$ data for lanyard and belt, impact parameters for the combined system could be calculated. As is seen in Table A-12 agreement between our (static-based) force calculations and experimental (dynamic) values is generally good considering the inherent variability of the devices tested. In all cases manila rope gives the poorest fit. The large differences obtained when a sandbag was used can be attributed, in part, to the energy absorbing nature of this type test weight.

One consideration that should be borne in mind when comparing synthesized fall impact parameters (based on static L/E data) with actual drop test results is that most interference factors in drop testing (e.g., give in the anchorage, non- $Z$ axis motions, including rotations, imparted to the test weight by the release mechanism, etc.) tend to reduce the observed impact forces. 


\section{A.5 Computation of Load vs. Elongation Functions for Various Length Lanyards}

In order to facilitate the comparison of data generated in this project with results of other load vs. elongation tests of lanyards, the coefficients of the polynomial equations for complete $1.8 \mathrm{~m}$ ( $6 \mathrm{ft}$ ) lanyards (lanyard with snaphooks spliced onto each end) and center (pure rope) sections of these lanyards are given in Tables A-14 and A15, respectively. The equations with these coefficients correspond to the curves of Figures A-ll (adjusted for a lanyard six feet long) and A-12.

The information in Tables $A-14$ and $A-15$ can also be used to calculate values for lanyards of other lengths of interest by using Equation 9 (page 81). An example giving calculated data points for a $3 \mathrm{~m}$ ( $10 \mathrm{ft}$ ) lanyard of new, 9/16 inch spun nylon is given in Table A-16. The computed values of $\Delta \mathrm{L} / \mathrm{L}$ and $\Delta l / l$ were found by an iterative process from Tables $A-14$ and $A-15$. The values of $\Delta \lambda / \lambda$ were then calculated using Equation 9,

$$
\Delta \lambda / \lambda=\frac{\Delta L}{L} \frac{L}{\lambda}+\frac{p}{\lambda} \quad \frac{\Delta \ell}{\ell}
$$

where $\lambda=10$

$$
\begin{aligned}
& \lambda=6 \\
& P=\lambda-L=4
\end{aligned}
$$

An equation predicting the load vs. elongation function for a $3 \mathrm{~m}$ (l0 ft) lanyard can be obtained by fitting a third degree polynomial to the values in the last and first columns of Table A-16. 


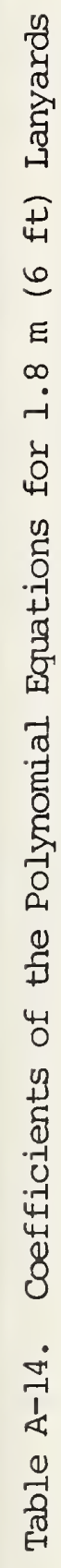

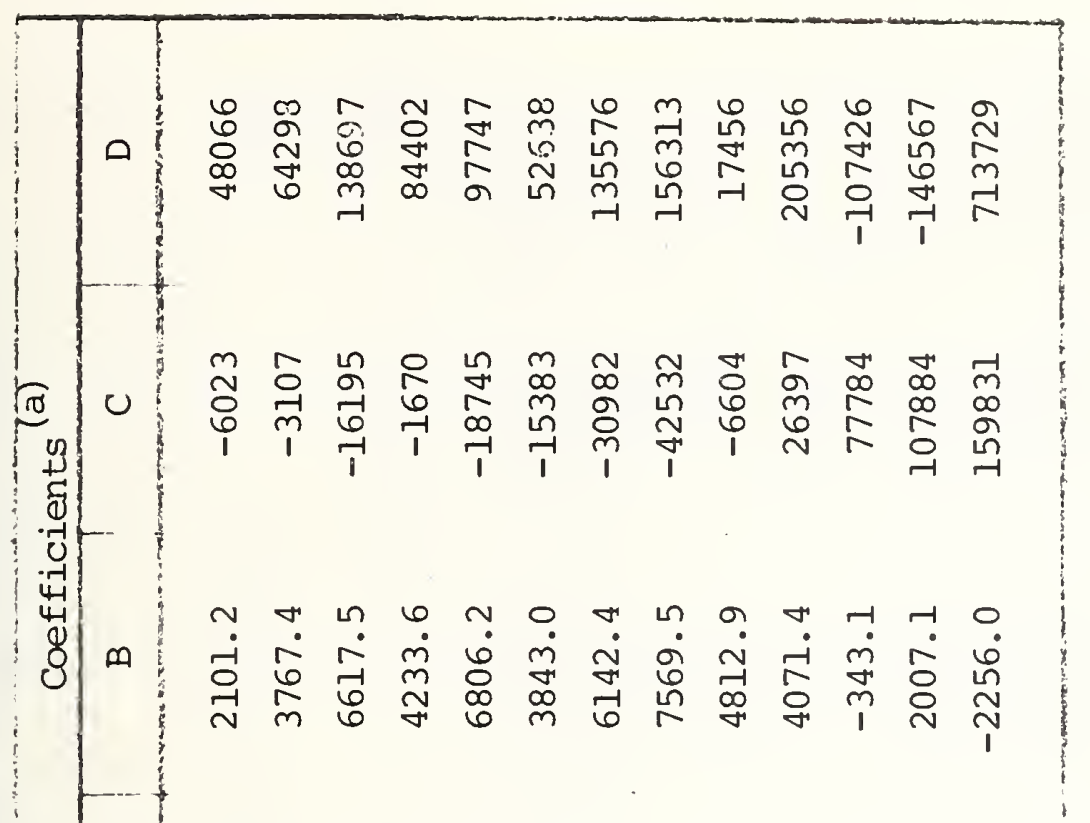

$m$



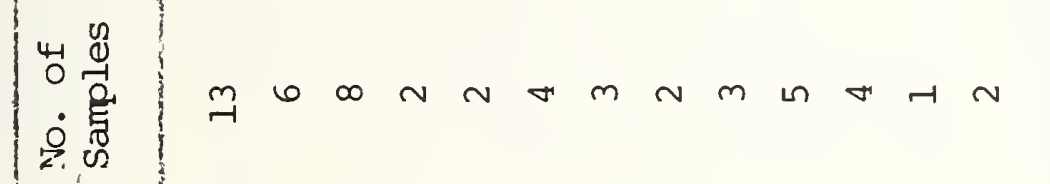

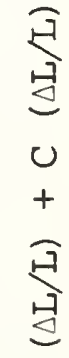

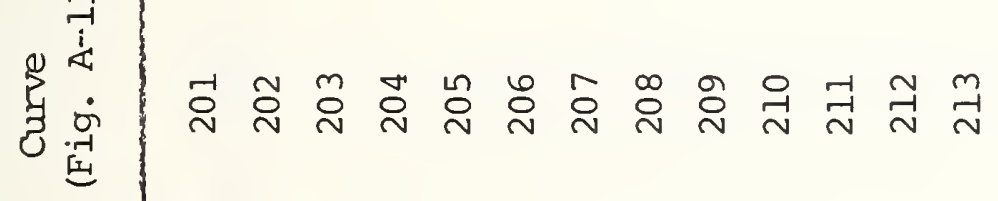

田画

5

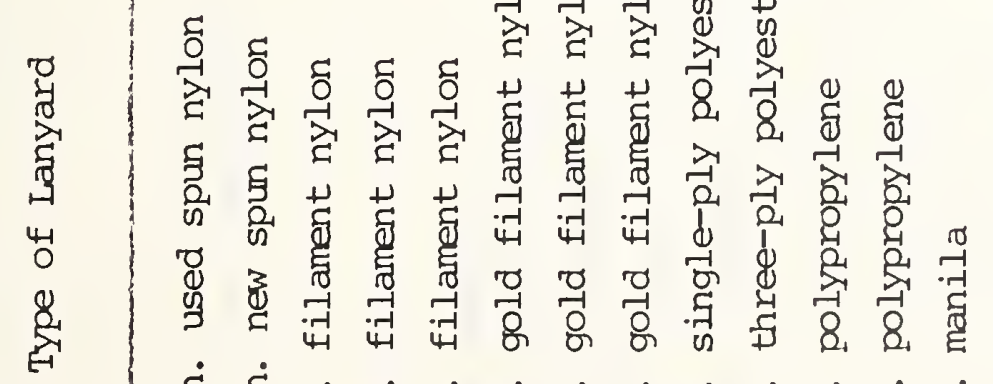

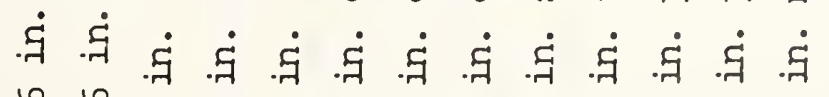

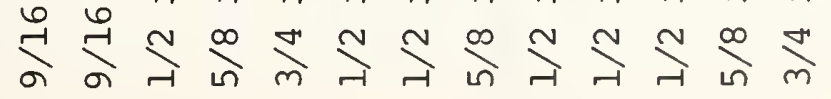


Table A-16 Elongation of 9/16 inch new spun nylon lanyard computed from test data

Elongation

\begin{tabular}{|c|c|c|c|}
\hline $\begin{array}{l}\text { Load } \\
\text { lbf }\end{array}$ & $6 \mathrm{ft.}{\underset{\text { percent }}{\text { lanyard }}}^{(\mathrm{a})}$ & $\begin{array}{l}\text { Pure rope } \\
\text { percent }\end{array}$ & $\begin{array}{c}10 \mathrm{ft} . \text { lanyard }^{(\mathrm{c})} \\
\text { percent }\end{array}$ \\
\hline 1000 & 18.96 & 18.18 & 18.65 \\
\hline 1500 & 23.45 & 22.47 & 23.06 \\
\hline 2000 & 26.91 & 25.58 & 26.38 \\
\hline 2500 & 29.76 & 28.08 & 29.09 \\
\hline 3000 & 32.22 & 30.18 & 31.40 \\
\hline 3500 & 34.38 & 32.02 & 33.44 \\
\hline 4000 & 36.33 & 33.65 & 35.26 \\
\hline
\end{tabular}

(a) $\Delta / \mathrm{L}$, computed using coefficients given in Table A-14

(b) $\Delta l / l$, computed using coefficients given in Table A-15

(c) $\Delta \lambda / \lambda=0.6 \Delta \mathrm{L} / \mathrm{L}+0.4 \Delta \ell / \ell$ 



\begin{tabular}{|c|c|c|c|}
\hline $\begin{array}{l}\text { U.S. DEPT. OF COMM. } \\
\text { BIBLIOGRAPHIC DATA } \\
\text { SHEET }\end{array}$ & $\begin{array}{l}\text { 1. PUII.I ATION OR RE:PORT NO. } \\
\text { NBSIR } 76-1146\end{array}$ & $\begin{array}{l}\text { 2. Gov't Accession } \\
\text { No. }\end{array}$ & 3. Recipient's Accession No. \\
\hline \multirow{2}{*}{\multicolumn{3}{|c|}{$\begin{array}{l}\text { 4. TITLE AND SURTITLE } \\
\text { A Study of Personal Fal1-Safety Equipment }\end{array}$}} & 5. Publication Date \\
\hline & & & 6. Performing Orazizario Code \\
\hline \multicolumn{3}{|c|}{$\begin{array}{l}\text { 7. AUTHOR(S) } \\
\text { Harold L. Steinberg }\end{array}$} & 8. Performing Organ. Report No. \\
\hline \multirow{2}{*}{\multicolumn{3}{|c|}{$\begin{array}{l}\text { 9. PERFORMING ORGANIZATION NAME AND ADDRESS } \\
\text { NATIONAL BUREAU OF STANDARDS } \\
\text { DEPARTMENT OF COMMERCE } \\
\text { WASHINGTON, D.C. } 20234\end{array}$}} & $\begin{array}{l}\text { 10. Project/Task/Work Unit No. } \\
4410433\end{array}$ \\
\hline & & & 11. Contract/Grant No. \\
\hline \multirow{2}{*}{\multicolumn{3}{|c|}{$\begin{array}{l}\text { 12. Sponsoring Organization Name and Complete Address (Street, City, State, 21P) } \\
\text { Occupational Safety and Health Administration } \\
\text { Division of Safety Standard Development } \\
\text { Department of Labor } \\
\text { 3rd \& Constitution Avenues, N.W., Wash., D.C. } 20210\end{array}$}} & $\begin{array}{l}\text { 13. Type of Report \& Period } \\
\text { Covered } \\
\text { Final }\end{array}$ \\
\hline & & & 14. Sponsoring Agency Code \\
\hline
\end{tabular}

15. SUPPI.EMENTARY NOTES

16. ABSTRACT (A 200-word or less factual summary of most significant information. If document includes a significant bibliography or literature survey, mention it here.)

A study has been made of the basic requirements for personal safety equipment that is designed to protect workers at heights against the danger of falls. The project was undertaken for the Occupational Safety and Health Administration as part of an effort to update the Code of Federal Regulations on fall-safety equipment. The investigation included an intensive literature review, numerous field visits, and a limited laboratory examination of some components. Some unique testing and evaluation approaches were developed, and a novel extensometer was designed.

17. KEY WORDS (six to twelve entries; alphabetical order; capitalize only the first letter of the first key word unless a proper name; separated by semicolons) Body belts; body harness; fall-arrest equipment; fall-safety systems; impact accelerations; impact forces; lanyards; 1inemen's equipment; load-extension data; occupational safety and health; performance standard; regulation; tensile testing; worker safety equipment.

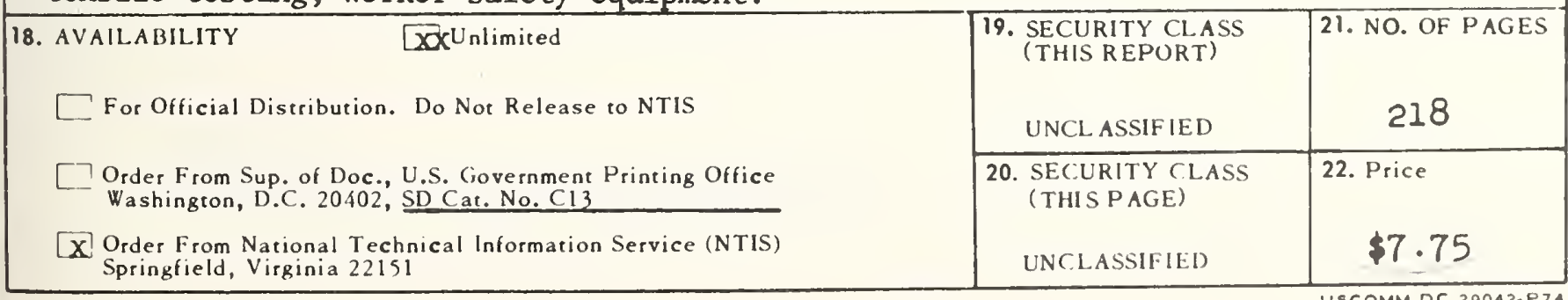


